\author{
Universidad Nacional de La Plata \\ Facultad de Humanidades y Ciencias de la Educación
}

Maestría en Escritura y Alfabetización

\title{
ESCRITURAS EXTRAORDINARIAS: \\ La experiencia de escritura \\ en jóvenes privados de la libertad
}

Tesis presentada para obtener el grado de Magíster en Escritura y Alfabetización

Ana Gabriela Barral

Directora de tesis: Alicia Inés Villa

Marzo/ 2017 
Agradecimientos:

A cada uno de los jóvenes privados de la libertad, porque son "mi único héroe en este lío"

A Alicia Villa, mi directora, gracias por acompañarme y orientarme; tan minuciosa. incansable y generosa

A Letizia Barbero, por ser mi compañera -codo a codo- en este viaje

A Diego Ceballos, docentes y autoridades de la escuela del Complejo Esperanza, por permitirme la entrada, arrimar el hombro y acompañarme en mi trabajo

A las autoridades y profesores de la Universidad Nacional de La Plata, a mis compañeras de cursada de la Maestría, en especial a Antonia Fernández, por ser mi amiga y maestra

A Graciela Puebla por sus horas, dias y semanas de ayuda en la revisión

A Marysel Segovia y a mi hermana María Elena Barral, por sus lecturas y precisas palabras

A mi familia, mis padres, mis hijas, mis nietos, SIEMPRE 


\section{Resumen:}

Este trabajo se propone conocer, documentar, describir y analizar la experiencia de la escritura en jóvenes en situación de encierro punitivo, en particular, un grupo de jóvenes varones de 14 a 18 años, alojados en el Complejo Esperanza1', en Córdoba, por encontrarse en situación de conflicto con la ley penal.

Planteamos una investigación de corte etnográfico, desde un enfoque descriptivointerpretativo. Nos basamos en la presencia de dos años de trabajo de campo puestos en diálogo permanente con el marco teórico histórico, social, político y legal. Partimos de la observación/participación en los talleres literarios que propuso la Biblioteca Abierta ${ }^{2}$. En el año 2014, un taller literario de escritura individual y en el año 2015, un proyecto de escritura colectiva: la novela La otra vida de los pibes pistoleros

En las entrevistas indagamos sobre sus biografías, la cuestión de alfabetización y las posibilidades de escribir en la institución de encierro: aquí aparece con fuerza la actual experiencia de escritura: la escritura cotidiana en la institución punitiva. Ponemos foco sobre esta última, en especial, la escritura en los muros y en particular, la del nombre sobre la pared. Si bien nos interesan sus biografías escritoras, nos concentramos en las escrituras de la vida del encierro, y en el significado que estas adquieren como táctica, como recurso extraordinario para sobrevivir.

\footnotetext{
${ }^{1}$ El Complejo Esperanza es el "Centro Socio-educativo" que concentra a todos los jóvenes varones privados de la libertad en la provincia de Córdoba

${ }^{2}$ Forma parte de la Red Nacional de Biblioteca Abiertas
} 


\section{INDICE}

$\begin{array}{lc}\text { INTRODUCCIÓN } & 8\end{array}$

$\begin{array}{ll}\text { PRIMERA PARTE } & 11\end{array}$

1. Breve marco conceptual, autores de referencia, antecedentes 11

1.1. Premisas generales en las que se inscribe esta tesis 11

1.1.1. Sobre la escritura: 12

1.1.1.1. La escritura ordinaria: 15

1.1.1.2. Escrituras populares: 17

1.1.1.3. Escrituras domésticas: 18

1.1.1.4. La escritura en el encierro 19

1.1.1.5. Escritura: práctica social y cultural 21

1.1.1.6. La alfabetización- apropiación de la escritura 22

1.1.2. Sobre los jóvenes 26

1.1.2.1. Sobre jóvenes y delincuencia: $\quad 27$

1.1.2.2. Sobre jóvenes en prisión 29

1.1.3. Sobre la experiencia: 31

1.2. Antecedentes 33

2. Contextualización del trabajo 36

2.1. Marco legal: adolescentes infractores de la ley: 36

2.2. El Complejo Esperanza $\quad 47$

2.2.1. Breve historización: antecedentes del actual Complejo Esperanza 47

2.2.2. Situación actual: años 2014-2015 50

2.3. La escuela en el Complejo Esperanza. 51

2.4. Educación en Contextos de Privación de Libertad: 54

3. Planteamiento del problema y resoluciones metodológicas 59

3.1. Objetivos generales y específicos 60

3.2. Problema/Preguntas 61 
3.3. Resoluciones metodológicas 61

3.3.1. Resoluciones metodológicas iniciales: $\quad 62$

3.3.1.1. Observación participante 62

3.3.1.2. Entrevista etnográfica 64

3.3.1.3. Registro de campo 66

3.3.2. Resoluciones metodológicas posteriores 68

3.3.2.1. Taller de escritura: Situaciones de escritura para el taller 68

3.3.2.2. Registro fotográfico/ Grupo de discusión 69

3.3.2.2.1. Registro fotográfico/ copiado: 69

3.3.2.2.2. Grupo de discusión: 69

3.3.2.2.2.1. Planificación del grupo de discusión: $\quad 70$

$\begin{array}{ll}\text { 3.3.3. Categorías de análisis: perspectiva cualitativa } & 71\end{array}$

$\begin{array}{ll}\text { SEGUNDA PARTE: } & 72\end{array}$

LA EXPERIENCIA DE LA ESCRITURA EN JÓVENES PRIVADOS DE LA LIBERTAD 72

$\begin{array}{ll}\text { INTRODUCCIÓN } & 72\end{array}$

4. Las condiciones sociales, escolares, el encierro y la escritura 74

$\begin{array}{ll}\text { 4.1. Los chicos } & 74\end{array}$

4.2. El paisaje social y político $\quad 79$

4.3. Trayectorias educativas 84

4.4. La escritura: posibilidades/ oportunidades de escribir 91

4.4.1. La apropiación de la escritura 91

4.4.2. El encierro: las oportunidades, posibilidades y prohibiciones de la escritura 104

4.5. Conclusión provisoria 111

5. Lo que los chicos escriben en los talleres de escritura creativa: 115

5.1. La entrada al campo. La planificación, convocatoria y organización. 115

5.1.1. Planificación, convocatoria y organización - Breve cronología 118

5.2. Descripción de los talleres literarios 122

5.2.1. Los talleres en la Biblioteca Abierta/ año 2014

5.2.1.1. Introducción. 122 
5.2.1.2. Descripción de los talleres en la Biblioteca/2014 123

5.2.1.2.1. Primer taller/ 28 de junio de 2014: Taller de presentación 124

5.2.1.2.2. Segundo taller/ 5 de septiembre de 2014: La mesa-las cartas 132

5.2.1.2.3. Tercer taller/ 25 de septiembre 2014: Presentación -acrósticospoemas con versos prestados 139

5.2.1.3. Otras escrituras en la biblioteca: Autobiografía/Carta 144

5.2.2. Talleres desde la Biblioteca Abierta en el Instituto Horizontes/ año 2015:

Escritura de Novela Grupal 152

5.2.2.1. Introducción: 152

5.2.2.2. Cronología de los talleres: escritura de la Novela Grupal 154

5.2.3. Lo que los chicos dicen sobre la experiencia de escritura en los talleres 190

5.3. Conclusión provisoria: “Un tiempo libre, un tiempo nuestro" 200

6. La escritura cotidiana en el encierro 207

$\begin{array}{ll}\text { 6.2. Introducción } & 207\end{array}$

6.3. Lo que los chicos escriben en la vida cotidiana. 208

6.3.1. Escritura de cartas 208

6.3.2. Escritura en el cuerpo 217

6.3.3. Escrituras en la pared: antes de llegar a ellas 222

6.4. La escritura en la pared: los registros, la escritura y lo que dicen sobre la $\begin{array}{ll}\text { escritura } & 227\end{array}$

6.4.1. Sobre el ingreso al campo 227

6.4.2. La escritura en las paredes: Descripción- Posible catalogación 235

6.4.3. ¿Dónde, cómo y con qué se escribe? 240

6.4.4. Ámbitos de la escritura: ¿qué y para qué escriben? 243

6.4.5. Presentación de las escrituras por ámbitos, en cruce con entrevistas a los jóvenes. $\quad 247$

6.4.6. Breve cierre y apertura: 254

6.5. El nombre en la pared: La pared te llama 255

6.6. Conclusión provisoria 265

$\begin{array}{ll}\text { 7. Conclusión final } & 268\end{array}$

$\begin{array}{ll}\text { POST SCRIPTUM } & 282\end{array}$

$\begin{array}{ll}\text { BIBLIOGRAFÍA } & 285\end{array}$ 
ANEXOS

ANEXO 1 : PLANES TALLERES 2015

ANEXO 2: NOVELA GRUPAL

ANEXO 3: TOTAL ESCRITURA PARED: 


\section{INTRODUCCIÓN}

Jóvenes, escritura, experiencia, libertad/encierro: conceptos, palabras, significados que interpelan y traen otros. Actualizan inquietudes y cuestionamientos, aparecen luces, sombras y muchas preguntas.

En esta tesis nos proponemos describir y analizar la experiencia de la escritura en jóvenes en situación de encierro punitivo. En nuestro primer acercamiento al tema desde la investigación académica, elegimos trabajar con un grupo de jóvenes adolescentes varones de 14 a 18 años, alojados todos ellos en el Complejo Esperanza, en la periferia de la ciudad de Córdoba, por encontrarse en situación de conflicto con la ley penal.

¿Qué sabíamos sobre el tema y qué nos propusimos conocer? Sabíamos que nos encontrábamos ante un escenario particular: una institución de alta complejidad, donde se articulan varias instituciones -educativas, sociales, judiciales, de salud-, inserta en un contexto de encierro y ante jóvenes sujetos de múltiples exclusiones, marginación, pobreza y violencia. Este escenario particular -la escuela en un instituto que aloja niños y jóvenes privados de la libertad-, puede presentarse como el "único refugio posible de promoción y difusión de la lectura y la escritura hacia los sectores históricamente marginados del saber/leer/poder", retomando el concepto de Cucuzza \& Spregelburd (Cucuzza \& Spregelburd, 2012, p.47).

Decidimos concentrar nuestra atención en la escritura, partiendo de la premisa de Michel De Certeau sobre las tácticas, pasadas del débil en el orden construido por el fuerte (De Certeau y Giard, 1996), pensando que la experiencia de la escritura podría llegar a constituirse en una de éstas.

Sabíamos también que dentro de la modalidad Educación en Contexto de Privación de la Libertad y en distintos programas educativos, se venían produciendo una cantidad de experiencias interesantes de proyectos de escritura. A través de estas propuestas vienen aconteciendo una gran variedad de acciones de las que existe poco registro documentado desde la investigación académica. Nos propusimos conocer y documentar una de ellas: la que se lleva a cabo en el Centro Educativo del Complejo Esperanza, donde, tal como da a conocer la revista Tumbando Rejas, se vienen desarrollando experiencias de escritura en un marco institucional. Nuestra idea inicial fue "hacer pie" en este territorio, tomar contacto con estas experiencias, y conocer los relatos de algunos de los jóvenes que participaban en estos trayectos. Nos interesaba 
comprender de qué manera estas experiencias podían ser construidas e interpretadas, y su significado en la construcción de su experiencia social, en su biografía, en el presente y hacia el futuro. Nos propusimos investigar acerca de las percepciones o transformaciones que surgían en relación a su realidad social y cultural.

En las etapas iniciales del trabajo de campo, indagamos sobre los primeros relatos de los jóvenes, a partir de nuestra participación en los talleres literarios. Luego, en las entrevistas etnográficas, apareció con fuerza la cuestión de la experiencia cotidiana de escritura en el encierro. Nos planteamos entonces la posibilidad de obtener información sobre el significado de unas y otras escrituras, las que surgen de los talleres de escritura creativa y las de la vida cotidiana en el encierro. La palabra escrita en una poesía, un relato, una carta, en el cuerpo, o en un muro.

Este trabajo de investigación se encuentra organizado en dos partes principales.

La primera presenta las premisas teóricas generales, la contextualización y las decisiones metodológicas. La construcción del marco teórico constituyó un trabajo de indagación en sí mismo, siempre puesto en diálogo con el trabajo de campo. Proponemos entonces para esta primera parte, tres capítulos:

El primer capítulo presenta el marco conceptual, los antecedentes y los autores de referencia que orientan este trabajo. Aquí planteamos nuestro posicionamiento sobre tres categorías que creemos fundamentales: la escritura, los jóvenes y la experiencia.

El segundo capítulo aborda la contextualización. En primer lugar, hacemos referencia al marco legal vinculado a adolescentes infractores de la ley y luego ponemos foco en la institución donde los jóvenes cumplen con su encierro punitivo: el Complejo Esperanza. Finalizamos este apartado con una breve descripción de la escuela en el Complejo Esperanza y algunas ideas centrales sobre la implementación de la Educación en Contexto de Encierro en nuestro país. El tercer capítulo presenta las resoluciones metodológicas. A partir del marco teórico y la información contextual de base planteamos el problema, las preguntas y los objetivos. Proponemos aquí una investigación de corte etnográfico, desde un enfoque cualitativo/descriptivo/interpretativo

La segunda parte, da cuenta de dos años de trabajo de campo que produjo una abundante información a través de los registros etnográficos, la palabra de los jóvenes en 
las entrevistas realizadas, sus textos escritos, los registros fotográficos de las escrituras y la información en terreno sobre el contexto. Todo este trabajo de campo, fue puesto en diálogo permanente con la búsqueda de la comprensión del marco histórico, social, político y legal, y con los conceptos de los autores de referencia. Esta presentación está dividida en tres capítulos, cada uno con sus conclusiones provisorias.

El capítulo cuatro, a partir de la información de las entrevistas a los jóvenes, busca acercarse a sus experiencias sociales y sus trayectorias escolares, a la apropiación de la escritura y a su experiencia actual de escritura. Finalmente indagamos sobre las posibilidades y oportunidades de escribir en la institución de encierro.

El quinto capítulo analiza la escritura creativa en los talleres literarios que propone la Biblioteca Abierta $^{3}$ de la escuela del Complejo Esperanza. Esta experiencia de escritura es diferente cada año: en el año 2014, se trata de una propuesta de escritura preferentemente individual, acorde a los planteos de un taller literario en cierta forma "tradicional". En el año 2015, se propuso un proyecto de invención propia del equipo de talleristas, en función a la realidad contextual, surgió así un proyecto de escritura colectiva: la novela grupal.

El sexto capítulo aborda la escritura cotidiana de los jóvenes en el encierro: la escritura de cartas, la escritura en el cuerpo, y sobre la pared. Proponemos un estudio más específico de esta última: la escritura en los muros o "graffiti carcelario". Ponemos foco finalmente en una escritura particular, de tipo ritual y cargada de contradicciones: el nombre en la pared.

Si bien pensamos que es fundamental la comprensión de la experiencia de escritura en el contexto de la biografía de cada joven, consideramos fundamental para esta tesis, conocer su experiencia escrituraria en el momento de transitar la privación de la libertad, en particular su propia explicación sobre el significado que adquiere la escritura en situación de encierro punitivo.

\footnotetext{
${ }^{3}$ Forma parte de la Red Nacional de Biblioteca Abiertas, será desarrollado más adelante
} 


\section{PRIMERA PARTE}

\section{Breve marco conceptual, autores de referencia, antecedentes}

\subsection{Premisas generales en las que se inscribe esta tesis}

Nos proponemos para empezar, presentar y desarrollar brevemente algunas categorías teóricas fundamentales en relación al tema elegido como así también señalar algunos autores de referencia importantes. Se trata de las premisas generales en las que se inscribe esta tesis, a las que recurrimos apuntando a lograr un cimiento conceptual inicial lo más sólido posible y a construir el entretejido de un enfoque epistemológico coherente.

Tuvimos en cuenta desde un comienzo, que al tratarse de una investigación de tipo cualitativo ${ }^{4}$, el objeto de conocimiento se iría complejizando y construyendo a lo largo del proceso investigativo, a partir de la "permanente e irresoluble tensión" entre referente empírico y referente teórico. (Buenfil Burgos, 2011). En este sentido, prestamos atención desde el inicio de este trabajo a lo que nos advierte Rosa María Buenfil Burgos sobre los usos estériles de la teoría y tomamos el desafío de tener en cuenta los "otros usos", en los que "la capacidad heurística, analítica, interpretativa o explicativa de las teorías mismas es puesta a prueba frente a las exigencias planteadas por las preguntas de investigación y por las características particulares del referente empírico”. (Buenfil Burgos, 2011).

Proponemos para este punto inicial enmarcar teóricamente tres categorías que consideramos fundamentales y que forman parte del título de nuestro trabajo: la escritura, los jóvenes y la experiencia. El desarrollo del marco teórico de estos conceptos se constituyó como un trabajo de construcción y ajuste permanente de acuerdo con datos surgidos del campo empírico. Esto requirió un proceso de investigación bibliográfica y búsqueda de antecedentes propios; una intensa tarea de exploración que acompañó al trabajo de investigación en el campo.

La pregunta que nos hacemos al abordar cada uno de estos conceptos es: ¿De qué hablamos cuando hablamos de...? Haremos algunas precisiones que luego pondremos en diálogo con los resultados del trabajo de campo, en la segunda parte. Nos

\footnotetext{
${ }^{4}$ Desarrollaremos este punto en el apartado sobre las resoluciones metodológicas.
} 
referiremos especialmente entonces a las tres categorías que mencionamos: la escritura, los jóvenes, y la experiencia.

\subsubsection{Sobre la escritura:}

Hablamos de la escritura como una práctica social, histórica, cultural, cognitiva y lingüística al mismo tiempo (Ferreiro, 2001; Cardona, 1994). Concebimos este objeto como un concepto complejo, sujeto a múltiples interpretaciones, enfoques y discusiones. En palabras de Emilia Ferreiro "Leer y escribir son construcciones sociales. Cada época y cada circunstancia histórica da nuevos sentidos a esos verbos" (Ferreiro, 2001).

Partimos de las conceptualizaciones de Giorgio Cardona, quien en Antropología de la Escritura (1994) diferencia escritura de lengua escrita. Cardona señala que "el fenómeno escritura asume características, connotaciones, empleos propios de tal complejidad interna que lo hacen comparable a todo el fenómeno "lengua" en su conjunto" (Cardona, 1994, pág. 10). Este autor rechaza las concepciones por las cuales se simplifica y se observa a la escritura como mero instrumento para transmitir mensajes "así como un carro sirve para transportar heno." Insiste en que, por el contrario, el fenómeno "escritura" abarca globalmente el sistema abstracto con sus realizaciones concretas, con los materiales, y con los objetos escritos; y se manifiesta como una matriz de significaciones sociales, y como un campo fundamental de producción simbólica (Cardona, 1994, pág. 10).

Desde una mirada histórica, Roger Chartier y Marta Madero, en Poderes de la escritura/ Escrituras del poder (2001) explican que la historia de la escritura se ha ido desarrollando de forma paralela -pero con diferentes lógicas- a la de la lectura. La historia de la escritura está focalizada en aspectos que le son propios, como la cultura del manuscrito, las capacidades gráficas, o las funciones de la escritura. La historia de la lectura, por su parte, está más relacionada a la historia del libro, de la literatura y de la recepción de los textos. En cuanto a la construcción de una y otra historia los autores aclaran que "si la historia, o mejor dicho, las historias de la lectura fueron sobre todo alemanas, inglesas y francesas, las de la producción y prácticas de la escritura manuscrita se construyeron en el seno de la tradición de la paleografía italiana, y más recientemente española. Así, durablemente, la lectura y la escritura se han constituido 
como objetos de estudio separados, movilizadores de saberes específicos y de tradiciones nacionales ampliamente extranjeras unas a otras." (Chartier \& Madero, 2001).

Sobre la base teórica fundamental del trabajo de Roger Chartier y Marta Madero, diferenciamos escritura de lectura: queda claro que cada una tiene su historización, sus espacios, sus tiempos y sus técnicas. En lo específico de la escritura aparece su rol como instrumento de gobierno y de administración, y por otro lado, la censura a la producción y el control al acceso a ella. Para estos autores, por su parte, la lectura puede representar "la sumisión, que se supone pasiva, a la autoridad del texto", y -lo que a los fines de este trabajo nos interesa- la escritura, podría llegar a escapar de las esferas del poder y aparecer como una posibilidad subversiva, nacida de una comunicación y en determinadas ocasiones sustraída a las censuras y los controles (Chartier \& Madero, 2001). Quede claro que esta dicotomía es aparente y debe ser considerada con grandes matices. En este sentido Chartier y Madero reconocen como fundamental el estudio de las relaciones múltiples, complejas y anudadas entre las prácticas de leer y de escribir.

Tomamos como referente teórico primordial al trabajo de Michel Petit y sus ideas sobre los jóvenes y la lectura. Nos interesa indagar sobre si la escritura, tal como la lectura, puede llegar a ayudar a las personas "a construirse, a descubrirse, a hacerse un poco más autoras de su vida, sujetos de su destino, aun cuando se encuentren en contextos sociales desfavorables" escritura, si puede -tal como sostiene Petit- además de describir la realidad, ser una parte constitutiva y constructora de la experiencia social y las subjetividades; y sobre todo, si este "dejar una huella" que es la escritura puede constituirse en "una forma activa de posesión del mundo". (Petit, 2009, p. 235). En los apartados específicos sobre la escritura, Michèle Petit recurre a los conceptos de otro especialista cuyos trabajos son imprescindibles cuando se habla de la escritura de la gente común: Daniel Fabre. Acudimos a sus nociones claves, las que desarrollaremos particularmente en el apartado sobre la escritura ordinaria. Fabre sostiene que la conquista de la letra se presenta como una "gesta heroica" y sobre la fuerza de la escritura, manifiesta:

La fuerza objetiva que yace en la escritura se verifica de la siguiente manera: es captada por el acto de escribir e incorporada por el escritor, a quien esta misma fuerza transfigura. (...) Esto emana de una necesidad indefinida, ya que la escritura manifiesta una eficacia al menos negativa: sin ella, cualquier

\footnotetext{
${ }^{5}$ En ese caso Petit hace referencia a la lectura
} 
acontecimiento social estaría incompleto, sería insatisfactorio, desprovisto de sentido $y$, en caso extremo, inexistente. El poder de la escritura, del cual acabamos de ver esclarecedores efectos distintivos, se encarna por todas partes en esta exigencia habitual y es probablemente ahí que se abre un espacio vasto $y$ lleno de sorpresas donde se puede trazar el mapa de una conquista que tiene mil rostros." (Fabre, 2008, pág. 14)

Michèle Petit se basa en el concepto fundamental de Michel de Certeau, quien caracteriza a la lectura como "caza furtiva". De este autor toma la célebre idea sobre el lector como cazador furtivo: para de Certeau el lector "caza furtivamente, se transporta, se hace plural como los ruidos de los cuerpos. Ardid, metáfora, combinatoria, esta producción es también una "invención" de memoria", en la lectura "un mundo diferente (el del lector) se introduce en el lugar del autor” (De Certeau y Giard, pág. LIII, 1996).

Michel de Certeau, en "La invención de lo cotidiano" define la escritura como una "actividad concreta que consiste en construir, sobre un espacio propio, la página, un texto que tiene poder sobre la exterioridad de la cual, previamente, ha quedado aislado" (De Certeau y Giard, 1996, pág.148). De Certeau, indaga sobre los tipos de operaciones que realizan los consumidores, aparentemente condenados a la pasividad y a la disciplina, y cuestiona la idea de un consumidor pasivo o dócil. Señala que existen múltiples modos de habitar un espacio social, disímiles: las artes de hacer, diversas maneras de estar a la pesca, de hacer trampa y escapar de ese orden existente. De Certeau se ocupa de estas artimañas -tácticas- del hombre sin atributos: el hombre ordinario. Coloca a las tácticas del lado de la inventividad del más débil, del que carece de espacio propio y ubica a las estrategias del lado del fuerte, el propietario "del teatro de operaciones". En este juego, las relaciones entre el poder y sus sujetos son siempre inequitativas (pág. XXIV). Para De Certeau "la táctica está determinada por la ausencia de poder como la estrategia está organizada por el postulado de un poder" (De Certeau y Giard, 1996, pág. 62). Tácticas y estrategias: unas no tienen sentido sin las otras. Las estrategias encuentran su resistencia en las tácticas, que se pueden entender como un ejercicio -no consciente- de resistencia frente a la alteridad: su movimiento depende de los movimientos del otro. Las estrategias se alimentan o se frustran en función de las tácticas que llevan a cabo los sujetos, y las coordinaciones tácticas adquieren sentido en función de los horizontes estratégicos. Partimos entonces de una idea central de De Certeau: las tácticas son las pasadas del "débil" en el orden construido por el "fuerte", y pueden llegar a posibilitar la construcción 
de una experiencia "otra" (De Certeau y Giard, 1996, pág. 46). Cuando De Certeau se ocupa de las prácticas cotidianas de los sujetos, remarca que no son homogéneas ya que se constituyen de manera cambiante y se transforman en función de las circunstancias.

Valen estas potentes ideas de La invención de lo cotidiano como guía para abordar las prácticas cotidianas de escritura. Nos preguntamos en relación a esto, qué lugar ocupa la escritura en este juego de tácticas y estrategias, si puede llegar a convertirse en una táctica para estos jóvenes, si en alguna medida puede funcionar como una de esas "trampas" sobre el orden impuesto. También nos interesa conocer el lugar que ocupa la escritura en la experiencia social de los sujetos. Creemos que estas ideas se complementan con las que mencionábamos de Roger Chartier cuando afirma que la escritura, y especialmente la escritura de la gente común -los "débiles"- puede llegar constituirse en una suerte de subversión del poder establecido.

Podemos seguir analizando a la escritura desde múltiples puntos de vista y desde distintas especificidades. Dedicaremos unos apartados especiales a algunas de estas cuestiones específicas: nos referiremos a la escritura ordinaria, las escrituras populares, la escritura doméstica, la escritura en cautiverio, y la escritura como práctica social y cultural,. Finalmente haremos referencia al tema de la apropiación de la escritura. Más adelante, en el desarrollo del trabajo, iremos retomando, ampliando y profundizando algunas de estas ideas a la luz de los datos del trabajo de campo.

\subsubsection{La escritura ordinaria:}

Tomamos los conceptos fundamentales de Daniel Fabre, vertidos en el libro Écritures Ordinaries (1991), allí se dan a conocer una serie de trabajos, fruto de un proceso de años de seminarios de investigación en torno a este tema. Tomamos esta obra de Fabre, que aborda las escrituras ordinarias -o escrituras de la gente común- y analiza minuciosamente sus diferentes formas y aspectos: las escrituras domésticas, las maneras de escribir, las escrituras religiosas, etc. En la introducción, Fabre caracteriza y diferencia las escrituras ordinarias:

"Éstas se oponen claramente al universo prestigioso de los escritos que se distinguen por la voluntad de construir una obra, por la firma que autentifica al autor, por la consagración de lo impreso. No aspiran ni al ejercicio escrupuloso del "buen uso" ni a la sacralización que, poco o mucho, acompaña desde hace dos siglos al distanciamiento literario. Además y sobre todo, la mayoría de estas 
escrituras asociadas a momentos colectivos o personales intensos o bien a la rutina de las ocupaciones cotidianas, parecen consagradas a una única función que las absorbe y las uniformiza: dejar huella. No tendrían otro sentido, ni otros efectos. Cuando mucho dan testimonio de una competencia que se hace evidente sólo cuando no se la posee" (Fabre, 2008, p 33) ${ }^{6}$

Daniel Fabre explica que las escrituras ordinarias son un conjunto de prácticas difusas y variadas, realizadas en el transcurso de actividades cotidianas, muchas veces de naturaleza irrelevante y con poca intención de pervivir en el tiempo. (Fabre, 2008). La escritura ordinaria es entonces una escritura sin prestigio ni consagración, pero no sólo es eso, aclara Fabre, quien propone dejar de lado simplificaciones y evitar una definición privativa que conciba a las escrituras ordinarias simplemente como una escritura sin escritor, de aficionados "una escritura dominguera". Fabre expresa que junto al equipo de trabajo vislumbraron "un territorio bastante mal explorado, el de las escrituras que nuestras sociedades demandan, exigen, suscitan" (Fabre, 2008, pág. 20)

Fabre -tal como Michèle Petit- retoma los conceptos básicos de Michel de Certeau, y analiza la escritura buscando comprender la densidad del objeto. En primer lugar, se diferencia de la idea de la dicotomía oralidad-escritura y propone, en este caso, otras posibilidades:

"Ya no se trata de trazar una línea entre lo oral y lo escrito sino entre leer y escribir o incluso entre los escritos brutos (o las contraescrituras) y las inscripciones del poder. Tal parece que la escritura ordinaria no tiene otra existencia posible más que como marca -impresión- del orden social o como tentativa, solitaria o colectiva, de escapar de éste con la inocencia, la locura, la revuelta escritas..." (Fabre, 2008, pág. 7)

Otro desafío que Fabre también propone es diferenciar la escritura de la lectura. Desde los conceptos de táctica y estrategia de Michel de Certeau, coloca a la escritura y a la lectura -en principio- en polos opuestos:

"Si la lectura es un "arte de hacer" incrustado en el arsenal de las "tácticas" cotidianas que orientan golpe a golpe las conversaciones, las maneras de habitar y de cocinar, la escritura, necesariamente, fija, da forma a la experiencia y se sitúa

\footnotetext{
${ }^{6}$ Edición traducida
} 
del lado de las normas enunciadas y de los modelos inculcados. La escritura es aplicación, en todos los sentidos de ese término. En ésta se intensifican todas las propiedades restrictivas de la lengua, con sus códigos, su autoridad, sus aserciones dominantes". (Fabre, 2008, pág. 5)

La escritura es académica y restrictiva por naturaleza, pero no siempre y necesariamente es así: el escritor puede rebelarse, puede apartarse del orden del lenguaje y el bronce de la letra (Fabre, 2008, pág. 6), burlarse los lugares comunes, y apartarse con heroísmo de la repetición interminable. Este sería el caso de lo que Fabre diferencia como la escritura ordinaria:

“las escrituras en las que triunfan los errores, es decir, la ignorancia, el desprecio a las reglas o su olvido. Los textos de los niños, de los ingenuos, de los dementes, que Dubuffet llamará "escrituras brutas", serían las únicas en deshacerse, sin saberlo ni quererlo, de las leyes de bronce de la letra." (Fabre, 2008, pág. 6)

Cuando Fabre analiza el curso denso e inaprensible de las prácticas de escritura, propone no caer en la trampa de los modelos dualistas que plantean de antemano una comprensión, ni imponer un marco rígido donde fijar lo cotidiano de la escritura, y se pregunta: si acaso la literatura moderna, la concepción moderna de la escritura literaria y sus usos ordinarios no son, muy a menudo, la misma cosa (Fabre, 2008, pág. 7). Reconoce de todas formas que los términos confrontados "(pensamiento oralpensamiento escrito; lectura activa-escritura pasiva; escritura del poder-escritura marginal) que parecían imponérsenos y cuya atracción indiscutible queríamos desviar, no han orientado, en un principio, nuestros pasos. A pesar de esto no hemos perdido de vista sus puntos de luz". (Fabre, 2008, pág. 7). Semejante, de alguna forma, a lo que advierte Stuart Hall cuando se refiere a la noción identidad, y propone tomar algunos conceptos "bajo borradura", ya que a veces expresan "una idea que no puede pensarse a la vieja usanza, pero sin la cual ciertas cuestiones clave no pueden pensarse en absoluto" (Hall, pág. 14)

\subsubsection{Escrituras populares:}

Las escrituras populares se ubican dentro del campo de las escrituras de la gente común. Antonio Castillo Gómez propone nombrarlas en plural "para sugerir toda la 
diversidad de sus manifestaciones" (Castillo Gómez, 2002, pág. 25). Se distinguen de la escritura ordinaria fundamentalmente por la condición social de sus autores. Estos son "escribientes antes que escritores", adscritos a una clase social medio-baja "comparten una cierta proximidad social y una similar experiencia escolar (...) Gente común, como también tiende a decirse para incluir a los individuos de la clase media poco o escasamente alfabetizados. (Castillo Gómez, 2002, pág. 25). Castillo Gómez aclara que se trata de personas que no son profesionales del escribir.

A partir del concepto de escrituras populares, relacionado a la subalternidad social, Castillo Gómez sostiene que "la escritura, pese a que sea más habitual entre las clases acomodadas y cultas, no por ello ha quedado enteramente al margen del avatar histórico de las subalternas. Estas, por el contrario, son artífices de un importante número de testimonios, variados en cuanto a las tipologías textuales y distintos en las motivaciones nutricias." (Castillo Gómez, 2002, pág. 23). Castillo Gómez explica que muchas veces se trata de escrituras del margen, los escritores a menudo, se sitúan en los márgenes de la sociedad, y desarrollan prácticas escriturarias con peculiaridades gráficas o de una competencia que se suele mover entre lo oral y lo escrito.

Este autor en sus estudios sobre escritura marca la diferencia de la escritura popular para "no eludir la conflictividad y la desigualdad social como uno de los vectores del análisis" (Castillo Gómez, pág. 24).

\subsubsection{Escrituras domésticas:}

La escritura doméstica es un aspecto de la escritura ordinaria. Bernard Lahire, en Escrituras domésticas. La domesticación de lo doméstico expone un trabajo de investigación sobre las prácticas domésticas de escritura. Allí las caracteriza:

Las prácticas de escritura de gestión doméstica permiten calcular, planificar, programar, prever la actividad y organizarla en un lapso más o menos largo, como preparar o demorar la acción directa y suspender en parte la urgencia práctica. Verdaderas técnicas de autocontrol, esas prácticas implican también un mayor dominio de los deseos y de las pulsiones. (Lahire, 2005)

Lo que Lahire en su investigación sobre escrituras domésticas de los franceses logra comprobar es la idea de que "las escrituras domésticas son reveladoras de disposiciones sociales (individuales, de género, etáreas o familiares) más generales”. Una 
de las conceptualizaciones que Lahire aporta para este trabajo es la idea de que la escritura "resuelve" la ausencia: el autor habla del "don de ubicuidad" ya que lo escrito "continúa marcando nuestra presencia mientras nuestro cuerpo está ausente. Compensa la ausencia corporal para continuar ejercitando una acción" (Lahire, 2005, p. 11)

Daniel Fabre -sobre las escrituras domésticas- señala que enmarcan distintas clases de escrituras: "Unas velan por el buen orden de la casa, concebida como un universo de cosas y como un tejido de relaciones que se extienden más allá de la familia residente. Las otras se desarrollan en el corazón mismo de la casa pero de cierta manera en contra de ella, en la esfera secreta en la que algunos se acomodan. Puesto que esta escritura doméstica es múltiple, es compartida de manera desigual”. (Fabre, 2008, pág. 8)

Sabemos que las escrituras de los jóvenes privados de la libertad se desarrollan, como mencionáramos en la Introducción, en una institución de encierro, en condiciones de vigilancia y masividad que en nada se parecen al espacio íntimo de lo doméstico. Resulta difícil relacionar dicho encierro con un espacio doméstico, éste más asociado a un lugar propio, la casa, el hogar, a veces más privado que otras. Pero creemos que, a pesar de ello, la institución de encierro, no deja de ser circunstancialmente el espacio donde los jóvenes viven y duermen, comen, conviven, pasan sus días y sus noches, y eso sería lo que lo hace al menos en parte, un espacio "doméstico".

\subsubsection{La escritura en el encierro}

Desde un ángulo cercano a los autores que venimos mencionando, pero más específico al contexto que estamos estudiando, abordamos el tema de la escritura en el encierro. Antonio Castillo Gómez desarrolla un amplio estudio sobre este tema, y en Letras bajo sospecha (2005) presenta una compilación de trabajos sobre la escritura de "esclavos, presos, "locos", huérfanos y adolescentes problemáticos que integran la extensa familia de los excluidos de la historia" (Castillo Gómez, Sierra Blas, 2005, pág. 11). Estos trabajos nos sirven a la vez de marco teórico, como antecedentes de la presente investigación. En Escribir para no morir (2003), Castillo Gómez aborda la escritura como resistencia en las cárceles franquistas, allí analiza la experiencia de escribir en el encierro como forma de combatir y resistir a la anulación del cautiverio:

"Cuando alguien es desposeído de todo, cuando pierde el control sobre el propio espacio y sobre el tiempo propio, cuando se ve reducido a la in-dignidad sólo 
queda la dignidad de la propia conciencia: sólo queda la memoria. Escribir y leer como formas de combatir esa anulación, de trascender el cautiverio y resistir la pretendida reeducación” (Castillo Gómez, 2003, pág. 21)

En el prólogo de Entre la represión y la libertad, Sierra Blas y Castillo Gómez (2003), explican que -en un sentido amplio- la prisión funciona como una "máquina de escritura", en la que coexisten las escrituras que crean las personas con la escritura de la institución. Las escrituras de las personas pueden estar a la vez más o menos inducidas, algunas de ellas como parte del procedimiento penal. Pero aparecen también las modalidades más personales y expresivas, capaces de aprovechar "los resquicios mínimos del sistema o transgredirlos" (pág. 13), a pesar de la vigilancia y de la autocensura:

"Aunque muchas veces nacen de la necesidad de liberar lo más íntimo de uno mismo o de exorcizar ciertos pensamientos, tampoco es extraño que manifiesten los efectos de la censura intrínseca a cualquier régimen de confinamiento o expresen la autocensura que quien escribe se impone en tales circunstancias." (Castillo Gómez, Sierra Blas, pág. 12)

Diego Navarro Bonilla, en la primera parte del libro de Castillo Gómez y Sierra Blas (2003) Palabras cautivas. Cárceles y campos de concentración escribe el capítulo "Archivos y cultura escrita carcelaria: escribir y documentar la prisión desde el siglo XVI". Este autor analiza también las escrituras personales y la escritura de la institución. Desarrolla la idea de que, como cualquier otra experiencia de la prisión, la escritura puede ser mirada desde "arriba" o desde "abajo", por eso para abordar la producción escrita atiende a dos elementos esenciales: a la prisión como establecimiento burocrático y a los prisioneros como "individuos que desarrollan su particular universo de lo escrito sorteando las dificultades y restricciones impuestos por la vida privada de libertad (...) en su cotidianeidad privativa de la celda, los pasillos o los patios interiores" (Navarro Bonilla, 2005, pág. 19). En el mismo sentido, Philippe Artiéres (2005) desarrolla en el capítulo 5 del mencionado libro, el tema de la prisión como máquina grafómana, toma las ideas foucoultiana sobre el poder, el panóptico y la vigilancia. Artiéres habla del poder de la escritura para la "inversión de la sociedad disciplinaria”. Por su parte Leila Gándara (2005) en el capítulo 10, Voces en Cautiverio analiza el graffiti carcelario e identifica en la 
escritura su función reparadora. Seguiremos desarrollando estos conceptos más adelante, en la discusión teórica en juego con los datos del campo.

\subsubsection{Escritura: práctica social y cultural}

Ya sea escritura ordinaria, popular, doméstica, en libertad o en el encierro, la escritura es experiencia y práctica social y cultural: "heredera del concepto de praxis, la idea de práctica cultural recuerda la actividad productiva del ser humano, en el sentido material y también en la esfera simbólica." (Rokwell, 2002, pág. 14). Rockwell define práctica cultural en relación a la lectura y toma para eso palabras de Roger Chartier: "Chartier (1993, 1999) concibe la lectura como una práctica cultural realizada en un espacio intersubjetivo, conformado históricamente, en el cual los lectores comparten dispositivos, comportamientos, actitudes y significados culturales en torno al acto de leer". Creemos que la definición de la lectura como práctica cultural de Chartier es aplicable a la escritura.

En referencia a estas prácticas sociales, Delia Lerner explica que la lectura y la escritura aparecen siempre insertas en las relaciones con las otras personas, suponen interacciones entre lectores acerca de los textos (Lerner, 2001, pág. 94). La autora aclara que estas prácticas son totalidades indisociables (Lerner, 2001, pág. 94) en las que existe un denominador común que las atraviesa a lo largo de la historia, presente también en la actualidad. Para explicarlo, Lerner, cita a Olson (1998), quien describe el dominio de la escritura como condición social y cognitiva

"El dominio de la escritura es una condición social; cuando leemos o escribimos un texto participamos de una "comunidad textual': de un grupo de lectores que también escriben y oyen, que comparten una determinada manera de leer $y$ entender un corpus de textos. Volverse lector en un dominio específico significa aprender a participar de un paradigma, en el mismo sentido en que Kuhn propuso esa noción para describir una comunidad científica que comparte un mismo conjunto de textos, un mismo conjunto de interpretaciones y un mismo conjunto de creencias con respecto a los problemas que-se investigan. [... ] Pensamos en el dominio de la escritura como una condición al mismo tiempo cognitiva y social" (Olson, 1998, en Lerner, 2001, pág. 95) 
Bernard Lahire, desde la sociología, en el mencionado trabajo sobre escrituras domésticas, destaca que las prácticas de lo escrito revelan realidades sociales, son constitutivas y constructoras de la realidad social:

“Las prácticas del escrito no reflejan solamente disposiciones sociales y modos de organización de las actividades preexistentes; no sólo siguen las fronteras ya trazadas de diferencias sociales objetivas y previas entre los grupos sociales 0 entre los sexos, sino que son constitutivas de las realidades sociales y contribuyen a su construcción social” (Lahire, 1993, pág. 19)

\subsubsection{La alfabetización- apropiación de la escritura}

Entendemos la alfabetización como el desarrollo del conocimiento y uso de la lengua escrita en el mundo social y en actividades culturalmente validadas, por oposición a la concepción tradicional que la asume como el aprendizaje de los aspectos básicos de la lectura y la escritura (la correspondencia entre letras y sonidos).

(Kalman, Judith, 2004, pág. 20).

El concepto de apropiación tiene la ventaja de transmitir simultáneamente un sentido de la naturaleza activa y transformadora del sujeto y, a la vez, del carácter coactivo, pero también instrumental, de la herencia cultural. El término sitúa claramente la acción en las personas que toman posesión de los recursos culturales disponibles y los utilizan. Al mismo tiempo, alude al tipo de cultura arraigada en la vida cotidiana, en objetos, herramientas, prácticas, imágenes y palabras, tal y son experimentadas por las personas. Esta noción de apropiación está, por consiguiente, en consonancia con el concepto antropológico emergente, que define la cultura como compleja, múltiple, situada e histórica. (Elsie Rockwell, 2005, pág. 29)

No podemos abordar el tema de las prácticas escriturarias sin tener en cuenta un aspecto fundamental: la alfabetización, o apropiación de la escritura. Tomamos el concepto apropiación en el sentido de la alfabetización como toma de posesión del objeto cultural y social que es la escritura, como apropiación de la cultura letrada (Rokwell, 2005, Kalman, 2004, Ferreiro, 2001, Castedo, 2015, Lerner, 2001). 
Cuando Bernard Lahire en los años noventa realizó en Francia su trabajo sobre escrituras domésticas, hizo una aclaración previa sobre este aspecto "La sociedad francesa contemporánea es producto de un largo movimiento de alfabetización generalizada y de escolarización que fue constituyendo una base histórica inédita común a casi toda la población francesa. Sobre esta base de referencia común -y por lo tanto, invisible- comienzan a intervenir desigualdades, acuerdos, especificidades y diferencias alrededor de la escritura" (Lahire, p. 7, 1995). No es la realidad en la institución en la que estamos trabajando, ni la de los jóvenes privados de la libertad. No nos encontramos con un escenario de alfabetización generalizada, sino más bien, con un escenario diverso y complejo. Algunos jóvenes leen y escriben cotidianamente, pero otros poseen un contacto precario con la experiencia de la escritura o se encuentran en un proceso de alfabetización apenas iniciado. Incluso, en algunos casos, no llegó a completarse la alfabetización inicial, es decir, nos encontramos con jóvenes que no leen ni escriben.

Emilia Ferreiro señala en Pasado y Presente de los verbos leer y escribir (Ferreiro, 2001): "El tiempo de escolaridad obligatoria se alarga cada vez más, pero los resultados en el "leer y escribir" siguen produciendo discursos polémicos. Cada nivel educativo reprocha al precedente que los alumnos que reciben "no saben leer y escribir"'. Ferreiro concibe la alfabetización como un derecho: el derecho a la práctica ciudadana de la lectura y la escritura. De ser inicialmente una marca de sabiduría, pasó a ser hoy, una marca de ciudadanía. El compromiso de la escuela para Ferreiro no debe ser la enseñanza de meras técnicas sino un paso de ingreso a la "cultura letrada". Lo que Emilia Ferreiro remarca con preocupación es que son muchos los escolarizados que no pueden dar ese paso justamente "en aquellos lugares donde más falta hace la escuela, precisamente por ausencia de una tradición histórica de cultura letrada”.(Ferreiro, Emilia, 2001, pág. 13).

En el mismo sentido que Ferreiro, Giorgio Raimondo Cardona, en Antropología de la Escritura (1994), en relación a la circulación de la escritura, sostiene que como forma de producción cultural -una de las varias formas de producción simbólica- la escritura es una de las menos igualitarias: "su circulación es la que más evidentemente mostrará los condicionamientos y las presiones, las contradicciones y los desniveles del modelo social" (Cardona, 1994, Pág. 87)

Esa circulación incide en las posibilidades de mayor o menor acceso a la cultura escrita. Elsie Rockwell, en sintonía con Ferreiro y Cardona -en relación a la cultura 
letrada- propone, al igual que Judith Kalman (2005) en la cita inicial, el concepto apropiación de la cultura escrita. En un trabajo sobre comunidades de tradición indígena en México (Rockwell, 2000) la autora elige la idea "apropiación", la que toma a la vez de Roger Chartier, y lo justifica:

"Permite -más que otros conceptos, como difusión, socialización, o adquisicióninsistir en dos cuestiones. Primero, acentúa el rol activo de los sujetos involucrados en tomar para sí y hacer uso de la escritura. En segundo lugar, permite examinar los cambios que pueden sufrir los bienes culturales, como la escritura, cuando son apropiados por los sujetos. En palabras de Chartier, "...la apropiación siempre transforma, reformula y excede lo que recibe..." (Chartier 1991:19, mi traducción). Estos cambios se marcan en los productos de las diversas prácticas culturales que involucran a la lengua escrita”.

Rockwell vincula a la apropiación de la escritura con el entretejido social y las historias personales de los que aprenden a leer y escribir, y analiza la distribución desigual de oportunidades. Sostiene que además "la escuela no siempre detenta el monopolio pretendido sobre el acceso a la escritura, ni tampoco garantiza este aprendizaje, como lo evidencia el gran número de analfabetos funcionales que egresan del nivel básico." Y agrega que "una apreciación del carácter múltiple de la cultura escrita requiere entrelazar las trayectorias particulares de los individuos con las historias sociales de diseminación de la escritura." (Rockwell, 2000)

Incorporamos para este trabajo entonces este concepto de apropiación de la cultura escrita y sobre este punto indagaremos, ya que no podemos suponer que tal como la sociedad francesa, estamos ante un escenario de alfabetización generalizada. Más bien lo dudamos ya que, como se mencionó, nos encontramos ante jóvenes internados en una institución por haber cometidos delitos, pobres y excluidos del sistema escolar, con trayectorias escolares fragmentadas, con características de sobreedad, multirepitencia, abandono, expulsión; una experiencia escolar de exclusión o en el mejor de los casos una escolaridad de "baja intensidad" (Kessler, 2004)

En sintonía con el trabajo de Rockwell, pero dentro de las investigaciones en Argentina sobre el tema, tomamos algunas precisiones importantes del trabajo de Kurlat y Pellerman sobre la cuestión de la apropiación del sistema de escritura: 
“La apropiación del sistema de escritura es una cuestión política, social, identitaria, cultural y lingüística. La historia de la escritura evidencia cómo la lengua escrita ha sido y continúa siendo una herramienta de poder (Sampson, 1997; Senner, 1992; Catach, 1996). Como plantea Jouve-Martín (2009), el estudio de la escritura es prácticamente inseparable del estudio de la desigualdad y las relaciones de poder: dónde, cómo, quiénes, producen la escritura y quiénes quedan excluidos de ella por sus 'deficientes conocimientos y medios de expresión'." (Kurlat, Perleman, 2013, pág. 64).

En referencia a la relación entre la pobreza, la desigualdad social y la apropiación de la escritura en nuestro país, las autoras se encuentran con sujetos atravesados por una historia de exclusión: “los fracasados', 'marginados', integrantes de 'sectores populares', las personas que han sido excluidas o expulsadas del sistema escolar y negadas en su derecho a la educación, principalmente por su condición de pobreza. Las huellas de la desigualdad son constitutivas de los procesos de apropiación del sistema de escritura." (Kurlat, Perleman, 2013, pág. 67). Describen de una forma clara y gráfica la idea de complejidad de estas historias y en consecuencia, la del proceso de apropiación de la escritura en jóvenes y adultos: lo definen como una "trenza" en la que se entretejen distintas marcas y experiencias, en la que incluso, pueden aparecer "nudos"

"La trenza que caracteriza a los procesos de construcción del sistema de escritura en jóvenes y adultos, entonces, está constituida por las siguientes hebras: los niveles de conceptualización sobre la lengua escrita, las marcas de exclusión, las marcas de enseñanza. Dichas hebras pueden llegar a formar nudos que será necesario desatar para promover prácticas alfabetizadoras más potentes" (Kurlat, Perleman, 2013, pág. 69)

Para terminar este apartado, reconocemos que la alfabetización/ apropiación de la escritura es un tema que nos interpela, dado que, como ya mencionamos, a lo largo del trabajo de campo de esta investigación fuimos comprobando que muchos jóvenes no han logrado completar el proceso de alfabetización inicial, lo cual agrega una marca más al estigma social y a la vulnerabilidad. Lo seguiremos desarrollando en la segunda parte, en el capítulo 4.2.1. 


\subsubsection{Sobre los jóvenes}

Tomamos de la investigadora mexicana Rossana Reguillo Cruz, la idea fundamental de que "los jóvenes, en tanto sujeto social, constituyen un universo social cambiante y discontinuo, cuyas características son resultado de una negociación-tensión entre la categoría sociocultural asignada por la sociedad particular y la actualización subjetiva que sujetos concretos llevan a cabo a partir de la interiorización diferenciada de los esquemas de la cultura vigente” (Reguillo Cruz, 2002, pág.50). Reguillo Cruz sostiene que "Resulta urgente "deconstruir" el discurso que ha estigmatizado a los jóvenes, a los empobrecidos principalmente, como los responsables del deterioro y la violencia". (Reguillo Cruz, 2002)

Para posicionarnos sobre este tema tomamos palabras de Víctor Mekler, quien es citado a su vez por Mariana Chaves en el Informe: Investigaciones sobre juventudes en Argentina: estado del arte en Ciencias Sociales. (Chaves M. 2006). Mekler sostiene que: "más que un "grupo generacional" o un "estado psicosocial", la juventud es un fenómeno sociocultural en correspondencia con un conjunto de actitudes, patrones y comportamientos aceptados para sujetos de una determinada edad, en relación a la peculiar posición que ocupan en la estructura social. La juventud como período no es igual para todos los grupos sociales, es evidente que como etapa vital se valora socialmente de manera diferenciada para los jóvenes de capas medias y altas que para los de sectores populares. No debe hablarse entonces de "juventud" sino de jóvenes concretos, porque además de tener origen en sectores sociales diferentes, los jóvenes son sujetos que poseen una condición social”. (Mekler, V., 1992, pág. 20-21)

En el artículo Juventud negada y negativizada (Chaves, 2005), en el marco de su investigación doctoral, la autora desarrolla una descripción y análisis de las representaciones y discursos vigentes acerca de las y los jóvenes en la Argentina urbana contemporánea, allí concluye que "Se interpreta que las miradas hegemónicas sobre la juventud latinoamericana responden a los modelos jurídico y represivo del poder. Tomando la propuesta foucoultiana sostengo que la juventud está signada por «el gran NO», es negada (modelo jurídico) o negativizada (modelo represivo), se le niega existencia como sujeto total (en transición, incompleto, ni niño ni adulto) o se negativizan sus prácticas (juventud problema, juventud gris, joven desviado, tribu juvenil, ser rebelde, delincuente, etc.)" (Chaves, 2005, pág. 9) 


\subsubsection{Sobre jóvenes y delincuencia:}

Para abordar un tema como el de los jóvenes, la marginalidad y la delincuencia, proponemos distanciarnos de una idea simplificadora de supuesta correspondencia juventud/ pobreza/ delito, y más bien partir de un enfoque de vulneración de derechos. Tomamos por eso, de Alicia Villa y César Barletta (2014), en Niños Criminales: intervenciones pedagógicas sobre "otras" infancias y juventudes una referencia elemental para este trabajo: "la mayoría de los niños, las niñas y los jóvenes que se identifican como marginales, delincuentes, peligrosos/as portan historias de vida marcadas por la vulneración de sus derechos y la irresponsabilidad de una sociedad que los victimiza. Asociados a la delincuencia o al desamparo, se desarrolla detrás de estos jóvenes toda una maquinaria judicial (causas, expedientes, prontuarios, peritajes) que los sobreinterviene a partir de lenguajes, prácticas y medidas cautelares que pueden desembocar en el encierro o en un conjunto de prácticas alternativas en pos de ser "debidamente cuidados" o protegidos por hallarse desamparados o en situación de peligro moral o material." (Villa, A, Barletta, C, 2014, pág. 92). A lo citado hay que agregar que "a partir del cautiverio de los jóvenes en la trama punitiva o asistencialista terminan insertos en una trama de relaciones que habilita a distintos agentes a intervenir sobre estas vidas" (pág. 92).

Una referencia teórica fundamental son los trabajos del sociólogo Gabriel Kessler, su trayecto investigativo desarrolla temas tales como el delito juvenil, los jóvenes en conflicto con la ley y la desigualdad. Analiza estas cuestiones relacionadas con la experiencia escolar, el tema de la droga, los grupos de pares, la sociabilidad, la identidad social, etc. En Sociología del delito amateur (2004) reconoce que "sin haberlo buscado, nuestro universo de estudio se fue conformando con jóvenes que provenían de sectores populares y de clase media baja. Es obvio el riesgo que esto conlleva: plantear la relación entre delito y jóvenes de sectores populares" (Kessler, 2004). Los resultados de su investigación relacionan al delito, entre otros aspectos, con la descomposición de una sociedad salarial "los jóvenes de nuestra investigación nacieron y crecieron en el período más álgido del proceso de desestructuración del mercado de trabajo y de protecciones sociales de las últimas décadas". Kessler señala además una situación de desdibujamiento de la ley: ésta no actuaría como límite ante los jóvenes, además "no aparece ninguna institución que represente la ley: obviamente no lo es la policía, a la que perciben como una banda más, enfrentada a muerte con ellos, pero tampoco la dimensión 
ley parece haber sido una experiencia sistemática en sus familias, sus escuelas o sus experiencias en el barrio" (Kessler, 2004).

Otro sociólogo argentino referente esencial en este tema es Daniel Miguez. Tomamos en particular su trabajo Los pibes chorros. Estigma y marginación (Miguez, 2010). Miguez analiza la cuestión de la opinión pública sobre los jóvenes y afirma que esta es fomentada por los medios de comunicación. Este concepto lo resume con la siguiente idea/prejuicio: "estamos cada vez más expuestos a ser asaltados por jóvenes pobres, drogados y desesperados", pero demuestra luego que su indagación y las estadísticas ponen en cuestión esta afirmación. En relación a la pregunta “¿Roban porque son pobres?" advierte que desde una perspectiva humanista o progresista se trata de evitar una vinculación del crimen con la marginación social ya que esto llevaría a suponer que todos los que viven en espacios marginados como las villas de emergencia son potenciales delincuentes. Miguez reconoce que el análisis es complejo, y que es necesario diferenciar pobreza de desempleo y desigualdad, ya que cada una de estas situaciones es diferente y en sí misma cada una tiene su propia complejidad. Como concepto fundamental este autor rescata la importancia de la experiencia social: "Pibe chorro no se nace, se hace. $Y$ el proceso por el que se llega a serlo resulta de la interacción entre los individuos y las condiciones sociales en las que estos se desarrollan (...) tienen como rasgo compartido entre otras cosas el haber sufrido desde su infancia desestructuración y privaciones” (Miguez, 2010, pág. 59)

Ampliando este concepto, Miguez (2012) considera como un factor a tener en cuenta la cuestión de la pobreza estructural:

"El incremento de la actividad delictiva no debe asociarse tanto con el mero aumento de la cantidad de desempleados o pobres, sino con una transformación de los tipos de pobreza existente. Como lo han mostrado Beccaria y Vinocour (1991), los procesos que se desencadenaron desde mediados de los años setenta implicaron una transformación no solo en la cantidad de pobres, sino también de las formas de la pobreza. Si hasta esa década la pobreza era mayoritariamente de carácter transicional (en un contexto de movilidad social ascendente, quienes sufrían de carencias materiales tenían expectativas de superarlas mediante el trabajo aplicado y la apuesta a ciclos educativos prolongados),

a partir de esos años la pobreza comienza a ser incrementalmente estructural: la ausencia de movilidad social ascendente o, peor, formas descendentes de la 
misma generaron una pobreza "permanente" que se perpetuó intergeneracionalmente."

Es necesario e ineludible al abordar este tema, hacer referencia a los conceptos desarrollados por el Dr. Eugenio Raúl, Zaffaroni. Para este trabajo recurrimos especialmente a La cuestión criminal (2011). Allí Zaffaroni explica la relación del poder punitivo con la verticalización social, y presenta a la prisión como un factor de riesgo. En cuanto a los jóvenes que cometen delitos, Zaffaroni -como Miguez- analiza el rol de los medios de comunicación social y se remite a datos estadísticos:

"Basta mirar las estadísticas para verificar que son muchos los países donde hay más adolescentes muertos por la policía que víctimas de homicidios cometidos por adolescentes. La criminología mediática naturaliza estas muertes, pues todos los efectos letales del sistema penal son para ella un producto natural (inevitable) de la violencia propia de ellos, llegando al máximo encubrimiento en los casos de fusilamientos disfrazados de muertes en enfrentamientos, presentadas como episodios de la guerra contra el crimen, en que se muestra el cadáver del fusilado como signo de eficacia preventiva, como el soldado enemigo muerto en la guerra. Como todos los muertos en esa guerra se contabilizan y publican porque se consideran enemigos abatidos" (Zaffaroni, 2011)

\subsubsection{Sobre jóvenes en prisión}

Sobre la cuestión de adolescentes y jóvenes en prisión, tomamos de la página oficial de la Procuración Penitenciaria de la Nación ${ }^{7}$-Argentina- algunas definiciones que aparecen en el apartado Colectivos Vulnerables, sobre la cárcel como Institución total y el régimen penitenciario al que se ven sometidos los jóvenes. Desde este organismo oficial se sostiene que la privación de la libertad y las acciones de estigmatización y criminalización "producen un fuerte impacto que afecta la integridad de las personas" con un "proceso de deterioro socio-psico-biológico". Estos efectos tienen lugar tanto durante el

\footnotetext{
${ }^{7}$ Organismo oficial dependiente del Poder Legislativo dotado de plena autonomía e independencia para en principio, y como objetivo fundante, proteger los derechos fundamentales de las personas privadas de libertad en el ámbito federal y asimismo, para controlar la actuación del Servicio Penitenciario Federal. - See more at: http://www.ppn.gov.ar/?q=presentacion\#sthash.QtiXZpsH.dpuf
} 
período de encarcelamiento como al momento de recuperar la libertad "y son agudizados por las acciones de estigmatización y criminalización que se despliegan dentro y fuera del encierro. Sumado a ello, la sistemática y reiterada vulneración de derechos de los adolescentes ejercida por las autoridades penitenciarias: castigo y malos tratos, aislamiento, ausencia de educación, trabajo y salud, entre otros".

Alcira Daroqui, en La cárcel del presente, su "sentido" como práctica de secuestro institucional (Daroqui, 2002) define a la cárcel como: "una maquinaria de producción de sufrimiento que produce a su vez, sujetos degradados que poco tienen que perder a la hora de construir verdaderas carreras delincuenciales en donde la muerte y el encierro son los futuros más certeros (Daroqui, Alcira, 2002, pág. 191). En cuanto al impacto de la violencia institucional, los jóvenes presos se caracterizan por ser uno de los grupos más sobrevulnerados dentro de la ya vulnerada población carcelaria. En relación con este tema Giuseppe Mosconi (2006) describe:

"Para los jóvenes es más frecuente la aplicación de sanciones disciplinarias de manera discrecional e injustificada, golpizas y bastonazos (sufridos por la mayoría de los entrevistados, y no denunciados por miedo o desconfianza), casi sistemáticos al momento del ingreso, a modo de una cruenta iniciación, requisas continuas bajo modalidades humillantes" (Mosconi, G. 2006, pág. 7)

Contrariamente a los supuestos objetivos de la cárcel: reinserción o reeducación, Mosconi insiste en que estos conceptos están vacíos de funcionalidad y de sentido, ya que la supuesta reeducación "se transforma en instrumento de control disciplinario, de arbitrio y de ulteriores vejaciones a los detenidos y detenidas" (Mosconi, G. 2006, pág. 7). El autor concluye en que "las estructurales instancias de orden, junto a la necesidad de punir y de provocar sufrimiento sobre aquellos que han sido declarados culpables y peligrosos prevalecen sobre cualquier otra lógica y retórica." (Mosconi, G. 2006, pág. 8).

Seguiremos trabajando y profundizando sobre estas cuestiones a lo largo de toda esta investigación, y en particular, en el apartado "Contextualización del trabajo". Luego serán puestas en diálogo con los datos de la realidad en la Segunda Parte, en la discusión teórica en juego con los datos. 


\subsubsection{Sobre la experiencia:}

Nos interesa desarrollar qué entendemos por experiencia, en principio porque creemos que la escritura, además de ser una práctica, una actividad, un conocimiento, o un saber, es una experiencia. Tomamos del filósofo de la educación Jorge Larrosa la idea de que la experiencia es "subjetiva, siempre de aquí y de ahora, contextual, finita, provisional, sensible, mortal, de carne y hueso, como la vida misma. La experiencia tiene algo de la opacidad, de la oscuridad y de la confusión de la vida, algo del desorden y de la indecisión de la vida." (Larrosa, 2006, pág. 110).

Partimos entonces de esta idea de la experiencia, conscientes de la complejidad de su descripción, ya que, como formula Larrosa, el sujeto de la experiencia es “inidentificable, irrepresentable, incomprensible, único, singular” (Larrosa, 2006, pág. 104). La propuesta de la categoría experiencia supone, entonces, intentar evitar cualquier posición genérica cuando se hable de los sujetos.

Tomamos como fundamental el concepto de experiencia social que desarrollan François Dubet y Danilo Martuccelli en Sociología de la Experiencia Escolar, allí manifiestan que "la experiencia individual permanece socialmente construida en el juego de relaciones con otros y con vinculaciones sociales, debe ser captada a través de la actividad de un grupo que testimonia una actividad común y socialmente situada" (Dubet, F, Martuccelli, D, 1996, pág. 16).

Sobre la idea del carácter social de toda experiencia, Teresa de Laurentis, agrega que la experiencia es "el proceso por el cual se construye la subjetividad para todos los seres sociales. A través de ese proceso uno se ubica o es ubicado en la realidad social y de ese modo percibe y comprende como subjetivas (referidas a y originadas en uno mismo) esas relaciones - materiales, económicas e interpersonales- que de hecho son sociales y, en una perspectiva más amplia, históricas” (de Laurentis, pág. 159).

En el mismo sentido, Joan W. Scott, sostiene que "la experiencia es tanto colectiva como individual", y agrega que "la experiencia es la historia de un sujeto. El lenguaje es el sitio donde se representa la historia" (Scott, 1992, pág. 66). En coincidencia con lo que venimos diciendo la autora advierte sobre el peligro de naturalizar la experiencia: la experiencia no refleja una relación simple y transparente entre las palabras y las cosas, y tampoco ocupa el lugar de "evidencia incontrovertible". La autora concluye: 
"No son los individuos los que tienen la experiencia, sino los sujetos los que son constituidos por medio de la experiencia. En esta definición la experiencia se convierte entonces no en el origen de nuestra explicación, no en la evidencia definitiva (porque ha sido vista o sentida) que fundamenta lo conocido, sino más bien en aquello que buscamos explicar, aquello acerca de lo cual se produce el conocimiento. Pensar de esta manera en la experiencia es darle historicidad, así como dar historicidad a las identidades que produce. Este modo de dar historicidad representa una réplica a muchos historiadores contemporáneos que han argumentado que una "experiencia" no problematizada es lo que fundamenta su práctica, y es una manera de dar historicidad que implica un escrutinio crítico de todas las categorías explicatorias que han sido dadas por hecho, incluyendo la categoría de la "experiencia". (Scott, pág. 49-50)

Volvemos a la idea de experiencia que desarrolla Jorge Larrosa, y a la relación experiencia/subjetividad/alteridad. Larrosa aclara: "la experiencia supone, que algo que no soy yo, un acontecimiento, sucede. Pero supone también, en segundo lugar, que algo me pasa a mí. No que pasa ante mí, o frente a mí, sino a mí, es decir, en mí" (Larrosa, 2003, pág. 88). Este autor, a propósito de la idea de experiencia de sí de Foucault, expresa que hay un enlace entre "subjetividad" y "experiencia de sí mismo". La ontología del sujeto no es más que esa experiencia de sí que Foucault llama "subjetivación". Lo que el sujeto como ser propio expresa cuando se observa, se descifra, se interpreta, se describe, lo podemos entender a partir de la narración de sí. Larrosa agrega "la experiencia de sí está constituida, en gran parte, a partir de las narraciones. Lo que somos o, mejor aún, el sentido de quién somos, depende de las historias que contamos y que nos contamos". (Larrosa, 1995, pág. 264).

Sobre la base de las ideas de Jorge Larrosa en la conferencia La experiencia y sus lenguajes, queda claro que el relato es el lenguaje de la experiencia, ya que "la experiencia se elabora en forma de relato, la materia prima del relato es la experiencia, la vida", (Larrosa, 2013, pág. 9). Los relatos de estos jóvenes -en cuanto a su experiencia de escritura- constituyen uno de los ejes de este trabajo de investigación. Sabemos, como también afirma Scott, que no son "evidencias definitivas", ni tampoco transparentes. Queremos, a través de estos relatos, explorar en el significado de algunas de las experiencias de escritura desde la situación de la privación de la libertad. 
Las experiencias concretas sobre las que indagaremos serán: los talleres de escritura que propone la Biblioteca de la escuela del Complejo Esperanza y su producción de escritura creativa, las escrituras cotidianas de los jóvenes, específicamente la escritura en la pared, la biografía escrituraria, escolar, social. Nos interesa fundamentalmente el relato de los jóvenes sobre cada una de ellas. La reconstrucción de estas experiencias y los relatos, de una forma cercana a la microhistoria propone reconstruir las biografías de estos jóvenes, y poner lupa en los relatos de sus experiencias, de las que pueden escrutarse, como en un microcosmos, las características de todo un estrato social (Ginzburg, C., Martín, F., \& Cuartero, F., 1997, pág. 9)

\subsection{Antecedentes}

Del relevamiento realizado tomamos como antecedentes a aquellos trabajos directamente relacionados con la presente tesis. Muchos de estos trabajos de investigación se convirtieron a la vez en marco teórico a través de sus conclusiones. Marco teórico y antecedentes son la base sobre la que nos proponemos seguir indagando y poner en diálogo o discusión con las propias preguntas, análisis y conclusiones.

Encontramos un grupo de investigaciones vinculadas con distintos aspectos del tema de la escritura en el encierro, en especial el importante material investigativo de Antonio Castillo Gómez y el equipo de la Universidad de Alcalá. Castillo Gómez investiga sobre la experiencia de escribir, sus significados y la plural tipología de los escritos carcelarios dando prioridad a los usos más cotidianos u "ordinarios" de las gentes "sin atributos". En particular tomamos como antecedente la recopilación de trabajos ya mencionados en el marco teórico relacionados a la escritura en centros de internamiento realizada por Antonio Castillo Gómez y Verónica Sierra Blas, publicada en el libro: "Letras bajo sospecha". Cada uno de los capítulos corresponde a un aspecto de la escritura en reclusión. El libro está dividido en dos partes. La primera parte -los doce primeros capítulos- aborda las "Palabras cautivas, cárceles y campos de concentración". Si bien nos interesan todos los trabajos, prestamos particular atención a:

- Capítulo I, de Diego Navarro Bonilla: "Archivos y cultura escrita carcelaria: escribir y documentar la prisión desde el siglo XVI". Allí se analiza la escritura de la 
institución, burocrática y de control, versus las artimañas de escritura de los privados de la libertad.

- Capítulo V, de Philippe Artiéres: "La prisión a finales del S XIX: Una máquina grafómana". Allí se presenta la prisión como máquina de escritura, y coexisten la escritura como huella única del individuo, con las escrituras institucionales.

- Capítulo 10: "Voces en cautiverio: un estudio discursivo de graffiti carcelario" de Lelia Gándara en el que aborda la escritura carcelaria, en particular el graffiti como posible contrapanóptico.

Existe una abundante cantidad de trabajos de castillo Gómez como es el caso de "Escrito en prisión. Las escrituras carcelarias en los siglos XVI y XVII" (2003) o el mencionado "Escribir para no morir. La escritura en las cárceles franquistas."(2003). Cabe señalar que si bien estos trabajos son antecedentes muy cercanos a esta investigación, se diferencian de la presente investigación, entre otros aspectos, en que allí se analizan escrituras de distintos momentos de la historia -desde varios siglos atrás, hasta un pasado cercano- por lo tanto analizan la escritura de un tiempo pasado en el que los escritores no están presentes, como sí ocurre en nuestro caso.

Tomamos también como antecedente en relación al contexto a la tesis de Vanessa Tatiana Azeñas Mallea "Una experiencia de educación no formal por medio del arte en contexto de encierro y su relación con acciones de resistencia por parte de los sujetos privados de libertad" (2012). Allí analiza la posibilidad del arte de "romper el sistema, desde adentro del mismo sistema, de un modo no violento" (Azeñas Mallea, p 114, 2012)

Se ha hallado además abundante información y proyectos dentro de la Modalidad Educativa Nacional Contexto de Encierro que resultan interesantes. Estos trabajos fueron publicados en el Blog de la modalidad, la Red Girasoles, en particular las Monografías Finales de acreditación del Postítulo que ofreció el INFOD ${ }^{8}, 2010-2011$. Tomamos específicamente los trabajos finales de docentes que en ese momento estaban en ejercicio en el Complejo Esperanza: los profesores Letizia Barbero y Diego Ceballos. De Barbero: "Análisis de la experiencia "Tumbando Rejas", y de Ceballos: "Implementación del uso del timbre como elemento instituyente".

Tomamos otro significativo antecedente -como antecedente del problema- a la experiencia de escritura y la producción escrita y audiovisual de César González. Este 
joven escritor y hoy cineasta, con el seudónimo de Camilo Blajaquis, empezó a escribir y tomar contacto con las bibliotecas en los pabellones y celdas de diferentes institutos de menores y unidades penitenciarias de nuestro país donde estuvo privado de la libertad. Hoy lleva escrito su tercer libro de poemas. Publicó: "La Venganza del Cordero atado" (2010), "Crónica de una libertad condicional" (2014), "Retórica al suspiro de queja" (2015). Como cineasta es Director de: "Diagnostico Esperanza" (2013), ¿Qué Puede un cuerpo? (2014), de la serie documental "Corte Rancho"(Canal Encuentro, 2013) y de los cortometrajes; "Guachines" y "Truco", entre otros. Contamos con varias entrevistas hechas por diferentes medios de comunicación gráficos y audiovisuales donde relata su experiencia de vida, y dentro de ella, lo que significó para él, el contacto con la lectura y la escritura en el encierro.

Aparecen además abundantes proyectos de escritura en la cárcel: proyectos educativos institucionales dentro de la modalidad Educación en Contexto de Privación de la Libertad y otros proyectos de escritura dentro de los distintos programas universitarios de extensión en cárceles. Muchos de ellos se centran en publicaciones de revistas, como la mencionada Tumbando Rejas, y otras como Seguir Soñando, Atrapamuros, El Rancho, Rotas Cadenas, y demás revistas de distintas cárceles y provincias de nuestro país.

Es importante así también mencionar el I y II Encuentro Nacional de Escritura en la Cárcel 2014/2015, Buenos Aires, organizado por la Facultad de Filosofía y Letras de la Universidad de Buenos Aires (Departamento de Letras, Programa de Extensión en Cárceles), su objetivo fue "abrir un espacio de reunión y debate sobre la palabra escrita y su vínculo con las acciones, lenguas y políticas que atraviesan el encierro" $\%$. De estos encuentros participaron escritores, editores, periodistas, docentes y talleristas que trabajan intramuros.

También podemos mencionar otros trabajos y publicaciones, como los del GESEC Grupo de estudio sobre educación en cárceles- y los artículos publicados en revistas de divulgación: como algunos de la Revista El Toldo de Astier, de la Cátedra de Didáctica de la Lengua y la Literatura I del Departamento de Letras de la UNLP.

\footnotetext{
${ }^{9} \mathrm{http}: / /$ novedades.filo.uba.ar/novedades/i-encuentro-nacional-de-escritura-en-la-c\%C3\%A1rcel
} 


\section{Contextualización del trabajo}

\subsection{Marco legal: adolescentes infractores de la ley:}

Haremos una acotada referencia al régimen penal para jóvenes. Señalamos para empezar que se trata de un complicado campo de articulación de leyes Nacionales y Provinciales, en entrecruzamiento con la Convención Internacional de los Derechos del Niño, ésta última de fuerza mayor. ${ }^{10}$

Desde una mirada histórica, partimos de 1919 con la sanción de la emblemática Ley de Patronato o "Ley Agote", ley que inaugura en nuestro país el desarrollo de las políticas de minoridad. En su el artículo $14^{11}$ indica que:

“Los jueces de la jurisdicción criminal y correccional en la Capital de la República y en las provincias o territorios nacionales, ante quienes comparezca un menor de 18 años, acusado de un delito o como víctima de un delito, deberán disponer preventivamente de ese menor si se encuentra material o moralmente abandonado o en peligro moral, entregándolo al Consejo Nacional del Menor o adoptando los otros recaudos legales en vigor"

Roxana Mazzola en el artículo "Un nuevo paradigma"12 analiza el contenido de dicha ley: "Allí se considera al niño pobre como una amenaza o patología individual y objeto de tutela del Estado, a ser atendido focalmente por instituciones especializadas para su tratamiento. La función distributiva del Estado se volvió tangible en la creación y refuerzo de instituciones como los Tribunales de menores, los Consejos de Minoridad, la seguridad y las transferencias de ingresos a instituciones privadas o estatales (hogares y casas del niño, orfanatos, tribunales)."

Esta ley marcó un hito en las concepciones sobre la niñez: la responsabilidad tutelar del Estado y la patria potestad. Su aparición marca cierta continuidad de un proceso que ya venía desarrollándose en el siglo XIX: "Desde fines de la década de 1890 se

\footnotetext{
${ }^{10}$ Ley 22.803. Art. 2

${ }^{11}$ LEY 10.903/Sanción: 29/IX/1919/ Promulgación: 21/X/1919/ Publicación: B.O. 27/X/1919) (texto conforme decreto-ley 5286/57)

12 http://www.pagina12.com.ar/diario/suplementos/cash/17-5496-2011-10-09.html
} 
multiplicaron los discursos en los que funcionarios y profesionales solicitaron una intervención específica del Estado, diferente a la que cabía esperar para el resto de la población infantil, en la educación y en la localización de los menores. Sus proyectos, presentados en el ámbito legislativo, o expuestos en publicaciones y eventos científicos, se estructuraron en torno a dos demandas: el establecimiento de la tutela o patronato estatal sobre los niños caracterizados como menores, y la creación de instituciones estatales de corrección a las cuales enviarlos" (Zapiola, María Carolina, 2010). Carolina Zapiola deja claro entonces que la Ley de Patronato de Menores de 1919 "colmó en gran medida aquellas expectativas" que la precedieron.

El documento publicado por el Ministerio de Justicia y Derechos Humanos de la Nación del año 2012 "Niños, niñas y adolescentes en conflicto con la ley penal” señala que la idea de niño "tutelado" — fundamentalmente, niño pobre - se equiparaba a "niño abandonado" y "niño delincuente", ya que ambos pasaban a la órbita judicial y se transformaban en "menores" que recibían, a través de la benevolencia del Estado, su protección y tratamiento. (Vasile V., Reyes F., Perriello A., Olaeta, H., 2012). Explica además la mirada correccionalista del paradigma tutelar:

El surgimiento del denominado "complejo tutelar" en relación al tratamiento de los niños y adolescentes nació y se desarrolló dentro de una visión de tipo correccionalista; es decir, se trata de una forma de control social que surge desde un paradigma que estigmatiza a ciertos grupos sociales — "vulnerables", "peligrosos", "desviados"- y les impone políticas "correctivas" o "curativas". (Vasile V., Reyes F., Perriello A., Olaeta, H., 2012)

El paradigma del Patronato aún hoy es tangible en prácticas y discursos del sistema penal juvenil. Si bien -según Guemureman y Daroqui (2001)- ha sufrido embates en la última década por cuenta de otro paradigma, el de la Protección Integral (basado en distintos instrumentos internacionales como la Convención sobre los Derechos del Niño), "aún hoy es tangible en las prácticas y discursos 'producidos' en ámbitos de la justicia de menores, del ministerio público y de los consejos del menor; el predominio del primero sobre el segundo". (Guemureman y Daroqui, 2001). De ahí la importancia de esta ley fundacional: su continuidad y permanencia. En particular en la provincia de Córdoba. 
Para analizar la situación Córdoba, recurrimos al documento de la Comisión por la Memoria en conjunto con la Universidad Nacional de Córdoba "Mirar tras los Muros" (2013), allí se aclara la situación en esta provincia: "nos encontramos en un momento de transición de paradigmas respecto de la niñez y la adolescencia, del patronato a la protección integral, que implican tensiones y contradicciones en el marco de una fuerte construcción social y mediática de los jóvenes como peligro y una creciente selectividad del sistema punitivo"13

Volviendo a la perspectiva histórica, en Córdoba se crea en 1945 la Dirección General de Menores. Alfredo Díaz, en su trabajo "Dirección General de Menores de Córdoba creación y organización" (1945-55), ubica esta decisión en el contexto político ya que forma parte de un proceso histórico de evolución de la estructura del estado provincial:

"La nueva estructura y organización funcional del estado provincial, que se inscribe dentro de la aparición de características del moderno estado de bienestar que aun hoy reconoce la Constitución Provincial, permite la introducción del concepto de planificación gubernamental de un Estado que se asume como responsable del diseño y ejecución de políticas públicas (en este caso políticas sociales, que como tal superan las nociones relativas de caridad y beneficencia) al mismo tiempo que se observa una re significación de los conceptos de familia, mujer e infancia, y especialmente de los niños como futuro y capital humano de la provincia. Esto es el resultado de la aplicación de políticas fundadas en principios propios del peronismo “los únicos privilegiados son los niños" y en una nueva mirada más comprensiva de quienes tenían situaciones familiares distintas a las consideradas aceptables, deseables y válidas hasta entonces, intentando integrarlos social y culturalmente. Estas transformaciones se verán en las normas legales, en las acciones de los poderes del Estado provincial y en su repercusión en la sociedad cordobesa, que aún hoy a tantas décadas de distancia aún guarda en su acervo y su memoria palabras y conceptos que remiten a dichas transformaciones." (Díaz, 2014)

Volviendo a la mirada general de la protección de la minoridad en nuestro país, debemos aclarar que fue siempre conflictiva. Pasó por momentos especialmente difíciles durante los años de dictadura militar (1976-1983), años en los que se plasmaron reformas

\footnotetext{
${ }^{13}$ Mirar tras los Muros. Situación de los derechos de las personas privadas de libertad en Córdoba (2014)
} 
legislativas "en las que se endurece el régimen penal de menores (leyes 22.277 y 22.278); todo esto en el marco de la Doctrina de Seguridad Nacional imperante con los sucesivos gobiernos de facto". (Vasile V., Reyes F., Perriello A., Olaeta, H., 2012, pág. 5)

Hoy, la ley Nacional vigente en el "Régimen Penal de la Minoridad" es la ley de la época de la dictadura: la mencionada ley $N^{\circ} 22.278$ reformada por la ley 22.803 , de los años 1980 y 1983 respectivamente. Allí se establece en su ARTíCULO $1^{\circ}$ que: "No es punible el menor que no haya cumplido dieciséis (16) años de edad. Tampoco lo es el que no haya cumplido dieciocho (18) años, respecto de delitos de acción privada o reprimidos con pena privativa de la libertad que no exceda de dos (2) años, con multa o con inhabilitación" Pero aclara que "Si existiere imputación contra alguno de ellos la autoridad judicial lo dispondrá provisionalmente, procederá a la comprobación del delito, tomará conocimiento directo del menor, de sus padres, tutor o guardador y ordenará los informes y peritaciones conducentes al estudio de su personalidad y de las condiciones familiares y ambientales en que se encuentre."

Con el advenimiento de la democracia se crean la Secretaría de Desarrollo Humano y Familia y la Subsecretaría del Menor y la Familia. En el año 1994 -con la reforma a la Constitución Nacional- se incorpora con rango constitucional la Convención de los Derechos del Niño, suscripta años antes por nuestro país.

Pasamos ahora a otro hito en este tema: en el año 2005 se promulga la Ley 26.061 "Ley de Protección Integral de los Derechos de las Niñas, Niños y Adolescentes". Esta ley establece garantías para el ejercicio y disfrute pleno, efectivo y permanente de sus derechos: a la vida, a la dignidad y a la integridad personal, a la vida privada, a la identidad, a la salud, a la educación, a la libertad, etc. Esta nueva norma, que se inscribe en la "doctrina de protección integral de la adolescencia", concibe a los niños, niñas y adolescentes como sujetos dignos de reconocimiento especial de derechos en su condición de ser humano en desarrollo, elimina toda posibilidad de "disposición tutelar" y consagra el principio rector en la materia: "el interés superior del niño" (Vasile V., Reyes F., Perriello A., Olaeta, H., 2012, pág. 23). Con esta ley se crea la Secretaría Nacional de la Niñez, Adolescencia y Familia (SENNAF):

“La SENNAF es el organismo encargado de establecer los lineamientos y parámetros de las políticas públicas de infancia, teniendo como meta efectivizar 
los derechos y garantías reconocidos a los niños, niñas y adolescentes. Además, como influjo del proceso de reformas, se fueron produciendo cambios en los programas y dispositivos penales y en los Centros de Privación de libertad para adolescentes llamados “Institutos de Menores" (Vasile V., Reyes F., Perriello A., Olaeta, H., 2012, pág. 5)

En Córdoba, La ley Provincial efectiva es la Ley 9944, de "Promoción y protección integral de los Derechos de las niñas, niños y adolescentes en la Provincia de Córdoba”. El Articulo 82 de esta ley define su objetivo primordial: “El procedimiento penal juvenil tiene por objeto primordial la protección y asistencia integral de las niñas, niños y adolescentes en conflicto con la ley penal, garantizando lo conducente al logro de su integración social a través de una atención que dé prioridad al abordaje educativo multidisciplinario, con especial énfasis en su capacitación para el acceso al mercado laboral."

Esta ley cordobesa, en su Artículo 63 establece que la Cámara de Niñez, Juventud y Violencia Familiar es el órgano competente para conocer y resolver en única instancia en los delitos atribuidos a niñas, niños o adolescentes que fueren punibles. El Artículo 65 señala que el Juez Penal Juvenil es quien dispondrá "las medidas cautelares, de coerción y de protección". El Artículo 71 agrega que "En el caso de niñas, niños o adolescentes que siendo menores de edad hubieren cometido hechos tipificados como delito penal por el ordenamiento vigente, el Juez Penal Juvenil deberá mantener contactos de manera periódica y personal con las niñas, niños y adolescentes institucionalizados, a los fines de oírlos e informarles periódicamente sobre el estado de las causas respectivas"

Por su parte desde el Ministerio de Desarrollo Social del Gobierno de Córdoba se reconoce que "existe una brecha importante entre el reconocimiento jurídico de los derechos de niñas, niños y adolescentes y su grado de efectividad" y se propone "concretar en lo referido a las prácticas, las perspectivas, valores y principios operativos planteados en nuestras leyes"14

\footnotetext{
14 Ley N 9944 Promoción y protección integral de los Derechos de las niñas, niños y adolescentes en la Provincia de Córdoba http://senaf.cba.gov.ar/ws40397/senaf/wp-content/uploads/Ley9944.pdf
} 
El mencionado Informe Mirar tras los Muros (2013), en el capítulo V "Situación de los derechos humanos en las instituciones de privación de libertad que alojan a jóvenes menores de 18 años en Córdoba", hace una mirada crítica desde los datos de la realidad y señala que la ley vigente "es abiertamente contraria al ordenamiento jurídico vigente constituido por la Constitución Nacional, Convención Internacional de los Derechos del Niño" ya que concibe a los niños y a los jóvenes "como objetos de protección-tutelarepresión, y no como sujetos de derechos" ${ }^{\text {"15 }}$. Aclara dicho informe en nota al pie ${ }^{16}$ que "En provincia de Buenos Aires se sancionó a través de la ley 13.634 en el año 2007 un procedimiento penal juvenil adecuado a los principios de la Convención Internacional Sobre los Derechos del Niño".

Dicho informe manifiesta que en Córdoba, y en la mayoría de las provincias argentinas, persiste la mirada tutelar, y que fundamentándose en la ley vigente, los jueces continúan tomando medidas que violan las garantías constitucionales para el proceso penal y los principios establecidos en la Convención Internacional Sobre los Derechos del Niño y demás normativas internacionales. Al avanzar sobre la situación de la provincia de Córdoba señala que: "el procedimiento judicial dirigido a niños y jóvenes menores de 18 años en conflicto con la ley penal, prácticamente se ha mantenido sin modificaciones sustanciales desde la vigencia del Decreto-Ley del Estatuto de Minoridad 4873 ordenado en 1966"; por lo tanto "alrededor de 150 o 200 niños y jóvenes privados de libertad en Córdoba por conflictos con la ley penal continúan sin acceder a la fundamental garantía de un proceso donde existan de manera diferenciada un órgano acusador (Fiscal), un defensor y otro órgano que juzga y ordena las medidas de privación de libertad (juez)"(2013, pág. 529)

En la Provincia de Córdoba, es la Secretaría de la Niñez, Adolescencia y Familia SeNAF- quien hoy tiene a cargo poner a disposición de la justicia una serie de acciones y programas en relación a los jóvenes privados de la libertad. Desde la página web oficial de este organismo se sostiene que se "acompaña y supervisa" a los adolescentes infractores de la ley penal; que la privación de la libertad, es una medida de "última instancia"; que en ese caso se interna a los adolescentes en los denominados "Centro

\footnotetext{
15 Informe: Situación de los derechos humanos en las instituciones de privación de libertad que alojan a jóvenes menores de18 años en Córdoba, UNC http://www.unc.edu.ar/extension/vinculacion/observatorio-ddhh/informe-mirar-tras-los-muros
}

${ }^{16}$ Nota 12 , pág. 524 
Socioeducativos" - a su cargo- ; y que es allí donde se pretende brindar protección, asistencia integral y una serie de actividades educativas, deportivas, recreativas, y de formación laboral. Sostienen además que: "Los equipos técnicos de los Centros Socioeducativos informan periódicamente a los jueces correspondientes sobre la situación de la niña, niño o adolescente, su evolución y posibles alternativas de movilidad del sistema de protección."

Por su lado, desde la Comisión Provincial de la Memoria, en el informe mencionado, se señala que lo expresado por los responsables de estas instituciones no se cumple, ya que: "de las entrevistas realizadas a jóvenes que pasaron por el Complejo Esperanza, sus familias y algunos profesionales se puede conocer que son múltiples las situaciones de destrato y malos tratos que sufren los jóvenes presos. A esta situación contribuyen además de los factores propios del contexto de encierro, la falta de formación y capacitación del personal de guardia, la ausencia de un reglamento interno que determine reglas claras de convivencia, la falta de actividad y tiempo ocioso que viven los jóvenes." Cabe aclarar en este sentido que en los años 2014-2015 se propuso la construcción y posible próxima implementación del reglamento de convivencia del Complejo Esperanza, hasta ese momento inexistente. Allí se establecerían derechos y obligaciones de los jóvenes y el personal a cargo, a través del cual se abriría la posibilidad, por ejemplo, de que los jóvenes puedan opinar y denunciar malos tratos o malas condiciones de vida.

Contamos también con los datos del Informe elaborado por el Centro de Estudios y Proyectos Judiciales -Tribunal Superior de Justicia- en el año 2015 sobre adolescentes privados de la libertad en Córdoba Capital por presunta infracción a la ley penal, conforme procedimiento penal juvenil ${ }^{17}$. La fuente de datos es la Mesa de Defensoría Pública en Niñez, Juventud y Violencia Familiar. Allí se ofrece una información cuantitativa sobre los adolescentes -varones y mujeres- privados de la libertad, y en particular -lo que más nos interesa a los fines de este trabajo- los varones ingresantes al CAD, el Centro de Admisión del Complejo Esperanza:

- Un total de 1.425 privaciones de la libertad a adolescentes en Córdoba Capital.

17

https://www.google.com.ar/url?sa=t\&rct=j\&q=\&esrc=s\&source=web\&cd=4\&cad=rja\&uact=8\&ved=0ahUKEw iYie-

M0OHNAhXCjJAKHfhEB6sQFggsMAM\&url=https\%3A\%2F\%2Fwww.justiciacordoba.gob.ar\%2Fcepj\%2F Nove dades\%2FFileArchivo.aspx\%3Fid\%3D63\&usg=AFQjCNGdd1pbhxa2UMf4Cu8KLS1cDEVdw\&sig2=tWviEjHDGIOw pJv-LGOtA\&bvm=bv.126130881,d.Y2I 
- Un total de 1.179 adolescentes privados de la libertad.

- Del total de adolescentes privados de la libertad, un $91 \%$ son varones, el $9 \%$ son mujeres

- En cuanto a las edades: 0,1\% de 11 años, 0,4\% de 12 años, 2,7\% de 13 años, $10 \%$ de 14 años, $18 \%$ de 15 años, 34\% de 16 años, $32 \%$ de 17 años, y 1,8\% de 18 años (estos últimos ingresan en su mayoría a la cárcel de adultos).

- El $31 \%$ son Niños y Adolescentes no punibles, el $69 \%$ son Adolescentes sometidos a proceso penal

- El 65,5\% de los jóvenes que ingresan al CAD son alojados en el Complejo Esperanza, el $32 \%$ son entregados en guarda provisoria a un familiar o un tercero

- Derivaciones dentro del Complejo Esperanza: 63\% al Módulo II (Ex - Instituto Nuevo Sol), 29\% al Módulo IV (Ex - Instituto San Jorge), 4\% al Módulo III (Ex Instituto Pasos de Vida), el $1 \%$ al Módulo I (Ex - Instituto Horizontes).

A todo lo mencionado, debemos agregar la inevitable referencia al Código de Faltas de Córdoba, ley 8431. Este código fue sancionado por la Legislatura de Córdoba en $1994^{18}$ por unanimidad, reaprobado en al año 2007 -ley 9444- y vigente hasta diciembre del año 2015, cuando se promulga y aplica en su reemplazo el Código de Convivencia Ciudadana ${ }^{19}$.

El trabajo de campo de esta tesis se hace en plena vigencia y aplicación del Código de Faltas de 1994. Una de las características normativas de este código cordobés es la existencia de una multiplicidad de penas: arresto, multa, inhabilitación, clausura, decomiso, prohibición de concurrencia, y otras penas sustitutas como cursos educativos, tratamiento terapéutico o trabajo comunitario. Quien decide la conveniencia de la aplicación de una u otra pena es el comisario. En "Policía, seguridad y Código de Faltas" (Brocca, Morales, Plaza y Crisafulli, 2014) se hace referencia a esta cuestión, y se aclara que pese a la variedad de penas en materia contravencional, la más aplicada es el arresto : "la reina de las penas, es decir, aquella que más se aplica (...) lo que significa cotidianamente dificultades en el acceso al trabajo y la educación para cientos de jóvenes de los sectores populares de nuestra provincia” (Brocca, Morales, Plaza y Crisafulli, 2014, pág. 23)

\footnotetext{
${ }^{18}$ La Legislatura provincial aprobó en el año 2007 la ley 9444, que aprueba el texto ordenado del Código de Faltas sancionado en 1994. Renumeró algunos artículos y sistematizó las numerosas reformas incorporadas en los últimos 13 años http://www.lavoz.com.ar/files/Codigo_de_Faltas.pdf

19 El "Código de Convivencia Ciudadana" de la Provincia de Córdoba entró en vigencia el primero de abril de 2016 tras haber sido aprobado por mayoría en la Legislatura Unicameral, en diciembre de 2015. Se presenta como una superación del cuestionado código de 1994. Las organizaciones sociales lo denuncian como una continuidad "disfrazada" del código anterior.
} 
Lo más emblemático de este código tal vez lo constituye la aplicación de la cuestionada figura del "Merodeo", la que permite que la policía detenga a aquellos que "permanecieran en las inmediaciones de (edificios o vehículos) en actitud sospechosa, sin una razón atendible, según las circunstancias del caso, o provocando intranquilidad entre sus propietarios" (Art. 98 del Código de Faltas). El perfil de "actitud sospechosa" queda a criterio del policía. En el informe antes mencionado, en referencia a las imprecisiones del código, se explica:

"El Código de Faltas, mediante estas vaguedades, habilita la discrecionalidad policial: se traslada al agente de calle la facultad de completar la definición de la conducta prohibida en el Código. Es el propio agente que realiza la detención quien define lo que en cada caso, es "sospechoso", "escandaloso", "indecente" o "molesto" y decide también si la conducta de la persona se ajusta al tipo descripto. De este modo es que el Código de Faltas permite arbitrariedades y discriminaciones, además de ser violatorio de la Constitución Nacional (viola groseramente el principio de legalidad, mediante el cual se establece que una conducta, para estar prohibida, debe estar perfectamente definida). En el Código de Faltas de la Provincia de Córdoba no se sabe qué es lo que se castiga, pero sí podemos saber a quién está dirigido: a jóvenes provenientes de las barriadas, a los sectores más vulnerados. (Brocca, Morales, Plaza y Crisafulli, 2014, pág. 23)

Distintas organizaciones de Córdoba hace varios años vienen denunciando públicamente este Código de Faltas y su aplicación por parte de la Policía. En particular el Colectivo de Jóvenes por nuestros derechos, año tras año, en las sucesivas Marchas de la Gorra denuncia las sistemáticas violaciones de Derechos Humanos hacia determinados grupos de jóvenes que constantemente son estigmatizados y criminalizados:

“La aplicación del Código genera cientos de detenciones arbitrarias y discriminatorias por día, donde las personas son sometidas a encierro y maltratos físicos, psicológicos y sexuales, encontrando el extremo de violencia en la desaparición de personas y los asesinatos que, junto a las familias de quienes hoy ya no están, llamamos muertes por Gatillo Fácil."20

\footnotetext{
${ }^{20}$ Del "Kit de resistencia” publicado por la organización social Colectivo de Jóvenes por Nuestros Derechos http://marchadelagorra.org/ni-codigo-de-faltas-ni-codigo-de-convivencia-kit-de-resistencia/
} 
El informe antes mencionado analiza el Código de Faltas como instrumento de disciplinamiento social de los sectores marginados, y a la relación de los jóvenes con la policía como "uno de los puntos más complicados de abordar en la provincia de Córdoba" (Brocca, Morales, Plaza y Crisafulli, 2014, pág. 2)

Transcribimos, para finalizar, un fragmento de la entrevista realizada por los jóvenes del Complejo Esperanza al jurista argentino, Dr. Eugenio Raúl Zaffaroni ${ }^{21}$. En el marco de la octava edición de la revista Tumbando Rejas (TR), jóvenes y docentes del Centro Educativo del Complejo Esperanza tuvieron la oportunidad de entrevistarlo personalmente, en una visita que realizó a la ciudad de Córdoba:

Registro de entrevista, 14 de agosto de $2015^{22}$

TR: ¿Qué opina respecto de la Ley de Responsabilidad Penal Juvenil que aún está pendiente en Argentina?

Zaffaroni: Es un serio problema. Por un lado le tengo confianza y por otro miedo. Hay una cuestión que es normativa. Bajarla a la realidad es peligroso. Cualquier ciudadano, si tiene que ser objeto de una medida restrictiva de su libertad, habrá que probar que hizo algo que daña a otro. $Y$ tiene derecho a defenderse, tenga la edad que tenga. En la medida en que nos manejemos con: "el menor pobrecito necesita ser tutelado", eso es inquisitorio.

Ese es el principio general y lo deseable. Ahora no puedo desconocer que eso permitiría bajar la edad de procedibilidad. Tendría derecho a estar en un proceso. No la de punibilidad. Pero cuando lo llevamos a la realidad, hay una distorsión temporal, los procesos duran mucho, el chico deja de ser chico durante el proceso. El riesgo que veo es que vayamos a una prisión preventiva. No es pena pero es lo mismo. La cuestión es que eso no sirva como pretexto para una institucionalización mayor.

TR: En la práctica, las medidas tutelares y cautelares les permiten a los jueces privarlos de su libertad indefinidamente. Las cautelares se renuevan cada 3 meses, según el juez. No pueden planificar sus vidas, porque no saben cuándo van a recuperar la libertad.

Zaffaroni: La idea tutelar implica que va a haber un juzgado único que va a tutelar al nene desamparado y al nene infractor que también es un desamparado. Obviamente,

${ }^{21}$ Ex Juez de la Corte Suprema de Justicia de la Nación y actual Juez de la Corte Interamericana de Derechos Humanos

${ }^{22}$ En el marco de su visita a Córdoba el 14 de agosto, a las 18 hs para la conferencia realizada en el Auditorio Hugo Chávez (Ciudad Universitaria). Actividad organizada por la Facultad de Filosofía y Humanidades y la Secretaría de Extensión Universitaria de la UNC. 
todas las paradojas y las contradicciones absurdas que tiene el aparato punitivo se manifiestan mucho más claramente cuando nos referimos a adolescentes. Eso es inevitable. Tres años de prisión preventiva es una barbaridad para cualquiera, mucho más si está en una edad evolutiva; lo estás metiendo en una institución que deja una marca mayor que en un adulto. En todo lo que sea tratar de llevar garantías procesales hay que tener mucho cuidado, porque el discurso penal es siempre perverso

TR: ¿El poder judicial legitima un sistema socio económico desigual?

Zaffaroni: No tengo dudas. El poder judicial es un aparato que se monta para eso. No todo el Poder Judicial. No todos los jueces lo hacen, hay algunos que actúan disfuncionalmente, y eso molesta.

TR: En el Complejo ingresan cada vez más chicos menores de 15 años.

Zaffaroni: Si, y ¿Cuáles son las infracciones? La incidencia real que tiene el pibe menor de 16 años en delitos graves es muy baja. En homicidios es un índice muy bajo. El estereotipo del pibe dado vuelta que sale a matar no existe. Este no es el problema del derecho a la vida. No es que tengamos bandas de pibes matando gente por la calle. Los mayores índices de homicidios en las villas son por los grandecitos, son bandas que se disputan el reparto de tóxicos.

Las palabras del Dr. Zaffaroni ponen en relieve la complejidad del asunto y el cuidado necesario al desarrollar ideas sobre esta cuestión, dadas las complicaciones y contradicciones que pueden aparecer.

Finalizamos este apartado reconociendo haber realizado apenas una aproximación al contexto legal y a la problemática vigente -pendiente de solución- del régimen penal juvenil. Sí podemos aquí reafirmar que el modo en que están establecidas las competencias de los jueces penales juveniles en la ley 9944, no se ajusta en absoluto a los estándares de derechos humanos de las normativas internacionales, ya que los jueces en Córdoba siguen dictando medidas por tiempo indeterminado, aplicando la privación de la libertad como la principal medida desde una mirada tutelar.

A lo largo de este trabajo van a seguir apareciendo las dificultades y contradicciones mencionadas en cuanto a la confrontación de lo establecido, la teoría y la realidad; como las que aparecen entre la prioridad que propone la ley 9944 respecto a un abordaje educativo, que plantea como objetivo del procedimiento penal juvenil: "lograr una integración a través del enfoque educativo multidisciplinario", y el espacio que se le da a la educación en la implementación de las medidas que adoptan los jueces. 
Tomamos a propósito las palabras de la docente y bibliotecaria de la escuela del Complejo Esperanza, Letizia Barbero, de su trabajo de la Especialización Docente de Nivel Superior en Contextos de Encierro: "está claro que entre el discurso jurídico y la efectiva práctica existe un largo camino sembrado de contradicciones legales, superposición de modelos y luchas de intereses".

\subsection{El Complejo Esperanza}

En algún momento se los llamó Colonias, Hogares, Centros de Reeducación o Centros de Tratamiento del Menor. En el año 2005, al inaugurarse el Instituto Nuevo Sol, el predio recibió el nombre de Complejo Esperanza.

2.2.1. Breve historización: antecedentes del actual Complejo Esperanza

María José Ortiz Bergia en "Historia de los menores abandonados y la tutela estatal en Córdoba, cambios y continuidades en un período de transición 1930-1943" estudia las modificaciones que se produjeron a partir de los años treinta en el modelo de tratamiento de la problemática de la minoridad en Córdoba. Bergia describe que por esos años "al Asilo de Menores Varones y de Huérfanas del Buen Pastor, entre 1936 y 1942 , se agregaron cuatro establecimientos de internación de menores en la ciudad capital: la Colonia-Hogar de Menores Huérfanos y Desamparados Dr. Vélez Sarsfield, el internado de la Escuela del Trabajo Presidente Roca, un internado en Villa Belgrano y el Hogar de Menores Madres" (Ortiz Bergia, 2012)

Nos interesa poner el foco en La Colonia Hogar Vélez Sarsfield, también conocida como Escuela de Niños Granjeros, creada en1936, ya que se trata del (hoy) Complejo Esperanza:

"A los cuatro meses de su creación, con una población de sesenta asilados, se producian quejas por las condiciones en que la colonia estaba funcionando. Según las denuncias canalizadas por medio de la prensa, ésta no había sido provista de los instrumentos correspondientes a su finalidad agrícola ganadera y de los recursos para el mantenimiento de los menores" (Ortiz Bergia, 2012). 
Esta descripción que hace Ortiz Bergia nos llama la atención, y aunque se trata de una situación puntual, decidimos no omitirla, porque marca la continuidad en el tiempo de las problemáticas y reclamos que hoy, ochenta años después, siguen apareciendo en la prensa de la provincia, en trabajos de investigación y en las redes sociales: las malas condiciones de vida, la falta de recursos, a la que hoy se suman malos tratos y otros reclamos.

En 1945 se crea en Córdoba la Dirección General de Menores y se realiza "la fusión y el traslado de los internos del Reformatorio a la Escuela de Niños Granjeros de Camino 60 Cuadras en el predio de más de 130 hectáreas de la Colonia Hogar "Dr. Dalmacio Vélez Sarsfield”. Entre 1954 y 1955 los establecimientos en la toda la provincia aumentan y Córdoba ya cuenta con más de diez institutos, siendo el Hogar Vélez Sarsfield el más grande (Díaz, Alfredo, 2014)

Durante el último período de la dictadura militar (1976-1983), en 1980, se crea el CROM (Centro de reeducación del menor). "Sus autoridades estaban conformadas por un director, vicedirector, dos regentes y un cuerpo de 45 maestros, aproximadamente. El CROM estaba dividido en 4 pabellones: el pabellón color verde, color crema, color naranja y color azul. La división no respondía a ningún criterio de causa penal, o de otra índole; solo era por cuestiones distributivas. El cuerpo docente en su mayoría integrado por hombres (aunque luego ingresaron algunas mujeres), tenían un régimen de trabajo de lunes a lunes, de 7 a 19 h. La rutina diaria de los chicos comenzaba a las 8 de la mañana con el desayuno, luego limpiaban el pabellón y las habitaciones. Después se pasaba a los talleres o a la escolaridad, según le tocara a cada uno..."23.

Luego de 1983 las actividades educativas se fueron incrementando. Un ex docente da su testimonio para el informe "Mirar tras los muros":

“la relación de alumno-docente era fraternal, humanizada. A partir de esto, existía un sentido de pertenencia de los espacios, lo que implicaba en algunas oportunidades desmalezar los espacios de las canchas de fútbol y de los alrededores del instituto (la zona en ese momento era más baldía que en la actualidad); se organizaban campeonatos de fútbol, de ping-pong, campamentos de verano en pueblos vecinos, actividades de carpintería, entre otras."

\footnotetext{
${ }^{23}$ Del Informe de la Comisión Provincial de la Memoria: Mirar tras los Muros. Situación de los
} derechos de las personas privadas de libertad en Córdoba (2014) 
"Una particularidad del instituto de jóvenes (menores de 21 años) era que tenía un régimen semi abierto. Este sistema implicaba que no había "guardia cárceles", que las puertas permanecían abiertas desde las 7 de la mañana hasta las 8 de la noche, y se cerraban por cuestiones de seguridad de los jóvenes; sólo había dos guardias afuera del CROM. Al ser un régimen semi abierto, contaba con la posibilidad de salidas, las que podían darse los fines de semanas, que según el comportamiento o delito cometido, podían durar un día, o todo el fin de semana".

A fines de 1994 autoridades del Consejo Nacional del Menor y la Familia, mostraban preocupación por las fugas que se estaban produciendo en este sistema semi abierto. En los medios de prensa algún funcionario expresaba que había que trabajar desde la "contención efectiva y no meramente afectiva", y que el objetivo principal era terminar con las fugas. A partir de aquí se inició la construcción de institutos de máxima y mediana seguridad en la zona campo Bouwer a 14 kilómetros de la ciudad

Entre 1998 y 2000, se produce el cierre definitivo del CROM que se encontraba dentro de la ciudad, ya avanzada la construcción del grupo de Institutos en el predio del Hogar Vélez Sarsfield, que inicialmente se consideró que debían ser de máxima seguridad.

Se crearon allí entonces el CETRAM I y el CETRAM II, ya denominados Institutos Correccionales, éstos albergaban jóvenes varones entre 14 y 18 años de edad privados de su libertad, bajo la tutela de los juzgados de menores por tramitación de causas penales de diversa gravedad: "es a partir de la construcción de los macro Institutos en Bouwer con los convenios firmados con el entonces Consejo Federal del Menor (a fines de los 90) que se inició un proceso de profundización en el deterioro de las condiciones de vida, de trato, de intervención sobre los jóvenes presos por conflictos con la ley penal."24

En el año 2003, ya estaban ampliadas las plazas de los macro Institutos en Bouwer para alojar a los jóvenes presos. Pasaron a ser de unas 100 plazas, a unas 500, lo que en la práctica fue ampliando el número de jóvenes enviados a prisión. Después del cierre del CROM, en el año 2005 se creó oficialmente el llamado Complejo Esperanza, adonde la totalidad de los jóvenes en situación de conflicto con la ley penal son hoy trasladados.

\footnotetext{
24 Del Informe de la Comisión Provincial de la Memoria: Mirar tras los Muros. Situación de los
} derechos de las personas privadas de libertad en Córdoba (2014) 
2.2.2. Situación actual: años $2014-2015$

Desde el año 2005, el Complejo Esperanza es el "Centro Socio-educativo Cerrado" que concentra a todos los jóvenes varones "menores de edad" atravesando procesos penales de la provincia de Córdoba. Desde la página web oficial de la SeNAF (Secretaría de Niñez, Adolescencia y Familia) se justifica la privación de la libertad, esgrimiendo que "en los casos que la situación procesal no permite a la justicia penal juvenil disponer de medidas de acompañamiento en libertad, las niñas, niños o adolescentes son derivados de manera excepcional a un Centro Socioeducativo, donde se les brinde protección y asistencia integral priorizando un abordaje educativo multidisciplinar" (SeNAF Córdoba, 2015)

El Complejo Esperanza se encuentra en la localidad de Bouwer, a $14 \mathrm{~km}$ de Córdoba Capital (Camino 60 cuadras Km 14 1/2) en un predio de 5 hectáreas. A la fecha del trabajo de campo de la presente investigación, en dicho predio se distribuyen cinco Centros de encierro con diferentes tipologías, según diferentes criterios que pueden ser el tipo de medida judicial y la edad del adolescente:

- El Centro Socio Educativo Módulo I (Ex Horizontes)

- El Centro Socio Educativo Módulo II (Ex Nuevo Sol).

- $\quad$ El Centro Socio Educativo Módulo III (Ex Pasos de Vida),

- El Centro Socio Educativo Módulo IV (Ex San Jorge);

- EI CAD (Centro de admisión y diagnóstico) donde los chicos permanecen un tiempo cuando ingresan, antes de ser derivados a los institutos mencionados

En otro espacio, el Instituto San José, se ubican los equipos técnicos y administrativos. ${ }^{25}$

Cada instituto funciona con cierta autonomía, con sus respectivas autoridades y personal. Físicamente están distanciados dentro del gran predio como construcciones independientes con sus propios cercos o murallas. Estos institutos se articulan entre sí a través de las autoridades del Complejo Esperanza y de la SeNAF.

\footnotetext{
${ }^{25}$ Esta organización corresponde hasta el año 2015, ya que en el 2016 hubo modificaciones organizativas
} internas 
Los jóvenes son distribuidos en los diferentes institutos con distintos criterios, en general de acuerdo al delito cometido: consumo o tráfico de drogas, delitos contra la propiedad, delitos contra la privacidad, homicidio, etc.; o de acuerdo a la edad, como es el Instituto San Jorge, donde se agrupan los más jóvenes, en algunos casos niños de solo 11 años. La distribución también puede depender de cuestiones de convivencia y conducta de los jóvenes en el encierro.

\subsection{La escuela en el Complejo Esperanza.}

El Profesor Diego Ceballos, actual Coordinador del Área Educativa ${ }^{26}$, nos explica que antes de la creación del Centro Educativo, en el año 2009, la educación en el complejo era informal, con docentes que enseñaban a los jóvenes pero sin poder certificar los trayectos.

Para realizar una breve historización de la educación y la escuela dentro del Complejo Esperanza tenemos que inevitablemente retomar la realizada en el apartado anterior en cuanto a la institución macro.

Nos remontamos a fines de los años noventa al momento del cierre de los institutos en Córdoba Capital y la unificación de todos los institutos de internación en Bouwer. La situación de los docentes era precaria, y el cierre del CROM "implicó la baja de contratos de quienes permanecían en esa modalidad y el traslado a otras áreas de la provincia a quienes tenían cargos estables" los funcionarios provinciales "se hicieron presentes en el CROM comunicando que era una decisión política tomada que a partir de ese momento todos los docentes del área correccional serian derivados al área prevencional y sus lugares serian ocupados por los becarios. ${ }^{.27}$ Vale aclarar aquí que de ser docentes quienes estaban a cargo de la educación hasta entonces, los nuevos empleados son becarios, empleados administrativos, no docentes.

La secretaria adjunta de la Unión de Educadores de la Provincia de Córdoba de ese momento, Carmen Nebreda, en una nota publicada en Revista gremial La Tiza en julio de 1998 sostenía: "las modificaciones aplicadas desde ayer revelan la intención del

\footnotetext{
26 Trabajo Postítulo Diego Ceballos "Implementación del uso del timbre como elemento instituyente" 2011. Enlace web: https://bibliotecasabiertas. files.wordpress.com/2012/05/implementacic3b3n-deluso-del-timbre-como-elemento-instituyente-diego-ceballos1.pdf

27 Del Informe de la Comisión Provincial de la Memoria: Mirar tras los Muros. Situación de los derechos de las personas privadas de libertad en Córdoba (2014)
} 
gobierno de cambiar el perfil del CROM - un instituto de rehabilitación y educación de menores- para pasar a ser un centro de represión. Ello queda demostrado-dijo-porque los becarios fueron formados para la represión carcelaria y no como maestros".

El cierre del CROM -de régimen semi abierto- dio además por finalizada una posibilidad para los jóvenes: su participaran en la educación formal en escuelas de la ciudad junto con otros jóvenes no institucionalizados.

Fue a partir de la Ley de Educación Nacional $N^{\circ} 26.206$, que se empieza a organizar la educación formal en contextos de encierro en todo el país y en la provincia de Córdoba, a partir del año 2006. Dedicaremos más adelante un apartado a esta Ley.

Desde el año 2009, ya con la denominación "Centro Educativo Complejo Esperanza", la escuela ofrece oficialmente educación Primaria y Secundaria; depende del Ministerio de Educación de la Provincia de Córdoba, que acredita los trayectos educativos realizados en el Centro Educativo. En esta institución educativa convergen y se articulan tres escuelas del "afuera" que tienen su anexos en el Complejo Esperanza: CENMA Prof. María Saleme De Burnichon -Sede 03 y Anexo 08-; Escuela Paulo Freire Anexo Complejo Esperanza, pertenecientes a la Dirección de Educación de Adultos; y el IPEM 124 Prof. María Rosa Oviedo de De La Vega, Programa de Inclusión y Terminalidad Secundaria Para Jóvenes de 14 a 17 años (P.I.T), perteneciente a la Dirección de Enseñanza Media.

Se articulan, en una compleja trama institucional actividades de las distintas escuelas, unas dependientes de la Dirección de Educación de Jóvenes y Adultos y otras de la Dirección de Educación Secundaria.

Dentro de la primera -Educación de Jóvenes y Adultos- funciona un CENMA Centro de Educación de Nivel Medio de Adultos- y un CEMPA -Centro de Educación de Nivel Primario de Adultos.

Dentro de la segunda -Educación Secundaria- funciona desde el año 2010 el programa PIT: se trata de un Programa de Inclusión / terminalidad, propuesto por el Ministerio de Educación de la Provincia de Córdoba. En la página oficial se presenta como "El Programa de inclusión para la terminalidad de la educación secundaria y formación laboral para jóvenes de 14 a 17 años, posibilita a los adolescentes que hayan abandonado la escuela al menos un año antes de la puesta en marcha del programa (en el 2010) o que no la iniciaron, finalizar sus estudios a través de un servicio educativo, que 
en razón de su diseño más flexible, permite a cada estudiante construir su propio trayecto formativo"28.

A la vez unas y otras se articulan con la Coordinación de Educación en Contexto de Encierro de la Provincia de Córdoba, quien articula a la vez acciones con la Modalidad Nacional de Educación en Contexto de Privación de la Libertad.

La escuela funcionaba en sus comienzos en aulas dentro de los institutos socioeducativos, lo que acarreaba la complejidad de la presencia física de varias instituciones en un mismo espacio físico compartido, ya que allí se cruzaban actividades dependientes de distintas áreas y ministerios: Educación, Desarrollo Social, Justicia, Salud; cada uno de ellos con sus lógicas y complejidades propias.

Actualmente -desde el año 2009- el CENMA y la escuela primaria funcionan en un edificio por fuera de los módulos donde los jóvenes están encerrados, dentro del predio del Complejo Esperanza, en una construcción que originariamente iba a ser destinada a actividades deportivas.

Es importante señalar que las autoridades escolares y los docentes fueron quienes realizaron todos los pedidos y las gestiones necesarias para que la escuela funcionara fuera de los institutos y contara con un espacio propio. Se les ofreció este lugar adaptado donde se realizaron subdivisiones en durlock, La escuela actualmente cuenta con una oficina administrativa, biblioteca, dos aulas, cocina y baños. Esto se logró desde el convencimiento de los docentes de que la escuela estuviera lo más fuera posible de los sectores de los institutos donde la situación de encierro y vigilancia es mayor para los jóvenes.

La escuela, especialmente el CENMA y el CENPA (no una gran parte del PIT que aún se desempeña al interior de los Centros Socioeducativos por falta de espacio) funciona en este edificio. Este espacio tiene una infraestructura insuficiente, motivo por el que los docentes aún reclaman la construcción de una escuela adecuada a las necesidades de los alumnos.

Como la definen los docentes, la escuela es "el afuera del adentro". Diego Ceballos, Coordinador Pedagógico del CENMA, destaca en su trabajo de pos título: "Implementación del uso del timbre como elemento instituyente" que la escuela desde su creación no tuvo ni tiene rejas, ni alambrados, ni cercos, ni muros, allí sostiene que "sin

${ }^{28} \mathrm{http}: / /$ www.cba.gov.ar/programa-14-17-otra-vez-en-la-escuela/ 
dejar de pensar que aun siendo particulares, la escuela tiene aspectos igualitarios con las demás escuelas, porque si sostenemos que esta organización es una escuela "en tránsito" para nuestros alumnos, debe si o si parecerse a cualquier escuela en contextos diferentes al nuestro."

Ceballos defiende en su trabajo el derecho a la educación "la educación que los jóvenes reclaman solo puede cumplirse con un joven realizando las actividades con sus profesores y no solo se garantiza por que esté en el ámbito de la escuela sin cumplir con las exigencias que la escuela tiene". Defiende la necesidad de que existan normas para "crear un orden que permita trabajar aspectos como el respeto al otro, las garantías constitucionales, la responsabilidad y la defensa de los derechos humanos". El caso del uso del timbre es, como el derecho a la educación, un ejemplo de la relación entre obligaciones y derechos. Ceballos concluye así: "Puedo decir que el timbre igualó a los alumnos de la educación en contexto de encierro con alumnos de cualquier otro contexto, al menos en ese aspecto que tiene que ver con el sentirse alumno, como decía Matías $P$., quien pudo reconocerse en su rol de estudiante, aun cuando estaba preso."

La organización mencionada, tanto del Complejo Esperanza, como del centro educativo (articulación de escuelas), es vigente hasta el mes de diciembre del año 2015.

\subsection{Educación en Contextos de Privación de Libertad:}

Al mes de diciembre del año 2015, se trata de una modalidad educativa cuyo objetivo principal es garantizar el derecho a la educación a todas las personas privadas de libertad, promover su formación integral y su desarrollo pleno.

Para hacer una breve historización podemos decir que en el año 2000, dentro del área de Educación de Jóvenes y Adultos del Sistema Educativo se abre una nueva línea de trabajo: La Educación en Establecimientos Penitenciarios. Es interesante aclarar que hasta ese año, la educación en las cárceles estaba a cargo del Área Educación del Servicio Penitenciario, a través de capacitaciones o trayectos informales, la mayoría de las veces sin acreditación. Se necesitará la realización de convenios entre el Ministerio de Justicia y el Ministerio de Educación de la Nación, para lograr así la transferencia de la educación penitenciaria a los Sistemas Educativos Provinciales. En el año 2003 se crea el Programa Nacional de Educación en Establecimientos Penitenciarios y de Minoridad; en 
el año 2005 se cambia a la denominación a Programa Nacional Educación en Contextos de Encierro.

En el año 2006, se promulga la Ley № 26.206 - Ley de Educación Nacional- que en su Capítulo XII, dedica los artículos 55 a 59 a la Educación en Contextos de Privación de Libertad:

ARTíCULO 55.- La Educación en Contextos de Privación de Libertad es la modalidad del sistema educativo destinada a garantizar el derecho a la educación de todas las personas privadas de libertad, para promover su formación integral y desarrollo pleno. El ejercicio de este derecho no admite limitación ni discriminación alguna vinculada a la situación de encierro, y será puesto en conocimiento de todas las personas privadas de libertad, en forma fehaciente, desde el momento de su ingreso a la institución.

ARTíCULO 56.- Son objetivos de esta modalidad: a) Garantizar el cumplimiento de la escolaridad obligatoria a todas las personas privadas de libertad dentro de las instituciones de encierro o fuera de ellas cuando las condiciones de detención lo permitieran. b) Ofrecer formación técnico profesional, en todos los niveles y modalidades, a las personas privadas de libertad. c) Favorecer el acceso y permanencia en la Educación Superior y un sistema gratuito de educación a distancia. d) Asegurar alternativas de educación no formal y apoyar las iniciativas educativas que formulen las personas privadas de libertad. e) Desarrollar propuestas destinadas a estimular la creación artística y la participación en diferentes manifestaciones culturales, así como en actividades de educación física y deportiva. f) Brindar información permanente sobre las ofertas educativas y culturales existentes. g) Contribuir a la inclusión social de las personas privadas de libertad a través del acceso al sistema educativo y a la vida cultural. ARTÍCULO 57.- Para asegurar la educación de todas las personas privadas de libertad el Ministerio de Educación, Ciencia y Tecnología acordará y coordinará acciones, estrategias y mecanismos necesarios con las autoridades nacionales y provinciales y de la Ciudad Autónoma de Buenos Aires, con institutos de educación superior y con universidades. Corresponde al Ministerio de Justicia y Derechos Humanos y sus equivalentes provinciales y de la Ciudad Autónoma de Buenos Aires, así como a los organismos responsables de las instituciones en que se encuentran niños/as y adolescentes privados de libertad, adoptar las disposiciones necesarias para el cumplimiento de lo establecido en el presente capítulo. 
ARTÍCULO 58.- Los sistemas educativos jurisdiccionales ofrecerán atención educativa de nivel inicial destinada a los/as niños/as de cuarenta y cinco (45) días a cuatro (4) años de edad, nacidos/as y/o criados/as en estos contextos, a través de jardines maternales o de infantes, así como otras actividades educativas y recreativas dentro y fuera de las unidades penitenciarias.

ARTÍCULO 59.- Todos/as los/as niños/as y adolescentes que se encuentren privados de libertad en instituciones de régimen cerrado según lo establecido por el artículo 19 de la Ley $N^{\circ} 26.061$, tendrán derecho al acceso, permanencia y tránsito en todos los niveles y modalidades del sistema educativo. Las formas de implementación de este derecho responderán a criterios de flexibilidad y calidad que aseguren resultados equivalentes a los de la educación común.

En el material bibliográfico para formación docente ofrecido por el Ministerio de Educación de la Nación: "Pensar la educación en contextos de encierro" (2010) se explica que a partir de la Ley Nacional de Educación se asumió el desafío de "construir y desarrollar una política universal para esta modalidad del sistema educativo" y que esta construcción ha supuesto un recorrido de luchas, avances y retrocesos, dificultades y logros que han permitido legitimar la existencia de este contexto particular del sistema educativo intentando dar respuesta a las necesidades educativas de los sujetos que se encuentran privados de la libertad (pág. 13). Se agrega que otro desafío fundamental para esta modalidad educativa es el de construir una escuela que reconozca la complejidad propia de un contexto en el que se cruzan diversas prácticas y lógicas institucionales: "cruces, interacciones, diferencias y similitudes entre nuestras prácticas educativas y la lógica propia de las instituciones de encierro: sus presupuestos, finalidades, modos de funcionamiento" (pág.14).

Quede claro entonces, que la educación en contextos de encierro es un campo relativamente nuevo y en construcción, tanto en su dimensión práctica como teórica. Esta situación de construcción de lo nuevo interpela a todos sus actores. Una de las decisiones estratégicas de política educativa para dar respuesta a la cuestión de la formación docente fue la realización del Postítulo de "Especialización en Educación en Contextos de Encierro" destinada a docentes en ejercicio en la modalidad.

Para terminar, citamos un fragmento de las palabras de la Profesora Letizia Barbero, en su discurso de graduación de dicho Postítulo en Córdoba, en diciembre del año 2011: 
"No es suficiente la mera enunciación del compromiso político-educativo si éste no se hace acción, si éste no se vuelve práctica concreta. El compromiso vuelto acción requiere imaginar, buscar, construir, compartir las mejores "estrategias político-pedagógicas" para remediar las situaciones de inequidad social que albergan la gran mayoría de nuestros alumnos. Consideramos que estas estrategias orientadas a una educación anti-destino sólo podrán ser construidas por educadores formados, solidarios, comprometidos, atentos a sus prejuicios y naturalizaciones, esperanzados críticamente, confiados en las posibilidades de transformación propias y de sus alumnos, capaces de pensar y pensarse, capaces también de actuar en la tensión y la incomodidad presente en estos contextos, dispuestos a construir colectivamente y a reflexionar siempre sobre el camino recorrido"29

\subsection{Biblioteca, talleres de escritura y Revista Tumbando Rejas}

La Biblioteca de la escuela pertenece a una red de bibliotecas en contexto de encierro: el programa "Bibliotecas Abiertas". Incluimos una breve descripción de este programa en particular ya que el trabajo de campo se realiza centralmente a partir de las actividades que propone la Biblioteca Abierta del Complejo Esperanza, cuya Bibliotecaria es, desde el año 2014, la mencionada profesora, Letizia Barbero.

Se trata de un programa del Ministerio de Educación de la Nación implementado a través de la Coordinación Nacional de Educación en Contextos de Encierro que incluye acervo bibliográfico, equipamiento tecnológico y capacitación de bibliotecarios. Desde la página web del Ministerio de Educación de la Nación se destaca que "Estas bibliotecas constituyen un espacio privilegiado para poner a disposición de las personas privadas de libertad diversidad de materiales que los contacten con la cultura y que permiten su acercamiento gradual hacia la recomposición del lazo social’30

\footnotetext{
${ }^{29}$ https://bibliotecasabiertas.wordpress.com/2012/02/13/discurso-de-leticia-barbero-al-graduarse-encordoba-con-el-postitulo-de-especializacion-en-educacion-en-contextos-de-encierro/

${ }^{30}$ http://www.me.gov.ar/curriform/noticias biblio09.html
} 
Revista Tumbando Rejas:

Tumbando Rejas es un proyecto socioeducativo de formación y del Centro Educativo del Complejo Esperanza. Se trata de un trabajo del equipo docente, en torno a la publicación de la revista Tumbando Rejas. Este proyecto comenzó a desarrollarse en 2008 en el marco de los espacios formales y no formales de la escuela. Desde entonces se va publicando una revista por año. En el año 2015 se publicó su octava edición.

Letizia Barbero, la profesora coordinadora del proyecto desde sus inicios, actualmente bibliotecaria, relata en su trabajo de pos título "Análisis de la experiencia: Tumbando Rejas"31 que la revista surgió "en el marco de los espacios formales y no formales de la escuela, particularmente del área de Ciencias Sociales" y que "el proyecto nació como respuesta a una multiplicidad de problemáticas presentes en este contexto de encierro, centralmente vinculadas a la deshumanización y vulneración de los derechos de los jóvenes privados de su libertad"

La revista funciona actualmente como el Proyecto Institucional del Centro Educativo. Se trabaja durante todo el año en forma articulada desde las diferentes áreas y niveles para la publicación. Se realizan reuniones periódicas con todo el equipo docente y representantes de los alumnos, se elige una temática de manera consensuada, se divide el trabajo, se establecen criterios de escritura y acuerdos conceptuales. Finalmente se toman también en equipo las decisiones de edición, diseño y publicación.

Se trabajó en números anteriores en trono a diferentes temáticas: el derecho a la identidad, a la sexualidad, al trabajo, a la libre expresión, a la participación, y temas como el consumismo y de la participación ciudadana y política.

Barbero en su trabajo, explica que: "esta propuesta pretende brindarles herramientas para la transformación de su visión de la realidad desde su propia realidad vivida, creando un espacio de libertad en donde se reflejen, a través de la palabra escrita principalmente, los aspectos emotivos de los alumnos y sus concepciones del mundo, construyendo un espacio de análisis crítico, participación constructiva y libre expresión de los jóvenes alojados en las instituciones de encierro”. Agrega luego: “¿Qué puede Tumbando Rejas? Creemos que nuestro proyecto puede constituirse en un camino de transformación e inclusión. Frente a las dolorosas trayectorias de vida de nuestros alumnos, consideramos que Tumbando Rejas puede ser una instancia que interrumpa ese destino de exclusión

\footnotetext{
31 Trabajo Postítulo Letizia Barbero. Enlace Web: https://bibliotecasabiertas.files.wordpress.com/2012/05/anc3a1lisis-de-la-experiencia-tumbandorejas-letizia-barbero.pdf
} 
prefigurado y entendido como inexorable, brindando la posibilidad real de transitar experiencias inclusivas y dignas."

A modo de introducción, la nota editorial del número 1 de la revista. que se repite en todas las ediciones, se presenta a sí misma como un modo de: "tender puentes de comprensión y construir nuevas relaciones sociales, en donde la tolerancia, la solidaridad y la justicia sean valores primordiales. Tumbar rejas se refiere no solo a las rejas materiales y visibles que nuestros alumnos padecen diariamente, sino también a las mentales en las que todos estamos de una u otra manera, atrapados."

\section{Planteamiento del problema y resoluciones metodológicas}

A continuación, desarrollaremos el proceso de problematización de la tesis, a partir de consignar los objetivos, las preguntas de investigación y la estrategia metodológica. Sobre el particular terreno donde desarrollamos nuestro trabajo, tomamos, para empezar, la advertencia de Giuseppe Mosconi, en la presentación de Voces del encierro (2006):

La cárcel representa seguramente uno de los terrenos más difíciles para la investigación social. No tanto y no sólo por los obstáculos burocráticos y formales, las restricciones espaciotemporales, el carácter rígido, inquietante, ansiógeno en los cuales la investigación se desarrolla, sino sobre todo por la red de ambigüedad de significados y de lenguajes dentro de la cual debe interactuar, en distintos niveles. En lo que respecta a la Administración Penitenciaria, a las autoridades que autorizan la investigación, como aquello que emerge y que se va registrando no puede resultar otra cosa que un elemento de denuncia, una acusación más o menos directa a quien gentilmente y con incuestionable corrección profesional ha concedido las autorizaciones del caso, ha actuado como mediador en consentir los accesos, ha guiado a los investigadores en la fruición de las fuentes y en la directa investigación en el campo. En lo que concierne a los sujetos recluidos o que han sufrido los efectos de la aflicción penal, como su actitud puede aparecer como victimizante, instrumental, o autoexcusatoria, como es natural que surja de parte de quien ha padecido sufrimientos $y$ descrédito social sin poder aceptar, y a veces siquiera sin comprender las razones. En relación a la misma autopercepción del investigador, fácilmente dividido entre reconstruir la imagen más objetiva y exhaustiva posible 
del objeto de investigación, y denunciar aquello que resulta como más grave e inaceptable, entre la tendencia a desdramatizar los hechos y las situaciones, como si todo estuviese bajo control, casi normal, aun como una forma de autodefensa respecto de las tensiones y de los obstáculos emotivos que el ambiente impone, y la imposibilidad de desconocer los aspectos más evidentes de sufrimiento, de opresión y de deshumanización, sino también la necesidad de hacerlos emerger y de denunciarlos. Este conjunto de ambivalencias constituyen riesgos que pueden afectar el buen resultado de las investigaciones de este tipo, atemperando la realidad emergente, manteniendo en las sombras, por malintencionado sentido de respeto, los aspectos más graves y preocupantes, o bien enfatizando a los mismos con un puro intento denunciatorio (Giuseppe Mosconi, 2006, pág. 4)

\subsection{Objetivos generales y específicos}

1. Describir y analizar la experiencia de escritura de un grupo de jóvenes alojados en el Complejo Esperanza

1.1. Indagar y documentar en torno a la experiencia de escritura literaria propuesta en los talleres de la biblioteca

1.2. Indagar y documentar sobre la experiencia de escritura cotidiana en el encierro

2. Conocer las posibilidades y oportunidades de acceso a la experiencia de la escritura

2.1. Indagar y analizar sus relatos sobre la experiencia de apropiación de la escritura, la biografía escritora, las experiencias sociales de escritura

2.2. Describir y analizar las oportunidades y posibilidades de escritura dentro de la institución de encierro

3. Comprender el significado de la escritura, en tanto experiencia de expresión personal, social y política para los jóvenes privados de la libertad

3.1. Documentar y analizar en los relatos de los jóvenes sus propias percepciones sobre el significado de la experiencia personal y social del escribir

3.2. Indagar sobre las potencialidades de la experiencia de escribir en general, y en particular sobre sus posibilidades de transformación de la experiencia personal, social y política 


\subsection{Problema/Preguntas}

Presentamos las preguntas en un cierto orden, lo que no refleja una jerarquía fija o gradualidad en la investigación, cada pregunta actúa más bien como "una onda en el estanque" -en palabras de Rodari- respecto al problema que queremos abordar.

Nos preguntamos entonces,

- ¿Cuál es la experiencia de escritura de los jóvenes privados de la libertad, desde su apropiación hasta la experiencia actual en el encierro?

- ¿Cómo es la experiencia de escritura en los talleres literarios que propone la biblioteca de la escuela? ¿Qué, cómo, para quién y para qué escriben estos jóvenes en los talleres literarios?

- ¿Qué escriben los jóvenes en la cotidianeidad del encierro? ¿Dónde, cómo y con qué escriben? ¿para quién y para qué lo hacen?

- ¿Cómo funcionan estas experiencias de escritura, entre las posibilidades y las imposibilidades de la institución de encierro?

- ¿Qué experiencias y qué significados personales, sociales, religiosos, políticos u otros, se encuentran asociados a la escritura de los jóvenes en situación de encierro?

\subsection{Resoluciones metodológicas}

Nos propusimos para esta investigación una perspectiva de corte cualitativo por lo tanto descriptivo/interpretativo, partiendo de un enfoque etnográfico.

Entendemos que el enfoque etnográfico, tomando palabras de Elsie Rockwell, es un modo de "abordar las grandes preguntas sociales mediante estudios en pequeños mundos en los que es posible, como investigadores, observar y acercarnos personalmente a las vicisitudes de la vida cotidiana y a los significados que éstas tienen para los habitantes del lugar" (Rockwell, 2005, Pág. 3).

Podemos hablar en nuestro caso concreto, de varios niveles de ingreso al campo. Primero, el ingreso a la institución total: el Complejo Esperanza. Luego, el ingreso y permanencia en el Centro Educativo dentro del Complejo, que posibilitó el conocimiento y contacto cotidiano con los diferentes actores de la escuela y la convivencia con la 
comunidad educativa toda; en particular el ingreso al espacio de la biblioteca y la participación en los talleres de escritura que ella ofrece. Esto permitió ir acercándonos cada vez más a lo específico de nuestro trabajo, el vínculo con los sujetos -los jóvenes privados de la libertad- y con el objeto de investigación -la experiencia de la escritura-. También logramos el ingreso a los institutos donde los chicos viven, para registrar la escritura en las paredes y finalmente el ingreso a un espacio más personal e íntimo: el de la entrevista etnográfica. Como define Fabre en la presentación de su libro Écritures Ordinaries: "elegimos lanzarnos a la etnografía de algunas situaciones de escritura, considerar los espacios sociales restringidos y las prácticas bien caracterizadas."

En nuestro trabajo en particular, participar y permanecer en el Complejo Esperanza por un tiempo prolongado -más de dos años- nos brindó una extraordinaria información acerca del contexto. El rol del investigador se enmarcó dentro de lo que conocemos como observación participante, con distintos matices y niveles de observación/participación que se detallarán en la segunda parte.

Como afirma Rockwell, la etnografía es un proceso de producción de textos, y "documentar lo no documentado" sigue siendo una representación válida del quehacer diario del investigador. Pensamos con la autora que el proceso de escritura se da desde el inicio del trabajo de investigación y coincide en un solo proceso con la interpretación y el análisis. La escritura de los otros y el proceso de la propia escritura permitió dar sentido al proceso etnográfico.

Expondremos aquí algunas de las resoluciones metodológicas en general. Más adelante se explicitarán en forma más detallada y concreta las estrategias y decisiones tomadas en cada caso y en cada momento particular de la investigación.

\subsubsection{Resoluciones metodológicas iniciales:}

\subsubsection{Observación participante}

Como señala Rosana Guber, la observación participante se caracteriza por la inespecificidad de sus actividades y su ambigüedad es, más que un déficit, una cualidad distintiva (Guber, 2011, pág. 51). Supone la presencia del investigador, experiencia directa, percepción y testificación, ésta es la fuente del conocimiento: "él estuvo allí". La 
participación es la condición sine qua non del conocimiento cultural, que incluye la subjetividad y las nociones del investigador. Su voz se presenta, no como una realidad objetiva, sino como un posicionamiento. Este enfoque reconoce que en todos los casos sería imposible la idea positivista de poder ser un "testigo neutral", pero también reconoce que tampoco se podría lograr la idea de "ser uno más". En palabras de Guber "en el campo también se negocia el sentido del investigador, de su labor inmediata y de su fin último" (Guber, 2011, pág. 92).

En cuanto a la pretensión de objetividad, tomamos un concepto explicado por la cordobesa Claudia Mónaco Felipe, en una entrevista realizada por la revista Ciudad X, sobre la presentación de su libro "Ayotzinapa, horas eternas". Ella sostiene que "hay quienes piensan que la objetividad es un propósito a alcanzar y que es posible, yo creo que no. Habrá gente a la que eso le puede molestar, pero me siento tranquila porque lo que hago es honesto. Cuando uno es consciente de que todo tiene un por qué y un para qué, es más valioso que el precepto de la objetividad". Mónaco Felipe agrega que en la construcción del relato histórico se integran "fuerzas hegemónicas y contrahegemónicas", y aclara que ella, en su trabajo, decidió hablar desde aquellas voces "invisibilizadas, calladas, ninguneadas." 32

Retomamos a Rosana Guber, que en "El salvaje metropolitano" desarrolla el concepto de observación/ participación: "Desde la práctica de la observación participante concebimos la participación como un puesto de observación desde donde es posible divisar prácticas y sentidos, por ejemplo, en un campo de actividades, en un haz de relaciones sociales, en el funcionamiento institucional, etc.” (Guber, 2004, pág. 117). Guber señala asimismo que la participación es una instancia necesaria de acercamiento a los sujetos, y que "no tiene por qué ubicarse en las antípodas de la observación, la cual puede ser entendida, a su vez, como la disposición general del investigador hacia lo real: su conocimiento". Propone hablar de observación participante "concibiendo a dicho conocimiento no como una captación inmediata de lo real, sino como una elaboración reflexiva teórico-empírica que emprende el investigador en el seno de relaciones con sus informantes." (Guber, pág.119)

\footnotetext{
32 Mónaco Felipe, Paula. (2016, febrero 25). Historias de dolor: el libro de Paula Mónaco Felipe sobre las desapariciones en México [Ciudad Equis]. Recuperado a partir de http://www.lavoz.com.ar/ciudad-equis/historias-de-dolor-el-libro-depaula-monaco-felipe-sobre-las-desapariciones-en-mexico
} 
Pedro Javier Cruz Sánchez en "Una primera catalogación de las escrituras expuestas del medio rural en Castilla y León" -en cuanto a la etnografía de la escriturahace un repaso de la investigación etnográfica o antropológica en referencia a la escritura, y señala que desde estos enfoques se han realizado "interesantes aportaciones, al centrar su objeto de estudio en la conexión que existe entre los espacios sociales, los cuales comprenderían el espacio doméstico, las creencias y prácticas religiosas y la actividad laboral y profesional y, por otro, la ritualización de buena parte de los usos de la escritura"

Para poder concretar la observación participante en nuestro trabajo, se creó un dispositivo que consiste en formar parte de los talleres de escritura que ofrece la biblioteca de la escuela. Planteamos un trayecto inicial de observación, registro, descripción, interpretación y análisis de situaciones, en el marco de los talleres o experiencias de escritura anteriormente señaladas

\subsubsection{Entrevista etnográfica}

Dentro del proceso general de investigación la entrevista acompaña dos grandes momentos: el de apertura, y el de focalización y profundización. En el primero, el investigador debe descubrir las preguntas relevantes; en el segundo, implementar preguntas más incisivas de ampliación y sistematización de esas relevancias (McCracken, 1988, citado por Guber, 2012)

Durante y después de los talleres que mencionamos, se fueron seleccionando actores significativos, informantes claves para la realización de entrevistas en profundidad. Como afirma Guber no existe un orden o momento preestablecido ya que "la entrevista es una alternativa más entre otros tipos de intercambios verbales, entre los cuales no hay un orden preestablecido. Puede aparecer al principio o ya avanzada la investigación, dependiendo del lugar que tenga esta situación en la rutina local y de las decisiones del investigador" (Guber, 2011, pág. 78).

Esta selección se realizó teniendo en cuenta que los entrevistados estuvieran interesados en participar en esta búsqueda conjunta de las preguntas (Rockwell, 2005) y fundamentalmente, teniendo en cuenta que hayan participado en trayectos de escritura en forma intensa, discontinua o extendida, en el marco de los talleres de escritura en la Biblioteca Abierta de la escuela.

Nos sostenemos en el concepto de trayectoria de Bourdieu (Bourdieu \& Kauf, 1999 pág. 82), y en una idea de relato, no como visión lineal, sino "como serie de posiciones 
sucesivamente ocupadas por un mismo agente (o un mismo grupo) en un espacio en sí mismo en movimiento y sometido a incesantes transformaciones”. También tomamos de Bourdieu el concepto de construcción de sentido, teniendo en cuenta que, por un lado, estos relatos están sujetos a "unas coerciones y unas censuras específicas" y, que al mismo tiempo, a través de ellos, estos jóvenes pueden "convertirse en ideólogos de la propia vida seleccionando, en función de un propósito global, unos acontecimientos significativos concretos $y$ estableciendo entre ellos unas conexiones que sirvan para justificar su existencia y darle coherencia" (Bourdieu \& Kauf, 1999, pág. 76).

Guber advierte que "los hablantes generan contextos que exigen determinados posicionamienlos de los participantes. En algunos sectores sociales la entrevista es un instrumento del estado para aplicar políticas sociales o medidas de control legal." (Guber, 2011, pág. 72). En nuestro caso, nos encontramos en esta delicada situación, ya que los jóvenes poseen una vasta experiencia en entrevistas a partir de la institucionalización, al estar intervenidos por diferentes profesionales afines al orden punible. Tales entrevistas han tenido una connotación particular de control/intervención sobre sus vidas. Hemos comprobado en nuestra estadía en el lugar que un mismo joven es interrogado sucesivas veces, va pasando por una serie de entrevistas realizadas en distintos momentos de su internación: desde las de la policía o los jueces, hasta las de los equipos técnicos del encierro y equipos docentes, e incluso las de los practicantes y tesistas de distintas carreras de institutos superiores o universidades de Córdoba.

Nuestras preguntas a realizar en las entrevistas a los chicos se han ido revisando y modificando a lo largo del proceso. La siguiente pauta de entrevista finalmente se construyó; solo como una herramienta orientadora que buscaba no perder de vista a las preguntas de la investigación. En ningún caso se realizaron todas las preguntas, ni se siguió al pie de la letra, sino que se tomó como un disparador, una guía abierta. De todas las pensadas, entonces, las preguntas realizadas se fueron eligiendo, y se intentó dejar espacio a la conversación y a lo que surgía de la espontaneidad. Si bien la pauta aquí consignada puede parecer extensa, en ella aludimos a los temas que nos interesaban conversar, pero que en muchos casos surgían espontáneamente y no necesitaba repreguntarse ${ }^{33}$.

Se realizaron siete entrevistas, tres en el año 2014, cuatro en el 2015, en tres de ellas tuvimos la oportunidad de una segunda entrevista para repreguntar. Todas fueron desgrabadas en su totalidad.

\footnotetext{
33 Pauta de la entrevista: en Anexo
} 
De las primeras entrevistas realizadas surgieron, y con mucha fuerza, otras escrituras, las que se sumaban a las del taller de escritura creativa: las escrituras cotidianas, y en particular la escritura en la pared. Hasta ese momento íbamos a centrarnos fundamentalmente en la escritura en el taller. Pensamos a partir de aquí en una nueva posibilidad y una nueva posible línea de trabajo: la escritura en la pared, a la que en principio habíamos descartado por la dificultad de registro en ese contexto. Nos aventuramos, realizamos las consultas a las autoridades y pedimos los permisos necesarios para realizar un registro fotográfico de las escrituras de las paredes de los sectores donde los chicos viven, lo cual fue aceptado. Desarrollaremos este tema en el punto 3.3 .2

\subsubsection{Registro de campo}

Sostenemos, para empezar, que un registro de campo no es ni la realidad, ni el reflejo fiel y transparente de la realidad, sino más bien "la materialización de nuestra propia perspectiva del conocimiento sobre la realidad.", y creemos que, como sucede en todo el proceso de investigación, "el registro forma parte de una construcción reflexiva". (Guber, 2004). Partimos entonces de que el registro es siempre un recorte de lo que como investigadores consideramos relevante, y que nuestra incidencia en ese recorte de lo relevado es inevitable.

Un registro de campo da cuenta siempre de la relación investigador/informantes. Tomamos el concepto de Rosana Guber de que un registro es "una especie de cristalización de la relación, vista desde el ángulo de quien hace las anotaciones o fija el teleobjetivo de la cámara" (Guber, 2004). Dentro de las posibilidades de registro: notas, grabación, registro posterior, hemos tomado distintas decisiones adaptándonos a lo que las diferentes circunstancias permitían y a lo que considerábamos conveniente en cada momento.

En el caso de los talleres del año 2014, dictados en la biblioteca, la mayoría de éstos fueron grabados con el necesario permiso de los chicos que participaron; y además sobre la mayoría de ellos se escribió un registro posterior. En cambio, los talleres del año 2015 dictados en el Instituto Horizontes, de máxima seguridad, en su mayoría no fueron grabados por varios motivos. En principio por suponer que se infringían las reglas -no 
muy claras- del lugar, además de problemas de acústica, por el tipo de actividad que proponían los talleres, ya que en general los chicos hablaban "todos juntos" y había música. De manera que estos últimos talleres fueron descriptos en un registro inmediatamente posterior a la sesión de campo. Guber lo considera conveniente "por varias razones: en contextos conflictivos que impliquen persecución, suspicacia, enfrentamiento" (Guber, pág. 169). A través de estos registros de campo posteriores, además, fuimos ampliando nuestra mirada, aprehendiendo el campo y a nosotros mismos. En relación a este tipo de registro, Guber agrega:

"Esta modalidad obliga al investigador a realizar una profunda introspección -y con ello, un arduo y fructífero proceso de autoconocimiento- para recordar. Ello supone, paralelamente, un aprendizaje de la elaboración de datos al tiempo que se procede a su registro, de manera que el análisis de datos es, en buena medida, paralelo (de hecho y no de palabra) al trabajo de campo mismo" (Guber, Pág. 170)

Estas decisiones, además, tienen relación con lo que afirma Guber cuando sostiene que: "la viabilidad y practicidad de diversos medios de registro depende de cuestiones tales como la temática a tratar, su conflictividad y grado de compromiso para los informantes, la personalidad de los presentes, la etapa de la investigación y el método de análisis de datos".

Para cerrar este apartado tomamos esta reflexión de Roxana Guber en referencia a la permanente relación de las decisiones del investigador y sus expectativas, con la "totalidad" de lo registrado:

"Aunque nunca se alcance, quizá sea conveniente seguir cultivando aquella vieja y productiva utopía de registrarlo todo, pero siempre y cuando se tenga claro que la amplitud de ese todo no excederá, en mucho, las referencias impuestas por el marco cognitivo del investigador. En todo caso la apertura de la mirada será paralela a la apertura del conocimiento y de las conexiones explicativas. (Guber, Rosana, pág. 171) 


\subsubsection{Resoluciones metodológicas posteriores}

\subsubsection{Taller de escritura: Situaciones de escritura para el taller}

En la contextualización mencionábamos que el trabajo de campo se realizó alrededor de las actividades de la Biblioteca Abierta, y que el momento de la llegada al campo coincidió con la inauguración de la biblioteca en la escuela.

La realización de talleres de escritura es una línea de acción importante dentro de los objetivos de las bibliotecas en el encierro. Este trabajo, en el momento de nuestro ingreso, era aún una "tarea pendiente". Consideramos entonces dos cuestiones:

- Que, ya que como investigadores necesitábamos permanecer en el lugar, ser parte, observar y participar. entonces podíamos iniciar nuestro trabajo en este caso, como partícipes activos de los talleres de la biblioteca.

- Y que, a los encargados de la organización de las tareas de la biblioteca les podía ser útil nuestra participación y colaboración. ${ }^{34}$

Dado lo anterior, hicimos nuestra propuesta de participar en la organización, planificación y realización de los talleres de escritura, la que fue aceptada por el equipo diectivo de la escuela y la Biblioteca Abierta en particular ${ }^{35}$.

Los talleres de escritura propuestos por la Biblioteca Abierta fueron entonces el dispositivo que permitió la entrada al campo. A través de ellos se logró ser parte, iniciar el vínculo con los jóvenes y con su experiencia de escritura.

La planificación de los talleres requirió de una cuidada "ingeniería" tanto en el año 2014, como en el 2015, para lograr la participación de la mayor cantidad posible de chicos. La experiencia y el conocimiento del campo que se fue construyendo en el proceso nos sirvieron para lograr en la segunda etapa del año 2015, una serie de talleres con un grupo estable de chicos que escribieron una novela grupal autobiográfica. Se tuvieron en cuenta para la planificación, una serie de estrategias en relación a la realidad

\footnotetext{
${ }^{34}$ En las conversaciones iniciales con el Coordinador ya nos había expresado que desde la escuela estaban "cansados" de que los diferentes "tesistas" que entraban al campo, se "llevaban" la información y casi nunca aportaban nada a la escuela.

${ }^{35}$ La Biblioteca Abierta forma parte de la Biblioteca Provincial de Maestros, a quien presenta los proyectos anuales y específicos, para su aprobación y financiamiento si es necesario
} 
y los condicionamientos de la institución de encierro, casi obvios para la cotidianeidad del lugar, como, por ejemplo:

- Que los horarios y días propuestos no coincidieran con días de visita, con horarios de clases, ni con otros talleres.

- Que los grupos de jóvenes estuvieran conformados de manera estratégica para que no coincidan en un mismo espacio y momento chicos que no puedan "cruzarse" por problemas personales, ya sean, de convivencia del encierro o "cuentas pendientes" de "la calle", para evitar situaciones de violencia.

- Lograr una articulación y acuerdos, por medio de los coordinadores, con las autoridades y guardias de los institutos.

- Otra cantidad de cuestiones más puntuales, como por ejemplo que los guardias que participaran en un inicio, fueran los que, desde la mirada de los coordinadores, tuviesen un buen vínculo con los chicos y con la escuela para la buena predisposición en la formación de los grupos.

\subsubsection{Registro fotográfico/ Grupo de discusión}

\subsection{Registro fotográfico/ copiado:}

Para abordar la escritura cotidiana o "escritura doméstica" (Lahire, 1995) pudimos realizar registros fotográficos de las escrituras en las paredes de algunos sectores donde los jóvenes viven, y de la escritura en las mesas de la escuela; y un registro copiado a mano de las paredes del Centro de Admisión. Como entendemos que la escritura es una práctica social, y que la experiencia está necesariamente inserta en la situación social, nos propusimos acompañar este registro con una indagación a través de la estrategia metodológica de "grupos de discusión".

\subsection{Grupo de discusión:}

Entendemos como grupo de discusión a una "técnica no directiva que tiene por finalidad la producción controlada de un discurso por parte de un grupo de sujetos que son reunidos, durante un espacio de tiempo limitado, a fin de debatir sobre determinado tópico propuesto por el investigador." (Gil Flores, 1994., pág. 
201). Convocamos entonces, para poder comprender mejor estas escrituras, a un grupo de jóvenes, algunos de ellos participantes de los talleres literarios, otros alumnos de la escuela. Concretamente estas escrituras fueron proyectadas y con una mínima intervención se intentó propiciar el comentario o discusión al respecto. Tomamos la técnica de grupo de discusión, la que fue empleada "para la interpretación de los resultados obtenidos por otros medios" (Gil Flores, pág. 208)

\subsection{Planificación del grupo de discusión:}

El grupo está formado por siete jóvenes, y se realiza en una hora de clases en la escuela, en Primer año del CENMA. La materia que cede las horas es Ciudadanía y Participación. Se proyectan en una pantalla las fotografías de las escrituras. Se organiza en 2 etapas:

- $1^{\circ}$ etapa: presentación de los registros de las escrituras del CAD -Centro de Admisión y Diagnóstico-, en este caso no son fotos, sino que fueron copiados a mano de la pared del lugar, por no haber tenido autorización de fotografiar. Están transcriptos en un PDF: nueve páginas con tres a cinco escrituras por página, muchas de ellas coinciden en la temática. Se van presentando página por página y para generar un intercambio, se les pregunta cuál de estas "eligen" o les parece "más interesante", y se indaga en torno a esa elección. A partir de ahí se formulan las preguntas básicas orientadoras. En todos los casos se deja un espacio especial para los comentarios espontáneos de los jóvenes

- $2^{\circ}$ etapa: se proyecta una selección de las noventa fotos del Instituto San Jorge (fotos de las paredes tomadas el año 2014) y se van comentando libremente intercalando con alguna de las preguntas básicas orientadoras

Preguntas básicas orientadoras: ¿Qué dice? ¿Qué quiere decir? ¿Quién lo escribió? ¿Cuándo lo escribió? ¿Dónde lo escribió? ¿Dónde se puede escribir y dónde no? ¿Cómo y con qué lo escribió? ¿Con quién lo escribió? ¿Para quién lo quiso escribir?

¿Para quién no lo quiso escribir? ¿De quién quiere proteger su escritura? o ¿Quién no tendría que leerlo? ¿Para qué lo quiso escribir? ¿Para qué le puede haber servido haberlo escrito?

¿Le puede servir a otro su escritura? 


\subsubsection{Categorías de análisis: perspectiva cualitativa}

Desde una perspectiva cualitativa, el establecimiento de categorías acompaña el análisis durante todo el proceso de trabajo de campo y el análisis posterior, por eso no son necesariamente establecidas con anterioridad. Guber llama a este tipo de categorización, categorización diferida:

“La categorización diferida se ejerce a través de la formulación de preguntas abiertas que se van encadenando sobre el discurso del informante, hasta configurar un sustrato básico con el cual puede reconstruirse el marco interpretativo del actor. Este tipo de diálogo demanda un papel activo del entrevistador, por un lado, al reconocer que sus propias pautas de categorización no son las únicas posibles; $y$ por otro lado, al identificar los intersticios del discurso del informante en donde "hacer pie" para reconocer/construir su lógica" (Guber 2012)

Para el estudio de la experiencia de escritura, tanto en la escritura en el taller literario como en la escritura cotidiana, se analizaron los textos escritos por los jóvenes y sus relatos. A partir de estos textos fueron apareciendo posibles categorías de análisis. Si bien planteamos tres categorías de base: escritura- jóvenes- experiencia, se propuso para el trabajo de campo un abordaje desde una amplitud conceptual e ideas no esencialistas, en búsqueda de coherencia con el enfoque cualitativo que estamos planteando. 


\section{SEGUNDA PARTE:}

\section{LA EXPERIENCIA DE LA ESCRITURA EN JÓVENES PRIVADOS DE LA LIBERTAD}

\section{INTRODUCCIÓN}

Dijimos al comenzar que reconocíamos la complejidad del campo en el que nos proponíamos realizar este trabajo de investigación: una escuela en una institución de encierro, jóvenes privados de la libertad, trayectorias de exclusión, marginación y violencia. También éramos conscientes de que la escritura es un objeto multifacético y difícil de abordar: "objeto de interés de múltiples disciplinas y a la vez tierra de nadie." (Ferreiro, 2007). Giorgio Cardona señala que la escritura no es un mero instrumento para transmitir mensajes "así como un carro sirve para transportar heno", sino más bien lo contrario, se trata de un fenómeno complejo que abarca globalmente el sistema abstracto con sus realizaciones concretas, con los materiales, y con los objetos escritos; y se manifiesta como una matriz de significaciones sociales y como un campo fundamental de producción simbólica (Cardona, 1994, pág. 10).

Tenemos hasta aquí dos años de trabajo de campo realizado y contamos con abundante información: la palabra de los jóvenes en las entrevistas, sus textos escritos, los registros etnográficos, las grabaciones de algunos talleres, los registros fotográficos de las escrituras y la información sobre el contexto. Todo este trabajo de campo, puesto en diálogo permanente con la búsqueda de la comprensión del marco histórico, social, político y legal, y con los conceptos de los autores de referencia. El marco teórico en sí mismo, también se convirtió en un trabajo de indagación y construcción permanente.

Tomamos la premisa fundamental de Juarez Dayrell, sobre los jóvenes: no son un mero objeto, ni sujeto de la observación: 
"Son personas en relación con aquel que observa. Tenemos claro que construimos un texto que se refiere a hechos socialmente construidos, con la consciencia de la lejanía que separa la interpretación de la "realidad"." (Dayrell , 2003, pág. 75)

Nos proponemos prestar especial atención y cuidado a la descripción y al relato de sus experiencias, sus trayectorias y sus biografías. Sabemos que sus problemáticas forman parte de cuestiones candentes en la sociedad y aparecen con "letras luminosas" en las "malas noticias" de los medios de comunicación. Por eso tomamos como propia la advertencia que hace Gabriel Kessler (2004) sobre el peligro de "contribuir a profundizar los prejuicios existentes en la sociedad: es decir que el delito es una cuestión de jóvenes de sectores populares". Kessler admite una incomodidad, que como investigador lo acompañó siempre, y reconoce: "puedo decir que nunca la pude saldar" (Kessler, 2004, pág. 9). Esa incomodidad de la que habla Kessler nos acompaña también a lo largo de todo este proceso. Es una tensión que parte de la preocupación por -involuntariamentecontribuir al estigma social general, o -desde otro extremo- caer en el mito romántico y burgués del "buen salvaje", como advierte Julián Axat (Axat, 2015, pág. 180).

Para desarrollar esta investigación entrevistamos a siete jóvenes que nos ayudaron a comprender su experiencia de escritura. Además, cada uno de los jóvenes que participaron en los talleres, jornadas y actividades de las que fuimos formando parte fueron dando un valioso aporte a esta investigación. Como Juarez Dayrell sostiene en Cultura e Identidades juveniles (2003), ellos son "sujetos concretos, con experiencias singulares, cuyas trayectorias de vida pueden ofrecer elementos para mejor comprenderlos" (pág. 75). Junto a este autor creemos que cada uno de ellos revela mundos propios y expresa experiencias y momentos de vida diferenciados.

Desde este lugar partimos entonces, acompañados por una cantidad de tensiones, incertidumbres, y algunas certezas. 


\section{Las condiciones sociales, escolares, el encierro y la escritura}

\subsection{Los $\operatorname{chicos}^{36}$}

\section{FACUNDO}

Facundo tiene 17 años y estuvo 11 veces privado de la libertad, la primera vez fue a los 13 años. En la última causa lleva cuatro meses, y actualmente está alojado en el Instituto Nuevo Sol, del Complejo Esperanza.

Vivía en el barrio José Hernández con su padre, su madre y tres hermanos. Hasta hace poco también vivía allí su abuelo, que falleció estando él preso. En los últimos tiempos además vivía su novia, que está embarazada, y a punto de nacer su primer hijo.

Estando en libertad empezó primer año del secundario tres veces -repitió dos veces- y hoy está cursando el segundo año, dentro de la modalidad PIT implementada en la escuela del Complejo Esperanza.

Empezó el taller de escritura para mejorar en la conducta, para pasar el tiempo, para despabilarse, y porque le gusta escribir, sobre todo escribir cartas.

Desde que empecé a caer, a los trece años, empecé a escribir cartas a mi mamá, para Navidad, para los cumpleaños, para todas esas fechas importantes le hacía cartas, y bueno, desde los trece años... ahora voy a cumplir dieciocho (Facundo)

\section{NICOLÁS}

Nicolás tiene 17 años, y está viviendo desde hace once meses su cuarta internación en el Complejo Esperanza, en el Instituto Nuevo Sol.

Su mamá lo abandonó a los tres años, y fue criado por una familia vecina, que lo adoptó a él y a sus hermanitos en la ciudad de Rio Tercero. Está cursando el segundo año del secundario en la modalidad PIT. Participó de los talleres que se dictaron en las horas de Lengua de la escuela.

Se puso en contacto desde chico con el ambiente del Hip Hop. Hoy compone canciones con sus compañeros de sector. Es un referente para los demás chicos por su capacidad de escribir canciones y de interpretarlas.

\footnotetext{
${ }^{36}$ Los jóvenes son presentados con nombres de fantasía, para preservar su identidad
} 
A lo mejor con una canción me puedo sacar toda la bronca, a lo mejor bronca que tengo adentro hace mucho, que por ahí me pinta la locura y me ayuda a no mandármela, porque por ahí sino tenés que ir y matar a alguien o vas ahí a robar, en vez de descargarte en todo eso, me descargo en una canción con un lápiz y un papel me descargo todo (Nicolás)

\section{DANIEL}

Daniel Tiene 17 años y está alojado en el Instituto Nuevo Sol del Complejo Esperanza. Antes de estar privado de la libertad vivía con su mamá, su novia y hermanitos en la Villa La Tela. Luego de su primer salida de permiso, Daniel nos contó que su mamá es alcohólica y que se siente responsable de la situación de su madre y su familia.

Empezó a participar en los primeros talleres itinerantes que propuso la Biblioteca Abierta en el año 2014, finalmente acompañó a prácticamente todas las actividades de la Biblioteca mientras estuvo privado de la libertad.

Estuvo presente en la presentación de la revista Tumbando Rejas en la Feria del Libro de Córdoba donde leyó una poesía escrita en los talleres. Un día después fue trasladado de manera compulsiva dentro del Complejo Esperanza, lo que originó un intento de suicidio. Luego de este incidente siguió participando en algunos talleres y al poco tiempo salió en libertad. Daniel expresó que para él fue una experiencia inédita escribir poesía y valoró positivamente el hecho de su publicación

No me molesta que otros lean lo que escribo. Me gusta, porque por ahí hay cosas que me salen ahí adentro, y me gusta que lo lean, no me gusta que los otros vean la parte mala, a mí no me gusta ser malo, no me gusta que vean que soy malo, fui malo, le hice mucho daño a mi mamá y a mis hermanos...ahora ya pagué lo que tenía que pagar. (Daniel)

\section{JOAQUÍN}

Joaquín tiene 19 años, y está privado de su libertad por quinta vez en el Complejo Esperanza. La primera vez fue a los 13 años y lleva casi tres años por la última causa, con una fuga de por medio. Se encuentra alojado en el sector D del Instituto Horizontes, de máxima seguridad. Este año recibió un fuerte golpe de un joven de otro sector, que le quebró la mandíbula. Sus brazos están marcados por los cortes que se hace cuando "le pinta" la locura del encierro. 
Es de un barrio de los márgenes de Córdoba: General Savio. A los ocho años, a partir de la muerte de un hermanito, fue judicializado, separado de su madre, y finalmente, junto a sus hermanos, llevado con sus abuelos. En las entrevistas expresó que le cuesta recordar experiencias de la infancia. Hoy en día la abuela es la única "que no lo deja tirado", y tiene perspectivas de reencontrarse y volver a vivir con su mamá.

Hizo la primaria en la escuela de su barrio, la "José Gabriel Brochero". Fue a la escuela hasta los quince años, empezó dos veces primer año del secundario estando en libertad, la segunda vez, ya en una escuela de adultos se peleó con un policía que cuidaba la escuela "me trató mal delante de los directores y ellos no dijeron nada, le dieron la razón". Desde que está en el Complejo Esperanza empezó tres veces primer año en la escuela de adultos en contexto de encierro. Va a la escuela "cuando la guardia quiere". Este año pasó a segundo año.

Es lector de César González y fan de Esteban el As. Participó activamente de los talleres literarios del año 2015 en la escritura de la novela grupal. Llegó a tener libros en su pieza, y un cuaderno para escribir y desahogarse, pero en las diferentes requisas le fueron sacando todo.

\begin{abstract}
Cuando estaba solo...al pedo... acá...cajeteando ${ }^{37}$, estaba loco...me ponía a escribir. Me acuerdo que la asistente me preguntaba por qué me había cortado, porque estaba loco...que se yo... ¿Y por qué te cortás? me decía... para sacarme la bronca... y bueno si querés sacarte la bronca, agarrá un cuaderno, una lapicera y ponete a escribir, una carta, algo. Qué se yo, para no cortarme, no pelearme, no estar renegando... (Joaquín)
\end{abstract}

\title{
JERÓNIMO
}

Jerónimo tiene 18 años y está privado de su libertad por segunda vez, estuvo un mes por la primera causa, y un año y siete meses por la causa actual. Estaba alojado en el instituto Nuevo Sol, pero fue trasladado luego de un motín al sector D del Instituto Horizontes.

Es del Barrio Santa Cecilia, y en el año 2006 su familia se mudó a Argüello, a Sol Naciente "un barrio que dio el gobierno", allí vivía con su mamá, su padrastro, cuatro

\footnotetext{
${ }^{37}$ Cajetear: "hacerse la cabeza" pensar, extrañar, sufrir e incluso llorar por el encierro, sufrir las culpas y la ausencia de los seres queridos
} 
hermanos y una sobrina hija de su hermana. Su papá biológico lo ha ido a visitar algunas veces al Complejo Esperanza.

Hizo el primario en la escuela Maestros Puntanos, en el barrio Poeta Lugones, empezó el secundario y luego de hacer dos veces primer año, dejó los estudios y empezó a trabajar en una panadería. Está cursando primer año en la escuela secundaria de adultos

Jerónimo en las entrevistas recuerda a Nicolás, con quien, siendo compañeros de sector, escribían canciones; también recuerda a su tío fallecido y su bandera del Che Guevara, y al libro con la vida del Che que una maestra le acercó estando en el Nuevo Sol, al que no pudo terminar de leer. Participó en los talleres literarios del 2015, y fue quien, recién ingresado al sector y en su primer taller, aceptó el desafío y se animó a escribir la escritura grupal, fue así que comenzó con la escritura del primer capítulo de la novela.

E: ¿Cómo ven los chicos que un chico escriba, lo pueden cargar?

Jerónimo: No. ¿Por qué? No pasa nada, VEMOS lo que escribe, y DESPUÉS de ver, vemos si nos reímos o no

\section{RENATO}

Renato tiene 18 años, cayó preso por primera vez a los 16 años. Ahora lleva un año, por su segunda causa, y está alojado en el sector D del Instituto Horizontes. Jugaba al fútbol en un club de Córdoba, era un buen jugador, y hoy sigue entrenando cuando puede. Este año, estando encerrado en una oportunidad prendió fuego su pieza, pero pudieron sacarlo antes de que sucediera algo grave. Hoy todas sus expectativas están centradas en salir pronto en libertad

Nació en barrio Acosta, luego su familia se mudó a Maldonado. Es el mayor de cuatro hermanos, sus padres siguen juntos y su mamá es ama de casa. Es padre de una nena, se enteró de su paternidad cuando ya había nacido su hija, a la que no ve desde que está privado de su libertad.

Nos cuenta que le iba bien en el colegio, pero que tenía problemas con la conducta, y que su mamá siempre le exigió que fuera a la escuela. Dejó el secundario en tercer año cuando "cayó" por primera vez, y este año cursó el primer año del secundario 
de adultos. Renato dentro del grupo es el que más trayectoria tiene en la escuela, sus compañeros lo valoran y destacan: "fue como hasta cuarto año".

Renato participó del taller literario del 2015, los demás compañeros lo invitaron. Reconoce sentirse capacitado para escribir historias, por lo que decidió participar de la escritura de la novela grupal

Me gustaría escribir... así... agarrar un cuaderno y escribir mi vida... y lo he pensado... y cuando lo quería hacer no tenía ni la hoja ni la lapicera... Me gustaría hacerlo para ver, para ver todo lo que ya pasó... lo pasado... me llamó la atención eso de escribir, todo lo mío, todo lo mío... (Renato)

\section{ENZO}

Enzo tiene 18 años y está alojado en el sector D del Instituto Horizontes, de máxima seguridad, desde hace 8 meses. Es la segunda vez que está privado de la libertad. La primera vez estuvo en el Nuevo Sol. No tiene perspectivas de salir pronto en libertad.

Su familia es de Ciudad Evita, tiene 9 hermanos, él es de los mayores -su hermanito menor tiene dos años-, además viven en su casa dos sobrinos. Su hermana está embarazada.

Cursó casi toda la escuela primaria pero no aprendió a leer y a escribir.

Ahora está cursando la primaria de adultos en el Complejo Esperanza, el primer grado, o sea la alfabetización inicial. Participó durante el 2015 de todos los talleres de escritura de la novela grupal. En los momentos de escritura individual pedía ayuda o le dictaba a un adulto lo que quería escribir. Renato es su compañero de pieza, y por las noches le está enseñando a leer.

${ }^{38} \mathrm{E}:$ ¿Cómo te sentís ahora en esta escuela?

Enzo: Nada... si acá no se siente nada... No sé, me siento bien, que se yo, corte que TENGO que aprender. Tengo que aprovechar lo que tengo, la primaria, para aprender a leer. Una vez que salga de acá, ya está, no voy a aprender más si no es que me enseñan en la calle, mi familia.

${ }^{38} \mathrm{E}:$ Entrevistador 


\section{YANDEL}

Yandel tiene 18 años, nació en la villa el Tiradero. Cuando su padre fue a la cárcel se mudaron con su madre y su padrastro a la Villa la Tablita. La primera vez que estuvo preso, fue a los 13 años y "de garrón”. A los 15 ya había dejado la escuela y se pasaba el tiempo en la esquina con sus amigos. Cayó preso por segunda vez y vivió largo tiempo encerrado. Conoció a su padre biológico Juancho, cuando lo fue a visitar al Complejo Esperanza. Su padre le había escrito en la pared de la comisaría y una carta que nunca recibió. Juancho murió un tiempo después en un tiroteo

Yandel ya es papá, su pequeño bebé se llama Juancho, como su padre, y le escribió una canción. Hoy ya está en libertad, junto a Gaby, el amor de su vida.

Yandel no existe. Es el personaje que los chicos crearon como protagonista de la novela grupal.

\subsection{El paisaje social y político}

"Yo nací en un barrio bajo donde la pobreza y los problemas me hicieron crecer ahí donde uno se curte que en el frente de batalla cada uno hace lo que tiene que hacer Porque el sol sale, el barrio se ilumina, nadie regala nada y hay que ganarse la vida. Cae la noche, se activan las esquinas y empieza la secuencia de la vida clandestina (Yo vengo del barro, yo vengo del barro, yo vengo de barrio bajo)" Esteban el $\mathrm{As}^{39}$

Para comenzar el análisis del presente capitulo tomamos algunos datos del Informe del Ministerio de Justicia y Derechos Humanos de la Nación del año 2012: Niños, Niñas y Adolescentes en Conflicto con la Ley Penal:

\footnotetext{
${ }^{39}$ Fragmento de la letra de Barrio Bajo. Rap de Esteban el As. En su cuenta de Twitter Esteban el As se define como: "Rebelde, Salvaje y Loco. NEGRO DEL BARRIO". URL video:

https://www.youtube.com/watch?v=AhDOkN_2IVM
} 
- "De acuerdo a los datos generales que surgieron del censo, en su mayoría las personas privadas de libertad eran jóvenes varones, argentinos, con bajo nivel de escolarización, detenidos desde hace menos de un año, con antecedentes penales e imputados principalmente por la comisión de delitos contra la propiedad. Es decir, se trata de la obtención del sector más proclive a la criminalización, llevada a cabo por parte del sistema penal” (pág. 12)

- $\quad$ EI relevamiento sobre niños y adolescentes en conflicto con la ley penal privados de libertad muestra que casi la totalidad (97\%) eran varones y, en cuanto a la edad, el $80 \%$ tenía 16 o 17 años, el $11 \%$ tenía entre 11 y 15 años, y el $9 \%$ tenía 18 o 19 años". (pág. 13)

- "un $71 \%$ de los autores del delito de robo no concurría a un establecimiento educativo al momento de la comisión del hecho" 40 (pág. 14)

Los datos arriba transcriptos aportan información que nos interesa: mencionan a los jóvenes varones con bajo nivel de escolarización como el sector más proclive a la criminalización, o sea, como el sector más estigmatizado. Específicamente en cuanto a los niños y adolescentes en conflicto con la ley penal privados de libertad informan que un alto porcentaje no concurría a un establecimiento educativo al momento de la comisión del hecho.

Observamos cierta concordancia con las breves reseñas de las biografías de los jóvenes con las que comenzamos este capítulo, información surgida de las entrevistas personales y los registros. Podemos decir aquí, en términos generales, que los barrios de donde provienen la mayor parte de los chicos son los -llamados por ellos mismos- "barrios bajos" o "villas" de la periferia de la ciudad de Córdoba. Barrios, unos más que otros, fuertemente marcados por el estigma social, tal como expone Javier Auyero:

"Difícilmente uno pueda dar con una configuración urbana que haya sido (y aún sea) la depositaria de tantas (la mayoría de las veces malas) representaciones, de tantas esperanzas en el pasado y tantos miedos en el presente. Las villas fueron retratadas como el ejemplo acabado del fracaso del populismo peronista durante

\footnotetext{
${ }^{40}$ Datos obtenidos del trabajo de relevamiento, investigación y sistematización de la problemática de niños, niñas y adolescentes frente a la ley penal, publicado por el Ministerio de Justicia de la Nación en el año 2012
} 
los años cincuenta, como suerte de laboratorios para los sueños modernizadores de los años sesenta, como cunas de la revolución en los setenta, como obstáculos para el progreso y como germinadores de subversión durante la última dictadura, como lugares de inmoralidad, crimen y ausencia de ley en la Argentina contemporánea. En la actualidad, la discusión pública sobre la inseguridad recurrentemente menciona a 'la villa' y 'los villeros' como una amenaza» (Auyero, 2001, Pág. 20)

El sociólogo francés Loic Wacquant, en su trabajo Parias Urbanos describe a la pobreza en el comienzo de este milenio, y la ubica como establecida "en barrios relegados de mala fama en los que el aislamiento y la alienación sociales se alimentan uno al otro, a medida que se profundiza el abismo entre las personas allí confinadas y el resto de la sociedad" (Wacquant, 2001, pág. 169). A la definición de Wacquant, podemos agregar: allí viven los "niños pobres", en palabras de Roxana Mazzola, quien explica que "el concepto de "niño pobre" como "amenaza" se profundizó a lo largo del siglo XX y se observa aún hoy en los debates de imputabilidad o no de los menores." (2011)

Cuando hablamos de delincuencia y pobreza en Argentina, existe un importante y extenso trabajo de sociólogos que venimos mencionando, que pone en relieve las variables sociales-político-económicas que convergen en dichos fenómenos (Auyero, 2001; Kessler, 2004; Miguez, 2004; Rodríguez Alzueta, 2015). No olvidemos que estos jóvenes nacieron entre los años 1997 y el 2001, época en nuestro país que, como resultado de las políticas neoliberales de los años 90, desemboca en una de las mayores crisis económicas de desocupación, violencia, saqueos, represión, y de caída del gobierno. Estos jóvenes nacieron y crecieron en el contexto de la crisis desatada en el año 2001, donde la situación de vulnerabilidad era extensible a niños y adultos. No pretendemos con esto desarrollar una perspectiva lineal entre la crisis económica mencionada, las situaciones de marginalidad y pobreza por la que ellos atravesaron y atraviesan con las complejas causas del delito, pero no podemos negar la realidad social y económica y la falta de acceso al trabajo digno de sus familias como parte de las variables.

Es importante señalar que existen varios factores decisivos que completan el contexto delictual que se complementan con la realidad política y económica. Estos salen 
a la luz especialmente en los momentos en que los indicadores económicos mejoran, pero la vulnerabilidad persiste. De estos factores, mencionaremos aquí dos: uno es el desdibujamiento de la ley. Sobre él, en el documento Miradas interdisciplinarias sobre la violencia en la escuela (2006), Kessler explica, que para los jóvenes - y para muchos sectores de la sociedad- "no había ninguna institución -ni la familia, ni la escuela, ni por supuesto la policía- que ocupara el lugar de la ley. Había poca experiencia de ley, en un sentido general (Kessler, 2006, pág. 18). El otro factor es la desigualdad social. Según un trabajo de Kessler y Tizziani, del año 2014:

"En la actualidad es posible reconocer diversas tendencias contrapuestas que están reconfigurando la estructura social de gran parte de los países de la región. Aunque ciertos indicadores económicos, sociales y educativos hayan experimentado una mejora en la última década, estos avances no impiden que subsistan desigualdades perdurables, y en algunos casos crecientes, respecto de la situación de diferentes grupos sociales (minorías étnico-nacionales, lingüísticas, sexuales, entre otras) o de territorios relegados" (Kessler, Tizziani, 2014)

El sociólogo Esteban Rodríguez Alzueta, en el trabajo reciente "Los pibes chorros no existen" (2015), destaca la variable estigmatización. Según este autor los jóvenes en el barrio son objeto de un triple proceso de estigmatización: "resultan estigmatizados por los vecinos y policías, y sobre-estigmatizados por los mass media” (Rodríguez Alzueta, Pág. 184). Rodríguez Alzueta se pregunta por qué razón el delito y las conflictividades sociales asociadas a los jóvenes más pobres no han disminuido a pesar de que otras condiciones han mejorado, al menos un poco. Su tesis remarca que se debe a que se han profundizado los procesos de estigmatización social. Por eso insiste en la necesidad primordial de evitar las mitificaciones y el uso de categorías que esencializan y otrifican al otro "porque cuando eso sucede las palabras se cargan de connotaciones peyorativas que, antes que buscar comprender la realidad, se apresuran a abrir un juicio negativo sobre los actores alcanzados con esas categorías y se los desautoriza y vuelve a excluir" (Rodríguez Alzueta, 2015, Pág. 182) 
Tomamos en consonancia con lo expresado hasta aquí, las palabras de César González, quien, en respuesta a la pregunta ${ }^{41}$ sobre su reafirmación en la utilización de la palabra "villero", responde:

"Yo escucho todos los días a cualquier horario y en cualquier lugar a la hora que un ciudadano quiere aconsejar a otro la frase "No seas un negro de mierda", "No seas villero". Es como un consejo saludable, una recomendación amistosa para "mejorar como persona", no seas villero y eso "te garantizará ser mejor persona", tendrás más amigos y serás más valorado, en cambio, si "te comportas como villero" estás haciendo algo malo, te estas equivocando y es probable que te quedes solo. Y el mismo villero siente vergüenza del lugar donde vive, lo niega" (2016)

En el taller de escritura creativa, los jóvenes escribieron en un proceso de escritura grupal la descripción de un barrio inventado: "Las Chalitas", el texto final fue una suma de lo que cada uno escribió en forma individual sobre su barrio real:

En el barrio las Chalitas abunda la delincuencia y las mujeres lindas. Se escuchan gritos, motos, disparos. Es un barrio kilombero donde los transas en vez de venderla le pagan amparo a los choros, arruinan a los chicos. Hay olor a marihuana y a agua podrida, también olor al pan calentito de las panaderías. Por ahí molesta la maldita policía que no deja progresar trankilos a los pibes. Es un barrio bajo donde la gente trabaja o roba para sobrevivir, donde los jueces condenan sin piedad a los guachos de la calle. Es un barrio bajo porque el gobierno no los ayuda a salir de la pobreza y por eso roban para tener dinero y cuando perdemos nos matan o nos encierran de por vida

Sin pretender dar por terminado este breve análisis, queremos dejar en claro es que para nuestro trabajo es primordial y necesario reconocer en todo momento la densidad y la complejidad del tejido social y político en el cual la vida de estos jóvenes se desarrolla.

Podemos afirmar por lo dicho hasta ahora que nos encontramos frente a un grupo de jóvenes que además de vivir en situación de privación de libertad, se encuentran, sobre todo, en situación de vulnerabilidad y marcados por el estigma social. A partir estas constataciones creemos que es importante indagar sobre sus trayectorias escolares.

${ }^{41}$ Entrevista realizada por la revista cultural La más Médula, enero de 2016 


\subsection{Trayectorias educativas}

Existe un abundante material investigativo en nuestro país en cuanto a la cuestión de las biografías escolares, las trayectorias educativas, la exclusión, y la inclusión escolar.

En respuesta a la pregunta sobre ¿Qué son las trayectorias escolares? Terigi (2009) diferencia, en principio, las trayectorias escolares teóricas de las trayectorias escolares reales: "Las trayectorias teóricas expresan recorridos de los sujetos en el sistema que siguen la progresión lineal prevista por éste en los tiempos marcados por una periodización estándar" (Terigi, pág. 19). Las trayectorias reales de los sujetos, se reconocen como "itinerarios frecuentes o más probables, coincidentes con o próximos a las trayectorias teóricas; pero reconocemos también itinerarios que no siguen ese cauce, "trayectorias no encauzadas", pues gran parte de los niños y jóvenes transitan su escolarización de modos heterogéneos, variables y contingentes" (Terigi, pág. 19). Es sobre este último tipo de trayectoria, que nos interesa indagar.

Las conceptualizaciones sobre la inclusión educativa condujeron a una reconsideración del problema de las trayectorias escolares. Este concepto sustituyó a la idea de "fracaso escolar" como problema individual, a la idea de trayectoria escolar como un problema que debe ser atendido sistémicamente (Terigi, 2009, pág. 18). En estudios recientes de la realidad argentina comienza a verse que, si bien la desigualdad social es una parte sustantiva de la trayectoria escolar, se tiene cada vez mayor conciencia de que "algo sucede dentro de la escuela, por lo cual las trayectorias escolares de los alumnos más pobres siguen interrumpiéndose” (Terigi, 2009, pág. 14).

Consideraremos también oportuno en este tema, lo desarrollado por el mencionado sociólogo Gabriel Kessler (2004), que señala la importancia de poner el eje en la idea de trayectoria educativa. Este autor insiste en considerar que más que la deserción, lo relevante es el tipo de experiencia escolar, y propone indagar sobre las marcas de esta experiencia. (Kessler, 2004, pág. 25). Kessler da cuenta de que la mayoría de los jóvenes a quienes entrevistó habían concurrido o estaban concurriendo a la escuela, o sea, había algún tipo de trayectoria escolar. Lo interesante que remarca este autor es que las respuestas de los entrevistados rompieron con las ideas previas que los investigadores tenían sobre su vínculo con la escuela. Ellos suponían que en el relato de 
los chicos se iban a encontrar con una dosis considerable de queja sobre la escuela, pero no fue así:

"En primer lugar, no había un relato muy armado sobre la escuela, no había una crítica previamente armada. Lo que notábamos, en realidad, era que hablaban poco de la escuela, sin mucho encono, sin muchas críticas, más bien una especie de lejanía de la escuela. Pero al mismo tiempo, cuando hablaban de la educación en general todavía aparecía como valorada genéricamente. Se repetía la idea de que la educación es importante para conseguir trabajo, de que la educación es importante para el futuro". (...) "Sobre la escuela se reiteraba mucho "no entiendo nada de la escuela". La sensación de "no entiendo nada" era muy interesante. Nosotros empezamos a indagar qué era no entender nada, qué era entender la escuela y qué no, y cuáles eran los puntos de anclaje de la experiencia escolar de estos jóvenes. No era solamente una falta de recursos pedagógicos para entender los contenidos, sino que era también una dificultad de articular la escuela con otras esferas de sus acciones, la escuela era la sensación de "no entiendo nada". (Kessler, 2014, pág. 22)

El 26 de marzo de 2015 participamos en una reunión en la SeNAF-Secretaría de Niñez, Adolescencia y Familia- de la Provincia de Córdoba. Dicha reunión se propuso el objetivo de la construcción del Proyecto de Vinculación Institucional -PIV-. Este proyecto busca articular e involucrar a las diferentes instituciones educativas que integran actividades dentro del Complejo Esperanza. En dicha reunión se plasmó la complejidad de esta articulación y se brindó información de una encuesta realizada por la SeNAF durante el año 2014.

De la mencionada encuesta tomamos nota de algunos datos que -desde una mirada cuantitativa- aportan una interesante información:

- En cuanto a los niveles de estudio: de los 230 jóvenes internados, el 83\% no había terminado la escolaridad primaria, y el 17\% restante había iniciado el secundario.

- En cuanto al trabajo: el 90\% afirmaba que no estaba trabajando en el momento de la detención.

- En cuanto a la situación familiar: el 55\% expresó como principal preocupación a la familia y el $35 \%$ afirmó tener hijos 
- En cuanto a otros intereses: el $74 \%$ reconoció consumir sustancias, el $67 \%$ manifestó usar frecuentemente redes sociales.

Desde una mirada más cualitativa la encuesta recoge otras informaciones generales como: el interés por participar de proyectos de educación sexual integral, la valoración de la escuela en el encierro como ambiente saludable, las experiencias sociales de estigmatización y de vulneración de derechos, y las trayectorias escolares de exclusión y expulsión.

Si repasamos las trayectorias educativas de los jóvenes que entrevistamos, al momento de la entrevista, casi todos -excepto Enzo que va al Primario- estaban cursando la secundaria de la escuela en Contexto de Encierro, algunos, en la modalidad PIT, y otros en la propuesta de Educación de Adultos.

Facundo, terminó el primario "afuera" y llegó a empezar el secundario:

\section{Entrevista a Facundo}

"Primer año empecé (el secundario), pero repetí dos veces y no seguí más”

Actualmente cursa segundo año en la escuela en contexto de encierro.

Nicolás, al igual que Facundo, está haciendo el segundo año del secundario común -modalidad PIT-. Su percepción es que la mayoría de los jóvenes dejaron de estudiar antes de la privación de la libertad:

\section{Entrevista a Nicolás}

"De la mayoría de los chicos que están a acá nadie va al colegio en la calle".

Renato, está cursando el primer año de la escuela de adultos, su imagen de la escuela es positiva, y explica que tuvo que dejar cuando "cayó" preso:

\section{Entrevista a Renato:}

"Siempre en el colegio me fue bien a mí, lo que fui al colegio acá y afuera, siempre me fue bien, siempre. Hice todo el primario completo, primero, segundo y tercer año... y dejé en tercero...a los $15,16 \ldots$ Cuando caí preso tuve que dejar, pero me iba de diez, de diez, lo único que siempre era... la conducta..." 
En el relato de Renato aparece la madre como alguien que exige a su hijo que estudie:

\section{Entrevista a Renato:}

"mi mamá cada vez que tenía que ir al colegio, me levantaba, me bañaba y "vamos al colegio", por ahí había algunas veces que no quería y me hacía el enojado, como que lloraba, y bueno... por ahí alguna vez faltaba, pero era muy raro que faltara, porque mi mamá me levantaba igual, solo faltaba por ahí cuando hacía mucho frío por ahí decía "no quiero ir" ... pero mi mamá me ponía un cancán y me mandaba...(risas)".

Jerónimo también cursa actualmente el primer año en la escuela de adultos y recuerda del secundario "en la calle":

\section{Entrevista a Jerónimo:}

"me hacían escribir una banda de cosas, sí, de esa banda de cosas no me entró ni UNA!".

Joaquín, entre los jóvenes entrevistados, es el que más tiempo lleva en las diferentes instituciones, por lo tanto, lleva allí buena parte de su escolaridad. Respecto a la experiencia escolar de su infancia repite una y otra vez: "No, de mi infancia no me acuerdo de nada...". Cuando seguimos indagando sobre si le gustaba ir a la escuela, recuerda que "estaba piola" pero aclara:

Entrevista a Joaquín

"cuando yo era chico vivía con mi mamá, después me separaron de mi mama me fui con mi abuela y bue... eso es como otra historia...".

El relato de Joaquín continúa: nos cuenta que fallece su hermanito menor, y por una situación que no aclara, él y todos sus hermanos son judicializados hasta que son entregados a su abuela. De esta etapa de su vida no recuerda nada o prefiere no hablar. La experiencia escolar de Joaquín en los últimos años, es dentro del Complejo Esperanza, donde cursa el primer año de la escuela de adultos. Nos explica:

\section{Entrevista a Joaquín}


"estoy haciendo primero y segundo. Hace como tres años que estoy haciendo primero y segundo...Todavía no puedo pasar de año. No sé por qué no puedo pasar...cansado estoy de hacerlo al colegio y todavía no puedo pasar".

En este breve relato de Joaquín subyace la idea de esa escuela del "no entiendo nada" de la que habla Kessler. Joaquín lleva varios años iniciando un proceso interminable e incomprensible para él en la escuela del encierro. A la fragmentación de su trayectoria y a la cadena de exclusiones que viene viviendo, se le suman la fragmentación y las exclusiones que produce la misma institucionalización: las salidas al juzgado, a los talleres de capacitación, las entrevistas con el equipo técnico, las medidas de fuerza de los guardias, los motines, los castigos, las fugas. Joaquín no entiende las lógicas de la escuela, y mucho menos en la complejidad institucional del contexto de encierro.

Para Kessler, las experiencias escolares de los jóvenes son experiencias de "baja intensidad", y aclara que no por ello desprovistas de tensión: "asisten a la escuela, continúan inscriptos, van de manera más o menos frecuente, pero sin estudiar, sin realizar las tareas, sin llevar útiles, sin llevar nada." (Kessler, 2004, pág. 24). Terigi habla de los modos heterogéneos de estas trayectorias, y menciona en particular, trayectorias que se interrumpen (Terigi, 2009, Pág.14).

Estas formas heterogéneas de las trayectorias aparecen con fuerza en las entrevistas a los jóvenes, heterogeneidad que se manifiesta también en las formas de las interrupciones: desde la interrupción abrupta: "Cuando caí preso tuve que dejar", pasando por múltiples factores que van construyendo la idea -o realidad- de que "acá nadie va al colegio en la calle", llegando al presente, a la situación escolar de su vida privada de la libertad y a las interrupciones inherentes a la institución de encierro que acabamos de mencionar.

A propósito de interrupciones, Carlos Skliar en "Desobedecer el Lenguaje (alteridad lectura y escritura)" hace referencia a otras interrupciones, ya no sólo las de una trayectoria escolar, sino la interrupción de la niñez y de la infancia:

"A veces la interrupción es una guerra, un exilio, una bomba. Otras veces ocurre bajo las formas del hambre, de la miseria, del abandono. Y otras veces la interrupción coincide con el inicio de la escolarización. Y es que también una interrupción puede ocurrir con suavidad, necesidad y elegancia. Y no deja de ser interrupción” (Skliar, 2015, pág. 177) 
¿Cuántas y cuan variadas interrupciones pueden haber ocurrido en las trayectorias de los niños/jóvenes, hoy privados de la libertad? Creemos en principio, y de acuerdo a lo indagado, que como afirma Skliar: "antes o después. En mayor o en menor medida. Con más amorosidad o con más crueldad. Con más autoridad o con más autoritarismo. Con más homogeneidad o con más diversidad. Con más exclusión o con más inclusión" (Skliar, 2015, pág. 180), las trayectorias escolares son interrumpidas en medio de otras interrupciones.

Kessler explicaba cómo, en su indagación aparecía -para su sorpresa- un tipo de percepción en el imaginario de los jóvenes que valora y le da importancia de la educación. En el discurso de los jóvenes entrevistados en nuestro trabajo, se trasluce algo similar, como por ejemplo Nicolás, cuando relaciona a la escuela con la posibilidad de conseguir un mejor trabajo

\section{Entrevista a Nicolás:}

"no te estoy charlando, quiero hacer a la noche en el CENMA ${ }^{42}$, bueno, cosa que pueda trabajar".

Renato se dice, como a sí mismo:

\section{Entrevista a Renato:}

"Es que tengo que seguir. Tengo que seguir. En el CENMA, dos años. Ahí nomás en San Vicente, en Muller, me tengo fe que para fin de año te voy...".

En este sentido, sobre esta sensación de que es bueno para su vida continuar la escuela, y sobre el hecho de que no se manifiesten "en contra" de la institución escolar, afirma Kessler

"No es que la educación se ha perdido totalmente, sino que algo queda, quizás uno podría pensar que son restos de fragmentos aislados, como si fueran bloques de hielo en una especie de mar; pero no está borrado, ni tampoco hay un discurso contracultural contra la escuela como uno ve en trabajos de otros países". (Kessler, pág. 23)

\footnotetext{
${ }^{42}$ C.E.N.M.A.: Centro de Educación Media de Adultos, denominación de la modalidad de educación secundaria de adultos en la provincia de Córdoba
} 
Sobre su experiencia en la escuela Renato nos explica:

\section{Entrevista a Renato:}

"No era burro, porque siempre prestaba atención, bien, pero la conducta era pésima, es lo que era pendejo, me cansaba de joder y por ahí las profesoras me decían que yo no sabía nada.... pero sí, sabía todo...”.

Vemos que Renato -como los otros jóvenes- no culpa a la escuela, piensa que el problema es suyo, su conducta, no cuestiona a los docentes, pero deja a la vista que estaban equivocados en el preconcepto que tenían sobre él: no lo conocían: "me decían que yo no sabía nada". Pone al descubierto no solo un posible desconocimiento, sino también un prejuicio, o valoración negativa de sus posibilidades.

No seguimos indagando en las entrevistas sobre la experiencia actual en la escuela en contexto de encierro, tratamos de obtener información general en relación a las trayectorias, y el rol de la escuela en sus experiencias de inclusión/exclusión.

Respecto al acompañamiento de la trayectoria escolar de estos jóvenes cuando salen en libertad, consultamos con docentes y el coordinador pedagógico de la escuela. Nos señalaron que la realidad es que éste es mínimo, y que existe una necesidad urgente de dar una continuidad al proceso que se inicia en la escuela del encierro, de construir espacios de acompañamiento para y con los jóvenes, orientados en la promoción y ejercicio activo de sus derechos, de acompañarlos en su trayecto socio-educativo y laboral, que apuesten a lo colectivo y al crecimiento personal.

Para terminar este apartado, podemos concluir en que nos encontramos ante trayectorias escolares fragmentadas, que, con mayor o menor intensidad, y de diferentes modos son interrumpidas, y signadas por mecanismos de exclusión.

En relación a las trayectorias escolares y a nuestro objeto de estudio, la escritura, no podemos exceptuar una cuestión fundamental, la tarea alfabetizadora de la escuela, sobre todo por su posible relación con la experiencia de escritura actual de los jóvenes. Para profundizar sobre el tema específico de la alfabetización o apropiación de la escritura, sus posibilidades y oportunidades, desarrollamos el próximo capítulo. 


\subsection{La escritura: posibilidades/ oportunidades de escribir}

\subsubsection{La apropiación de la escritura}

"El observar a quien lee y escribe en nuestro mundo, y a quien no lo hace, nos lleva a lo que es tal vez una conclusión obvia: la lectura y la escritura (y la educación en general) se distribuyen de una manera desigual. La investigación ha aportado importantes evidencias para comprender cómo ocurre esto, demostrando que el alfabetizarse, lejos de ser sólo un asunto de voluntad individual, requiere de oportunidades socialmente construidas para aprender a leer y escribir, y que éstas están inmersas en relaciones de poder que influyen sobre quién lee y escribe, qué se lee y qué se escribe, quién lo decide, quién decide las convenciones normativas y ejerce poder a través de la lengua escrita". (Judith Kalman, 2003, Pág. 5)

A lo largo del camino en el trabajo de campo se fueron sumando a los problemas pensados originariamente, otros aspectos importantes que fueron complejizando el análisis, uno de ellos, y que apareció con mucha fuerza, fue el problema del acceso a la alfabetización o apropiación de la cultura escrita.

A partir de las entrevistas y de la cotidianeidad en los talleres de escritura, tomamos conciencia de que lo que la realidad nos aportaba, era que nos encontrábamos con chicos que no sabían leer y escribir. Muchos jóvenes expresaron que apenas sabían escribir, otros, que escribían un poco y algunos que escribían mucho, la mayoría signados por un generalizado "no sé". A pesar de todo, la escritura estaba presente en su vida cotidiana, y sentían la necesidad de escribir.

Julián Axat -poeta y defensor penal juvenil- en Violencia y cultura: reflexiones contemporáneas sobre Argentina (2015) desarrolla el capítulo “Los pibes chorros" junto a Esteban Rodríguez Alzueta. Axat profundiza en lo que él denomina "El mito de los pibes chorros poetas". Allí plantea que la supuesta "poética villera" o creación poética marginal es parte de un "mito etnocentrista", más un invento de la exterioridad que una construcción genuina del propio lugar (Axat, Pág. 177). Sobre este asunto ahondaremos en la descripción de la escritura en los talleres literarios. Por ahora nos detendremos en 
una cuestión básica que plantea Axat y que se relaciona con el panorama con el que nos encontramos en los talleres de la biblioteca de la escuela del Complejo Esperanza:

“Los pibes chorros pueden hacer hip-hop, cantar cumbia villera, tantear poesías o escribir poesía en el encierro. Pero antes, muchas veces, necesitan manejar la lecto-escritura. La alfabetización, la mayoría de las veces no existe. Aun cuando algunos sigan soñando con pibes chorros poetas, la mayoría tiene dificultades para la comprensión de textos más básicos. (Axat, 2015, Pág. 177)

En la entrevista realizada a Jerónimo, respecto a su percepción sobre el vínculo que tienen con la práctica de escritura la generalidad de los jóvenes internados en el Complejo, nos explica:

\footnotetext{
Entrevista a Jerónimo

“Jerónimo: la mayoría de los chicos no saben, no sé si han ido a la escuela o no, pero no saben.

$\mathrm{E}:$ ¿Cómo sabés que no saben?

Jerónimo: Porque, ponele, una vez le digo a un chico: "tomá, mandemos un mensaje a tu mamá ..." "no, si no sé escribir", me dice... y con varios chicos me pasó lo mismo".
}

Cuando conversamos sobre su experiencia de escritura en el taller de la biblioteca, Jerónimo aclaró que no fue precisamente la escuela la principal fuente de aprendizaje de la escritura, ya que aprendió primero, con su madre en su casa y luego de una forma "autodidacta" basada en la escritura de cartas:

Entrevista a Jerónimo

"cuando escribía una carta no tenía un maestro que me corrigiera ni nada".

El 7 de octubre de 2015, realizamos la primera entrevista con Enzo. Él ya había participado en los talleres en el Instituto Horizontes. Su presentación, en el primer encuentro, había sido acompañada por una aclaración que repitió cada vez que se planteaba una nueva situación de escritura: "no sé escribir". Así y todo, Enzo formó parte del grupo estable del taller, participó activamente de la escritura de la novela grupal, e hizo intentos de escribir solo y con ayuda.

En la entrevista, sobre su biografía escolar, nos contó que hizo casi toda la escuela primaria, pero a pesar de eso no aprendió a leer y a escribir: 


\section{Entrevista a Enzo:}

"Fui a la escuela de mi barrio, hice hasta sexto grado, pero no aprendí a leer y escribir. De primero me pasaron a segundo, después a tercero, después a cuarto, a quinto, después de quinto me bajaron a cuarto, después de cuarto a quinto, y después a sexto. Sí... fue un buen trecho lo que hice... tendría que haber aprendido, pero no sé por qué no aprendí, calculo que es porque no prestaba atención"

En el relato de Enzo se trasluce algo más que una escolaridad de baja intensidad (Kessler, 2005). Lo que vemos es, en primer lugar, una escuela que claramente no cumplió con su compromiso alfabetizador. Enzo "pasaba de grado", pero no aprendía ¿La escuela no lo vio? ¿Lo vio y no encontró una solución? ¿Evadió el problema? No podemos saberlo y él no tiene una respuesta, no lo entiende: "no sé por qué no aprendí". El relato de Enzo multiplica las preguntas. Lo que podemos afirmar es que a pesar de haber ido más de siete años a la escuela primaria, Enzo no aprendió a leer y a escribir. Avanzando en la entrevista, podemos agregar que luego, la escuela lo expulsó:

Entrevista a Enzo:

"Me echaron a lo último, hace como tres años. A mi hermana un chico le había quitado la merienda, y bueno, yo fui y lo hice cagar ${ }^{43}$, y bueno, me echaron, uno porque no iba nunca al colegio, otra porque si iba, iba a molestar"

Enzo fue expulsado de la escuela primaria a los 13 años de edad, a poco de terminar el nivel, y él se carga a sí mismo con todas las culpas:

\section{Entrevista a Enzo:}

“...molestaba, hacía renegar, no estaba en silencio, prestando atención, y después cuando tenía que leerlo no lo leía, la maestra me quería enseñar a leer y aprender algo... yo no le daba bola....me hacía el sordo"

Hoy él está seguro de algo: no va volver a la escuela "en la calle", pero ve en la escuela en el encierro una oportunidad. Tomamos otro fragmento de la entrevista:

\section{Entrevista a Enzo:}

“Enzo: Siento... que se yo... corte que... tengo que aprender. Tengo que aprovechar lo que tengo la primaria acá para aprender a leer. Una vez que salga de acá, ya está, no voy a aprender más si no es que me enseñan en la calle, mi familia.

\footnotetext{
${ }^{43}$ Le pegó
} 
E: ¿Y si vos salieras en libertad, no se te ocurriría ir a una escuela de adultos?

Enzo: No

E: ¿Ni siquiera para aprender a leer y a escribir?

Enzo: No, me cansó el colegio, no quiero saber nada"

Es interesante corroborar lo que Kessler afirma: lo que aparece claramente como un gran valor en relación a la escuela es la idea de estar alfabetizado, el saber leer y escribir "aunque sea un poco" (Kessler, 2004, Pág. 23). A pesar de su negación a volver la escuela, para Enzo aprender a leer y a escribir vale la pena "es lo más importante, es lo que más quiero...".

Avanza el relato de Enzo y se van sumando interrogantes respecto a su paso por la escuela. Si se supone la obligatoriedad de la escolaridad primaria ${ }^{44}$ como principio, derecho y garantía, si por ley es imposible expulsar a un niño de la escuela: ¿qué pasó con el sistema legal en la expulsión de Enzo? Creemos necesario al menos introducir esta cuestión, aunque no lleguemos aquí a una respuesta. Lo que sí podemos decir es lo que queda a la vista: la vulneración del derecho a la educación y al conocimiento.

En cuanto al rol clave de la escuela en la alfabetización, Giorgio Cardona sostiene que la escritura es un aprendizaje rígidamente formalizado en la sociedad y señala que, a diferencia de muchos otros aprendizajes, "la escritura es lo único que todavía aprendemos estando sentados en los bancos de la escuela" (Cardona, pág. 108). Cardona atribuye este fenómeno, a la intersección de varios factores, pero el fundamental es que se trata de un saber al que la sociedad le atribuye un gran peso, por lo tanto es un saber que "debe enseñarse de manera conservadora". De allí la utilización de técnicas cristalizadas en la escuela, las que se presentan como un ritual de iniciación:

“...tiene hasta cierto punto el carácter de iniciación de un conocimiento que no es de todos y que por lo tanto no puede dejar de exigir cierto esfuerzo y cierta duración del aprendizaje. Aprender a escribir es un acto de iniciación y no asombra que se lo realice sin fluidez y en formas rituales" (Cardona, pág. 109)

\footnotetext{
${ }^{44}$ La Ley de Educación Nacional vigente: Ley 26.2016, en su artículo 16 declara la obligatoriedad escolar "desde la edad de cinco (5) años hasta la finalización del nivel de la Educación Secundaria". Siendo las autoridades competentes quienes asegurarían su cumplimiento, brindando "alternativas institucionales, pedagógicas y de promoción de derechos, que se ajusten a los requerimientos locales y comunitarios".
} 
Cardona destaca que "es grande la influencia del iniciador, de aquel que enseña a escribir; este desempeña un papel preciso pues no cualquiera que sepa escribir puede enseñar la escritura”. En este sentido, ahora, desde un lugar diferente a la escuela, aparece en nuestra indagación un relato de otro tipo de iniciador: un compañero. Renato era el compañero de pieza de Enzo, y nos cuenta como fue que llevó ese rol de pariniciador-alfabetizador, y no solo de Enzo, sino también de otros compañeros ${ }^{45}$.

\section{Entrevista a Renato:}

"Me canso de ayudarlo... ¡todos los días! Él no sabe leer la letra minúscula, sabe la mayúscula. Bueno, yo le escribo palabras en mayúscula y él está aprendiendo, sabe... sabe... Yo por ahí también le digo así: le hago una palabra, que la lea, que después la memorice y que la escriba, así. Y la hace el loco... ¡la hace!"

\section{Renato nos cuenta sus conversaciones con Enzo respecto a la escuela:}

Entrevista a Renato:

"Anoche estuvimos hablando de eso, yo le dije: "ponete las pilas chino, la escuela te va a servir el día de mañana, cuando vayas al colegio. Ponete las pilas hermano, te va a favorecer una banda de cosas, leer y escribir va a ser lo primero, es algo grande" ... Yo le dije: "porque el día de mañana vas a querer ir a hacer algo y te va a faltar el colegio y no vas a poder y te va a dar bronca..."

Renato también les enseñó a leer y escribir a otros chicos dentro del encierro: Entrevista a Renato:

"A Ezequiel... que no sabía escribir, ni leer, y yo le estaba enseñando a leer así: yo le iba dictando, y él iba escribiendo...o él me iba diciendo y yo le iba escribiendo y después él lo iba leyendo... sí, que memorice....así ... Estábamos viviendo los dos juntos en la pieza, era más burro que la bosta, no sabía cómo escribir una carta... y tenía una hermana en Bouwer $^{46}$... ese día lo llevaban del Instituto a ver a la hermana, y me pidió a mí que lo ayudara a hacer una carta, "ayudame a escribir"... yo escribía y él decía lo que le quería poner, pero por ahí me decía cosas que no tenían sentido, y yo le explicaba más o menos cómo se hacía una carta... cómo tenía que ir diciendo ... porque él quería poner dos renglones y ya está, ya! Yo le explicaba: ponele “¿cómo andás?” lo primero... después, “¿cómo está tu situación?” “¿cómo estás viviendo?” ... alentala: “iya te falta poco!... hay

\footnotetext{
${ }^{45}$ Los jóvenes utilizar la palabra "compañero", diferenciándola de "amigo", ellos dicen ser compañeros, ya sea de la delincuencia, de la causa, o del encierro. Prefieren no designarse como amigos, pareciera ser que ser compañero es superior a ser amigo, al menos en este momento de su vida.

${ }^{46}$ Cárcel de adultos de Córdoba
} 
que tener paciencia" ... yo le iba dando ideas y yo le iba escribiendo, así... chocho se la llevó la carta..."

En el relato de Renato, aparece otra clase de alfabetizador / alfabetización, que no sucede en la escuela: una alfabetización "entre pares", una cierta "red solidaria" de alfabetización. A partir de aquí buscamos material acerca de otras experiencias de este tipo de aprendizajes informales. Pudimos encontrar -sobre alfabetización y empoderamiento de las mujeres- un documento publicado por la Unesco (2014), de Anna Robinson-Pant, sobre una experiencia de alfabetización de mujeres en Bolivia y otros países. Allí la autora destaca que "las mujeres participan en diferentes tipos de aprendizaje gracias a los medios de comunicación, la organización social, la migración y el trabajo" (Robinson-Pant, Pág. 15). Desde un enfoque de la alfabetización como "práctica social" explica que la alfabetización así entendida excede a lo que sucede en la escuela. La autora parte de un concepto de Rogers y Street, de la alfabetización como práctica social: "la alfabetización no se practica en el vacío: está inserta en un conjunto de actividades socioculturales" (Rogers y Street, 2012: p. 17). A lo que la autora agrega:

"este modelo de alfabetización propone que la alfabetización es colaborativa en lugar de individual como en las perspectivas tradicionales de alfabetización "escolarizada"47 - y que las personas desarrollan redes de apoyo para las actividades de alfabetización”. (Robinson-Pant, Pág. 17)

En la cotidianeidad del encierro, los jóvenes que saben escribir un poco más que los otros, ofician no solo como escribientes sino también como maestros alfabetizadores y más aún en la medida que aparecen necesidades sociales o culturales que requieren de la práctica social de la escritura, como la escritura de una carta. Con la visualización de estas redes de alfabetización colaborativa no queremos mermar la responsabilidad antes mencionada de la escuela, sino visibilizar que existen otros modos "no formales" de alfabetización. Robinson-Pant, en consecuencia, propone que la educación formal debería tenerlas en cuenta, ya que "los programas formales y no formales pueden facilitar $y$ construir sobre el aprendizaje informal” (Robinson-Pant, Pág. 18).

\footnotetext{
${ }^{47}$ En este punto es necesario aclarar que la alfabetización en la escuela se puede presentar como práctica social y no necesariamente en forma individual, tal como se propone desde los enfoques constructivistas latinoamericanos.
} 
Estos jóvenes que saben un poco más y actúan como alfabetizadores y escribientes, nos remontan al concepto de Daniel Fabre sobre los que poseen este SABER, que es el saber escribir:

"es la escritura la que, cuando se posee plenamente su uso, nos hace acceder al rango del escribano, trascendiendo lo ordinario de una condición mediante un saber que parece portar en sí el germen de revoluciones extraordinarias. Así es como algunos de los que experimentan este cambio se encuentran, a los ojos de prójimos, dotados de virtudes particulares. (Daniel Fabre, Pág. 13)

Fabre reconoce el lugar que ocupa este saber en el contexto de las escrituras populares: "este saber-hacer saca al que lo posee de la chusma". Este lugar de reconocimiento de sus pares, es el que ocupa Renato entre sus compañeros, quienes lo respetan y reconocen por su habilidad para la escritura y el estudio. En los talleres se hacían comentarios entre ellos como "Renato SABE, hizo como hasta cuarto año" o "este va a la escuela a pasear... si ya terminó el secundario", o "míralo al abogado". Fabre remarca: "todos aquellos que ocupan un lugar reconocido, suscitan una forma de deferencia; más aún los autodidactas, para quienes la escritura autoriza de la misma manera el inventario de un universo y el resarcimiento de la persona." (Fabre, 2008, Pág. 14).

Por su parte Antonio Castillo Gómez, en De la suscripción a la necesidad de escribir, explica que "para que pueda darse esa toma popular de la escritura se requieren unas determinadas condiciones que la hagan factible". El autor pone énfasis en la histórica desigualdad respecto a la difusión social de la capacidad de escribir y de leer y sostiene que "es evidente que la mayor o menor amplitud y riqueza de las prácticas populares de la escritura está directamente relacionada con la extensión del alfabetismo en cada etapa y con la importancia asignada a la tecnología escrita en cada momento. Por todo ello, la conquista popular del alfabeto entraña un ejercicio de subversión, en la medida en que representa la ruptura del "pacto» social en sus efectos sobre la alfabetización y el uso de la competencia gráfica (Castillo Gómez, 2002, Pág. 29).

Esta desigualdad en la apropiación de la escritura a la que todos los autores hacen referencia, tiene -dado el rol alfabetizador fundacional de la escuela- una relación ineludible con las desigualdades de acceso a la educación. Son varios los especialistas que vienen analizando desde hace varios años la relación entre desigualdad social y desigualdad escolar (Dussel, 2004, Tedesco, 2005, Filmus, 2006, Puiggrós, 2014). Otros se preguntan asimismo sobre el vínculo entre las desigualdades escolares y las 
desiguales posibilidades de acceso a la apropiación de la escritura, o la relación entre el supuesto "fracaso escolar" y el fracaso en la alfabetización inicial (Ferreiro, 2001).

En cuanto a la relación entre la desigualdad escolar y la desigualdad social, Inés Dussel (2004) en su trabajo Desigualdades sociales y escolares en Argentina reconoce que históricamente "pese a la retórica y al "ethos" igualitario, el sistema educativo argentino sostuvo formas de integración escolar diferenciada que perpetuaban las diferencias sociales" (Pág. 4). La autora enfatiza de todas formas que la variable socioeconómica no es la única ya que la relación entre sistema educativo y desigualdad en la Argentina es compleja (Pág. 3) y agrega que "el "provecho" que los individuos pueden obtener de su experiencia escolar está mediado por muchas otras variables además de su origen social". Esto queda a la vista en nuestro pequeño universo de indagación: en situaciones sociales siempre diversas, pero coincidentes en cuestiones como por ejemplo los barrios de origen, o la vulnerabilidad social, las experiencias escolares no son correspondientes en forma lineal. A pesar de que casi todos los relatos de los jóvenes -no todos- pueden coincidir en una trayectoria escolar fragmentada, se tienen que haber puesto en juego otras variables para que, por ejemplo, unos aprendan a leer y a escribir y otros, no.

Elsie Rockwell (2000) sostiene que la escuela no posee el monopolio del acceso a la escritura, y que tampoco lo garantiza. La autora pone como evidencia el gran número de personas analfabetas funcionales que egresan, lo que nosotros en este trabajo pudimos corroborar, como dijimos, ya que -como Enzo- muchos jóvenes a pesar de haber ido a la escuela, no leen ni escriben. Sabemos que algunos de estos jóvenes tuvieron probablemente pocas ocasiones de acceso a la cultura letrada en su círculo social cercano, lo que convierte a la escuela en una oportunidad, a veces única, y resignifica su responsabilidad alfabetizadora. Como expresa Graciela Montes en La Gran Ocasión: en el terreno del aprendizaje de la lectura -y de la escritura, agregamos nosotros- y en muchos otros terrenos, "la escuela tiene la gran posibilidad de igualar oportunidades" (Montes, 2006, pág. 8)

Emilia Ferreiro (2001) se adelanta a lo que posteriormente plantean Terigi (2014), Dussel (2004) y otros respecto a cuestionar la noción tradicional de "fracaso escolar". Ferreiro explica que esta noción fue y aun es frecuentemente concebida como un fracaso en el aprendizaje y no de la enseñanza. A este fracaso lo relaciona directamente a la cuestión de la alfabetización inicial, y afirma en forma contundente: "el fracaso escolar es, 
en todas partes y masivamente, un fracaso en la alfabetización inicial que mal puede explicarse por una patología individual” (Ferreiro, 2001, Pág. 14). Luego esta autora narra cómo se fue desplazando esta "culpa", que parte siempre de poner el déficit en el alumno, ya sea 'desde su propia patologización, a la de su familia, su situación social o su entorno cultural:

“Los estudios en sociología de la educación desplazaron la responsabilidad de la incapacidad para aprender hacia el entorno familiar: en lugar de algo intrínseco al alumno habría un "déficit cultural". De hecho, una cierta "patología social" (suma de pobreza + analfabetismo) sería responsable del déficit o hándicap inicial. Efectivamente, pobreza y analfabetismo van juntos. El analfabetismo no se distribuye equitativamente entre los países, sino que se concentra en entidades geográfico-jurídico-sociales que ya no sabemos cómo nombrar" (Ferreiro, 2001, Pág. 14)

Tanto los talleres de escritura como los relatos de los jóvenes pusieron en evidencia la situación de las oportunidades desiguales de acceso a la alfabetización: unos cuantos jóvenes privados de la libertad apenas sabían escribir. Esta realidad nos interpelaba fuertemente, ya que, retomando a Julián Axat (2004), para escribir poesía en el encierro, se necesitaba manejar la escritura. Pero dentro de estas desiguales oportunidades, en el conjunto de estos jóvenes, existían, como dijimos, algunas diferencias en las experiencias de apropiación de la escritura, por lo menos en algunos jóvenes. Es esta diversidad de experiencias lo que creemos, hace que puedan funcionar, como lo que observamos en los anteriores relatos de Renato y Enzo, las mencionadas "redes solidarias" de alfabetización.

Vamos a dedicar ahora unos párrafos a la experiencia de escritura de Enzo en los talleres literarios en el instituto Horizontes. Esta situación que como dijimos, interpelaba: Enzo no sabía leer y escribir, pero estaba interesado en participar. Surgieron en ese momento las inevitables preguntas ¿Cómo puede participar en un taller de escritura literaria un joven que no sabe leer y escribir? $O$ en forma más general ¿Cómo pueden escribir los que no escriben? 
A lo largo de los talleres en los que Enzo participó, pudimos observar un proceso, que pasaremos a describir aquí, a partir de algunos fragmentos de registros de campo:

Del registro etnográfico del séptimo taller/ 29 de septiembre 2015:

Proponemos un momento de escritura individual, Letizia les entrega sus cuadernos para que pongan su nombre y se presenten por escrito. Enzo la mira "pero si Ud. sabe que yo..." (Que no sabe escribir) "yo te ayudo" le responde la tallerista. Se sienta a su lado, miran su cuaderno. Letizia le propone que escriba él solo su nombre, y lo hace rápido, luego le dice que quiere escribir la palabra LIBERTAD, pero no puede, entonces Letizia le va deletreando y él la escribe en imprenta mayúscula, como su nombre, "yo conozco las letras, sé leer las letras, pero después no puedo unirlas", aclara Enzo

Del registro etnográfico del noveno taller/ 13 de octubre 2015:

Los chicos están escribiendo sensaciones del encierro en base a palabras dadas: noche, olores, ruidos, etc. Enzo busca a la tallerista y le pide ayuda. Se sienta a su lado, quiere escribir, tiene la lapicera, va pensando las palabras, piensa en la palabra "solitario" para describir "noche", él empieza a escribir solo y pregunta ¿con la ese? y va diciendo "so" y escribe la o. Las letras que no se acuerda y Letizia se las escribe en su cuaderno y él las copia. Completa la tarea, al final la muestra orgulloso.

Del registro etnográfico del décimo taller/ 20 de octubre 2015:

Está escribiendo Joaquín en la hoja grande en la pared, algunos chicos están dispersos, pero hay que tomar decisiones, entonces los llamamos y nos reunimos un momento todos en ronda frente a la lámina, leemos las posibilidades de las tarjetas, les proponemos que elijan una de dos. Luego se dispersan nuevamente, unos escriben, Renato y Enzo mientras tanto ven videos y escuchan música en la computadora, pero asombrosamente ninguno de ellos deja de estar al tanto de lo que se está escribiendo en el afiche grupal, van participando con sus ideas, por momentos se acercan y escuchan las consignas para tomar decisiones y dan sugerencias sobre la novela, incluso, van rotando los "escribientes". Por ejemplo, ahora deben decidir qué es lo primero que hace Yandel cuando sale de permiso -ir a ver a su madre- dice Enzo, todos acuerdan totalmente, expresan que no puede ser de otra manera.

Del registro etnográfico del undécimo taller/ 27 de octubre 2015:

Están todos amontonados frente a las palabras recortadas, Enzo también, y va agarrando algunas, y las trata de leer, deletrea, algunas ya las lee solo: ¿Acá dice luna?, en otras pide ayuda, finalmente él también arma su título, pega dos palabras sobre una pequeña 
cartulina: "guachos retobados", y la coloca en la exposición junto a las tarjetas de sus compañeros.

En estos fragmentos de los registros de campo, nos dan pistas sobre el proceso de escritura de Enzo en el taller que propuso la biblioteca: partiendo del "no sé", hasta a animarse a escribir o leer solo en los últimos talleres. Participó de distintas experiencias de escritura: de a poco, se fue sumando a algunas consignas grupales, formó parte de un proyecto de escritura grupal, escribió "a través de otro", y en los últimos talleres, empezó a intentar algunas escrituras por sí mismo. Pasó por el pedido de ayuda, la copia de un modelo, el reconocimiento de las letras (y la dificultad de "unirlas"), el dictado a sus compañeros o talleristas.

La cuestión del "no sé" que Enzo repetía permanentemente, se relaciona con algunas de las ideas que plantean Kurlat y Perelman (Kurlat y Perelman, 2013) cuando se refieren a la complejidad del proceso de apropiación de la escritura en jóvenes y adultos. Las autoras desarrollan la idea de una "trenza" de tres hebras, que está formada por las marcas de enseñanza, las marcas de exclusión y los niveles de conceptualización:

“un entretejido entre las 'conceptualizaciones más genuinas' acerca de lo que la escritura representa (producto del intento de los sujetos por desentrañar este objeto de conocimiento lingüístico-social a partir de sus prácticas culturales); las 'marcas de exclusión' que han dejado huellas a lo largo de su historia en la visión de sí mismos como aprendices en general y como lectores y escritores en particular; y las 'marcas de enseñanza' que se han ido forjando en sus experiencias educativas previas y actuales” (Kurlat y Perelman, 2013, Pág. 57)

Pudimos reconocer en Enzo -en la experiencia de la escritura en el taller- algunos hilos de esta trenza de tres hebras. El conocimiento de las letras y el deletreo como claras marcas de enseñanza en relación a las prácticas escolarizadas tradicionales de alfabetización inicial; el "no sé escribir" que repitió una y otra vez, aparece fundamentalmente como una marca de exclusión; y con menos claridad, posiblemente, en los intentos de escritura autónoma aparecen los niveles de conceptualización sobre la lengua escrita. No nos detuvimos a analizar ni nos atreveríamos aquí a hipotetizar al respecto de esta última "hebra" en Enzo, ya que no era tampoco nuestro objetivo, pero sí 
pudimos observar que, a lo largo de los trece talleres, fue atreviéndose a escribir solo, a veces en forma silábica o uniendo palabras a modo de "scrptio continua", y así desatando poco a poco algunos de los nudos de la trenza.

Si bien nunca fue el objetivo del taller la enseñanza de la escritura, quedaron a la vista una suma de elementos que confluyeron en tiempo y espacio, y que favorecieron al aprendizaje: la modalidad "taller de escritura", la oportunidad del acceso a los libros de la biblioteca, la experiencia de la escritura a través de los otros y con los otros, el trabajo articulado con las socio- educadoras en los sectores, la tarea "alfabetizadora" de sus compañeros y la enseñanza de la escuela del encierro. La suma y confluencia de estas acciones, posibilitaron que algo sucediera y que Enzo poco a poco, haya empezado a leer y escribir por sí mismo.

Sabemos que aprender a escribir es un deseo y una necesidad que él expresó: "es lo que más quiero". Sabemos que la escritura es una herramienta indispensable en una sociedad alfabetizada, y que puede ayudar a sus perspectivas futuras de estudio o trabajo, pero también reconocemos que esta apropiación no es sólo de escritura o lectura, sino que tiene que ver con algo que está más allá de la escritura: como una experiencia de trabajo con otros, como experiencia reparadora sobre su autoestima y la percepción de sí mismo.

Sobre las situaciones mencionadas de escritura a través de otros y con otros en los talleres, existe abundante material en las diversas propuestas de alfabetización inicial, denominadas "situaciones de escritura a través del maestro" (Ferreiro, 2002, Teberoski, 2002, Kaufman, 2010/2015, Lerner, 2015, Castedo, 2015). Kaufman explica que "efectivamente, los alumnos pueden planificar un texto determinado, dictarlo al maestro y luego, a partir de la lectura del docente, proceder a efectuar revisiones y correcciones" (Kaufman, 2010, Pág. 44). En el Documento Transversal N¹ de la Especialización Docente "Alfabetización en la unidad pedagógica" del año 2015, se explica que:

"En estas situaciones, como la tarea de anotar queda a cargo del docente, los chicos pueden centrarse en la composición del texto y liberarse de los problemas que seguramente les plantearía el sistema de escritura. Los alumnos son autores del texto, en la medida en que enfrentan los problemas involucrados en la escritura, toman decisiones acerca de qué van a escribir y cómo lo plasmarán e intentan ir adecuando su expresión a las características del género" (Lerner y Kaufman, 2015, Pág. 16) 
La experiencia de escritura en los talleres ${ }^{48}$, no es "escritura a través de un docente" ya que generalmente no era la tallerista quien escribía, sino por lo general lo hacía un par "que sabía un poco más". En cuanto a escribir con los otros, creemos que la participación en una experiencia de escritura grupal, el formar parte de una comunidad de lectores y de productores de textos, puede constituirse en una ocasión de ejercer los quehaceres del escritor y por lo tanto, una oportunidad de aprendizaje de la escritura. Como expresan Lerner y Kaufman (2015) en esta experiencia de "escribir con otros" se ponen en juego "los múltiples problemas que plantea la escritura y de este modo se constituyen en objeto de reflexión cuestiones que pueden permanecer implícitas cuando se escribe en soledad." (Lerner y Kaufman, 2015)

Consideramos, que es significativo para este trabajo abordar a la cuestión de la apropiación de la escritura, ya que es un factor determinante de lo que nos proponemos investigar: la experiencia de escritura de los jóvenes. Por esta razón creemos relevante reconstruir, en particular, la experiencia de Enzo, su relato, y su participación en el taller literario. Pensamos que toda experiencia está situada dentro de una trayectoria, de una historia y de un contexto. Somos conscientes de que esta cuestión es interesante y queda mucho para seguir indagando, por ejemplo: la cuestión de las redes solidarias de alfabetización, las prácticas de escritura de los jóvenes a través de los otros, o en particular el rol de los pares en este proceso.

Queda por indagar la experiencia de la escritura escolar, a la que nos acercamos transversalmente en los talleres de la biblioteca de la escuela, pero no a la escritura en el aula, ni a alguna disciplina en la escuela. De todas formas, sin ser nuestro objetivo, la escritura escolar aparece inevitablemente, porque aparece su "marca". Como lo expresan Kurlat y Perelman (2013), o Daniel Fabre, en Escrituras Ordinarias (2008) quien, sobre la presencia de escritura escolar, aclara: "nunca ha sido directamente el objetivo de este libro pero que le dibuja en muchos momentos la filigrana, como lo es el momento escolar de la escritura. No lo abordamos de frente, pero nos referimos a él con frecuencia, a partir de su marca identificable”. (Fabre, 2008, Pág. 10). Sobre la relación entre escritura y escuela, y en especial sobre su marca y su fuerza, el autor concluye "el orden de la escritura que ahí es inculcado desemboca rara vez en esta apropiación personal -sin embargo, dócil a las formas aprendidas porque ahí radica la fuerza de la escritura-, en la

\footnotetext{
48 La experiencia de escritura de la novela grupal será detalladamente descripta en el apartado 5.3. Talleres desde la Biblioteca Abierta en el Instituto Horizontes- 2015
} 
escuela se entreabre una vía, se nutre una creencia que se revela eficaz al elevar algunos destinos por encima de su trayectoria previsible." (Fabre, 2008, Pág. 12)

4.4.2. El encierro: las oportunidades, posibilidades y prohibiciones de la escritura

Hacía poemas, pero no podía escribirlos. No solo por carecer de tinta y papel. No podía escribirlos pues cualquier escritura se volvía trampa, incesante peligro. Carlos Skliar

Registro de campo, taller 29 de septiembre de 2014

Al terminar el taller me acerqué a Leandro que había estado sentado leyendo bastante y escribiendo en su nuevo cuaderno, le pregunté qué le había parecido, si le gustaría volver... me respondió que sí. Le pregunté si él escribía, si le gustaba escribir, me dijo que sí, que él tenía escondido un lápiz negro. Le pregunté si escribía en las paredes y me respondió que sí, y aclaró "escribo con jabón blanco, para que los guardias no vean"

Creemos que para abordar la experiencia cotidiana de escritura debemos conocer o al menos tener en cuenta las situaciones que la posibilitan, la condicionan o la impiden. En las conversaciones informales primero, luego en las entrevistas con los jóvenes, fue apareciendo la escritura en la cotidianeidad del encierro, y así nos fuimos dando cuenta de a poco, de las dificultades concretas para su concreción, indagamos en consecuencia. Los resultados de la indagación los desarrollaremos en forma especial en este capítulo sobre las oportunidades, posibilidades y prohibiciones de la escritura dentro del encierro.

En esta búsqueda nos encontramos con cuestiones imprevistas: si bien no éramos tan ingenuos como para imaginar que en la realidad cotidiana de una institución de encierro se fomentara o promoviera la escritura, lo que no sabíamos era que en la mayoría de sus formas la escritura estaba directamente imposibilitada e incluso prohibida. Toda escritura, como Skliar advierte, podría volverse una trampa, un peligro (Skliar, 2010). 
Pero tal como señalamos en la primera parte de este trabajo, también pueden llegar a existir ciertas artimañas frente al peligro, "trampas" para eludirlo. En palabras de De Certeau: tácticas, ejercicios, no siempre conscientes, de resistencia (De Certeau y Giard, 1996, pág. 46).

En este sentido, y a pesar de las restricciones, algunos jóvenes pueden desarrollar su particular universo de lo escrito, "sorteando las dificultades y restricciones impuestos por la vida privada de libertad" (Navarro Bonilla, 2005, pág. 19) y así consumar estas escrituras furtivas en la cotidianeidad privativa de la celda, en los pasillos o en los patios interiores del encierro.

Leandro, un joven de 17 años internado en el Instituto Horizontes, asistió a uno solo de los talleres de los propuestos por la biblioteca, y luego fue trasladado. Como suele suceder en este contexto, perdimos contacto con él. En ese único taller en el que participó estuvo callado, y leyó casi todo el tiempo, muy interesado especialmente en los tres libros de poemas de César González. Una vez terminado el taller, en una de las conversaciones que surgían espontáneamente mientras nos despedíamos, Leandro nos brindó una valiosa información que hoy nos sirve de epígrafe: nos habló sobre la mínima posibilidad de escritura en los espacios donde viven, nos dijo que él tiene un lápiz "escondido", a lo que agregó "escribo con jabón blanco, para que los guardias no vean". Estas palabras se manifestaron como alerta y pista a la vez, nos permitieron vislumbrar la fuerza de la prohibición y la dimensión de la necesidad de escribir. Este testimonio junto a otros, nos impulsó a seguir indagando.

Como dijimos al mencionar los antecedentes de esta tesis, existe un caudal de trabajos de investigación que se vienen realizando sobre la escritura intramuros, como son los de Castillo Gómez (2002, 2003, 2005), Sierra Blas (2005), Navarro Bonilla (2005), Artiéres (2005), Gándara (2005), Cruz Sánchez (2011), y otros. De estos trabajos tomamos para empezar, de Navarro Bonilla (2005) su análisis sobre el significado de la escritura para los sujetos que están viviendo una situación de encierro; este autor sostiene que la opresión de la privación de la libertad se vio siempre mitigada por la escritura:

"a modo de antídoto secular, tratando de superar el cautiverio mediante letras, incisiones y trazos. La escritura en prisión permitía cierta libertad de imaginación, así como la expresión de añoranza por el exterior o la 
costumbre, de ejercitar el ingenio en un espacio limitado". (Navarro Bonilla, 2005, Pág. 37).

Sobre las posibilidades de escribir, indagamos en las entrevistas a los jóvenes. En relación a muchos de los trabajos anteriores, tenemos una ventaja: los escritores están hoy y aquí presentes para explicarnos y ayudarnos a comprender.

En las entrevistas, preguntamos sobre las posibilidades concretas y materiales de escribir: les preguntamos sobre la posibilidad de tener cuadernos $u$ hojas, lapiceras o lápices en las piezas y sectores donde viven.

Jerónimo nos advirtió que son distintas las posibilidades en los diferentes institutos: por ejemplo, en el Instituto Nuevo Sol, de mediana seguridad, tienen más posibilidades en relación al Instituto Horizontes, de máxima seguridad:

\section{Entrevista a Jerónimo: \\ "Acá (Instituto Horizontes) no te dejan pasar NADA, en el Nuevo Sol sí "pasaban", porque estaba el colegio ahí adentro, y se conseguían, y ACÁ NO, no se puede entrar nada, igual allá estaban como... de contrabando."}

La expresión "pasaban" da la idea de una mercancía prohibida, a lo que él agrega luego, como para confirmarlo: de contrabando. Vamos viendo que, a pesar de las diferencias, Jerónimo explica que ni en uno ni en otro instituto se pueden ingresar "oficialmente" elementos para escribir, pero se entiende que en uno de ellos - el Nuevo Sol- hay ciertas reglas que se pueden trasgredir, no así en el Horizontes, de máxima seguridad.

Joaquín nos describe sus intentos de tener un cuaderno en el Instituto Horizontes, y reconoce también, que finalmente, la única manera es "de contrabando" o en sus propias palabras: "de chope" 49 :

Entrevista a Joaquín:

"Acá todo es "de chope", acá las reglas... no existen...demasiado que estamos en cana... que nos vengan a decir... que nos digan lo que tenemos que hacer..."

"Qué se yo, lo rescaté (al cuaderno), por ahí te hace falta y te ponés a escribir cosas... porque a veces estaba solo en la pieza... no sabía qué hacer, no me podía dormir, estaba

\footnotetext{
${ }^{49}$ de "de pecho": de "ponerle el pecho a las balas", o sea, con coraje, por las buenas o por malas, asumiendo los riesgos
} 
solo en la pieza... escribía una banda de cosas... después en una requisa me sacaron el cuaderno donde estaba escribiendo todo y... lo perdí... ahí después no me cabía nada... es que acá dentro de esta bosta no te dan ganas de hacer nada"

Yaiza Moreno Haro en Esos papeles tan llenos de vida (2009), presenta el capítulo "Correspondencia privada". Allí menciona las situaciones que generan la necesidad de escribir, una de estas situaciones sería la privación de la libertad. La autora manifiesta que esta escritura surge "como instrumento para superar la distancia y la soledad" (Moreno Haro, 2009, pág. 135) y explica el significado de la escritura en situaciones extremas: "Escribir se convirtió en sinónimo de sobrevivir. Sobrevivir a la experiencia del exilio o de la reclusión. Sobrevivir al hambre, a la pobreza y a la destrucción.” (pág. 136). Esta autora toma algunos conceptos de Antonio Castillo Gómez, quien en De la suscripción a la necesidad de escribir (2002) desarrolla la cuestión de la necesidad de comunicación escrita ya en los siglos XIX y XX. Castillo Gómez menciona la emigración, el exilio y la guerra, como circunstancias en las que "era tal la sensación de soledad y desarraigo, tal la tristeza y la desesperación, que no pocas personas buscaron su consuelo en la escritura, supieran o no escribir" (Castillo Gómez, 2002, pág. 32)

Cuando Joaquín narra "no sabía qué hacer, no me podía dormir, estaba solo en la pieza" está describiendo esa sensación de soledad y de desarraigo de la que venimos hablando. Ese cuaderno para él era seguramente un instrumento para superar la distancia y la soledad.

Acaso la privación de la libertad sea para estos jóvenes una forma de sentir la sensación de ser emigrantes, de estar exiliados, de vivir el desarraigo, por ser "jóvenes que crecen en un lugar distinto a aquel donde sus padres, o ellos mismos, han pasado la infancia” (Petit, 2012, pág.263). Michèle Petit, en el capítulo "La literatura, parte integrante del habitar" en La literatura que acoge: inmigración y lectura de álbumes se refiere a este espacio ajeno, distinto, desconocido. En este espacio agobiante Petit rescata la aparición necesaria de los relatos, de las historias: "para que el espacio sea representable y habitable, para que podamos inscribirnos en él, tiene que contarnos historias" (Petit, pág. 266). De alguna forma el cuaderno de Joaquín podría ser para él un espacio habitable, de reconstrucción de su historia, en ese exilio que para él es el encierro.

Renato, también interno en el Horizontes, y en el mismo sector que Jerónimo y Joaquín, nos contó sobre la necesidad/imposibilidad de escribir:

Entrevista a Renato 
Y justo cuando quería escribir no tenía ni la hoja ni la lapicera... Me gustaría poder hacerlo... para poder ver, ver todo lo que ya pasó... lo pasado... me llamó la atención eso de escribir, todo lo mío, todo lo mío...

Con un sentido práctico aparentemente diferente al de Joaquín y Jerónimo, Renato minimiza la situación de la prohibición y resuelve de otra manera:

\author{
Entrevista a Renato \\ Y bueno...tengo que hablar con un guardia y pedirle si me puede prestar una lapicera por \\ un rato y después se la devuelvo.
}

En nuestra búsqueda no encontramos ninguna reglamentación escrita que hiciese referencia a la prohibición de la escritura. Tal como expresa Joaquín: "acá no hay reglas". De hecho, al momento de este trabajo de campo, para nuestro asombro, se estaba intentando construir un reglamento de convivencia para todo el Complejo Esperanza: no habría hasta aquí reglas de convivencia escritas, en relación a una cantidad de aspectos de la cotidianeidad.

El 5 marzo del 2015, participamos en la reunión institucional a la que convocaron autoridades de la SeNAF, para trabajar sobre la construcción del Proyecto de Reglamento de Convivencia, hasta ese momento inexistente. Participaron diferentes actores institucionales. La primera reunión había sido con el personal del Complejo Esperanza dependiente de la SeNAF: guardias y jefes de los institutos, personal técnico, etc. Se propuso una reunión para todos los docentes de la escuela, es decir, dependientes del Ministerio de Educación. Se buscaba llegar a acordar bases de un régimen para todo el Complejo Esperanza. Habían sucedido diferentes situaciones de gravedad: motines, intentos de suicidio, denuncias de malos tratos, peleas, etc. Hubo acuerdo general en la urgencia de acordar pautas mínimas de convivencia que superaran las vigentes, que surgían desde el "sentido común" de las prácticas tradicionales del encierro, y básicamente consistían en castigos, sanciones como privación de actividades -a los talleres o a la escuela-, e incluso el aislamiento en una pieza por dos o tres días.

Desde la SeNAF se propusieron algunas acciones concretas, como por ejemplo la designación de nuevos equipos de socio-educadores que ingresarían a los institutos, formados en psicología, socio pedagogía, o trabajo social. Estos cumplirían un rol de acompañamiento en la convivencia de los jóvenes regulando sus actividades. Se presentó 
además un documento base, a consensuar, respecto a derechos y obligaciones de los guardias, y de los adultos en general, que cumplen distintos roles respecto a los jóvenes, y los derechos y obligaciones de los chicos privados de la libertad, quienes deberían ser informados, una vez acordado este nuevo reglamento.

Entre los derechos y propuestas mencionados, se dio especial importancia al acceso y la promoción a la lectura y la escritura. He aquí el interés particular por el cual mencionamos esta reunión, ya que demuestra con claridad, la contradicción que una vez más aparece entre los discursos oficiales y la realidad; y en este caso, entre las intenciones -posiblemente genuinas-, con la posibilidad real de acceso a la lectura y la escritura por parte de los jóvenes en conflicto con la ley. Se sugería el fomento a la escritura, pero ni antes ni después de la reunión se tomaron medidas concretas que favorecieran esta posibilidad en la cotidianeidad del encierro.

Las únicas decisiones y posibilidades reales del fomento a la escritura se dan en la escuela o en el marco de los diferentes talleres, en particular desde la Biblioteca Abierta, pero no como parte de la vida cotidiana dentro de los institutos. Con el ingreso del equipo de socio-educadoras, en el año $2016^{50}$, se empezaron a articular algunas acciones aisladas y puntuales para que los jóvenes puedan tener acceso a la lectura o la escritura.

Cuando conversamos sobre la situación de prohibir lápices, lapiceras, hojas y cuadernos, los docentes y autoridades de la escuela expresaron no comprender la prohibición y con ironía una docente respondió "parece ser que un lápiz es un arma letal". Lo cierto es que es posible y de hecho, frecuente, que los jóvenes se autolesionen, incluso con una lapicera. Respecto a la prohibición de los cuadernos, es más difícil de comprender. De todas maneras, en lo que nos interesa -la cotidianeidad del encierro- y por lo expresado por los chicos, cada vez que hay requisas los guardias les sacan los libros, los lápices y los cuadernos, y en los motines -que suceden varias veces por añodirectamente se pierde todo:

Entrevista a Jerónimo

... perdés todo. En un motín se pierde todo, todo, te quedás solo con lo que tenés puesto

Nos llamó la atención la cuestión de las requisas y la manera en que se pierde todo. Sobre el tema de la requisa, en La Bemba, Emilio de Ípola, hace un análisis sobre sistema carcelario-político. A pesar de no encontrarnos en una cárcel en sentido estricto, sino en

${ }^{50}$ Ya por fuera del período de tiempo de este trabajo de campo 
una institución que aloja jóvenes menores de 18 años que han cometido delitos, y en una coyuntura histórica distante ${ }^{51}$ al trabajo de Ípola, no se puede negar que estamos trabajando en una institución de encierro que sostiene prácticas y rutinas carcelarias. Ípola explica que el sistema "garantiza la desinformación de los detenidos por medio de medidas cuidadosamente articuladas y aplicadas". Entre esas medidas, están las requisas periódicas "ocasión a menudo de provocaciones y castigos corporales y de un despliegue deliberadamente inusitado de fuerzas en las cuales se concede especial atención a los papeles escritos que un detenido guarda en su celda”. Ípola detalla, por ejemplo, que "aunque se autoriza a veces la posesión de cuadernos para escribir, estos son, al cabo de un tiempo, retirados de las celdas" (Ípola, 2005, pág. 21) y aclara que "hay regímenes extremadamente duros y otros más tolerantes. Pero esas variaciones no exceden ciertos límites y no afectan por tanto a lo esencial” (Ípola, pág. 24)

Vemos a la requisa, como una manifestación de las continuidades de prácticas históricas en el encierro. Ípola realiza una descripción que tomamos porque da cuenta de un modus operandi carcelario que visibiliza que nos encontramos en una institución de encierro, que en cuanto a lo que explica Ípola, no es diferente a una cárcel en lo esencial. Respecto a la escritura vemos que los cuadernos son retirados como parte de estas rutinas de la institución total.

A la falta de cuadernos o papel, una de las posibilidades de escribir es la escritura en la pared, este tema lo desarrollaremos en un capítulo especial: 6.4. Pero en este pequeño fragmento de nuestro registro de campo del 24 de abril del 2015, podemos ir adelantando que la escritura en la pared tampoco está permitida:

Del registro de campo

"Saqué las fotos, registré, bajo la mirada desconfiada de los guardias. En ese momento caí en la cuenta de que toda escritura en la pared era y sería sancionada."

${ }^{51}$ El trabajo de Ípola se centra en su experiencia como preso político en la década de 1970 


\subsection{Conclusión provisoria}

Este capítulo está fundado en los relatos de los jóvenes sobre su vida, los que fueron entrecruzados con los aportes de los autores, el marco teórico y con nuestro propio análisis e ideas. Nos centramos en sus biografías, en las situaciones sociales y escolares que narraron, en la cuestión de la alfabetización, y finalmente, en las oportunidades y posibilidades de escribir en el encierro. Nos propusimos en esta descripción, prestar cuidado en no caer ni en estereotipos estigmatizantes, ni en una mirada compasiva o romántica sobre sus vidas.

Hemos dado cuenta hasta aquí de una información que es importante para nosotros, ya que nos sirve no solo de cimiento, sino que, el abordar cuestiones elementales de la experiencia social y personal, se va construyendo la materia prima que atraviesa toda esta investigación en forma constante.

Trabajamos, como sabemos, con jóvenes internados en el Complejo Esperanza por haber cometido delitos, nos referimos especialmente a siete jóvenes en particular, a los cuales conocimos primero en los talleres de escritura, y con los cuales tuvimos luego la oportunidad de conversar en profundidad en las entrevistas personales, ellos son: Facundo, Nahuel, Nicolás, Jerónimo, Renato, Enzo y Joaquín. El pequeño relato de sus historias singulares nos permite hacer visible un contexto de interpretación de lo que vamos a analizar con relación a nuestro objeto de estudio: la experiencia de escritura. También incorporamos los significativos aportes de otros jóvenes que fueron pasando por algunos talleres o por la biblioteca.

Respecto a sus biografías, dimos cuenta de que además de la situación de privación de libertad, los jóvenes se encuentran, sobre todo, en una situación de vulnerabilidad que atraviesa sus vidas y los atraviesa de una forma decisiva, en su vida en el encierro.

Provienen de barrios llamados por ellos mismos "barrios bajos" o "villas", marcados por el estigma social, barrios "de mala fama" en los que nacen y crecen los niños pobres que se acostumbran desde muy pequeños a ser vistos como una amenaza. Estos jóvenes nacieron en un contexto problemático: la crisis desatada en el año 2001. En los años 2014 y 2015, momento de este trabajo de campo, aunque los indicadores señalan un mejoramiento económico, los problemas persisten. En forma especial en el "barrio bajo": se convive con la desigualdad social, el estigma, en medio de un desdibujamiento de "la 
ley". La estigmatización es producida y reproducida fuertemente por los medios masivos de comunicación. Tal que finalmente, como describe César González, el mismo villero siente vergüenza del lugar donde vive" (2016)

Respecto a las trayectorias escolares, los relatos dan cuenta de trayectorias fragmentadas, y de exclusión. Este grupo social -jóvenes varones con bajo nivel de escolarización- es considerado el sector más proclive a la criminalización social (en el sentido que Zaffaroni da al término), y el más estigmatizado. Tal como indican las estadísticas, corroboramos que la mayoría de los jóvenes no concurría a un establecimiento educativo al momento de la comisión del hecho.

Partimos del concepto de trayectoria escolar, como problema socioeducativo, en contraposición a la idea de "fracaso escolar" como problema individual. Gabriel Kessler (2004), pone el eje en la idea de trayectoria educativa, considera que es relevante el tipo de experiencia escolar y las marcas de esta experiencia (Kessler, 2004, Pág. 25). Tomamos de Terigi, el concepto de trayectoria interrumpida (Terigi, 2009), al que relacionamos con la idea de la interrupción de la niñez y de la infancia de Carlos Skliar (Skliar, 2015)

Tomamos datos de una encuesta de la SeNAF (2014) que revela, entre otros datos que la mayoría de los jóvenes internos no había iniciado el secundario en el momento de la privación de la libertad. En la entrevista, Nicolás nos advierte: "de la mayoría de los chicos que están a acá nadie va al colegio en la calle".

Comprobamos - como Kessler- que hay algún tipo de percepción en el imaginario de los jóvenes sobre la importancia de la educación. Como Renato, cuando se repite a sí mismo: "tengo que seguir, tengo que seguir". Hoy Renato salió en libertad, y al día de la escritura de esta tesis, sabemos que está nuevamente preso, pero esta vez en la cárcel de adultos. Vemos que no siempre es posible "seguir" sin acompañamiento en libertad. Así le ocurrió a Renato, un joven con herramientas, y con ganas de superar su situación.

Respecto a la alfabetización: nos encontramos con chicos que -como Enzo- no sabían leer y escribir. A pesar de eso -aunque un buen número apenas escriba y algunos lo hagan con dificultad-, la mayoría de los jóvenes practican la escritura cotidianamente en formas no convencionales. Como Castillo Gómez sostiene: en situación de soledad y desarraigo, son muchos los que buscan un desahogo en la escritura, sepan o no sepan escribir (Castillo Gómez, 2002, pág. 32) 
Tomamos el relato de Enzo, quien cumplió con casi toda la escolaridad primaria, pero no logró alfabetizarse. A pesar de que, como afirma Giorgio Cardona, la escritura se aprende en la escuela, esto a Enzo no le pasó. Aparece entonces otra clase de alfabetización: "entre pares", unas ciertas "redes solidarias" e informales de alfabetización colaborativa, tal como las define Robinson-Pant, "redes de apoyo para las actividades de alfabetización". Renato nos relató su trabajo de alfabetizador con Enzo en la soledad de la pieza del encierro, lo que también había hecho con otro compañero.

Observamos que la desigualdad en la apropiación de la escritura tiene una relación ineludible con las desigualdades de acceso a la educación, dado que el rol fundacional de la escuela es justamente la alfabetización (Emilia Ferreiro, 2001). Pero también observamos que dentro de las desiguales oportunidades, en el conjunto de estos jóvenes, existen diferentes experiencias de apropiación de la escritura. Esta diversidad de experiencias es lo que hace que funcionen, como observamos en los anteriores relatos de Renato y Enzo, esas mencionadas "redes solidarias" de alfabetización en las que los que saben "un poco más" actúan de alfabetizadores en la convivencia del encierro.

Kurlat y Perelman, en referencia a la complejidad del proceso de apropiación de la escritura en jóvenes y adultos (2013), desarrollan la idea de una trenza formada por las marcas de enseñanza, las marcas de exclusión y los niveles de conceptualización. En Enzo pudimos reconocer estas tres hebras: el conocimiento de las letras y el deletreo como claras marcas de enseñanza; el "no sé escribir", como marca de exclusión; y con menos claridad, posiblemente, en los intentos de escritura autónoma, su nivel de conceptualización sobre la lengua escrita.

Pudimos observar en el proceso vivido por Enzo una suma de condiciones: la participación en el taller de escritura, la escritura a través de los otros y con los otros, el trabajo articulado con las socio-educadoras en los sectores, la tarea alfabetizadora de sus compañeros y la enseñanza cotidiana de la escuela del encierro. Observamos en los talleres literarios un proceso en el que Enzo empezó a animarse a leer y a escribir por sí mismo.

Finalmente, en cuanto a la cuestión de la alfabetización, lo que quedó claro es que no nos encontramos ante un escenario de alfabetización generalizada, y esto se corresponde con trayectorias escolares fragmentadas, interrumpidas y de exclusión, lo que revela condiciones de vulneración de derechos. 
Indagamos también sobre las oportunidades, posibilidades y prohibiciones de la escritura dentro del encierro. Podemos decir que, al momento de este trabajo de campo, los chicos no contaban con los materiales para escribir, ni tenían permitido su ingreso a los sectores donde vivían, situación más o menos rígida de acuerdo a las características de cada Instituto. El material para escritura no podía entrar al sector, en especial los lápices o las lapiceras por la posibilidad de convertirse en objetos peligrosos contra los otros o contra sí mismos.

Aunque no encontramos ninguna reglamentación que haga referencia a la prohibición de la escritura, la realidad es que en la cotidianeidad del encierro existen dificultades concretas para escribir. Si bien el reglamento de convivencia del Complejo Esperanza está en proceso de construcción, como expresa Joaquín: “acá no hay reglas”. Queda claro que la institución de encierro presenta un doble discurso respecto de la escritura: en las intenciones se propone la promoción y el fomento, pero no se habilitan los medios para que esto ocurra, o se hace en forma mínima. Las posibilidades reales de práctica de la escritura se dan en la escuela o en el marco de los talleres, en particular desde la Biblioteca Abierta, pero no como parte de la vida cotidiana dentro de los institutos.

Al no tener acceso a la escritura en los sectores donde viven, la mayoría de los jóvenes internos ven vulnerado su derecho a acceder a la práctica de la escritura cotidiana, y a la experiencia de la escritura creativa.

Aun así, a pesar de las prohibiciones y la alfabetización incipiente, los jóvenes escriben y expresan una necesidad de escribir. La escritura forma parte de su vida en el encierro, y al no tener cuadernos ni hojas, tratan de encontrar la manera o escriben en la pared. Es que escribir los ayuda a sobrevivir al encierro, a superar la distancia y la soledad. Cuando abordemos la escritura cotidiana intentaremos acercarnos a estas experiencias furtivas de escritura. 


\section{Lo que los chicos escriben en los talleres de escritura creativa:}

\subsection{La entrada al campo ${ }^{52}$. La planificación, convocatoria y organización.}

Registro de campo/ 23 de mayo de 2014 / primer entrada al Complejo Esperanza: Vamos para el Complejo, el camino en mal estado, pozos, charcos, el tráfico enredado con camiones y colectivos que también van saliendo de la ciudad, maneja Letizia en su auto viejo, vamos recorriendo barrios del margen de la ciudad de Córdoba, ranchos, casas pobres que contrastan con algunos "countries". Vamos llegando a una zona rural, se ven basurales, campos de papas o soja, se llama camino "60 cuadras", que pasados varios km. tiene una bifurcación con un cartel con una flecha que indica "Complejo Esperanza". Ingresamos a la recta final, con plantaciones a los costados, avanzamos aproximadamente uno o dos $\mathrm{km}$. por esa calle solitaria. La recta finaliza en una enorme arcada que cruza la ruta con la leyenda: "Complejo Esperanza". La arcada tiene escrituras pintadas en aerosol a modo de graffiti en su base: "trabajo de riesgo" "trabajo insalubre", "traidor" ... explica Letizia: "son reclamos del sindicato de los guardias"

Ese enorme cartel cruza toda la calle: "Complejo Esperanza" a modo de "bienvenida" aparece como una rotunda muestra de la escritura de la institución prisión, en este caso: la escritura de entrada a la privación de la libertad. La bienvenida al encierro es parte de la escritura de los establecimientos de reclusión. Estas arcadas aparecen en la historia de los centros de reclusión y permanecen "como exponente de la utilización del poder de todos los medios, incluido el ad extra y ad intra para legitimar su discurso de control y hegemonía" (Navarro Bonilla, Pág. 23). Los graffitis con reclamos de los guardias, nos anticipan que entramos a un territorio conflictivo. La frase "Complejo Esperanza" aparece como una de las paradojas que caracterizan este tipo de inscripciones e instituciones: "esperanza" posiblemente en base a la premisa del ingreso a un lugar donde "se brinda protección y asistencia integral", tal como la institución se presenta a sí misma en su página web. Los graffitis en la base "trabajo insalubre" nos dan cuenta de que la realidad es, por lo menos, contradictoria. Una vez traspasada la arcada de "bienvenida", nos acercamos al predio:

52 Pasamos un momento descriptivo/narrativo de este trabajo. Articularemos algunos fragmentos textuales de las desgrabaciones con los registros de campo, para tener así una descripción lo más completa posible. Respetamos de los registros la forma coloquial y la primera persona del singular. Iremos a la vez analizando algunas cuestiones teóricas, que seguiremos profundizando en las conclusiones parciales y finales. 
Del registro de campo:

Nos acercamos al predio de varias hectáreas con arboleda -eucaliptus-. El lugar está rodeado de un alambrado muy alto, de alambre tejido y alambre de púa, y está custodiado por el Servicio Penitenciario. Se ven pequeñas cabinas distribuidas en el perímetro, con guardias adentro. Veo -todavía desde afuera- algunas grandes construcciones distanciadas, con sus respectivos alambrados o muy altos paredones, son los institutos. Llegamos a un gran portón con una garita, del lado de afuera esperan grupos de personas que se bajaron del colectivo, cargadas de bolsas, en su mayoría mujeres con niños, gente humilde, me explica Letizia que son las madres de los chicos y demás familiares esperando su turno para entrar el día de visita. A nosotras nos abren los guardias, el saludo es casi imperceptible. Avanzamos unos cien o doscientos metros y llegamos a la escuela. Es una construcción chica en medio del predio, con murales con colores en las paredes exteriores y en el frente una galería con vigas de madera. A la derecha, a unos 50 metros se ve un gran instituto con alambrado y varios guardias apostados en la entrada -es el Nuevo Sol- me aclara Letizia.

Entramos a la escuela, ubicada prácticamente en el centro del predio. Es una construcción pequeña que iba a ser destinada originalmente a los vestuarios de un complejo deportivo, transformada posteriormente en el espacio donde actualmente funciona el centro educativo.

Del registro de campo:

Hacemos un recorrido: una pequeña sala de administración, luego la biblioteca: un espacio estrecho con cantidad de libros en pilas o en cajas, Letizia me explica que acaban de llegar y que tiene que catalogarlos, luego un pasillo, una cocina que oficia de sala de profesores y dos aulas, una más pequeña y otra más grande, todos los espacios están separados de manera provisional con durlock de poca altura, lo que hace que haya poca aislación acústica. En el camino me va presentando a varios docentes, algunos están almorzando en la cocina, la comida en bandejas y cubiertos descartables, la misma de los jóvenes internados. Uno de los docentes es el coordinador pedagógico de la escuela del Complejo.

Luego de las presentaciones personales nos reunimos con la autoridad presente, el coordinador pedagógico, para presentar este proyecto de investigación: 
Del registro de campo:

Después de comer, nos reunimos con el coordinador y Letizia en la Biblioteca. Les explico sobre el Proyecto de Tesis, y la idea de permanecer un tiempo largo en el lugar para "formar parte", le propongo colaborar en algunas tareas de la biblioteca y que mi estadía sea un proceso productivo para ambas partes. Les parece bien, y me explican que en el Complejo hay mucho movimiento de tesistas que entran y salen, y que la verdad es que muy pocas veces aportan algo al concluir su trabajo. Por cuestiones administrativas me comprometo a escribir una nota de presentación y pedido de permiso para poder permanecer en el lugar el tiempo que dure mi investigación. Mientras tanto por la biblioteca pasan profesores que van y vienen, personal administrativo, algunos alumnos que saludan con un beso. Mientras entran y salen, todos miran las cajas y comentan sobre los hermosos libros recién llegados. Se conversa también sobre las novedades, en particular, sobre el motín de hace unos pocos días. Un profesor, Edgardo. nos muestra una foto que él mismo tomó del sector donde fue el motín, la pared del lugar destruido está escrita: "Dios te lo pido ayudame".

El espacio de la biblioteca se perfilaba como un espacio privilegiado por donde, a lo largo del día, circulaban docentes, no docentes y alumnos. El ingreso al campo coincidió con la inauguración de la Biblioteca Abierta en el Centro Educativo del Complejo Esperanza. Este fue el lugar por donde ingresamos y donde definitivamente permanecimos desde el primer día del trabajo. Nos propusimos llegar a "formar parte" de ese espacio particular de circulación de personas y circulación de la palabra, oral y escrita. Nuestro rol y tarea -la investigación- a partir de este momento se concentró en la biblioteca: fue Letizia -la bibliotecaria- el nexo para nuestra entrada al espacio. La biblioteca se encontraba en ese momento sobrepasada de tareas: la catalogación de los nuevos libros y la planificación de las actividades del año. Nos ofrecimos entonces, a colaborar con diversas tareas que la biblioteca estaba iniciando. Fue luego, a través de este espacio que terminamos siendo parte del equipo que llevó a cabo los talleres literarios y otras propuestas. Esto nos permitió después realizar las entrevistas a los chicos, además de lograr, posteriormente, el permiso para entrar a diferentes sectores donde viven los jóvenes para registrar las escrituras en las paredes. Dedicamos un párrafo a la bibliotecaria, persona que acompañó nuestro trabajo de campo durante todo el trayecto de la investigación 


\section{LETIZIA}

Letizia es Profesora de Historia y docente en el Centro Educativo del Complejo Esperanza, anexo del CENMA Profesora María Saleme de Burnichon hace 10 años. Como profesora de Ciencias Sociales es la impulsora y coordinadora del proyecto de la Revista Tumbando Rejas. Tiene una vasta experiencia en la modalidad y el Pos título en Educación en Contexto de Encierro. Fue nombrada bibliotecaria en el 2014, entre otros motivos, como reconocimiento de la necesidad de legitimar su rol en la coordinación del proyecto de la revista, para que Tumbando Rejas tenga un espacio propio y que se pueda coordinar desde la biblioteca.

No podemos dejar de mencionar que Letizia, "La Colo" para los alumnos de la escuela del Complejo, es una referente importante para ellos, ya que, a través de su presencia, el conocimiento, el cariño, el respeto, el compromiso hacia los jóvenes, ganó un lugar de confianza y un vínculo humano de afecto, condiciones claves para el trabajo educativo con los jóvenes en este contexto.

Como dijimos, una de las tareas de la Biblioteca Abierta es la organización de los talleres literarios. Como parte del equipo acompañamos a Letizia durante los años 2014 y 2015 en la planificación, puesta en marcha y coordinación de los talleres de escritura creativa.

\subsubsection{Planificación, convocatoria y organización - Breve cronología}

Haremos una síntesis en forma de breve cronología de las actividades de los dos años

\section{AÑO 2014:}

La Biblioteca Abierta propuso en el 2014 una serie de talleres itinerantes "de invitación", para que la mayor cantidad posible de chicos internos en el Complejo pudieran acceder y conocerla. La modalidad del taller literario y el espacio disponible requería que los grupos estuvieran conformados por unos 8 chicos aproximadamente, como máximo. Se pensó entonces una secuencia de 3 o 4 talleres por cada grupo para que los jóvenes 
que quisieran participar, tuvieran la oportunidad de hacerlo. La idea de estos talleres iniciales fue que funcionaran como manera de "invitación" a las actividades que posteriormente ofreciera la Biblioteca, pensando que, en un futuro, se pudiera establecer un taller en forma fija, un día en la semana, y que los más interesados pudieran participar.

Los talleres itinerantes se desarrollaron dentro de lo previsto, aunque incialmente con grupos de chicos más pequeños de lo esperado: cinco jóvenes como promedio. Las dificultades que se presentaron estuvieron dentro de lo previsto: que los guardias no "sacaran" a los chicos, que los chicos salieran "de permiso", o que salieran en libertad. Estas situaciones repiten las mismas dificultades que afronta cotidianamente la escuela en contexto de encierro, y están -como dijimos- dentro de lo esperable en este contexto, más aún para quienes conocen sus movimientos cotidianos y lógicas internas, pero no son tan obvias para quien no lo conocen. Las podemos resumir en algunos puntos:

1. La estadía incierta de los jóvenes en el encierro, en el que permanecen por un tiempo indeterminado, sin tener la mayoría de las veces claro cuál será su permanencia en el lugar, tal como dijimos al hablar del régimen penal juvenil. $A$ veces son tiempos cortos en el Complejo, otras, mucho más largos. Esta situación de poca previsibilidad dificulta pensar en procesos.

2. Situaciones de conflictos permanentes, ya sea entre los jóvenes o con los guardias. Por estas situaciones, se aplican distintos tipos de sanciones disciplinarias, la más general es que no se les permita salir del encierro de los sectores de los institutos, aunque los chicos pidan. Los castigos, como dijimos, se basan en general en la permanencia en el encierro, lo que repercute en la participación en las actividades de la escuela o de los talleres. Esta situación de reforzamiento del encierro va desde el encierro en su sector, hasta el aislamiento en una pieza de castigo ${ }^{53}$.

3. Los conflictos sindicales de los guardias, asambleas o medidas de fuerza que redundan en no trasladar a los jóvenes de los sectores a las actividades escolares, talleres, etc.

4. El entrecruzamiento de actividades de la Institución total: entrevistas con los equipos técnicos, otros talleres "de salida laboral" propuestos por la SeNAF, salidas a tribunales por temas judiciales, salidas por permisos, visitas, etc.

\footnotetext{
${ }^{53}$ Estos castigos han sido denunciados y van en contra del régimen de convivencia en construcción, pero en la práctica se han seguido realizando.
} 
5. Las cuestiones de comunicación o desinformación sobre la realización de tal o cual actividad. Los jóvenes expresan también que no se les avisa de la realización del taller, a pesar de que se entreguen las listas con los nombres.

6. Las situaciones personales de los chicos de desinterés e incluso depresión producida por el encierro, por lo que en ocasiones por decisión propia no salen a los talleres o a la escuela. ${ }^{54}$

Ya finalizando el año 2014, por los motivos mencionados, se sabía que no era sencilla la formación de grupos. Se presentó la siguiente oportunidad: un grupo de jóvenes que cursaba la escuela de adultos los días viernes, durlock de por medio con la Biblioteca, veían y especialmente escuchaban lo que en los talleres transcurría. Entraban cada vez que podían a mirar, a pedir libros, caramelos, cigarrillos y también reclamaban la posibilidad de tener ellos su taller. Dando respuesta al reclamo, el último taller del año se proyectó para este grupo, junto con las profesoras de Lengua y Ciencias Sociales, como parte de sus horas de clases, a modo de cátedra compartida, esta vez con un grupo un poco más numeroso, de unos quince jóvenes.

En el marco de los talleres del año 2014, y a raíz del vínculo construido con los jóvenes, se pudieron realizar tres entrevistas en profundidad: a Facundo, a Nicolás y a Daniel.

\section{AÑO 2015:}

EL año 2015 comenzó con talleres itinerantes en el mes de marzo. Pensados en esta oportunidad como talleres unitarios. Se recorrieron los distintos espacios, modalidades y grupos de la escuela: aulas de secundario y primario de adultos. La Biblioteca Abierta planeó varios proyectos para desarrollar a lo largo de año: talleres de escritura, un proyecto de audiocuentos, teatro, encuentros, jornadas, y todo lo referente a la Revista Tumbando Rejas.

Pero a poco de iniciados los talleres literarios de invitación se interrumpieron abruptamente, por la muerte de un joven en el Complejo Esperanza que se sumaba a los motines, a las medidas de fuerza de los guardias y a las denuncias de maltrato y malas condiciones de vida. El suicidio de un chico de 17 años dentro del Complejo Esperanza

${ }^{54}$ En la etapa de este trabajo de campo hubo varios motines, intentos de suicidio, lesiones por peleas, autolesiones, y un suicidio (año 2015). 
fue (y es) una situación traumática que generó complicaciones para acordar horarios, espacios, disponibilidades generales tanto en los jóvenes como en los adultos, y tanto en los talleres como en todas las actividades de la escuela.

El año empezó entonces, como venimos diciendo, con un problema grave, que se sumaba a las complejidades cotidianas propias del contexto. Recién en el mes de agosto, luego del receso invernal, se volvió a la actividad de los talleres de la biblioteca y se pudo volver a pensar y a replantear nuevas estrategias de manera que los jóvenes pudieran aprovechar las propuestas.

Surgió entonces una nueva posibilidad. Entraron en escena las socio-educadoras, que ingresaron a los institutos del Complejo Esperanza para resolver cuestiones vinculares y de convivencia. Formaban parte de una medida estratégica de la SeNAF ${ }^{55}$, algunas de ellas, becarias de las carreras Psicología Social o Trabajo Social de la Universidad Nacional de Córdoba. Se acercaron a la escuela y a la Biblioteca Abierta para articular actividades. En particular, Graciela, nos puso al tanto de que en el Instituto Horizontes, de máxima seguridad, había un grupo de jóvenes -del sector D- que no estaban saliendo a ninguna actividad, o sea, que permanecían encerrados todo el tiempo. Nos propuso que se acerquen los talleres allí, ya que sería imposible que ellos salieran por estar con "medida cautelar". Ese mismo grupo de chicos, del sector D, había participado de un taller de audiocuentos en la primera etapa, pero luego no habían podido "salir" más a la escuela los días viernes. Una particularidad de este grupo de jóvenes internados en el Instituto Horizontes, era que su tiempo de privación de la libertad sería, en general, más largo que el del resto de los jóvenes de los otros institutos.

Si bien, como se mencionó, una premisa de la escuela es que las actividades se desarrollen por fuera del encierro, en algunos casos -como este- se consideró que valía la pena "entrar" al instituto, sobre todo si no había otra opción para los jóvenes.

Se planificó entonces la segunda etapa de talleres en función de esta posibilidad. Se ganó un espacio, y un horario. El espacio: la sala de visitas del Instituto Horizontes; el horario: los martes por la tarde. Así semanalmente se realizaron los talleres con un grupo estable, con un proyecto de escritura grupal e individual. Todo esto con la ayuda de las negociaciones del Coordinador de la escuela, y la mediación de las socio-educadoras. Se

\footnotetext{
${ }^{55}$ Las socio-educadoras tienen en un rol clave: ingresan a los institutos, hasta ese momento, territorio prácticamente exclusivo de los guardias. Su tarea es compleja: se ocupan desde el acompañamiento a los jóvenes, su asesoramiento y contención, hasta la mediación y articulación de acciones, para que, entre otras tantas cosas, se puedan realizar este tipo de actividades como los talleres literarios
} 
logró así la permanencia de un grupo de chicos interesados en participar. Se realizaron trece talleres, con el objetivo final de la producción de una novela grupal.

A raíz de estos talleres, y del vínculo con los chicos, se realizaron cuatro nuevas entrevistas: a Renato, a Jerónimo, a Joaquín y a Enzo.

\subsection{Descripción de los talleres literarios}

\subsubsection{Los talleres en la Biblioteca Abierta/ año 2014}

\subsubsection{Introducción.}

Como ya explicamos, los talleres de escritura propuestos por la Biblioteca Abierta fueron el dispositivo a través del cual se buscó "ser parte" e iniciar el vínculo con los chicos y su experiencia de escritura

Como mencionábamos, durante el año 2014 se realizaron los primeros talleres, en la Biblioteca. Para este análisis fueron seleccionados tres talleres, con el criterio de retratar distintos momentos del proceso, de acuerdo a la participación de los jóvenes y la escritura que surgió en cada uno, y con la idea de que fuesen representativos y significativos para el presente trabajo de investigación.

Los tres seleccionados del año 2014 fueron talleres unitarios, en el sentido de que cada uno contaba con su producción escrita final, aunque formaran parte del proceso de tres o cuatro talleres con cada grupo de jóvenes.

El rol que asumimos en los talleres, en correspondencia con el trabajo de investigación de corte etnográfico y observación participante, fue -como dijimos- formar parte del equipo que planificó y acompañó la coordinación de los talleres literarios que propuso la Biblioteca, tanto en los del año 2014 como en los del 2015. Formamos parte de este equipo, participando fundamentalmente en la planificación, junto con la bibliotecaria, con quien llevamos a cabo la coordinación. El rol de Letizia fue de permanente mediación, ya que ella era la docente a quien los chicos conocían y con quien tenían un vínculo, y por

ser además quien conocía la escuela y las lógicas institucionales. Participamos y observamos, esto en sintonía con la idea de que la participación es una instancia necesaria de acercamiento a los sujetos, que va siempre acompañada por una elaboración reflexiva y teórica. (Guber, 2004) 
En cuanto a la planificación de los talleres, partimos del concepto de Andruetto y Lardone de que el taller de escritura creativa es un espacio de expresión y circulación de la palabra:

"El objetivo último del trabajo de taller es la vivencia de una palabra propia, una palabra que siendo de todos (de todos y de uno es el lenguaje, social y a la vez individual) se sienta como propia, y en tanto propia, armada, desarmada, rota, modificada, descubierta, valorizada o revalorizada" (Andruetto y Lardone, 2011, pág. 22).

Desarrollaremos la descripción de los talleres y presentaremos algunas escrituras de los jóvenes. Nos interesa elegir un tono lo más descriptivo posible, no entraremos en el campo del análisis literario.

Para la programación de los talleres se tomaron de estas autoras los momentos básicos del taller literario: ambientación, motivación, consigna, tiempo de escritura, lectura y cierre (pág. 26), y algunas ideas de su batería de ejercicios (pág. 45). Se tuvieron en cuenta también las propuestas de Gianni Rodari en su Gramática de la fantasía (Rodari, 1997) e ideas de diferentes materiales de talleres literarios. Todas las propuestas fueron adaptadas al contexto y a la situación, y en muchos casos las consignas fueron creadas por el equipo de la biblioteca, de acuerdo a los tiempos, los espacios, el grupo de jóvenes, las circunstancias, los intereses, con la flexibilidad necesaria para poder reformular o incluso improvisar en el momento lo que fuera necesario.

\subsubsection{Descripción de los talleres en la Biblioteca/2014}

Como mencionamos, daremos cuenta de tres talleres seleccionados dentro de los realizados durante el año 2014:

- El primer taller -del 28 de junio- con un grupo de siete jóvenes, en un aula de la escuela primaria, que prestó el espacio.

- El segundo taller -del 5 de septiembre- con un grupo de tres jóvenes, en la biblioteca.

- El tercer taller - del 25 de septiembre- dentro de la clase de Lengua de la escuela secundaria, con un grupo de más de diez jóvenes.

Luego, analizamos otras escrituras que surgieron en forma espontánea dentro del espacio de la biblioteca: una autobiografía y una carta. 
Como ya mencionamos, para la descripción de los talleres que seleccionamos elegimos un tono descriptivo/narrativo (coherente también con la etnografía como texto), e intercalamos algunos fragmentos de los registros etnográficos y las transcripciones de las grabaciones ${ }^{56}$.

La descripción de los talleres va acompañada de los textos escritos por los jóvenes. Realizamos una selección de las producciones escritas en el segundo y tercer taller $^{57}$, y las presentamos junto a los fragmentos de los registros y el presente análisis. Al final de este capítulo, en el punto 5.3. incluiremos lo que los jóvenes expresaron sobre la experiencia de escritura creativa en el marco de los talleres propuestos, tanto en el año 2014 como en el 2015.

\subsection{Primer taller/ 28 de junio de 2014: Taller de presentación}

\section{Del registro de campo}

Preparamos el aula (un aula pequeña de la escuela primaria): armamos una mesa larga, unimos todas las mesas y las cubrimos con un mantel -una tela que encontramos-, colocamos una cantidad libros de la biblioteca sobre esa gran mesa (poesías de César González, Benedetti , Girondo, Neruda o Borges, novelas de Rodolfo Walsh, Saramago, libros álbum con grandes ilustraciones, libros en forma de comic, biografías del Che Guevara, etc.) todos son libros nuevos recién llegados a la Biblioteca abierta, de hermosas ediciones y coloridos, además agregamos fotocopias de poesías, y caramelos entre medio de los libros, ponemos también como fondo música suave (Cesária Évora). Un cartel escrito rápido en el pizarrón: "Taller Literario - ¡Bienvenidos!" Llegan enseguida con Mauro, el preceptor, siete chicos que entran de a uno, van mirando la mesa y los libros, extrañados. Saludan con un beso, se van sentando en silencio, se ponen a mirar los libros y van haciendo algunas preguntas y comentarios. En menos de un segundo agarran todos los caramelos, y los que no llegan a comer se los guardan en los bolsillos

Una mesa "servida" de libros es una propuesta del taller de escritura que busca favorecer el encuentro de los jóvenes con los libros y la literatura, supone la sorpresa, el placer, la exploración, la lectura individual y el intercambio informal. Este taller ofreció esta mesa de libros en circunstancias particulares: en una institución de encierro, cuyos

\footnotetext{
${ }^{56}$ Estos talleres por ser en la escuela, permitían la posibilidad de tener el grabador, lo que no sucedió con los talleres del 2015, por estar dentro de un instituto de máxima seguridad

${ }^{57}$ No contamos con los textos del primer taller, en el que la actividad fue fundamentalmente oral.
} 
participantes eran jóvenes que estaban viviendo una situación de institucionalización de sus vidas, aislamiento, reclusión. Los libros fueron seleccionados de la biblioteca de la escuela, además de haber sido elegidos por su contenido y autores en función de los objetivos del taller, se trataba de libros nuevos, atractivos, coloridos, en sus mejores ediciones ${ }^{58}$.

Michel Petit (2003), cita a Beatriz Helena Robledo, una joven colombiana que trabaja en talleres literarios con adolescentes enrolados en el conflicto armado que atraviesa su país, y sobre el significado del libro y la lectura en tales circunstancias y condiciones, explica: "Para ciudadanos en condiciones medianamente normales de desarrollo, un libro puede ser una puerta más que se abre, en cambio, para aquellos que por circunstancias de la vida han sido despojados de sus derechos fundamentales, o de sus mínimas condiciones humanas, un libro es quizás la única puerta que puede permitirles atravesar el umbral y saltar al otro lado" pero aclara "no es únicamente un escape o un lote de consolación para aquellas y aquellos que se sienten encerrados" (Petit, 2003, pág. 6). "Saltar del otro lado" en este contexto adquiere un significado potente en forma literal: saltar las rejas, los muros, saltar hacia la libertad. El taller de escritura todo, adquiere un valor especial en el contexto en el que hace la propuesta la Biblioteca Abierta. Además de la promoción a la lectura o a la escritura, el encuentro con la literatura habilita el derecho al acceso a los bienes culturales que fueron vulnerados, en palabras de Petit: "el derecho al extrañamiento, al desvío, a la metáfora, a la ampliación de su universo cultural" (Petit, 2003, pág. 19).

El primer grupo estuvo conformado por siete jóvenes, todos internados en el instituto Nuevo Sol y alumnos del PIT ${ }^{59}$ : Juan, Nicolás, Daniel, Facundo, Cristian, Fabián y Gustavo. Daniel y Facundo continuaron por varios talleres más y con ellos pudimos realizar entrevistas personales. Este grupo tenía clases dentro del instituto y no salían para asistir a la escuela -ya que el PIT funcionaba dentro del encierro-, de hecho, salían a muy pocas actividades. Esta salida era una oportunidad y una "prueba" para ellos, así nos explicó, Mauro, su preceptor. El taller empezó con las presentaciones personales, se plantearon los objetivos del taller. También se hizo la presentación del presente trabajo de investigación, y se aclaró que se iba a registrar con un grabador si a ellos no les molestaba, con la debida y necesaria aclaración que no iba a ser entregado a ningún juez, ni juzgado, ni a ninguna autoridad. Los chicos, más que sentirse intimidados, se

\footnotetext{
${ }^{58}$ Colecciones del Programa Bibliotecas Abiertas del Ministerio de Educación de la Nación

59 Programa de Inclusión/Terminalidad de la Educación Secundaria para Jóvenes de 14 a 17 años
} 
sorprendieron con el grabador de periodista, aparentemente les llamó la atención la cuestión tecnológica: pidieron permiso para verlo, lo tomaron en sus manos, preguntaron cómo funcionaba, hablaron, jugaron unos minutos, y luego lo dejaron en la mesa con naturalidad.

\begin{abstract}
Del registro de campo
Para comenzar el taller damos una consigna de presentación: escribir un fragmento de una canción que les guste o sientan que los represente, y que escriban tres motivos de esa elección. Los chicos se ponen a escribir en silencio, hacen algunos comentarios entre ellos sobre las canciones, uno de los chicos no arranca, espía lo que hacen los otros, algunos, como Daniel, se notan entusiasmados, y alientan a los demás. Murmullos y "silencio de escritura" de vez en cuando, risas.
\end{abstract}

Michel Petit, se refiere a este "silencio de escritura" en El arte de la lectura en tiempos de crisis (2009). En referencia a la experiencia de Mona Thomas, explica: "el silencio es el primer signo de que la escritura "está funcionando", de que la propuesta ha sido escuchada. "Son momentos de gracia" dice ella, donde los alumnos han dejado de sentirse agitados o agobiados, expresan el deseo de otra cosa" (Petit, pág. 234). Estas escenas de escritura: los chicos escribiendo en silencio, conversando por momentos, la aparición de alguna risa o alguna broma, son como dice Petit, "momentos de gracia" que se fueron repitiendo en diferentes etapas de los talleres, a lo largo de los dos años de trabajo de campo.

Transcribimos aquí fragmentos textuales del momento de la presentación y puesta en común de lo escrito, o sea, el momento en el que los chicos leían los fragmentos de las canciones que escribieron para presentarse. Gran parte de ellos, contrario a lo que hubiéramos imaginado, se animaron a leer en voz alta, algunos incluso cantaron y en su mayoría se mostraron desinhibidos. El primero en animarse a leer fue Juan:

De la grabación:

\title{
JUAN
}

Juan: Nombre, Juan, el fragmento... eso... acá esta la canción... (Señala, muestra la hoja) ... ah ¿tengo que leerla?

Tallerista: así todos sabemos cuál es la canción...

Juan: (mira el escrito) No entiendo nada....

Tallerista: ¿Qué no entendés? ¿Lo que escribiste?

Juan: "Ojalá", del Dami...se llama (y de nuevo muestra lo que escribió) 
Tallerista: ¡Bueno...! Las tres razones...

Juan: Esta canción la elegí porque me gusta, me hace acordar al chico que se alejó de su princesa, y la canta "el fenómeno"...

(Aplausos)

\section{FACUNDO}

Tallerista: (a Facundo) ....Bueno... te toca a vos... (Le tocaba leer su canción y no se animaba)

Daniel: Faltai vó nomas... (Exagera "el tono cordobés", risas) ... Dale, sacáte la vergüenza

Facundo: Vergüenza es robar

Tallerista: ¿Cómo es tu nombre?

Facundo: Ordoñez, Facundo. Es de Daniel Córdoba (lee en forma fluida) "Ojalá pudiera ir volando

a tu ventana, darte un beso en la cara y acariciarte el pelo sin que te despertaras"

Tallerista: ¡Es hermosa esa canción!

Facundo: ...Que se yo... porque me gusta, porque con ese tema me puse de novio y se la dediqué a mi novia

Daniel: Listo, listo... ¡definitivamente!

(Aplausos)

Juan y Facundo habían elegido la misma canción "Ojalá”, mientras Facundo leía, los demás tarareaban y continuaban con la letra de la canción: "quisiera ser el aire, pa" meterme entre tus rejas, mirándote a la cara, y solo si tú me dejas...”. El clima era de alegría, y se aplaudía en cada caso. Luego se pasó a un momento de lectura:

Del registro de campo:

Letizia lee en voz alta "Los sueños del sapo" de Javier Villafañe. Cristian y Gustavo continúan escribiendo sin parar la canción de la consigna anterior. Todo el grupo escucha, silencioso, atento. Cuando Letizia termina de leer, Facundo comenta "o sea que no le gustaba nada, le gustaba ser el mismo nomás", "así es" responde Letizia, y seguimos conversando sobre el cuento.

Luego de la lectura de otro cuento "El rey secreto", de Pablo de Santis, se pasó a otro momento de escritura:

Del registro de campo:

Les proponemos hacer una escritura sobre los sueños, si quieren, sueños inventados, o si quieren un sueño real. Les ofrecemos imágenes de revistas -que están sobre la mesa-, que elijan un personaje, y escriban el sueño de ese personaje, pensando que les iba a ser más 
fácil escribir en nombre de otro. Los chicos revisan un rato las imágenes, dan muchas vueltas, entonces Daniel interviene “¿Puedo escribir sobre mi propio sueño?” Los otros agregan: "yo soñé con mi libertad", "yo también" "yo también". Se ponen a conversar sobre sus "sueños de libertad", cuánto les falta para salir, etc. "Ya te vas" “vos decís?" "Ojalá" "Dios te oiga". Conversan y escriben...

Este momento de escritura fue un momento conversado, ya no era "en silencio", escribían y hablaban, compartían lo que escribían, esta vez se trataba de una "escritura conversada" sobre sí mismos:

Del registro de campo:

Juan nos muestra su escrito y aclara de manera contundente: "Eso es lo que sueño yo, no te voy a escribir canciones, yo sueño eso: estar con la familia" ... Facundo nos cuenta que está esperando un hijo y que está desesperado por salir a la calle: "11 veces estuve preso, desde el 2007 ando dando vueltas por acá" ... "una infancia perdida" ... comenta Daniel

Aidan Chambers (2007) en su libro Dime analiza el lugar de la conversación en torno a la lectura, allí valora el lugar de "una conversación cooperativa en la cual una comunidad de lectores realiza descubrimientos que van mucho más allá de cualquier cosa que hubieran podido encontrar solos.” (Chambers, 2007, pág. 101). ¿Podemos hablar de una conversación en torno a la escritura en el sentido en el que Chambers habla de la lectura? Pensamos que sí. Podemos afirmar que en los talleres observamos distintas formas de escritura: una escritura silenciosa, introspectiva, como la que antes describimos y otra escritura conversada probablemente propiciada por la modalidad del taller, por el estar sentados alrededor de una mesa, en un ambiente de confianza. Estas condiciones probablemente propiciaron, en palabras de Chambers, el "hablar a otro", "hablar juntos", "hablar de lo nuevo" (Chambers, pág. 36) en torno a la escritura. Más adelante, en el capítulo sobre escritura cotidiana, veremos que esta escritura conversada, es parte de las prácticas cotidianas de escritura en el encierro.

En este primer taller empezamos a tomar conciencia de la importancia que tenía para ellos la escritura sobre sí mismos: escribir sobre lo real, sobre la realidad. Cuando Daniel, con cierta timidez, propuso: “¿Puedo escribir sobre mi propio sueño?”, o Juan, contundente aclaró: "Eso es lo que sueño yo, no te voy a escribir canciones". Comprendimos que escribir "ficciones" -aunque supiéramos que toda ficción tiene un componente autobiográfico- en principio, no les interesaba: querían escribir sobre sí mismos. Retomamos en este sentido las palabras de Jorge Larrosa (2006), acerca de la escritura para uno mismo: "escribimos, en primer lugar, para nosotros, para aclararnos, para tratar 
de elaborar el sentido o el sinsentido de lo que nos pasa", lo que podríamos reformular con los dichos de los jóvenes en el taller: escribimos para nosotros y para los demás y sobre todo escribimos de, y desde nosotros, para contar lo que nos pasa, lo que sufrimos en el encierro, para ser leídos-escuchados.

Del registro de campo:

Entra Mauro para ver cómo está todo. La charla sigue, Daniel conversa mucho sobre las canciones, Mauro se queda con nosotros y les dice que después les va a dar un tiempo para que fumen tranquilos afuera, que "si la cosa viene bien podemos seguir, todo depende de los chicos, que hagan las cosas bien... vamos a seguir"; los chicos empiezan entonces a planear y a imaginar ideas para los próximos talleres, todas centradas en las comidas, como compartir un asado o unas empanadas árabes, mientras tanto siguen escribiendo, hablan de los sueños, todos sueños relacionados con la libertad.

De la grabación:

Mauro: ¿Cómo andan muchachos?

Daniel: Acá estamos, tranqui, disfrutando el momento, ya hace mucho que no nos saca al colegio

Mauro: y si...claro, por eso elegí algunos que no salen muy seguido...porque no están viendo las horas...

Daniel: ¿y nos van a sacar todos los días o de vez en cuando?

Tallerista: acá vamos a hacer tres talleres, una vez por semana, después a los que les guste, más adelante, vamos a seguir en la Biblioteca...

Mauro: a mí me interesa que les guste... y que lo disfruten... porque hay algunos chicos que no vinieron porque no saben qué es, por eso, si ustedes ven que a otro changuito le gusta, le dicen...

Los chicos: ¡Fonseca! ese chico no sale a ningún lado

Mauro: Si... si la cosa viene bien, podemos seguir así...

Del registro de campo:

Luego empezamos a leer lo que escribieron. Todos, sin excepción, cuentan sobre sus sueños de la libertad, "la calle", el día de su cumpleaños, su familia, su novia, su madre, los hijos o los que vienen en camino, las comidas de su casa "acá nos cocinan como para que no nos caguemos de hambre, nada más", leen y comentan, no se aferran al texto de 4 o 5 renglones que escribieron. Nos cuentan que después de soñar, se despiertan y se sienten "estrellados", "chocadazos", "quebrados", que cuando se despiertan les "baja la presión". Que "ahí adentro" todos sueñan lo mismo, el sueño se les viene solo a la cabeza, se duermen y sueñan, hasta que se despiertan con los ruidos del encierro "clac, clac", el ruido 
de los candados, las rejas, quieren seguir durmiendo, no quieren ver esa realidad, se levantan mal. Se quejan del maltrato de "los maestros" (los guardias), y de los amigos de la calle que nunca los vienen a visitar.

El taller terminó con una charla de cierre, que surgió en forma espontánea. Luego de finalizado el taller hubo un incidente imprevisto:

Del registro de campo:

Los chicos dicen que el taller les gustó, que les despejó mucho la cabeza. Letizia les explica que escribir les sirve para fugarse con la cabeza; la idea de "fugarse" a los chicos les da mucha gracia, hacen bromas, dicen que se van a fugar: que se van a ir con ella en su auto. Entonces Letizia se ríe y les dice "jahora van a decir que la profe les dijo que se tenían que fugar!" todos nos reímos. Se va haciendo la hora de irse, a los chicos les gustaron mucho los libros, se los quieren llevar. Letizia les propone ir a la biblioteca para hacerse socios y que así puedan retirar algunos.

Como había prometido el preceptor, se les deja un tiempo para que salgan a fumar, a tomar aire. Apenas unos minutos después de salir a la galería entra Daniel gritando que hubo una pelea y entra Gustavo con un golpe en la cara y la nariz sangrando. Los chicos están protegiendo a su compañero, que se limpia en el baño de la escuela (es abierto, las piletas están en un pasillo). Letizia les da pañuelos descartables, trata de tranquilizarlos, los chicos explican que vino un chico de otro sector y le pegó directamente, "de una". Luego entra Mauro, el preceptor, que presenció la situación, y nos cuenta (con satisfacción) que está asombrado porque Gustavo, el chico golpeado reaccionó "muy bien", ya que no devolvió la agresión, y por eso no pasó "a mayores", esto él lo asocia al taller, al hecho del clima tranquilo que se había vivido instantes atrás en el taller, nos dice que va informar al juez a favor de Gustavo sobre lo ocurrido. Finalmente vamos al otro edificio de la escuela, donde funciona el secundario y la Biblioteca, al lado de la primaria, donde habíamos trabajado. Algunos chicos se hicieron socios de la Biblioteca, y eligieron libros para llevarse, luego de que se retiraron, quedaron guardados los sobres con sus escritos

La conflictividad del encierro aparecía con fuerza y se mezclaba con la fraternidad vivida en el taller apenas unos minutos antes. La crudeza de la situación nos advertía que estábamos en un lugar en el que se ponían en juego una serie de variables que eran difíciles de controlar. La opinión de Mauro, su asombro y el reconocimiento de que el clima vivido en el taller, de calma -y escritura podríamos agregar- había favorecido a que la violencia no pasara "a mayores", nos hizo dimensionar, por un lado, la importancia de 
este espacio de creación y de habilitación de la palabra, y por otro, el cuidado necesario en la cuestión organizativa, en un terreno que aparecía como un "campo minado".

Queremos aquí dar cuenta de la información que tuvimos la oportunidad de registrar en relación con la trayectoria de algunos de los chicos participantes en este primer taller. Creemos que este registro complementa la comprensión de la diversidad y complejidad del contexto:

- De los siete chicos, tres -Facundo, Daniel y Cristian- no sólo participaran en la serie de los tres talleres programados, sino que, por pedido de ellos, continuaron participando durante todo el año acompañando a los demás grupos durante todo el 2014. Facundo y Daniel salieron en libertad ese mismo año, primero Daniel, después Facundo. Nicolás participó de los tres talleres planeados. Gustavo y Juan no volvieron al taller, nunca supimos si fue por decisión propia o cuestiones institucionales.

- Daniel, el lunes 1 de septiembre de 2014, antes de salir en libertad, obtuvo permiso para participar en la Feria del Libro/ Córdoba, para la presentación de la revista Tumbando Rejas. Allí, habló frente a un numeroso público sobre su experiencia en los talleres:

Del registro de campo del 1 de septiembre:

Daniel elige para leer una versión libre del poema de Mario Benedetti "Estados de ánimo". Luego de la lectura da su testimonio:

"Yo he hecho cosas malas, y bueno, estoy arrepentido de lo que he hecho. Salgo a muchos talleres ahí adentro, electricidad, panificación...a toda clase de talleres. $Y$ bueno... salgo a un taller literario... y acá tengo algo que leer... ... de poesía, muchas cosas lindas hay... pero nada como tener su libertad, todo chico prefiere eso..."

Luego de los aplausos, fue llevado de vuelta al Complejo Esperanza. Sin razones claras al llegar lo trasladaron dentro del Complejo al Instituto Horizontes, de máxima seguridad.

Del registro de campo del 5 de septiembre

Daniel nos contó algo que ya sabíamos en parte, ya que apenas llegamos a la escuela nos lo habían comentado: que después de leer su poesía en la Feria del Libro de Córdoba, ya ilusionado de estar a poco de su libertad, lo trasladaron al Horizontes, donde están los chicos más grandes y que además en general cometieron delitos más graves. Nos contó que allí no fue bien recibido, que los chicos le pegaron, lo 
maltrataron y como él estaba muy mal lo "agitaron" para que se ahorque, y que entonces trató de ahorcarse, "cómo me voy a querer ahorcar" ...repetía una y otra vez....

Fue encontrado a tiempo por los guardias, en medio de una crisis nerviosa, y fue atendido por los equipos técnicos. Pasados dos días de este suceso siguió participando en el taller -a continuación, transcribimos el taller del 5 de septiembre-, y al poco tiempo salió en libertad.

- Juan -el primer joven en presentarse en el primer taller- como dijimos, no volvió a asistir. Salió de permiso un fin de semana y fue a su ciudad, Villa María. Allí, fue detenido por la policía, en una situación confusa -aparentemente en un robo- y fue llevado a la comisaría, luego trasladado al Hospital de Urgencias de Córdoba supuestamente por una sobredosis de droga-, de allí al Complejo Esperanza o viceversa, ya que también este punto es confuso existen diferentes versiones y hay contradicciones. Ese fin de semana Juan murió supuestamente en el traslado, su muerte es dudosa y es una de las muertes denunciadas por abuso policial en la provincia de Córdoba.

\subsection{Segundo taller/ 5 de septiembre de 2014: La mesa-las cartas}

Este el taller fue dictado por el equipo de tres talleristas, del que formamos parte, al que se sumó Emanuel, estudiante del Profesorado de Lengua y Literatura, como voluntario, por estar interesado en formarse como docente en este contexto. Se preparó para esta ocasión la ambientación en la pequeña sala de la biblioteca: una mesa en la que se colocó un mantel, el mate, los criollos, y una torta. Había pocos docentes en la escuela del Complejo, y no estaban los coordinadores.

El lunes anterior había sido la presentación de la revista Tumbando Rejas en la Feria del libro de Córdoba, la presentación convocó gran cantidad de personas, en el patio mayor del Cabildo, incluso con un recital del grupo de Hip Hop "Rimando Entreversos" con los chicos de la Fundación "La Morera"60. Fueron a la Feria unos pocos jóvenes del Complejo, entre ellos Daniel, que, como comentamos antes, dio su testimonio. Este fue

\footnotetext{
60 Organización sin fines de lucro que trabaja en participación cultural, promoción de derechos e inclusión social en la ciudad de Córdoba. El proyecto Rimando Entreversos es un taller de producción musical (Hip Hop)
} 
transmitido en vivo, como toda la presentación en la Feria del Libro, por la radio comunitaria "La Ranchada" 61.

La participación de Daniel en este taller puede resultar una muestra de la suma de las contradicciones a las que nos enfrenta el sistema del encierro: entre el discurso y la práctica, la necesidad y la exigencia, el deseo y la exclusión, la posibilidad y la impotencia. Pero también las posibilidades que surgen de las grietas en las que el mismo sistema falla: un instante, un contacto, un texto, simple y agudo a la vez.

El taller que transcribimos es el siguiente consecutivo al anterior, unos días después de la Feria del Libro y del incidente que vivió Daniel:

Del registro de campo:

Llegan primero Nahuel y Daniel. Hay bullicio de los chicos de la escuela que van llegando a clase, algunos se asoman a la biblioteca. Daniel está nervioso, y nos dice que se va a ir, que no quiere pelear, porque lo están provocando (los chicos del Horizontes, donde estuvo alojado). Le pedimos que se quede, que piense que este es un momento bueno para él, que no le va a pasar nada malo, que si quiere cerramos la puerta "y listo", que no son tantos los momentos "buenos" para disfrutar que él tiene en este lugar. Luego de tanta insistencia finalmente lo convencemos. Le mostramos entonces el video de su exposición de la Feria, y el tema de "Rimando Entreversos" completo, lo pasamos rápido, queremos cambiar el clima. Daniel lo empieza a ver, le cuenta a Nahuel, se pone contento recordando ese momento. Letizia se va a buscar a Facundo, porque los guardias no lo trajeron, mientras tanto vemos los videos. Nahuel está muy interesado porque no fue, Daniel le va contando la experiencia. Luego llegan Facundo y Letizia, justo en la parte del video en la que Daniel lee y habla sobre su mamá. Todos escuchamos en un silencio respetuoso, todos lo felicitamos. Empieza el taller, somos tres adultos: Letizia, Emanuel y yo, y tres jóvenes: Facundo, Daniel y Nahuel. Comienza Emanuel, se presenta y les cuenta que vamos a hablar, a leer y a escribir sobre "mesas". Les comenta que muchos escritores escribieron poemas dedicados a sus mesas, como por ejemplo el texto "La Mesa", de Víctor Grippo. Les muestra la imagen de la mesa grabada con un texto escrito y lee en voz alta:

61 "Radio Comunitaria La Ranchada": Proyecto cultural comunitario que difunde -desde 1987- la música popular de Córdoba: el cuarteto, noticias barriales y noticias en relación a las personas privadas de la libertad, en especial en el programa "La vida y la libertad" 


\begin{tabular}{|l|l|}
\hline & $\begin{array}{l}\text { Sobre esta mesa, hermana de infinitas otras } \\
\text { construidas por el hombre, lugar de unión, de } \\
\text { reflexión, de trabajo, se partió el pan cuando lo } \\
\text { hubo; los niños hicieron sus deberes, se lloró, se } \\
\text { leyeron libros, se compartieron alegrías. Fue mesa } \\
\text { de sastre, de planchadora, de carpintero. Aquí se } \\
\text { rompieron y arreglaron relojes. Se derramó agua, y } \\
\text { también vino. No faltaron manchas de tinta que se } \\
\text { limpiaron prolijamente para poder amasar la harina. } \\
\text { Esta mesa fue tal vez testigo de algunos dibujos, } \\
\text { de algunos poemas, de algún intento metafísico } \\
\text { que acompañó a la realidad" (Víctor Grippo) }\end{array}$ \\
\hline
\end{tabular}

Del registro de campo:

Luego leemos otros textos, como la "Oda a una mesa" de Neruda. Facundo comenta que él tiene el libro de Pablo Neruda y que está bueno (lo había retirado en el primer taller). La lectura se realiza con gran atención de los tres chicos, a pesar del permanente bullicio de las aulas contiguas. Luego cada uno cuenta algo sobre una mesa de su vida, alguna mesa importante, relatos que van acompañados de algunos recuerdos de su vida en libertad y su familia. Emanuel les propone una actividad de escritura automática, empezando por la mesa, les da la consigna "no vale parar, no vale pensar, revisar ni mirar atrás" ... y los alienta a escribir, que empezaran por la mesa y después siguieran con lo que quisieran. Se les da un tiempo. Emanuel va a indicar el momento de terminar y empezar a leer.

De la grabación:

(Silencio de escritura...bullicio del aula de al lado)

Chicos: Risas

Emanuel: dale, dale, lo que se te viene a la cabeza...

(Todos escriben, incluso los talleristas)

Daniel: $m m m$...uh ya escribí como tres renglones mirá, bueno... escribí por ahí algo...que es medio...medio...

Emanuel: dale, dale seguí...no vale...

(Siguen escribiendo)

Facundo: (mira la hoja de Letizia) No sé cómo se te pueden ocurrir tantas cosas...

Letizia: ¡Lo que se te cruce por la cabeza! 
Facundo: Es que tengo otras cosas en la cabeza

Emanuel: Escribi de esas otras cosas entonces...

(Siguen escribiendo)

Daniel: No se me viene nada a la cabeza: la mesa, la mesa, la mesa...Eso me pasa a mí, escribo, escribo, escribo...con errores de ortografía, no me los saca nadie a mí...

(Silencio)

Daniel: Me duele toda la espalda me debí haber acostado mal...

Emanuel: escribí eso... todo eso

(Escriben en silencio unos minutos más)

Emanuel: ¡Basta!

Chicos: Risas

Del registro de campo:

Luego se hace la puesta en común, los chicos leen en voz alta lo que escribieron. Van apareciendo distintas mesas, unas más pobres, unas de madera, otras de chapa o de vidrio, unas más viejas que otras, unas más mojadas que otras, lee Daniel.

En "Taller de escritura creativa", Andruetto y Lardone (2011) proponen este ejercicio sobre "La mesa", cuya "zona a explorar" es la memoria, y sus consignas van "tras los ecos de un recuerdo" (Andruetto y Lardone, pág. 42). Las autoras proponen arrojar una o varias palabras "al estanque de la memoria”, parafraseando a Gianni Rodari en La Gramática de la Fantasía (2011, pág. 42) y en consonancia con el ejemplo de Rodari postulan: "cada palabra contiene una historia, se ha cargado de significados y evoca en cada persona sentimientos y sensaciones únicas. Así es como se vuelven propias” (pág. 43). En este caso la palabra, es la palabra mesa.

A la propuesta de Andruetto y Lardone se le sumó la idea de la escritura automática, partiendo de las ideas del Manifiesto del surrealismo, de Bretón (1924), se aconsejó a los jóvenes "escribir lo suficientemente rápido para no tener que frenarse y no tener la tentación de leer lo escrito. La primera frase se les ocurrirá por sí misma ya que en cada segundo que pasa hay una frase, que desea salir. Sigan todo el tiempo que quieran."

En cuanto al texto "la mesa" de Grippo, en el artículo Escrito sobre una mesa (2002) Jorge López Anaya escribe para el diario La Nación sobre la "Tabla" de Víctor Grippo: "una humilde mesa de madera, desgastada y manchada, en cuya superficie un texto escrito por el artista con caligrafía espontánea describe con tono poético los usos 
que pudo tener" y agrega sobre este autor "Su interés radicaba, ante todo, en los significados. La estética y la ética estaban en el centro mismo de su práctica artística. Siempre elementos pobres, negando sistemáticamente la frialdad anónima del universo industrial. Con énfasis reivindicó el calor de los materiales.”.

Tomamos las palabras de López Anaya porque son justamente esos sentidos los que entendemos, se pusieron en juego en el momento de escritura sobre una mesa: recordar alguna mesa, cualquier mesa, una mesa sencilla, cotidiana, recordar su material, su lugar, quienes se sentaban alrededor, y las cosas que pudieron haber pasado alrededor de ella.

Escritura de los jóvenes:

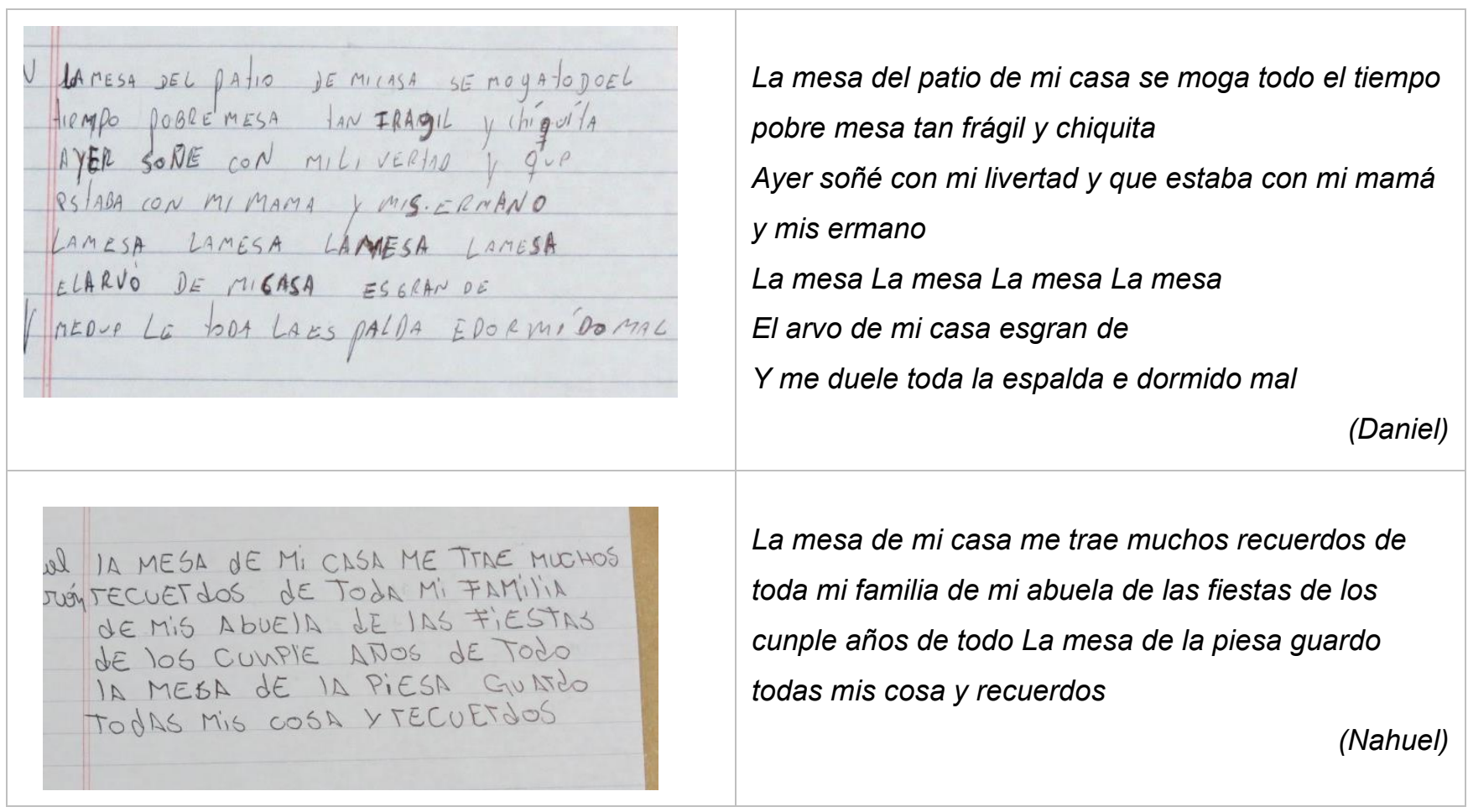

La escritura de los textos sobre la mesa evocó la memoria, las sensaciones y los sentimientos como señalan Andruetto y Lardone (2011). La descripción de la mesa de Daniel tan frágil y chiquita, la pobre mesa que se moja todo el tiempo, o la de Nahuel, en la que guarda todas sus cosas y recuerdos. La mesa significaba claramente algo más que un mueble en una casa, encarnaba trozos de memoria, de vida, para los jóvenes privados de la libertad, los "ecos" de los recuerdos de la familia y de la vida en libertad.

Por otro lado, la cuestión de la escritura en esta consigna, la escritura automática, fue una propuesta desafiante, y creemos que fue comprendida y tomada positivamente 
por los jóvenes, sobre todo por su aspecto lúdico, y consta en el texto escrito, como cuando Daniel deja que su escritura refleje el libre fluir de su pensamiento, en "La mesa La mesa La mesa La mesa"

Del registro de campo:

Luego de la lectura de los escritos Letizia les propone escribir cartas - como habían comentado que les gustaba- leemos algunas cartas, incluso una del Che Guevara, algunos lo conocen por la imagen, por el nombre, saben que era revolucionario, pero no mucho más. Letizia les comenta que hay libros en la biblioteca sobre el Che, que está la película y el libro de "Diarios de Motocicleta". Les muestra los libros. Emanuel comenta que la carta que vamos a leer la escribe a su hija Hildita. Letizia la lee. Después de la lectura lo vienen a buscar a Daniel, son del equipo técnico -probablemente psicólogas-, les pedimos esperar cinco minutos, pero no acceden porque "es tarde". Lo llevan. Daniel saluda y se va. Seguimos. Se les sugiere luego escribir cartas a cualquier destinatario con cualquier intención, Emanuel les lee una lista de sugerencias para que empiecen a escribir. Se hace un largo momento de silencio y escritura. Se escucha la clase del aula de al lado, están hablando con la profesora de la droga, el porro, los chicos se ríen. Escribimos.

Los chicos, sin dudarlo, eligieron destinatarios reales, como la familia y la madre:

el ketida familia les pido petdon for Todo rúmlo a aGo for todo lo a ise y lo Q UOi ASET AMi ME Gustarit ESTAT Gienpre con Todo pero nOSE pota soi asi aUESES pienso qeS POT MI PAPA Y AUESES POTA NO PUEdO ASET NAAA ESTO ES MAS POTO AUESES KIETO DSET otrA COSA
Kerida familia les pido perdón por todo lo que ago por todo lo que ise y lo que voi a aser A mi me gustaría estar siempre con todo pero no se porq soi asi aveses pienso $q$ es por mi papa a veces porq no puedo aser nada mas porq avese kiero aser otra cosa (Nahuel) 


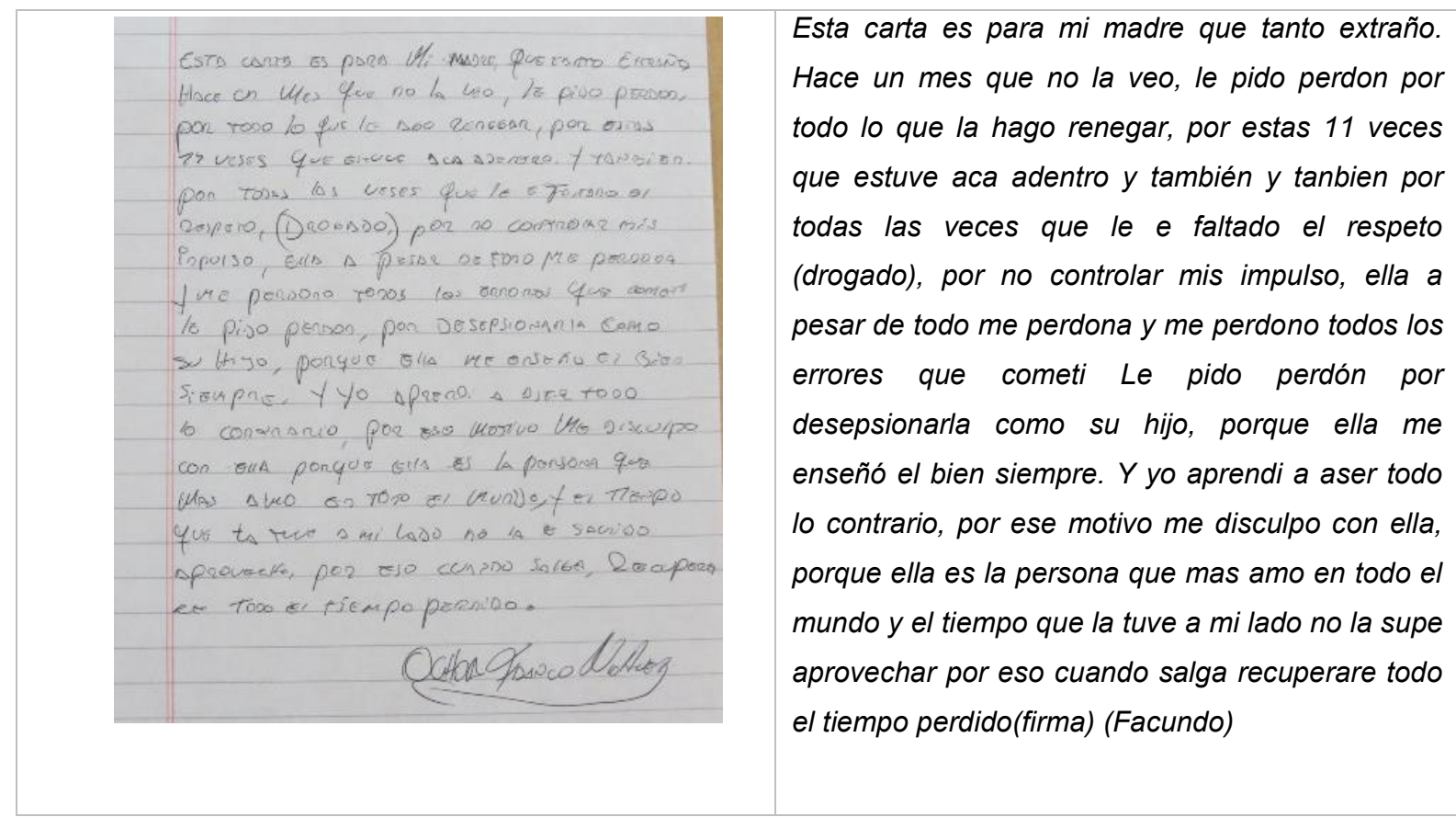

Las dos cartas están dirigidas a la familia, y en ambas la intención es un pedido de perdón. La de Nahuel es una carta breve, clara y concisa "les pido perdón por todo lo que hago por todo lo que hice y lo que voy a hacer'b2. Está escrita respetando la segunda persona y posee encabezamiento formal: "Querida familia”. En cuanto al contenido, él se pregunta “¿por qué soy así?” y “¿por qué no puedo hacer nada más?” y responde: "tal vez por mi papá" (luego nos cuenta que su papá está preso). Llama la atención el pedido de perdón por lo que va a hacer, en tiempo futuro, como si se sintiera predestinado, tal vez como su padre, a seguir en un camino de acciones que perjudican a su familia.

La carta de Facundo, la escribe a su madre, aunque en realidad escribe sobre su madre, en tercera persona "ella es la persona que más amo en todo el mundo". Da la sensación de que no pudo abstraerse a la situación de escritura en el taller, o sea, del hecho de que no se trataba de una carta real. Es un texto más extenso y elaborado, en el que Facundo va reformulando el pedido de perdón "perdón por todo lo que la hago renegar/ Le pido perdón por decepcionarla/ me disculpo con ella”.

La escritura de Facundo respeta ciertas convenciones ortográficas, pero no las del género epistolar. Nahuel, en cambio, atendió a algunas convenciones del género carta, con criterios de ortografía no convencionales (ausencia de $\mathrm{H}$, o el uso de la $\mathrm{K}$ en el lugar de Q). Nahuel salió en libertad al poco tiempo y no pudimos llegar a entrevistarlo.

\footnotetext{
${ }^{62}$ Aquí transcribimos los textos en forma de escritura convencional
} 


\subsection{Tercer taller/ 25 de septiembre 2014: Presentación -acrósticos- poemas con versos prestados}

Se trató del primer taller del tercer grupo del año 2014. La particularidad de este taller fue, como dijimos, que se trabajó en las horas de clase de Lengua y de Historia del secundario de adultos. A diferencia de los anteriores que eran grupos pequeños y voluntarios, participaron en el taller todos los chicos de primero y segundo año del CENMA: aproximadamente unos quince jóvenes. Este taller se presentó como un desafío, no solo por lo numeroso del grupo sino también porque los profesores habían anticipado que se trataba de un grupo "difícil" y que en general les "costaba hacerlos trabajar". Como se trataba del primer taller del grupo, se inició con la "mesa servida" de libros

Del registro de campo:

La mesa, llena de libros, frases, poesías, caramelos, música de fondo: la guitarra de Paco de Lucía, incluido perfume de ambientes y "sapitos de la suerte" 63 de origami con palabras y versos. Empezaron a llegar los chicos, de a poco, algo desconfiados se acercan, preguntan: “¿Qué es esto?” “¿Quiero tener clases!” ¿Que es un taller?” Saludan y se van sentando, algunos mantienen cierta distancia, se paran en el fondo y miran desconfiados.

"¿Qué es un taller? ¡Quiero clases!" En el comienzo, los jóvenes se mostraron extrañados: la distribución del aula -la mesa grande para sentarse todos alrededor-, la presencia de varios adultos, la ambientación -los libros, los caramelos-; algunos jóvenes reclamaban el formato habitual del aula, la rutina, la clase tradicional con el maestro al frente. Pero poco a poco empezaron a interesarse por lo que estaba pasando, a atender a las consignas, a escuchar las lecturas y fueron a integrándose en el taller.

Del registro de campo:

Son unos 15 chicos alrededor de una mesa grande, participan también las dos profesoras: Viviana y Lucía, además de Letizia, Emanuel y yo. La primera actividad propone la presentación, a través de un acróstico con su nombre. Para sorpresa nuestra, todos se ponen a hacerlo, algunos con la hoja en blanco piensan, algunos preguntan y arrancan, otros rápidamente escriben, finalmente casi todos escribieron, y los leemos en voz alta.

63 Juguete de azar tradicional de papel, también "adivinador" o "juguete de la fortuna" 


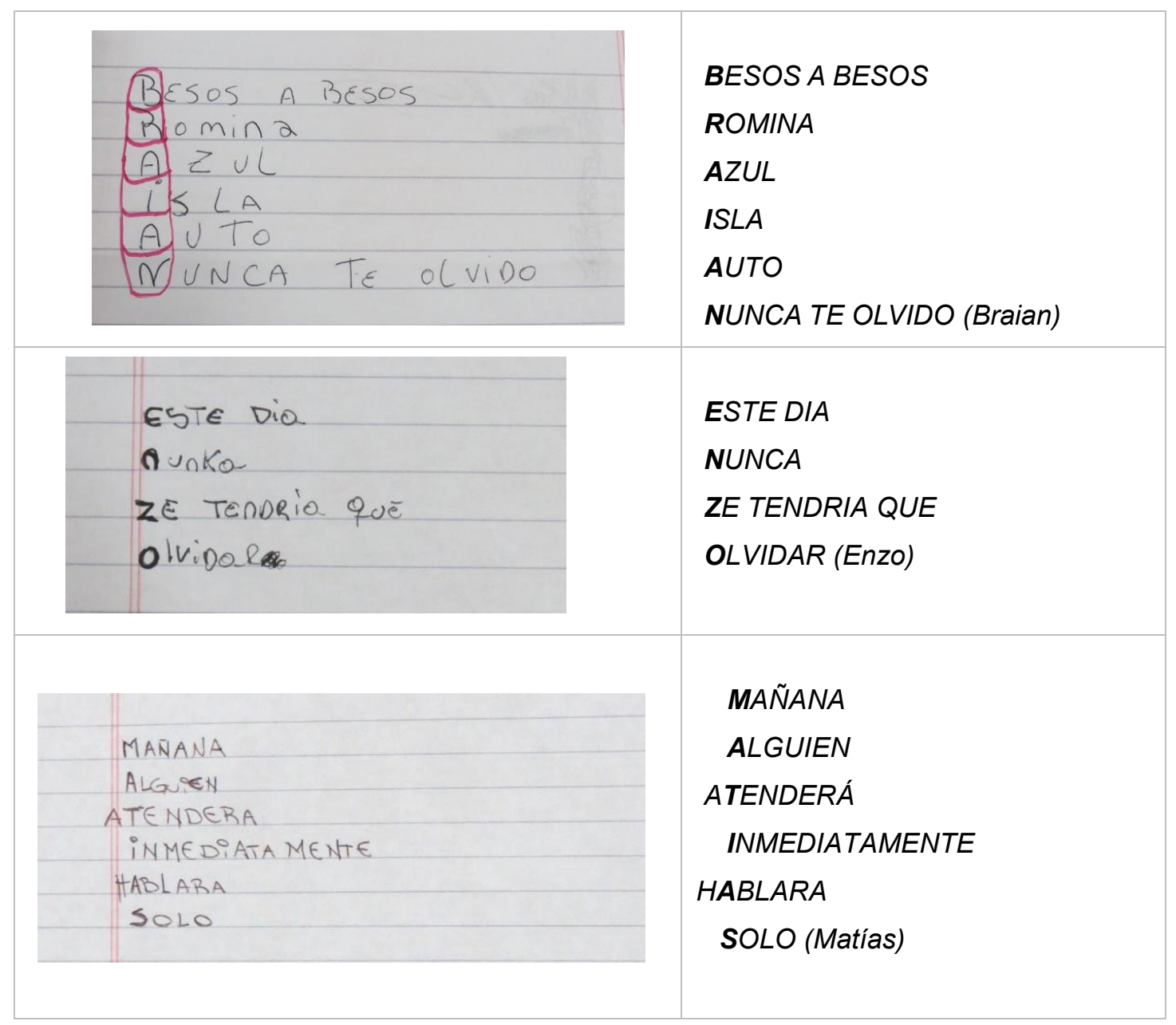

La escritura de acrósticos con los nombres significó un desafío para los chicos, y los entusiasmó, sobre todo, creemos, por su aspecto lúdico. El acróstico de Enzo "Este día nunca se tendría que olvidar", fue el último en ser leído. Enzo formaba parte del grupo que en un comienzo no quería participar, se quejaba por el taller, y se mantenía a distancia, sentado en una mesa en el fondo: nos asombró el contraste de lo dicho en su escrito con su actitud de aparente rechazo hacia la propuesta del taller.

Los acrósticos forman parte de los juegos con palabras que propone el maestro Gianni Rodari en La Gramática de la Fantasía (1997). En el capítulo 2, analiza el poder de las palabras, a través de la metáfora El canto en el estanque, a la que hacían referencia Andruetto y Lardone:

"Si tiramos una piedra, un guijarro, un «canto», en un estanque, produciremos una serie de ondas concéntricas en su superficie que, alargándose, irán afectando los diferentes obstáculos que se encuentren a su paso: una hierba que flota, un barquito de papel, la boya del sedal de un pescador... Objetos que existían, cada 
uno por su lado, que estaban tranquilos y aislados, pero que ahora se ven unidos por un efecto de oscilación que afecta a todos ellos. Un efecto que, de alguna manera, los ha puesto en contacto, los ha emparentado. (Rodari, 1997, pág. 8)

Para Rodari, "Lo que interesa es la forma en que una palabra, escogida al azar, funciona como una "palabra mágica» para desenterrar campos de la memoria que yacían sepultados por el polvo del tiempo" (pág. 10). El ejemplo que propone Rodari es la palabra canto (piedra), y ejemplifica sus infinitas posibilidades. Esta vez la palabra elegida es el nombre propio.

El trabajo con el nombre propio tuvo que ver, en principio, con las presentaciones personales. Pero sabemos que el nombre de cada uno está relacionado a cuestiones más significativas y profundas, y que posee una fuerza única, diferente a cualquier otra palabra. Tomamos de Mirta Castedo (2014) la idea del especial significado del nombre: "El nombre cumple una función muy especial y privilegiada para hombres y mujeres. En efecto, es a partir del nombre que un hombre o una mujer se inscriben como individuos, como sujetos de derecho y como parte activa de su comunidad y su cultura." (Castedo, 2014, pág. 15)

El taller continuó con la lectura de poesías, y su posterior "desarmado", la presentación de los versos en formas de tiras, mezclados sobre la mesa y luego un "rearmado" de los poemas propios, utilizando versos prestados de los poemas leídos:

Del registro de campo:

Hacemos una pausa, al volver leemos las poesías de Miguel Hernández, Alfonsina Storni, Vicente Huidobro, Mario Benedetti, César González. Durante la lectura se produce un silencio respetuoso. Proponemos después la escritura de poesías propias "pidiendo prestados" a los poetas algunos versos. La mesa ahora está repleta de versos en una especie de montaña, desordenada, casi caótica (de los poemas que leímos), la consigna es: pegar y armar con los recortes de las poesías anteriores su propia poesía, con la condición de intercalar con palabras propias. Además, jugamos con los sapitos de la suerte: "decí un número... elegí una palabra" (sale un verso) "usa ese verso o palabra para empezar la poesía", se armó un revuelo, algunos trabajan solos, otros en grupo, otros piden ayuda. Algunos usan más sus propias palabras, otros menos, otros construyen su poesía solo uniendo versos. Después leímos, y hasta se aplaudió a la lectura de cada uno 
Poesías con "versos prestados": ${ }^{64}$

COTTE CAMINA MAS ES POCO lauE IINH

Caminante, son tus huellas el camino y nada más

mañana el alma tuya estará vieja.

en la torre más alta de la iglesia

De las horas en visita,

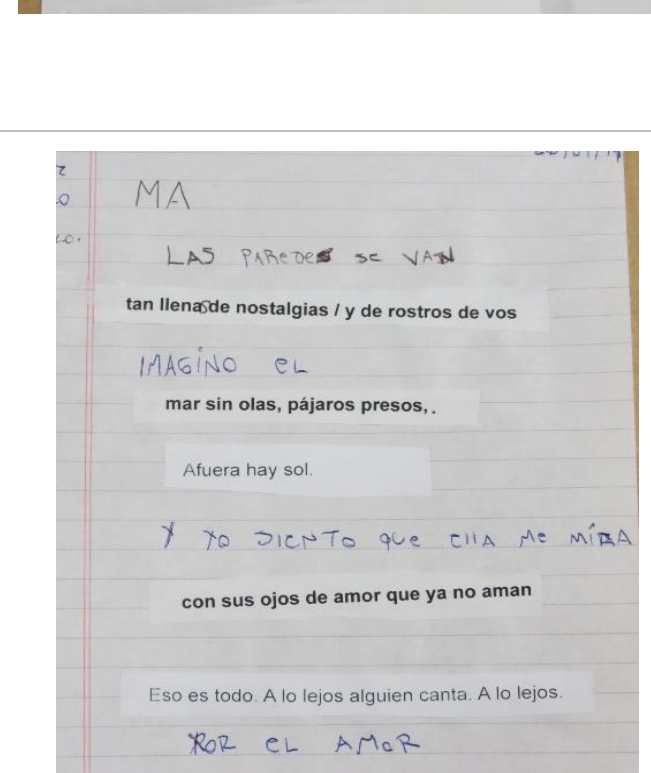

CORRE CAMINA MAS ES POCO AQUELLO

Caminante son tus huellas el camino y nada más

mañana el alma tuya estará vieja en la torre más alta de la iglesia

De las horas de visita (Nicolás)

$M A$

LAS PAREDES SE VAN

Tan llenas de nostalgia y de rostros de vos

IMAGINO EL mar sin olas pájaros presos

Afuera hay sol

Y YO SIENTO QUE ELLA ME MIRA

Con sus ojos de amor que ya no aman

Eso es todo. A los lejos alguien canta. A lo lejos

POR EL AMOR (Nahuel)
Besos Bienvenidos

gústalo todo porque todo es bello.

Y en cada requisa planeé mi futuro.

en donde todo y cada cosa tiene

SEntiDo EN LA LIGORTAD DE CMOB

UnOS DE nOSETROS PODEMOSSAIIR

PABA MEJORAR WUESTRES VIDAS.

\section{BESOS BIENVENIDOS}

Gústalo todo porque todo es bello

$Y$ en cada requisa planeé mi futuro

en donde todo y cada cosa tiene

SENTIDO EN LA LIBERTAD DE CADA UNO

DE NOSOTROS PODEMOS SENTIR PARA

MEJORAR NUESTRAS VIDAS (Luis)

64 Se transcriben en cursiva minúscula los versos recortados de las poesías para diferenciarlos de la escritura a mano en cursiva mayúscula 


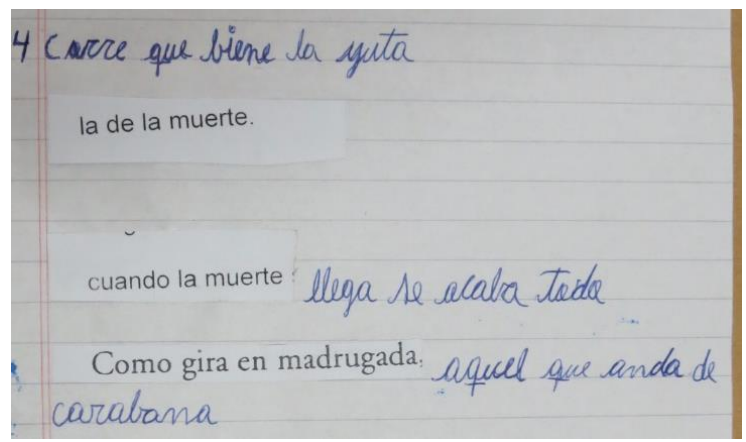

CORRE QUE BIENE LA YUTA la de la muerte.

Cuando la muerte LLEGA SE ACABA TODO

Como gira en madrugada AQUEL QUE

ANDA

DE CARABANA (Hugo)

Los textos que resultaron de esta actividad sorprendieron a todos los participantes del taller, jóvenes y adultos: los chicos, a pesar de las quejas iniciales, se sorprendieron al verse escribir nuevas poesías incorporando palabras propias y nuevas combinaciones. Encontraron palabras de otros para escribir un texto propio, un texto con palabras "prestadas", construido y entretejido con las palabras propias. Las poesías que presentamos dan muestra de cómo, con pequeñas intervenciones, los jóvenes fueron incorporando su propia impronta, y los temas que los atraviesan: el amor a la madre "ma, las paredes se van tan llenas de nostalgia y de rostros de vos", el odio a la policía "corre que viene la yuta, la de la muerte", la cotidianeidad del encierro: "los días de visita", la libertad "cada cosa tiene sentido en la libertad de cada uno".

Michel Petit, en el capítulo Leer. Escribir. Dibujar. Bailar de El arte de la lectura en tiempos de crisis. (2009), relata experiencias en las que los jóvenes escriben a través de palabras de otro "estos destellos de libros hurtados que se revuelven para dar forma a la ensoñación personal, a los deseos, a los temores son un acta de nacimiento del sujeto que encuentra poco a poco su propia voz: copio, luego existo" (Petit, 2009, pág. 225) y explica que "hay una incorporación de las palabras en el sentido literal del término y un desvío de la fuerza de lo escrito cuya eficiencia se intenta captar." (Petit, 2009, pág. 225).

La idea de recortar y pegar palabras, y no simplemente copiar, surgió desde la planificación, para encontrar solución a las circunstancias de que muchos chicos o escribían muy poco, o no escribían. Si era por dificultad, por desinterés o por negación no lo sabíamos, pero se precisaban herramientas para propiciar la escritura y los versos recortados la hicieron posible. Esta propuesta posibilitó empezar a escribir "Como si el 
texto de otro fuera una tierra de nacimiento para uno mismo, para su propia escritura" (Petit, 2009, pág. 227)

Los textos que resultaron y que transcribimos son poesías que, como dijimos, retratan con fuerza los sentimientos del encierro, el ansia de libertad, el amor a la madre, el odio a "la yuta" 65 , la muerte. Empezábamos a ver en ese momento las temáticas que iban a seguir apareciendo a lo largo de los diferentes talleres y en la escritura cotidiana, en particular, en la escritura en la pared. El final del taller presentó una escena que también -en sus distintas formas- se fue repitiendo a lo largo de los diferentes talleres:

Del registro de campo:

Después de la confección y decoración de los sobres, se guardaron los escritos y se dio por terminado el taller, los chicos se iban yendo y nos saludaban con un beso. Cada grupo era esperado por su guardia en la puerta, al verlos los chicos se iban retirando y se iban caminando en grupos, en silencio.

A lo largo de los dos años de talleres pudimos observar escenas o situaciones que se continuaban. Una: los chicos se retiraban, pero quedaban los escritos a buen resguardo en la biblioteca con la idea de que fueran retirados cuando saliesen en libertad; los escritos eran guardados en los sobres que cada joven confeccionaba y quedaban archivados en la biblioteca porque si no, como ellos contaban "se perdían en las requisas". Otra: luego de las risas, el bochinche, y a veces el caos, la escena de la llegada de los guardias, el silencio y la sumisión de los jóvenes ante su presencia mientras se retiraban a los sectores, nos representaba un contraste y el valor del taller de escritura como espacio de libertad y de expresión.

\subsubsection{Otras escrituras en la biblioteca: Autobiografía/Carta}

"escribir para no mentir para dejar de mentir con palabras abstractas para poder decir tan sólo lo que cuenta” Chantall Maillard (Fragmento de Escribir)

65 La policía 
Los textos que presentamos fueron escritos en la biblioteca, pero por fuera de las consignas de escritura del taller. Los colocamos al final de este capítulo por estar muy relacionados con la escritura cotidiana, que desarrollaremos en el capítulo 6.

- Autobiografía:

El escrito autobiográfico, junto con las memorias y las cartas, es uno de los géneros emblemáticos que se escriben en el encierro: "muchas de esas escrituras transitan la leve línea que puede separar la libertad de la falta de esta" (Castillo Gómez, pág. 12, 2005). Castillo Gómez, señala que "aunque muchas veces nacen de la necesidad de liberar lo más íntimo de uno mismo o de exorcizar ciertos pensamientos, tampoco es extraño que manifiesten los efectos de la censura intrínseca de cualquier centro de confinamiento o expresen la autocensura que quien escribe se impone en tales circunstancias" (Castillo Gómez, pág. 12,).

Daniel Fabre sostiene que "la autobiografía ordinaria no es más que la intensificación de una actividad no solamente legítima sino requerida o al menos fomentada". Con "fomentada" se refiere justamente al uso institucional del fuerte para el control sobre el débil. (Fabre, 2008, pág. 19).

Tomamos la definición de autobiografía de Lejeune, como "relato retrospectivo en prosa que una persona real hace de su propia existencia, poniendo énfasis en su vida individual y, en particular, en la historia de su personalidad" (1991, pág. 48). Los diferentes autores acuerdan en que para que haya autobiografía es necesario que coincidan la identidad del autor, la del narrador y la del personaje (Ocaña Arias, 2010, pág. 31). Esta escritura puede surgir desde la necesidad del sujeto de expresarse o de “cierto afán de exhibición y justificación propias” (Ocaña Arias, pág. 28).

Dentro del extenso campo de las autobiografías, podemos hablar de autobiografías "ordinarias" y literarias. Pero como se trata de una tipología textual en la que, tal como la carta, se cruzan la escritura cotidiana con la escritura literaria, resulta difícil trazar una línea donde termina una y empieza la otra. El escrito que presentamos, aunque espontáneo, surgió dentro del contexto del taller literario, por eso lo ubicamos aquí

Texto escrito por Facundo el 17 de octubre/2014 en la Biblioteca:

Del registro de campo 
Hoy Facundo pidió que lo sacaran. No hay taller, pero quiso salir y quiere escribir. En la mesa de la biblioteca hay una notebook, Letizia le pregunta si quiere pasar alguno de sus escritos, Facundo acepta y prende la computadora, pide ayuda para armar una carpeta con su nombre y abrir un archivo de Word. Empieza a escribir en silencio. En el aula de al lado los chicos levantan la voz, se quejan, uno de los ellos grita -parece haber una pelea- los docentes tratan de calmarlo, se escucha que se resiste, se enoja, lo retiran del aula. Mientras tanto Facundo sigue todo el tiempo escribiendo. Pero no está pasando los textos del taller. Está escribiendo un nuevo texto:

Hola me llamo Facundo nahuel , vivo en cordoba soi de barrio jose hernandez !! tengo 17 años cumplo la mayoria de edad ahora el 10 de enero ...

bueno todo esto empeso cuando yo era chiko vivia con mis padres y mi hermano en nuestra casa... iva al colejio asia una vida normal como cualquier chico de mi edad ,.. a los 12 año deje el colejio en 1 año porq empese a salir ah los bailes, fiestas, boliches, empesee ah fumar mariguana .. era una cosa q me encantava fumar hoy en dia sige igual pero mas tranki ... i buenoo fumaba todo el tiempo en mi casa ya se empesaron a dar cuentaa,empese ah pelia con mi familia .. empese ah dejar de ir ah mi casaa ... comia en otro lado dormia en otro lado ... me bañaba en la casa de mi amigoo ... venia a mi casa avese buscava ropaa i estava con mi amigitoos salia ah rovaR para consegir mariguana para pegarme mis caravana ... ii haci susesivamente ... y vestirme ...

llego un momento q la mariguana no me asia efecto, buscava algo mas fuerte para esta como yo keria ... andar mediio perdiido .. empese ah consumir pastilla todo lo dia , todo el dia.. ii mas problema me trajoo ii yo segii haci robando drogandomee ii poco tiempo con mi familia , a los 13 años cai por primera ves al intituto de menores, al san jorge !! aca en el complejo esperanza ... aaca adentro siempre dije q iva ah canviar . no me iva ah drogar, iva ah hacer una vida mas sanaa ... siempre lo dije ii nunca lo cumli , porq cuando sali segia $n$ la misma , con la misma junta, droga problemas en mi casa, ii todo eso me llevo ha hacer cosas malas, fui por un camino que no tenia q aver conosido ... pero bueno la vida es hacii te da golpes ,, !! para que nosotros aprendamos oh quizas es para que nos acobardemos i camviemos nuestra forma de vida ...

pero bueno hoy en dia tengo 17 años, estoi en el intituto ya es la 11 vese que estoi aca adentroo ii cada ves se hace mas largo el tiempo q estoi aca adentro .. ahora me falta poquito para mi cumpleaño, para las fiestas ... y gracias ah dios tambien estoi por ser papa en mui poquito tiempo, espero poder tenes la ultima oportunidad q me de el jusgado mio, para poder estar presente cuando nasca mi hijo i para poder estar para ayudarla ah mi señora ... en todo lo q le aga falta ... ahora hace 5 mese q estoi .. con fe i con suerte para una de las 2 fiesta estoi afuera ... le voi ha llevar 7 mese iii ahi nomas nace mi hijo ... por suerte tambien 
estoi haciendo conducta en el intituto, me sacan siempre ha hacer todo lo talleres, para poder pasar el tiempo ovio i para ver si aprendo algoo mas ... siempre la vida te enseña algo nuevo no ?? ... i bueno ya estariamos ya ,, me ah cansadoo estar enserrado ,, eh perido muchisimas cosas valiosa ... como mi compañero q fallecio ., mi abuelo ... ii problemas que an en casa ii nosotros sin poder hacer nada aca ,.. me explico como q ya no e negocio esta vosta .... ahora estoi aca en el taller literario .. con ana i la Letizia que vendrian ha ser ella las $q$ hacen este taller aparte de ser maestras, tambien estan con nosotros, ii me enseñaron ami i a varios chikos mas, escribir poemas, conosimos poemas de afuera ... palabras q nunca antes aviamos escuchado ... en todas las clases del taller este ... lo que trabajamos nosotros q esta escritoo en una hoja nosotros nos isimos un sobre grande q esta re piola ... i ahi guardamos todo, para tener un recuerdoo de cada clase pero bueno lo unico q espero i creo q todos estamos esperando es la livertad volver con nuestra familia ... empesar una vida nueva ... con nueva jente ,, i ser una persona ECHA Y DERECHA...

Facundo nahuel !!!

Antonio Castillo Gómez, en De la suscripción a la necesidad de escribir (Castillo Gómez, 2002) desarrolla el tema de las escrituras populares, y estudia algunas escrituras de autobiografías de "gente común". Castillo Gómez analiza la escritura de Clelia Marchi, mujer que escribió sobre la superficie de una sábana a raíz de la soledad tras la muerte de su marido. Explica que "escribe, a la edad de 60 años y lo hace mediante un italiano pleno de reminiscencias orales, básico y dialectal. Como tantos otros autobiógrafos de condición popular, Clelia se escusa por su desconocimiento de las reglas gramaticales, por su descuidada caligrafía, y pide a los lectores que lo entiendan, puesto que no cursó estudios más elevados que los de $2^{\circ}$ de primaria” (Castillo Gómez, 2002, pág. 21).

En el escrito de Facundo observamos algunos de los aspectos que Castillo Gómez describe sobre las escrituras populares: queda a la vista la poca atención a las reglas gramaticales. Aparecen también las marcas de oralidad, lo vemos por ejemplo en la repetición de muletillas como "buenoooo", el abundante uso de signos de exclamación y puntos suspensivos, y la repetición de las vocales para enfatizar en general. También encontramos algunos vestigios del lenguaje escrito por los jóvenes en los nuevos medios digitales como el chat o los mensajes de texto de los celulares: uso de la k para unificar c, q, k, como en "kiero" o la repetición de signos de exclamación al final de la frase.

Podemos decir que no se rige por las formas convencionales de escritura, pero no podemos dejar de reconocer que el texto es perfectamente legible y comprensible. $Y$ lo es incluso a pesar de la puntuación usada "a su forma". 
En referencia al contenido, la primera percepción es la espontaneidad, la naturalidad y sinceridad que trasluce el texto, como cuando escribe "siempre lo dije y nunca lo cumplí, porque cuando salí seguía en la misma,66. El relato es narrativo y avanza cronológicamente en un recorrido de sucesos concretos, con una escritura "sin adjetivos". Narra una serie de hechos puntuales, prácticamente sin valoraciones, y sin colocarse en un lugar de víctima.

Este "aquí estoy" o "este soy yo" en este relato sobre sí mismo aparece como una reafirmación constante del "soy lo que soy", que reaparece en las entrevistas y la escritura de los jóvenes a lo largo de los diferentes talleres.

Por otro lado, la expresión de Facundo de querer cambiar, "ser una persona hecha y derecha", nos interpela. Nos preguntamos fundamentalmente por el significado de ese deseo de cambiar su forma de vida, sobre esa necesidad de empezar a ser "otro". Pensamos que probablemente en todos estos años Facundo puede haberse sentido ese "otro anormal". Nos preguntamos cuántas veces habrá caído sobre él el estigma social "como si ser el diferente fuera sinónimo de sobra, de desperdicio" (Skliar, Carlos, 2015, pág. 168)

Facundo, en la entrevista personal, insiste: tiene que cambiar. El cambio es fundamental y en un punto, práctico: no quiere volver a estar preso, y tiene un solo motivo: su hijo.

"Una sola cosa me cambió, y cuando esté afuera lo voy a poner en prueba, y va a ser mi hijo. Ese va a ser el motivo para que yo cambie, todos dicen que el motivo tiene que ser mi voluntad... y yo la voluntad la tengo... pero no quiero que el día de mañana mi hijo me tenga que venir a ver acá en la cárcel, yo ya estuve un montón de años en la cárcel" (Facundo, 5 de septiembre de 2014)

Pero, más allá de los condicionamientos del encierro, del mismo taller, de la autocensura, y por encima de las interpretaciones o los análisis que podamos hacer del contenido de lo escrito; lo que sí podemos asegurar es que Facundo decidió ponerse a escribir un texto, el texto del que venimos hablando, necesitó decir: "aquí estoy yo", reafirmarlo.

Es que la escritura es una afirmación de la singularidad y en el caso de Facundo, lo escribe y lo firma, con signos de exclamación. Como sostiene Fabre (2008), la escritura registra una existencia, inscribe en ella lo social en todos sus estados y sobre todo, la

${ }^{66}$ Transcripto en forma de escritura convencional 
autobiografía -que sin firma perdería su razón de ser- lo que hace es "afirmar una singularidad a partir de la masa de textos anónimos o distantes que de diversas maneras nos rodean y se nos imponen." (Daniel Fabre, 2008). Vale lo dicho por Fabre para la escritura "autogestionada" de la autobiografía de Facundo: reafirmar la singularidad justamente en un momento de institucionalización de su vida, de ausencia de los afectos, de privación y vulneración permanente de derechos.

Terminamos esta breve alusión a la escritura autobiográfica, citando palabras de Antonio Castillo Gómez, que en De la suscripción a la necesidad de escribir, concluye, sobre la relación escritura autobiográfica- experiencia- vida- muerte:

“En el campo de las ordinarias, las personales y autobiográficas representan verdaderos actos de memoria, desencadenados, en general, por la intensidad de las experiencias vividas y por la voluntad de no arrojadas al silencio: es el caso de los epistolarios y diarios escritos desde y en el frente, en una cárcel, durante el exilio o desde la emigración. Entonces, el hecho de escribir contiene mucho de conjura contra el olvido, así como una elevada dosis terapéutica: escribir, en fin, para no morir y para vivir"

(Castillo Gómez, pág. 37)

\section{- Carta}

La carta que presentamos forma parte de una serie de cartas que los chicos intercambiaron con chicas de una escuela de adultos de "la calle" y las enviaban a través de una profesora. La ubicamos aquí y no en el apartado de las cartas de la escritura cotidiana, porque fue escrita en el contexto de la biblioteca de la escuela. Desarrollaremos más adelante la cuestión de la carta como género 


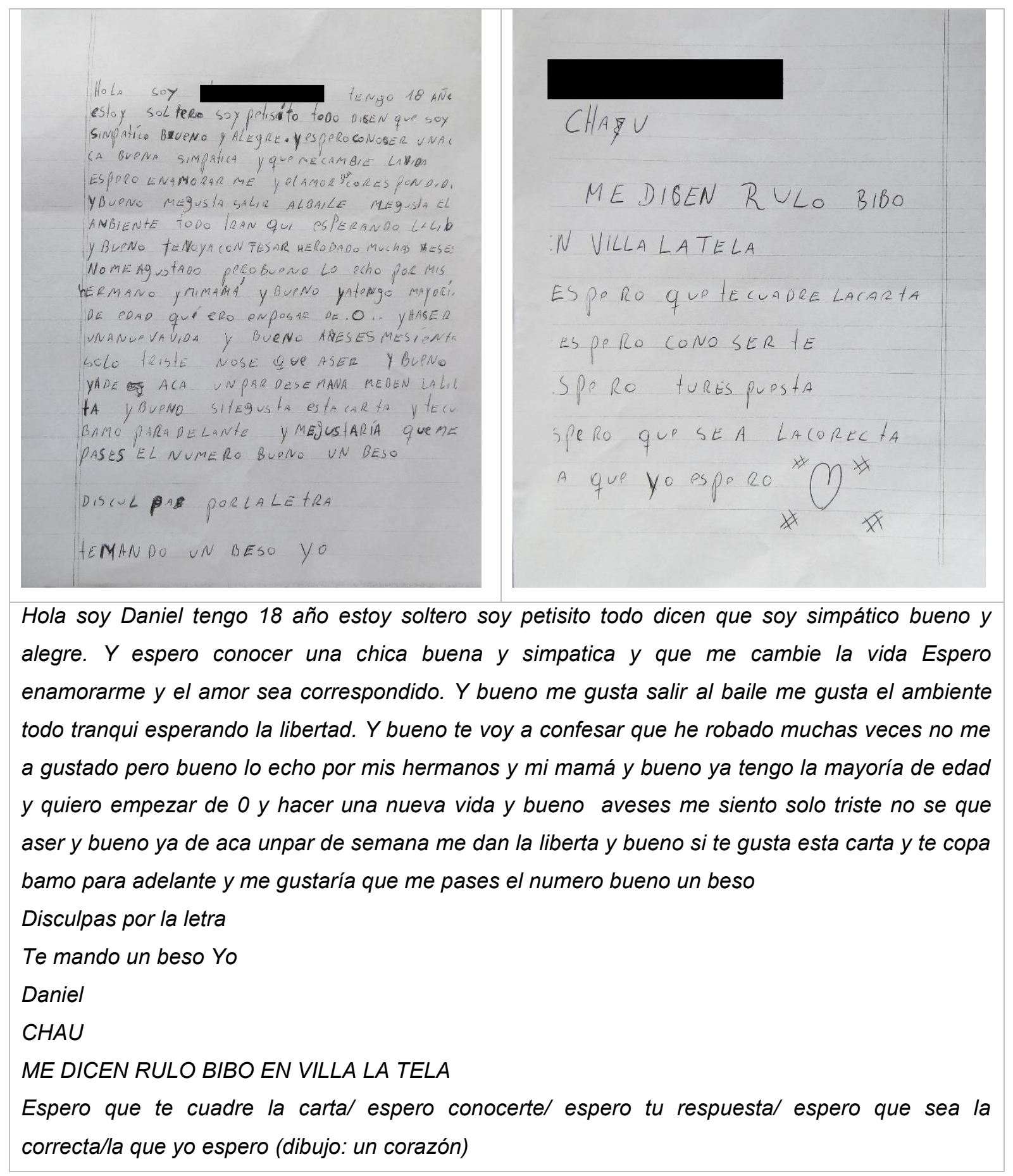

Esta carta se diferencia del texto anterior en su trama. La autobiografía de Facundo, es totalmente narrativa, como señalamos "sin adjetivos" y la carta de Daniel es un texto donde predomina lo descriptivo: "estoy soltero soy petisito todo dicen que soy simpático bueno y alegre". Encontramos algunas marcas de la oralidad como en el texto 
de Facundo, como la repetición de la muletilla "y bueno" pero su escritura respeta reglas gramaticales.

Daniel pide disculpas por su caligrafía: "disculpas por la letra”. Esta importancia dada a "la letra" nos remonta a los estudios de Antonio Castillo Gómez sobre la escritura hológrafa en el S.XVI ${ }^{67}$. En las cartas antiguas "la letra asumía la representación de la persona y se hacía transmisora del respeto, la consideración y el afecto dispensado al destinatario" (Castillo Gómez, 2005, pág. 862), el aspecto material de la carta "nos informa sobre su constitución material y vincula ésta a la condición social y a la educación gráfica de quien escribe" (Castillo Gómez, 2005, pág. 875). Parece ser que este valor dado a la caligrafía ha persistido en el tiempo, aún hoy en plena "era digital", en la escritura de cartas a mano: el cuidado de las formas materiales como parte de la presentación personal y el respeto al destinatario.

La carta de Daniel termina con un juego de palabras: "espero conocerte, espero tu respuesta, espero que sea la correcta, la que yo espero". Se podría apreciar aquí que además del cuidado de la forma existe también un cuidado en el uso del lenguaje, acercándose a lo literario.

Desarrollaremos el tema de la carta como género de manera específica en el capítulo sobre la escritura cotidiana. Adelantamos en relación a la carta de Daniel, que las cartas, en general, desarrollan un ejercicio de definición y auto representación: quien escribe está fabricando una imagen de sí para su destinatario (Sierra Blas, 2015). Esto queda a la vista en la carta de Daniel: la fabricación de una imagen. Nos da la sensación de que, del mismo modo que en la autobiografía de Facundo, se resalta el "yo inscrito" del que habla Fabre.

Una diferencia de la carta analizada -escrita en la biblioteca de la escuela- con las "cartas reales" -escritas en la cotidianeidad del encierro- es que no contamos con los textos de estas últimas, ya que pertenecen al campo de la privacidad -cuestión que los jóvenes remarcaron- pero pudimos indagar en su relato sobre la experiencia de escritura de cartas. Lo seguiremos analizando, como dijimos, en el capítulo específico.

\footnotetext{
${ }^{67}$ Caligrafía que en los S. XV y XVI, signo de deferencia en el lenguaje de la corte (Castillo Gómez, 2005, pág. 861).
} 
5.2.2. Talleres desde la Biblioteca Abierta en el Instituto Horizontes/ año 2015: Escritura de Novela Grupal

\subsubsection{Introducción:}

La planificación de la Biblioteca Abierta para la segunda etapa del año 2015 proyectó una secuencia de talleres que concluiría en la escritura de una novela grupal. El Proyecto se denominó "Novela grupal e interactiva", se propuso la construcción de una narrativa de ficción creada y escrita en forma colectiva por los jóvenes participantes de los talleres. Estaría basada en las historias de vida, saberes y relatos de los jóvenes en conflicto con la ley, y culminaría con una posible publicación, como producto final del proceso. Los objetivos planteados por la biblioteca fueron:

- Recuperar los saberes e historias de vida de los jóvenes participantes

- Reconstruir la historia personal, familiar y comunitaria.

- Reflexionar críticamente sobre la problemática de los jóvenes en conflicto con la ley.

- Construir colectivamente conocimientos basados en estas reflexiones.

- Promover la lectura y la escritura de textos narrativos.

- Desarrollar competencias de comunicación y expresión de ideas y emociones

- Fortalecer la confianza en sí mismos y hacia la comunidad.

- Vincularse con el afuera del contexto de encierro.

- Difundir la experiencia en medios de comunicación.

Como se mencionó en la cronología, a partir del mes de julio se organizaron los talleres dentro del Instituto Horizontes, de máxima seguridad. No se había encontrado la forma en que los jóvenes allí internados pudieran salir de manera regular -ni irregular- a la biblioteca. De hecho, como dijimos, los jóvenes internados en el sector D no estaban saliendo a ninguna actividad fuera del encierro por diversos problemas, a veces relacionados con medidas cautelares que imponen los jueces de menores en relación a su causa penal, otras, relacionados a la conducta y la convivencia dentro del encierro.

Se decidió estratégicamente entonces ir con la propuesta del taller a dicho instituto. Se dejó de lado la premisa inicial de que las actividades se desarrollaran en la biblioteca, dentro del espacio de la escuela, como dijimos antes: valorado como el "afuera del adentro". Se hizo una excepción y se habilitó la posibilidad de entrar a un instituto. 
Para ello hubo que tomar un tiempo para la realización de negociaciones, acuerdos y permisos de las autoridades del Instituto Horizontes. Como ya indicamos, estas gestiones las realizaron los coordinadores de la escuela. Se acordó un espacio: la sala de visitas del Instituto Horizontes, y un horario: los martes por la tarde. En los talleres participarían solamente los jóvenes internados en el sector D. El instituto Horizontes cuenta con dos sectores $C$ y $D$ que no podían, según las autoridades, compartir actividades por posibles peleas. Como mediadores dentro del instituto y participantes en los talleres estuvieron presentes las socio-educadoras, quienes fueron haciendo negociaciones, sobre todo relacionadas al uso de los tiempos, los espacios, y a la salida de los jóvenes al taller. Vale aclarar que "salida" en este caso es la salida desde el sector D, espacio donde los jóvenes viven y donde permanecen en celdas individuales o de a dos, o en un sector de usos comunes que comparten especialmente en las horas de las comidas, a la sala de visitas contigua. Este sector se encuentra a pocos metros de esta sala de visitas, espacio donde transcurrieron los talleres, pasillo y varias rejas de por medio.

Luego de esta organización, se iniciaron los talleres en el mes de agosto de 2015. Se logró, a lo largo de cuatro meses, la participación de un grupo de un promedio de seis y un total de diez chicos, en trece talleres de escritura, cuyo objetivo final fue de la producción de una novela grupal.

A los fines de la presente investigación, nuestra participación en el proyecto del taller de escritura de la biblioteca nos posibilitó establecer un vínculo con un grupo de jóvenes a lo largo de todo el proceso de escritura. Pudimos tomar contacto con su experiencia de escritura dentro de las propuestas de la biblioteca, que se planteó como meta en esta ocasión la escritura de un texto colectivo.

Buscamos, en función a las preguntas de la investigación, aproximarnos a algunas posibles respuestas sobre la escritura en los talleres del año 2015. Participamos a los fines de construir un conocimiento sobre qué escriben, cómo escriben, y para quién escriben los jóvenes en estos y fuera de ellos. Para eso indagamos en los talleres y en las entrevistas personales acerca de la interpretación de estos jóvenes sobre la experiencia de escritura como experiencia de sí y como experiencia social.

Nos proponemos a partir de aquí dar cuenta detallada sobre este proceso de escritura, para eso haremos un recorrido cronológico del trayecto de los trece talleres. Tomaremos extractos del registro de campo y fragmentos de la novela ${ }^{68}$. En algunos

\footnotetext{
${ }^{68}$ No contamos con registro grabado de estos talleres ya que por haber sido desarrollados dentro de un instituto de máxima seguridad, no tuvimos permiso para ingresar grabadores.
} 
puntos nos detendremos para analizar o reflexionar sobre aspectos teóricos que creemos relevantes.

En el anexo final agregamos dos textos que consideramos importantes para una comprensión más integral: en primer lugar, la transcripción completa del texto escrito por los jóvenes que resultó el producto de este proceso: la novela completa La otra vida de los pibes pistoleros y en segundo lugar, la totalidad de los planes de trabajo a partir de los cuales se organizó cada taller.

\subsubsection{Cronología de los talleres: escritura de la Novela Grupal}

Los talleres de escritura de la novela tuvieron dos premisas: que la escritura fuera grupal, y que todos los jóvenes participaran escribiendo "a través" de quien tomara la posta. Se comenzó con la confección de una línea de tiempo que señalaba los hechos más importantes de su vida hasta los 21 años aproximadamente, y de allí surgieron los núcleos narrativos. Se escribió luego, en cada encuentro, un capítulo de acuerdo a esos núcleos temáticos y a disparadores que surgían del mismo taller. La escritura se realizó en papeles afiches pegados en la pared, en las condiciones que el espacio de la sala de visitas lo permitió: no tenía ni mesas, ni sillas. A medida que avanzaban los talleres, se escribía en forma cada vez más autogestionada por los jóvenes. El protagonista de la novela, Yandel, terminó siendo prácticamente "uno más" dentro del grupo. Como autores, compenetrados en la historia, todos juntos escribían y discutían respecto a cada decisión sobre la novela.

Pasamos ahora a la descripción de los talleres de manera cronológica, lo presentamos de forma minuciosa con el objetivo de poder hacer lo más visible posible este proceso de escritura:

4 de agosto de 2015/ PRIMER TALLER: "Presentación / La escritura en el encierro/ César González"

Los objetivos principales del primer taller fueron: la presentación de los jóvenes y las talleristas, y la presentación del proyecto del taller de escritura. Se trabajó sobre la escritura en la experiencia del encierro, específicamente sobre las poesías de César González: se leyeron además entrevistas a este autor, hechas por distintos medios, tanto gráficos como audiovisuales. 
Empezamos por el comienzo: el ingreso al Instituto Horizontes. Allí percibimos en principio cierta resistencia hacia el taller por parte de los guardias, como consta, por ejemplo, en el siguiente registro de nuestro primer ingreso:

Del registro de campo:

Llegamos con Letizia al Horizontes, golpeamos y nos abrieron la puerta de hierro. Un guardia nos atendió, indiferente, y nos dijo que no estaba enterado de la realización del taller. Como nosotras sabíamos que estaban avisados le insistimos, le dijimos que estaban pedidos los permisos, entonces nos dijo que le iba a preguntar al jefe. El lugar es un espacio de entrada todo pintado de gris, con tres puertas y un ancho pasillo que conduce a una reja, al fondo, allí se ven unos guardias más. En el hall de entrada hay carteles con las normas del lugar. Una de las puertas a la derecha, al lado de la puerta de ingreso es la sala de las socio-educadoras, allí nos estaban esperando Graciela y José. Luego de idas y venidas de distintos guardias, uno de ellos nos acompañó hacia la sala de visitas que está al fondo del ancho pasillo, pasamos por varias pequeñas piezas vacías, una de ellas está abierta, se ve un colchón en el piso, otra tiene un cartel "sala de requisas a menores". Llegamos a una puerta de hierro de la que el guardia sacó un pesado candado y una vez que ingresamos, lo volvió a poner, y allí quedamos literalmente encerradas las cuatro: las dos talleristas y las socio-educadoras, esperando novedades durante unos quince minutos...

El espacio de la sala de visitas no era acogedor: oscuro y húmedo, no había ni mesa, ni sillas, solo una tarima de cemento en su perímetro. Transcribimos las primeras impresiones al entrar al lugar, del registro de campo:

La sala tiene dos puertas, una por la que ingresamos, y otra que está abierta, y conduce, reja de por medio, al sector de los pabellones donde los chicos viven. El espacio de visitas es un salón vacío y oscuro, con una tarima de cemento en el perímetro. La pared está pintada con murales, con colores en algunas partes, muy oscuros, hay dibujada una ciudad, una figura de una persona tras las rejas, también frases escritas como "a una persona no la hace el lugar". Hay poca iluminación, las lámparas están rotas, el techo es muy alto, unas ventanas angostas verticales dejan pasar algo de luz. Hay un poco de basura en el piso, restos de botellas y paquetes vacíos de galletitas, parecen ser restos de las visitas de la familia. Graciela trajo una escoba y barrió un poco. Ambientamos el lugar con los libros, fotocopias. Ya sabíamos que no iba a haber mesa, así que pusimos todo encima de una tela en el piso que oficiaba de mesa allí estaban los libros, los caramelos... 
Cuando llegaron los chicos, eran en principio solo tres. Entró primero Joaquín, a él lo conocíamos de un taller anterior en la biblioteca, en particular lo recordábamos por un texto que había escrito eligiendo palabras al azar ${ }^{69}$ :

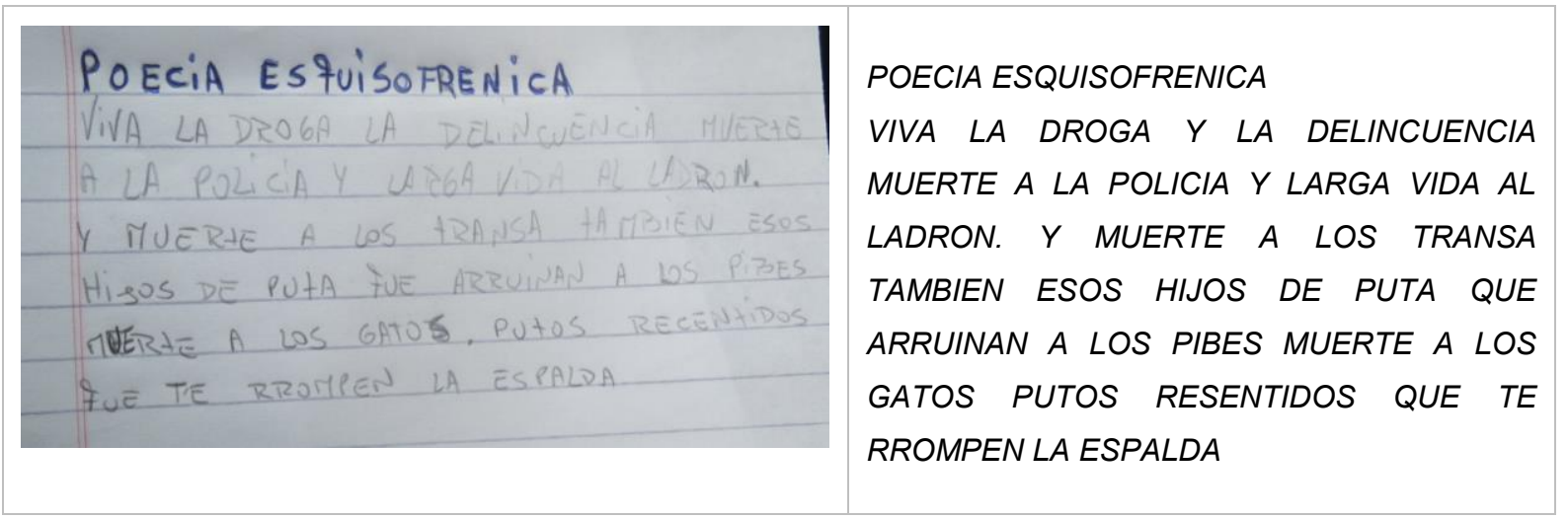

Esta escritura- provocación- desafío, nos presentaba una vez más lo que mencionábamos en la autobiografía de Facundo, como una reafirmación constante y necesaria del "soy lo que soy", en Joaquín de una manera más cruda. En la entrevista personal un tiempo después, le preguntamos por este escrito, y él nos explicó:

Entrevista a Joaquín:

Ah, sí una poesía, bah... no era una poesía, lo escribí al bardo así, bolaceando...es que estaba envenenado ese día, me puse a acordar de un par de problemas de la calle y me puse a escribir de los giles del barrio que esto que aquello. Yo estoy por problemas, no estoy por robo ahora, estoy por problemas que tuve en la calle y bueno... con un pibe, un traficante. Era un problema y bueno, me quería pegar y yo le pegué primero, le pegué mal, se me fue la mano y lo maté. Y bueno era yo o él, por lo menos estoy acá.

Reconocimos a Joaquín también porque habíamos presenciado -junto con otros docentes y estudiantes- un incidente en el que otro joven lo agredió y le quebró la mandíbula. Exactamente sucedió el día de la jornada Escuela Familia y Comunidad, el 4 de junio de 2015. Transcribimos un comentario sobre esta actividad, de la página web de Tumbando Rejas:

"Un gran día en nuestra escuela del Complejo Esperanza, nos encontró compartiendo un trabajo de reflexión, escucha y propuestas, con nuestros alumnos y sus familias, con representantes de organizaciones sociales y de la Universidad,

\footnotetext{
${ }^{69}$ Volveremos sobre este texto en las conclusiones parciales
} 
con equipos técnicos, y educadores. Un encuentro inédito en este contexto, que esperamos y deseamos se repita, se multiplique y se sostenga."

Pero inclusive en una Jornada tan positiva, inédita para la escuela en contexto de encierro, los conflictos cotidianos de la realidad aparecían por su propia fuerza. Transcribimos del registro de campo:

Los chicos estaban esperando, especialmente contentos los que veían llegar a su familia, mientras tanto los docentes organizaban los detalles. Cuando todo estaba listo comenzó la jornada con el izamiento de la bandera: un profesor, dos estudiantes, la hermanita de uno de ellos. La bandera que se levantó a media asta, ya que, a uno de los chicos, le llegó la noticia de que habían muerto su padre y su hermano en un tiroteo, además la semana pasada había muerto el hermano de otro joven: Yamil. Hoy acordaron docentes y alumnos que se iba a dejar la bandera a media asta cada vez que muriera un familiar de los chicos. El silencio de la mañana, los eucaliptus, el Aurora cantado por Víctor Heredia. En ese preciso momento se sienten ruidos de golpes, quejidos, algunos gritos: una pelea, el más golpeado es Joaquín, lo conozco porque es uno de los chicos que participó en los primeros talleres de este año, lo recuerdo como un chico muy inteligente...quedó muy lastimado, se lo llevaron los guardias...

Volvemos al 4 de agosto, acababa de llegar Joaquín a la sala de visitas del Instituto Horizontes. Le preguntamos cómo estaba y nos comentó que estuvo con la mandíbula cerrada cuarenta días, comiendo con mucha dificultad, que todavía no estaba del todo bien, y que probablemente tenía que pasar por una operación. Se lo notaba con dificultades para hablar.

Luego de Joaquín, entraron Bruno y Alejandro. Los tres chicos eran conocidos por las talleristas ya que habían estado en el primer taller en la biblioteca en la primera etapa del año, cuando aún era posible salir del instituto sin tantas dificultades.

El espacio no era exactamente lo que se entiende como el "espacio ideal" para un taller de escritura, en el sentido de "un lugar cálido", tal como proponen Andruetto y Lardone (2007). Pero se pudo, con la ambientación: los libros, los caramelos, la ronda, por lo menos en algún punto, lograr un espacio "diferente, aunque sólo sea de un modo ínfimo". (Andruetto y Lardone, pág. 20).

Del prólogo de la novela La otra vida de los pibes pistoleros, escrito por las talleristas: 
¿Cómo se pudo desarrollar el taller en un espacio como este? ¿Cómo se pudieron resolver las condiciones iniciales -que acompañaron el proceso-? O como dice la canción ¿En un pozo tan oscuro puede haber felicidad?

Para quienes conocemos el contexto, sabemos que nos podemos encontrar todos los días con todo lo que acabamos de describir, así que sin dudarlo un segundo, nos dispusimos taller por taller a inventar recursos para generar condiciones para trabajar y ambientar un espacio posible para un "taller literario": Ios martes llegábamos a la sala de visitas con los siguientes elementos: una manta para poner los libros en el piso, libros (abundante cantidad de libros de bellas ediciones de la Biblioteca Abierta), revistas (Tumbando Rejas, Seguir Soñando), cuadernos (uno para cada participante), lapiceras, computadora con música y videos, fotocopias de poesías (para que los chicos se las puedan llevar al sector), caramelos, un termo con café, galletitas, tarjetas con palabras, tarjetas vacías, plasticola, etc. Pero lo más importante, casi imprescindible para la escritura de la novela fue: un fibrón, un papel afiche y la cinta para pegarlo en la pared. La falta de mesa, generó la peripecia del soporte-pared, lo que finalmente posibilitó -y favoreció- la escritura grupal.

En El taller de escritura creativa se propone la construcción de un ambiente donde los participantes "puedan mirarse a la cara, sentados en sillas o en el suelo." (Andruetto y Lardone, 2007, 20). El formato "ronda" del taller se tuvo que adaptar a las condiciones del lugar: nos sentamos todos juntos -talleristas, socio-educadoras y jóvenes participantesen una esquina de la tarima que rodea todo del perímetro. A falta de una mesa se colocaron los libros, estratégicamente, en un lugar central en el piso, encima de una manta. Los chicos se sentaron de tal manera que les permitió "mirase a la cara", pero se negaron a sentarse en el suelo, esto sucedió a lo largo de los talleres: casi nunca aceptaron sentarse en el piso, dijeron que no querían ensuciarse la ropa, el piso estaba sucio. Siempre llegaron al taller recién bañados, y cambiados con ropa limpia, por eso no aceptaban sentarse en el piso y ensuciarse, parecía ser que la pulcritud representaba unos de los refugios de dignidad que les quedaban.

El primer taller comenzó con una charla informal como casi todos los que lo sucedieron. La consigna inicial para la presentación personal fue la escritura de la letra de una canción 


\begin{abstract}
Del registro de campo:
Escribimos todos, apoyados en las tarimas, bastante incómodos. En esa actividad participamos las talleristas y las socio-educadoras también (escribimos un fragmento de una canción). Luego de unos diez minutos de escritura, leímos lo que cada uno escribió. Joaquín escribió mucho y Alejandro bastante, Bruno muy poco. Joaquín, escribió la letra de un hip hop: "Por qué será", nos explicó que la eligió porque le gustaba y era de Esteban el As, un rapero de Fuerte Apache y que, nos explicó Joaquín, actúa en las películas de César González.
\end{abstract}

Las talleristas no contábamos con la información sobre Esteban el As que nos brindó Joaquín, pero más tarde investigamos y corroboramos que era exacta. Presentamos aquí, a continuación, el texto de la canción escrito por Joaquín en la actividad de presentación:

PR le SeRA

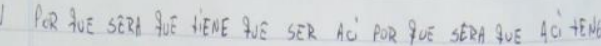

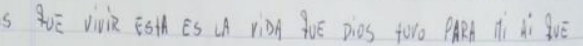

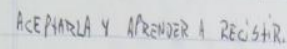

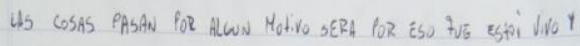

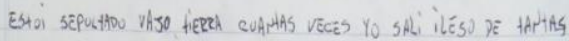

BRLAGERES Y NO TJEDE TIRAPO EN LA SERA SANGRANOO PENSANDS ON

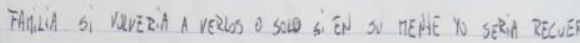

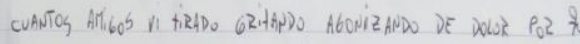

UNA BHLA LOS PERFORO HOY DIA ESAA VIDA ES UAh PORTUER'A

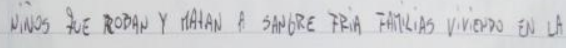

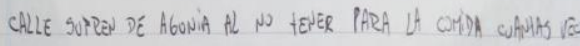

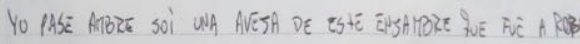

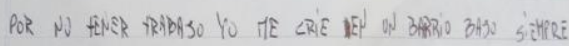

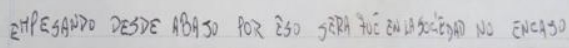

Por qué será que tiene que ser aci por que será asi tengo que vivir esta es la vida que dios tuvo para mi ai que aceptarla y aprender a resistir. Las cosas pasan por algún motivo será por eso que estoy vivo y no estoi sepultado vajo tierra cuantas veces yo sali ileso de tantas balaceras y no quede tirado en la sera sangrando pensando en la familia si volviera a verlos o solo si en su mente yo seria recuerdo cuantos amigos vi tirado gritando agonizando por el dolor porque una bala los perforo hoy dia esta vida es una porquería niños que roban y matan a sangre fría familias viviendo en la calle sufren de agonía al no tener para la comida cuantas veces yo pase ambre soy una abeja de este enjambre que fue a robar por No tener trabajo yo me crie en un barrio bajo siempre empezando desde abajo por eso será que en la sociedad no encajo

Luego de la lectura de la presentación personal, se conversó sobre el significado de las canciones elegidas. Se presentó la idea general del taller de escritura, sus objetivos, la propuesta de una producción final grupal. Luego se conversó especialmente sobre el significado de la escritura en el encierro, se tomaron algunas experiencias puntuales de escritura, poesías de escritores que escribieron estando presos, que se leyeron en voz alta, varias de César González, algunas entrevistas periodísticas y otros textos: 
Del registro de campo:

Leemos la entrevista a César González de Página 12, los chicos la escucharon atentos hasta el final, Joaquín mientas tanto lee en silencio el nuevo libro de César, sobre quien nos cuenta que lo conoce, que él tenía un libro que le habían regalado, al que luego en una requisa se lo sacaron. Después, en voz alta leemos un poema de Cesar elegido al azar, y luego, un par de cosas más: el artículo periodístico de otra experiencia en una cárcel de Bs As, y después un poema "El amor es un robo" de Leopoldo Marechal: "El amor es un robo -me dijiste una tarde-/robamos y nos roban, y así pasa de modo/que en los senderos quedan nuestras mejores galas/ resecas como lirios que marchitó el otoño...". Alejandro lo había elegido, lo tenía en la mano, pidió que lo leyéramos en voz alta, y después pidió llevarlo al sector.

A partir del primer taller se tomó apunte de varias cuestiones para tener en cuenta en las planificaciones siguientes: el vínculo que Joaquín ya tenía con la obra de César González, el interés que a la mayoría de los chicos les suscitaba la obra de César y las letras de Hip Hop, en particular de Esteban el As.

11 de agosto/ SEGUNDO TALLER: "La línea de tiempo/ la niñez y los juegos"

Del registro de campo:

Los guardias iban y venían, se escuchaba a lo lejos música de cuarteto cordobés. Un guardia se acercó y nos dijo que los chicos estaban durmiendo -motivo por el que no se podría dar el taller- pero insistimos, les dijimos los nombres de los tres chicos del primer taller, no sabíamos bien qué pasaba. Graciela nos dijo que tal vez Alejandro no vendría porque tuvo una mala noticia del juzgado respecto a su causa.

El once de agosto se realizó el segundo taller. La sala de visitas, como muchas veces, estaba sucia y con basura. Con la llegada finalmente de los jóvenes, se trabajó en función del proyecto de escritura de la novela. Como temas para trabajar en este taller se propusieron: "La línea de tiempo, la niñez y los juegos".

Del registro de campo:

Cuando logramos entrar a la sala de visitas para esperar a los chicos, no sabíamos si iba a venir alguno o no. El lugar tenía charcos, la tarima también estaba mojada. Graciela trajo un trapo y secó el piso con José, un becario que nos acompañó. Por momentos nos asomábamos a la reja que da a los sectores, se escuchaban las voces de los chicos, pero 
no los veíamos, mientras tanto fuimos acomodando la tela con los libros y las letras de las canciones en el piso, pusimos en la notebook, como fondo, unas canciones de Esteban el As. De pronto se empezó a escuchar más ruido, gritos de los chicos que se venían acercando, cantando...

Los jóvenes finalmente llegaron a la sala, acompañados de los guardias. La entrada fue alegre. Habíamos llevado café y galletitas. Sobre la manta en el piso había libros y algunas letras de Esteban el As para leer en voz alta, y en la computadora, algunos de sus video-clips:

Del registro de campo:

Llegaron los tres que empezaron el taller anterior: Bruno, Joaquín y Alejandro. Llegaron con una sonrisa, y nos saludaron con un beso. Los invitamos con café y galletitas. La atención se concentró rápidamente en el video de Esteban el As, por eso llevamos rápido la computadora a la esquina del lugar, y nos sentamos todos alrededor. Les comentamos a los chicos que estuvimos investigando y encontramos mucho material y letras de canciones de El As, los chicos se mostraron interesados, no leían las letras fotocopiadas, sino que miraban los videos y escuchaban las canciones. Luego hubo un momento de lectura.

Leímos algunos fragmentos de canciones y conversamos sobre las letras de las rap, les hicimos notar a los jóvenes que esas canciones contaban historias de vida, historias de la vida real. Los jóvenes insistieron -como en los talleres del año 2014- en la valoración de que las letras reflejaran lo que les pasa en la vida real, lo que ellos viven y experimentan en el día a día. Presentamos como ejemplo un fragmento leído de una de las canciones de Esteban el As: "Yo crecí en el barrio donde todos sobreviven / donde se escucha como prueban los fierros los pibes/ donde todo el mundo solo da lo que recibe / y si te portas mal, que pase el que sigue/ de chiquito vi muchos amigos que se fueron/ perdieron, salieron a ganar y no volvieron". Los chicos mientras leen y escuchan asienten con la cabeza, expresan aceptación.

Del registro de campo:

Luego de ver los videos y leer, comentamos que íbamos a trabajar con historias de vida, que íbamos a escribir una historia, y que eso era un gran desafío para todos. En ese momento se abrió la puerta, y llegaron dos chicos más: Carlos y Enzo. Nos presentamos con ellos, que se encontraron con los otros tres, se saludaron muy afectuosamente, y se 
pusieron a conversar entre ellos, se veían contentos, costó volver al momento de concentración

En este segundo taller se incorporaron Carlos y Enzo, llegaron más tarde por estar realizando un taller de refrigeración, pero "pidieron entrar" porque les interesaba participar, aunque llegaran un poco tarde. En los afectuosos saludos y charlas, empezamos a vislumbrar que el taller era también, una oportunidad de encuentro y acercamiento entre ellos.

Para empezar con el proyecto de la narrativa autobiográfica contábamos con un trabajo previo de Letizia, que como profesora de Ciudadanía y Participación de la mayoría de los jóvenes presentes -los que asistían al CENMA- ya había trabajado con la idea de una "línea de la vida". Los chicos entendían el concepto y tenían unas líneas bosquejadas en sus carpetas de la escuela. Habían trabajado desde el concepto de una línea de tiempo no rectilínea ni tampoco estática. En función de esta idea, para este taller se confeccionó una línea de tiempo grande, en dos papeles afiches unidos, con líneas curvas y rulos, dividida en septenios, para ser completada en forma grupal:

Del registro de campo:

Nos acercamos a una línea de tiempo que habíamos pegado en la pared, está línea tiene formas curvas y está vacía, lista para completar, solo tiene escritos los números 0 - 7 - 14 - 21. Quedamos todos parados mirándola unos segundos en silencio. Letizia les dice entonces que es una línea ondulada, como la vida misma, con subidas, bajadas, rulos... Les contamos que la propuesta es que a lo largo de los talleres vayamos completando esa línea gigante grupal, con sus hechos principales, con carteles con títulos, ideas, textos. Los jóvenes asienten, parecen interesados.

Luego de la presentación de la línea de tiempo, y como paso previo, el taller continuó con una lectura: la letra del tango "El sueño del pibe": "Golpearon la puerta de la humilde casa,/ la voz del cartero muy clara se oyó,/ y el pibe corriendo con todas sus ansias al perrito blanco sin querer pisó./ "Mamita, mamita" se acercó gritando;/la madre extrañada dejo el piletón/ y el pibe le dijo riendo y llorando:/"El club me ha mandado hoy la citación..."70 Este texto en formato de libro-álbum, fue leído en voz alta y dio pie para empezar a hablar de la infancia y los juegos. También habíamos llevado una caja con

\footnotetext{
${ }^{70}$ El sueño del pibe. Tango: 1945. Música: Juan Puey. Letra: Reinaldo Yiso
} 
juguetes pequeños que en ese momento les presentamos a los jóvenes. Transcribimos un fragmento del registro que da cuenta de la respuesta de los jóvenes/niños:

Del registro de campo:

Los chicos se ríen cuando la ven y empiezan a agarrar juguetes, les decimos que cada uno elija uno, pero toman varios a la vez y se ponen a jugar. Hay una honda, un yoyó, autitos, aviones, muñequitos de personajes, etc. Empiezan a jugar y por un rato largo siguen jugando, Letizia juega con ellos: hacen carreras de autos, tratan de usar el Yoyó, se ríen. Finalmente nos volvemos a sentar, algunos en la tarima de cemento, esta vez algunos se sientan en el piso. Luego proponemos que cada uno muestre el juguete elegido y cuente por qué lo eligió.

Esta actividad fue un momento en el que los jóvenes tuvieron la oportunidad de ser de nuevo los niños que fueron -y que son-, niños interrumpidos en el marco de su historia, como la infancia interrumpida de la que habla Carlos Skliar:

"Los niños desatentos, sordos, ciegos, pobres, inmigrantes, autistas, espectrales, destartalados, son interrumpidos todo el tiempo. A veces, incluso, hasta la muerte. Los niños que juegan a ser niñas y las niñas que juegan a ser niños son interrumpidos. Los niños que miran para otro lado y los que miran fijamente son interrumpidos. Los niños que no viven en casas bien construidas, son interrumpidos (...) Los niños padecen la interrupción de la infancia” (Skliar, 2015, pág. 181)

Dice Gianni Rodari en La gramática de la Fantasía (Rodari, Gianni, 1997) que "a menudo, mientras juega, el niño realiza un interesante monólogo, explicándose él mismo el juego, animando a los juguetes, o distanciándose de ellos para seguir los ecos de una palabra, de un recuerdo súbito". Rodari destaca el vínculo entre juguete y relato: es una relación directa, ya que, como también afirma este autor: "Inventar historias con los juguetes es casi natural, es algo que viene por sí solo si se juega con niños: la historia no es más que una prolongación, un desarrollo, una explosión festiva del juguete" (Rodari, 1997). Fue entonces a partir de esta escena de juegos, de esa momentánea vuelta a la infancia tan cercana, que comenzó un momento de escritura individual. Transcribimos del registro de campo, la escena de escritura que empezó a desarrollarse

Del registro de campo: 
Les proponemos que escriban un texto sobre algún recuerdo de un juego de su infancia. El lugar es incómodo para escribir. Nos dice José que uno de los chicos, Enzo, no sabe escribir, entonces se va aparte en silencio y lo ayuda, Enzo le dicta a José. Carlos se pone a escribir, Alejandro y Joaquín dan algunas vueltas, Bruno se bloquea, y no quiere ayuda. Y llega un momento -no sé bien cómo ni por qué- en el que todos están concentrados escribiendo, nosotras también. Esos momentos de escritura, son de los pocos momentos de concentración y silencio en el taller. Conversan por lo bajo, se ríen, Bruno le hace bromas a la Letizia, hace voz de nena, y le dice "yo jugaba con la casita y la cocinita". Carlos escribe, dice que le está escribiendo una carta a Letizia, es un texto largo, pero no tenemos acceso a leerlo porque es una carta personal que le entrega a Letizia, escrita y decorada. Hacemos la lectura de los textos sobre los juegos. Van leyendo todos, cada uno, los adultos también. Son textos muy cortos, Joaquín escribió que su juego era el ladrón y el policía, y Alejandro, la gomera:

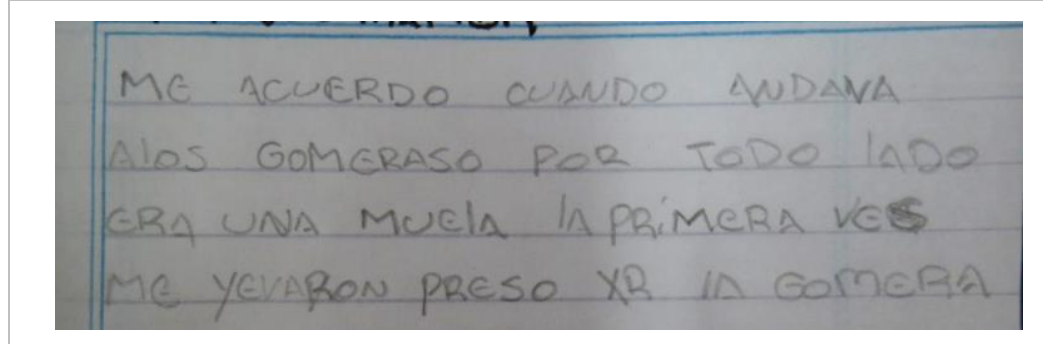

Me acuerdo cuando andava alos gomeraso por todo lado era una muela la primera ves me yevaron preso xr la gomera

"Me llevaron preso por jugar con la gomera", le preguntamos a Alejandro si era cierto que lo habían llevado preso por la gomera, nos dijo que sí, pero no dio detalles. Interrupciones de los juegos, interrupciones de la infancia. El taller continuó:

Del registro de campo:

Les preguntamos después de leer si quieren seguir o terminar el taller acá. Dicen que quieren seguir, parece que están entusiasmados, y les decimos: entonces seguimos: empezamos a completar la línea de tiempo

La actividad final, con la línea de tiempo, consistió en ubicar hechos importantes de su vida en distintos lugares de la línea dividida en septenios, escribiendo tarjetas y pegándolas. Como ejemplo, en el 0 pusimos la palabra "nacer".

Del registro de campo 
Letizia les explica: cada uno tiene que pensar algún (o algunos) evento/s $\mathrm{s}^{71}$ importante/s que hayan vivido, les damos tarjetas y fibrones, escriben unos cartelitos, los van pegando en la línea de tiempo, les explicamos que esa línea se va a ir construyendo en todo el transcurso de los talleres; van quedando algunos pegados: nacer, la muerte de un hermano, el nacimiento de un hijo, matar a un traficante, estar preso, etc.

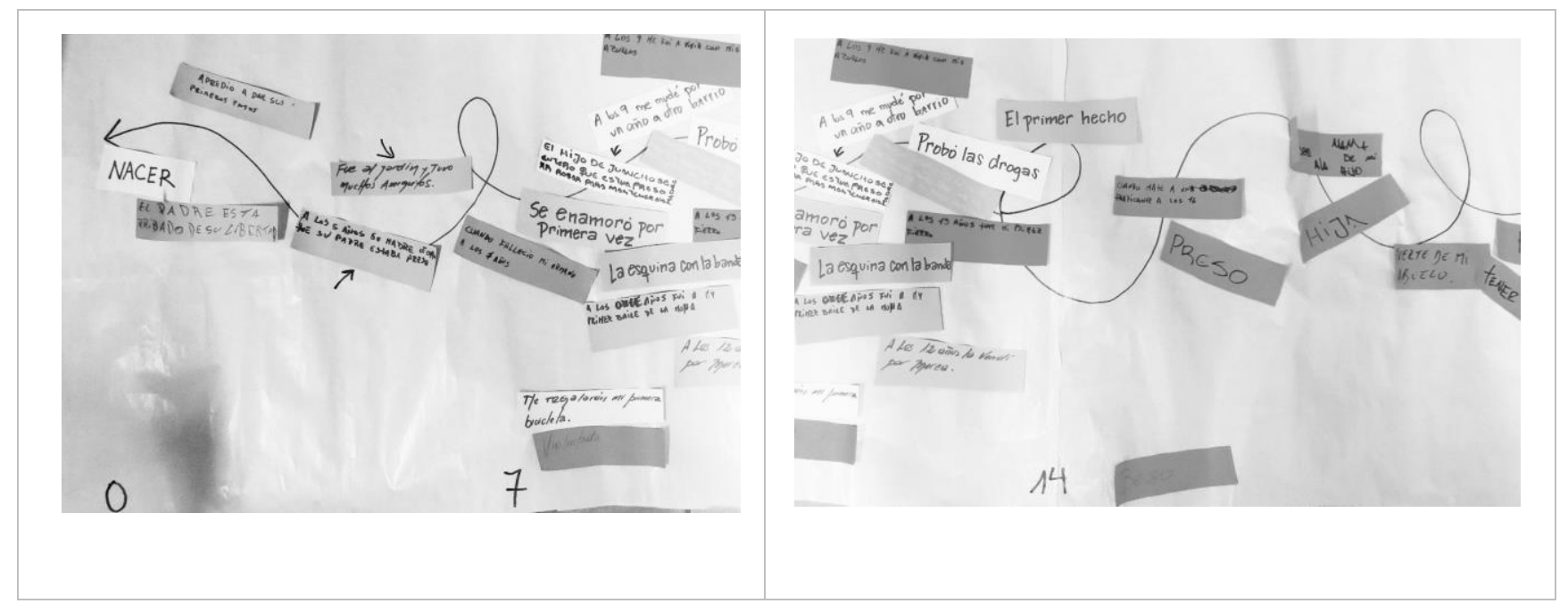

Del registro de campo tomamos un fragmento que retrata la impresión sobre el final del segundo taller:

Del registro de campo:

Quedamos en "seguirla" la próxima. Nos saludamos con afecto, los guardias ya esperan hace un rato en la puerta con cara de pocos amigos, porque nos retrasamos unos minutos, son fuertes los ruidos del abrir y cerrar de las puertas de hierro y rejas, nos vamos de la sala de visitas, los jóvenes quedan adentro. Nos vamos con inquietudes, preguntas...sabemos que en los textos individuales se escribió poco, pero completamos la línea de tiempo, y los chicos estuvieron contentos, estamos inventando una estrategia, los pasos de un proceso para llegar a un producto escrito que sea significativo para los chicos

18 de agosto/TERCER TALLER: "El comienzo de la historia"

Previo a la realización de este tercer taller, hubo una propuesta para trabajar en un "mejor lugar":

71 Letizia tiene especial cuidado al dar la consigna de trabajo: hablar de "eventos" o "sucesos" y no de "hechos", ya que pudo corroborar que para los jóvenes, los "hechos" son los hechos delictivos, en particular los robos. Esta confusión se había presentado en una clase en la escuela, en la que los chicos interpretaron que debían escribir en la línea de tiempo los "hechos" delictivos.. 
Del registro de campo del 14 de agosto $^{72}$ :

Un guardia, al que todos llaman "El soldado" se acercó a la biblioteca donde nos encontrábamos con Letizia ordenando libros y planificando, compartíamos el espacio y la charla con el coordinador de la escuela. El soldado nos dice que él tiene para ofrecer "un mejor lugar" para los talleres dentro del instituto Horizontes: que nos puede procurar una sala de una antigua biblioteca, cerca del sector $D$, que cuenta con mesas y sillas, siendo ahora un espacio limpio, que había estado abandonada y ha sido puesto en condiciones y recuperada por él y de la que él "tiene la llave". Nos asegura que el día del taller, el martes, él nos va a estar esperando. Nos cuesta comprender el ofrecimiento y esta cuestión de "la posesión" de los espacios dentro del instituto, pero por supuesto su ofrecimiento es bienvenido ya que la sala de visitas es muy incómoda. Luego de que el guardia se retira, como nos parece bastante extraña la situación, le preguntamos al coordinador de la escuela su opinión, él nos responde que para él el ofrecimiento del lugar expresa buenas intenciones, que son usuales esos manejos internos del espacio del instituto, que son particularidades del lugar y cuestiones internas de los guardias.

Durante los trece talleres de este proyecto nunca pudimos conocer ni acceder al nuevo espacio de la vieja biblioteca. Quedó en la memoria como una quimera, o una intención de "el soldado" que no se pudo concretar. Nunca lo supimos. Decidimos incluir el registro de este ofrecimiento, ya que da la idea de varias cuestiones del contexto: la arbitrariedad de las reglas del lugar, los "manejos internos" que pueden subyacer a lo que "está a la vista", y la importancia de contar o no con acuerdos con la institución total, desde los jefes hasta los guardias y desde lo más superficial-como el espacio- hasta lo más esencial -como la presencia de los jóvenes-, para llegar a contar con condiciones mínimas, como un lugar para realizar los talleres .

El 18 de agosto se concretó la realización del tercer taller: "El comienzo de la historia". En el momento de la llegada al Instituto Horizontes, no teníamos en claro donde se realizaría:

Del registro de campo:

Estaba la posibilidad de un nuevo espacio, pero, por si acaso, preparamos todo para hacerlo en la sala de visitas, sin mesa, o sea, como siempre. Llegamos cargadas con la línea del tiempo, fibrones, cuadernos, lápices, caramelos, criollos, unos libros y unos

\footnotetext{
${ }^{72}$ Nos encontrábamos en la Biblioteca colaborando en el inventario de libros, la planificación de los talleres, etc.
} 
afiches con renglones. Nos acompañó el coordinador para negociar el tema del nuevo espacio, respecto a lo cual tuvo respuesta negativa, ya que supuestamente querían pintar y arreglar ese lugar recuperado para que lo podamos usar, a todo esto "el soldado" no estaba presente como nos había dicho. Esperamos un largo rato en la puerta de la sala de visitas con todos los bártulos, con Letizia y Graciela, que nos comentó que los chicos habían estado preguntando por el taller y estaban esperando. Graciela consiguió un par de sillas de plástico. Todavía permanecíamos en la puerta de la sala de visitas cuando "sacaron" a los chicos. Aparecen sonriendo y saludan Bruno, Joaquín y Alejandro

Dadas las circunstancias, esta vez los jóvenes entraron junto con las talleristas a la sala de visitas y entonces ellos mismos ayudaron a acomodar y ambientar el lugar. Se trataba del tercer taller consecutivo, lo que se ya se consideraba un logro. Se había ganado el espacio, aunque sea de la sala de visitas y la disponibilidad de los jóvenes.

Del registro de campo:

Los tres chicos nos ayudaron a acomodar las cosas: poner los afiches con cinta en la pared, colocar las sillas insinuando una ronda, los libros y los caramelos sobre la tela en el piso. Esta vez tener un par de sillas no fue un detalle mínimo, nos permitía que el formato "ronda" estuviera más logrado. De un lado la línea de tiempo con algunas escrituras en las tarjetas pegadas. Enfrente los dos afiches, en blanco. Los chicos nos avisaron que un chico, Jerónimo, quería venir y que no lo sacaron, que por qué no lo "pedimos". Fue Graciela, y volvió con Jerónimo, se lo ve contento

Este taller se inició retomando la línea de la vida empezada el anterior, se volvió a conversar sobre la idea de que cada uno de nosotros tiene una vida distinta, singular, pero también que todos tenemos algunas cosas en común. Recordamos que la idea de completar la línea de tiempo grupal, era para, posteriormente, crear un relato biográfico ficcional que sea cercano a la realidad. Comenzamos entonces con la primera escritura grupal:

Del registro de campo:

La propuesta es empezar a escribir la novela. Para la organización proponemos que uno de ellos sea el que escriba en el afiche, y los demás "tiren ideas". Como ayuda ponemos en la tarima tarjetas con comienzos de historia, nexos, etc. El asunto es ver quien escribe, todos dicen que no, que tienen "fea letra", le preguntamos a Jerónimo, que duda... "isí! que escriba el ingreso" dicen los chicos, Jerónimo en principio se negó, pero también se reía, decía "a mí me gusta escribir, pero esto..." Le decimos entonces que va a ser entre todos y 


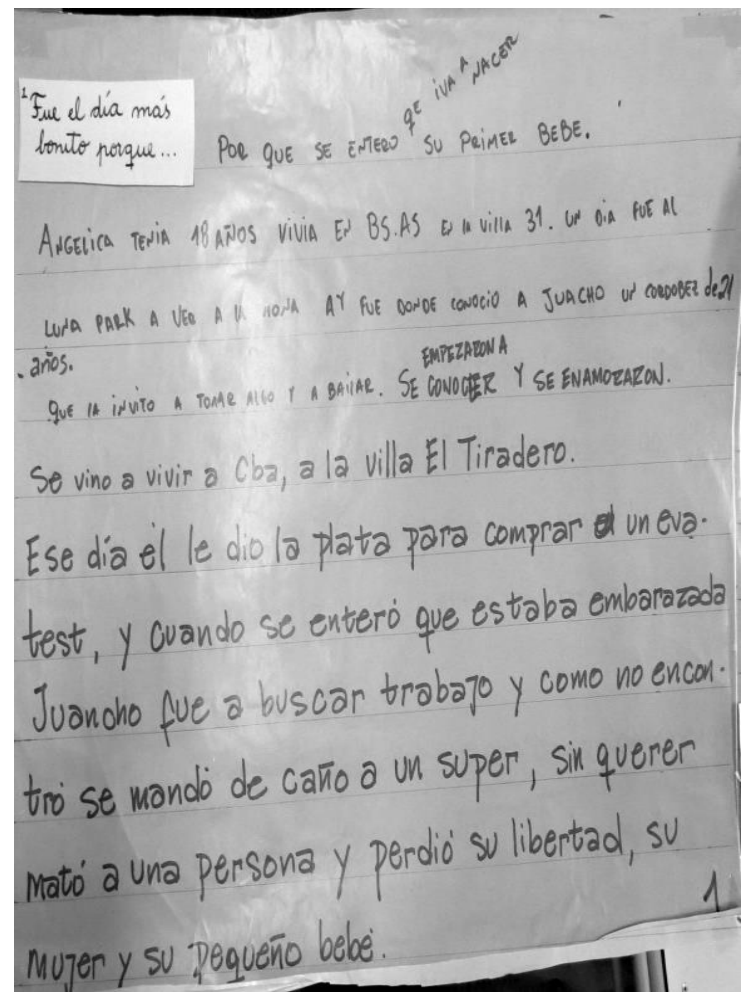

un poco cada uno. Finalmente, acepta. Todos parados alrededor de las láminas, miramos primero la línea de tiempo, y conversamos, les proponemos comenzar desde antes de su nacimiento, empezar, por ejemplo, cuando la mamá se entera del embarazo o algo así. Entre varias opciones de comienzos presentadas en las tarjetas, los chicos eligen "Fue el día más bonito porque..." a lo que agregan "porque se enteró que iba a nacer su primer bebé". A partir de ahí empiezan a armar una historia con entusiasmo y naturalidad. Jerónimo toma nota de lo que dictan los compañeros, hay que tomar muchas decisiones porque las ideas son abundantes, Jerónimo además de tomar nota de las sugerencias, toma decisiones específicas de escritura: puntos, conectores, sinónimos, etc. La historia continúa: la mamá se llama Angélica, es porteña y conoció a Juancho en un recital de la Mona Jiménez. ${ }^{73}$. Jerónimo pidió que otro chico siga y como no hay voluntarios, sigue Letizia, que va escribiendo lo que los jóvenes le dictan: el nacimiento del bebé: se llama Yandel, la caída de Juancho, su padre. Finalmente leemos varias veces en voz alta. Hacemos pequeñas correcciones. Los chicos quedan conformes De esta manera culmina la escritura de las dos primeras páginas de la Novela.

La escritura del primer capítulo terminó así:

“...Cuando Angélica le dio la noticia de que estaba embarazada Juancho se fue a buscar trabajo y como no encontró se mandó de caño a un Súper, sin querer mató una persona y perdió su libertad, su mujer y su pequeño bebé..."

El taller continuó con una escritura individual, sentados nuevamente en ronda, se sumaron Enzo y Carlos, que los martes salen de otro taller y llegan tarde.

Luego de la puesta en común y la merienda compartida, llegando la hora de irnos aparece una práctica cotidiana de escritura: la escritura en la pared ${ }^{74}$ :

\footnotetext{
${ }^{73}$ El texto completo de la novela se anexa al final, ANEXO 2

74 La escritura en la pared está prohibida y es censurada, lo desarrollaremos más adelante, en el capítulo sobre la escritura cotidiana
} 
Antes de irnos, Enzo nos "roba" un fibrón y sale corriendo y se pone a escribir en la pared con Jerónimo, se ríe, hacen un símbolo, parece una " $T$ "75, nada más. Letizia les llama la atención, les dice que ellos saben que no tienen permitido escribir la pared (la semana pasada, pasó lo mismo, Alejandro también escribió en la pared “iMuerte a la yuta!” antes de irnos)

\section{5 de agosto/ CUARTO TALLER: "Jornada de escritura y películas"}

Los jóvenes habían dicho que querían ver una película, se decidió entre todos entonces organizar una especie de festejo en alusión a haber llegado con éxito a la realización del cuarto taller. Se pidió más tiempo para el taller a las autoridades del Instituto -tres horas- y se proyectó la película paraguaya "Siete cajas". Pero previamente a la proyección de la película se dedicó un tiempo para la escritura de la novela grupal

Repasamos la línea de tiempo y leímos de nuevo la historia, observamos en la línea de tiempo los eventos escritos por ellos en el encuentro anterior, para tomar ideas para la escritura de la novela. Prestamos atención en particular al cruce de dos eventos: la mención a la sala de 5 en el jardín de infantes, y la noticia -también a los cinco años- de que el padre estaba preso. Ninguno de ellos quería pasar a escribir. Se ofreció Graciela. Los chicos tomaron la decisión de empezar a partir de que Yandel tenía 5 años, arrancaron proponiendo ideas, dictando, se notaban muy compenetrados en la historia. Nos explicaron que Angélica, cuando Juancho (el papá de Yandel) cayó preso, se juntó con Roberto, que era "peón de peón de peón de albañil", se reían, -parece que se burlan de Roberto- , que Juancho le había escrito una carta amenazándola para ver a su hijo, que se había puesto así, muy malo, después de tantos años de encierro. Los chicos discutían, tomaban decisiones de común acuerdo, y le dictaban a Graciela

Transcribimos un fragmento de la escritura de los jóvenes:

“...Angélica en esa época trabajaba en una empresa de alimentos, pero a esa altura ya la habían echado de su trabajo. La mamá de Juan los había volado de la casa y ahora vivían en la Villa La Tablita. En la plaza del barrio se veían chicos jugando, abundaban las mujeres hermosas, los transas, y la policía patrullaba por sus calles rotas..."

1 de septiembre/ QUINTO TALLER: “La esquina/el barrio”

\footnotetext{
${ }^{75}$ en el capítulo sobre la escritura en la pared, analizamos este tipo de el signos en forma específica
} 
El 1 de septiembre llegaron en un comienzo sólo dos jóvenes, acompañados por los guardias: Joaquín y Alejandro:

Loa chicos entraron serios. Joaquín nos aclaró que no tenían ganas de hacer nada. Alejandro, tampoco quería hacer nada, entonces nos dijo que la realidad es que ya no tiene ni ganas de vivir, que se quiere matar. Joaquín con total naturalidad le responde "está bien, matate hermano, y así dejás de sufrir". Las Talleristas, desconcertadas, no encontrábamos una respuesta, queríamos levantarles el ánimo sin saber cómo, y tratábamos de salir de ese clima con argumentos banales al estilo "te quedan muchos años por vivir", ellos insistían en que para vivir como viven es mejor estar muertos. Alejandro nos contó entonces que esta mañana la policía mató a su amigo.

En momentos como el que se presentó en este taller nos planteamos el sentido de nuestra presencia en el lugar. En ese momento nos preguntábamos como seguir, si seguíamos conversando, si debíamos dar una respuesta, si esa respuesta podía tener sentido, o si continuar con el taller y ponernos a escribir podía ser de alguna forma una salida. Carlos Skliar propone "responder éticamente a la existencia del otro. Lo que no quiere decir apenas afirmarlo en su presencia, aunque esté más que claro que la educación consiste en encontrarse de frente con un otro concreto, específico, cara a cara. Ese encuentro es con un rostro, con un nombre, una palabra, una lengua, una situación, una emoción y un saber determinados y singulares." (Skliar, 2010, pág. 109). Estábamos ahí, frente a ellos, presentes, percibiendo su sufrimiento, tratamos entonces de encontrar las palabras, intentamos dar una respuesta

Del registro de campo:

Les dijimos que tal vez a través de la escritura, la poesía o las historias podíamos "salir del encierro", que de eso se trata la Literatura, de buscar otras salidas, de salir de donde estemos con la imaginación, que por eso lo que pensábamos proponer hoy era salir a pasear por el barrio, por la esquina y escribir sobre eso, seguir escribiendo la novela.

La respuesta salía del convencimiento de que la literatura puede llegar a ayudar a las personas, en palabras de Michel Petit: "a imaginar otros mundos posibles, a soñar, a encontrar un sentido, a encontrar una movilidad en el tablero de la sociedad" (Petit, 2008, pág. 17). Más aún en situaciones y contextos violentos, nos sostuvimos en la idea de que, a través de la lectura, la escritura creativa, posiblemente "una parte de ellos ya no 
será rehén, una parte de ellos escapará a la ley del lugar, a los conflictos cotidianos" (Petit, 2003, pág. 8).

Del registro de campo:

Empezamos leyendo una poesía, dijimos que la poesía de Cesar González habla de esas cosas que ellos sienten, justamente. Entonces Letizia leyó Opacos Colores: "Celdas, sombras, risas, quien quiebra, quien banca..." los chicos escuchaban, se produjo silencio, otro de esos silencios, esta vez el de la lectura y la escucha atenta. Luego leímos Melancolía y Resistencia, también de César: "Soy un sobreviviente que maldecía estar vivo, y que soportó mil dolores aferrado a un misterio". Después volvieron a hablar del encierro, Joaquín dijo que estaba mal porque iba a pasar el cumpleaños otra vez encerrado, que no aguantaba más "esta bosta". Hicimos una pausa para compartir una merienda. Pusimos videos con música en la computadora

En ese momento se me acercó Alejandro con el cuaderno y un fibrón en la mano - ¿me escribe una poesía? - me pidió que la escriba en la tapa de su cuaderno, forrado con papel madera. Acepté y mientras los otros miraban el video nos sentamos a cierta distancia. “¿Me vas a dictar?" le pregunté, me aclaró que quería que le escriba en esa letra "linda", yo entendí que se refería a la letra cursiva, él asintió, y me dictó: "Una flor en el mar se puede marchitar, pero el amor de una madre no morirá jamás". "Traté de hacer la mejor letra que pude" le dije, y él sonrió. Mientras tanto llegaron Enzo, Carlos y Jerónimo, se sumaron al grupo que estaba viendo un video de Cesar González de Canal Encuentro: Corte Rancho. Después pusieron música, cuarteto, hasta propusieron armar un baile. Se pasó a un momento de caos y jolgorio. Luego seguimos con el taller, para pasar al momento de la escritura individual

Vimos luego el video clip de la canción Como que no del grupo La Liga y leímos su letra, que habíamos llevado impresa en hojas: "los pibes allá en la esquina / están como dibujados/ nadie paga sus pecados/ no les tocó religión... “. Luego les presentamos algunos fragmentos de la letra de la canción, recortada en tiras. Se utilizaron sus versos como disparadores para la escritura grupal. 


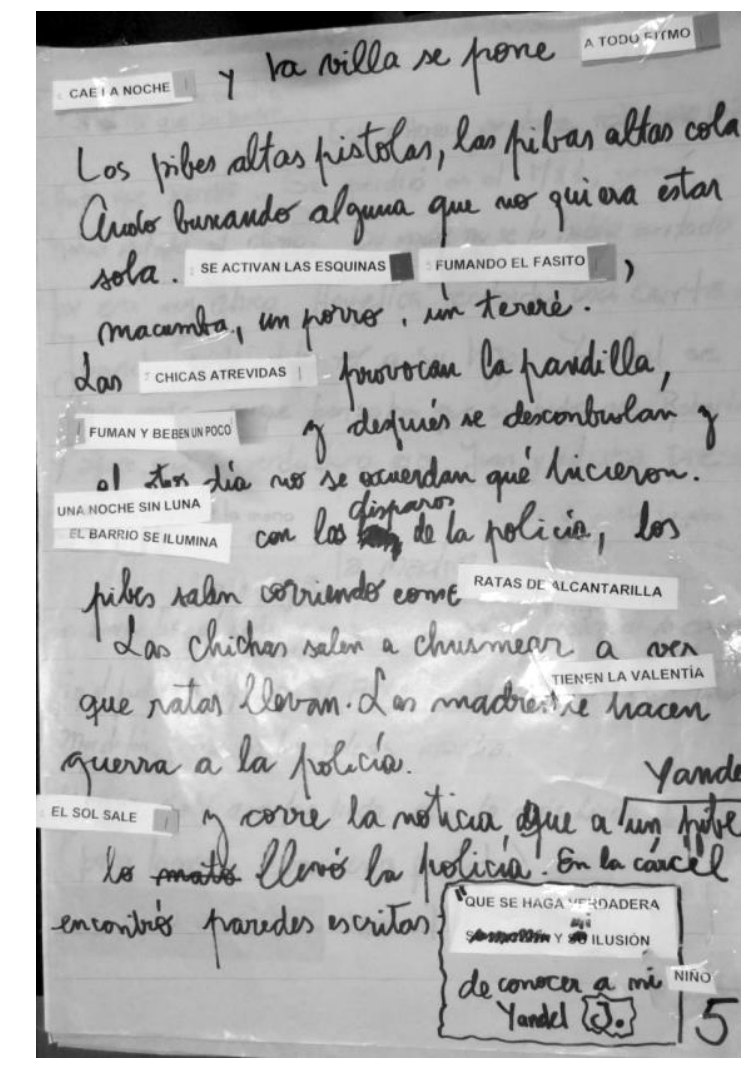

Del registro de campo:

Decidimos finalmente escribir la hoja 5 de la novela. Esta vez les ofrecimos las tiras con los versos de la canción que escuchamos para que ellos vayan eligiendo cual usar. Nadie aceptaba escribir "tengo fea letra" era otra vez el argumento. Enzo aclaraba una vez más "yo no sé leer y escribir". Arrancamos, nos acercamos todos a la pared, esta vez tengo que escribir yo. Se hace un amontonamiento, un caos muy productivo creativamente, por cierto. Los chicos van y vienen con ideas y forman nuevos versos. Van eligiendo partes de la canción, discuten, se ponen de acuerdo, se ríen. La historia empieza a salir. "Cae la noche en la esquina..." y cuenta que los chicos del barrio están en la esquina, fumando, tomando, hasta que llega la policía a los tiros "el barrio se ilumina con los tiros de la policía", los chicos salen corriendo "como ratas de alcantarilla" y Yandel cae preso por primera vez (habían dicho primero que lo mató la policía, pero pensaron que así se terminaría muy pronto la novela así que lo corrigieron)

Este taller en particular empezó con la tristeza de los jóvenes y con preguntas sin responder, en este espacio hostil y violento que es el encierro. Pero algo pasó, que permitió "un margen de maniobra" y una vez más la sorpresa: porque se terminó de otra manera, en otro espacio -tal vez- más habitable, un espacio que se construyó con la suma de varias voluntades unidas en la simple lectura de la letra de una canción y la entusiasta escritura creativa grupal, pasando entre medio por la música e incluso el baile. Sobre estas oportunidades que da la literatura y el arte, dice Michèle Petit:

"Te doy canciones y relatos para que escribas tu propia historia entre las líneas leídas, para que poco a poco puedas arreglártelas sin mí, pensarte como un pequeño sujeto distinto, y elaborar las múltiples separaciones que te tocará afrontar. Te regalo trozos de saberes y ficciones para que no tengas demasiado miedo a las sombras y sepas hacerlas bailar; para que puedas simbolizar la ausencia y enfrentar, en la medida de lo posible, las grandes preguntas humanas 
(los misterios de la vida y la muerte, de la diferencia de los sexos, el miedo al abandono, el amor, la rivalidad, etc.)" (Petit, 2012, pág. 267)

27 de septiembre/ SEXTO TALLER: “Mensajes en botellas"

El sexto taller se realizó veintiún días después del anterior, ya que se suspendieron dos talleres. El primer martes, por dificultades de las talleristas, y el segundo, por cuestiones de la institución. Ese segundo martes, al llegar al instituto, no se pudo dar el taller programado, por razones que resultaron dudosas: o los chicos no estaban, o los guardias no estaban predispuestos a buscarlos. Aparentemente algunos habían salido de "permiso" para ver a su familia, otros estaban con los equipos técnicos, o durmiendo, o en otras actividades. Nos encontrábamos entonces preparadas para el sexto taller, pasada una semana de la suspensión del taller anterior, y tres semanas del último encuentro con los jóvenes, y no sabíamos cuál era el panorama:

Del registro de campo:

Llegamos al Horizontes con expectativas y temores sobre si los chicos iban a venir o no. Los guardias nos recibieron con cara de pocos amigos, pero accedieron a buscarlos. Solo trajeron a Joaquín, que nos explicó que los otros chicos estaban castigados (Bruno y Jerónimo). Nos dijo también que Alejandro estaba en una actividad del curso de mediación.

Las dificultades de los dos últimos talleres -el anterior: suspendido y el actual: sexto taller- nos hicieron tomar conciencia de la importancia de sostener las rutinas en estos contextos. En una institución de encierro, cuando se gana un espacio y un tiempo, resulta imprescindible cuidarlo, cuidar las formas y respetar la regularidad para no perderlo. Consideramos que los tiempos en el encierro son distintos a los tiempos del "afuera" -tanto para los jóvenes como para los guardias- y que, en un tiempo de espera de quince días, pueden suceder infinidad de situaciones que obstaculicen la continuidad de un proceso. Por esta experiencia, y sumando en sentido contrario, la experiencia de los progresos que se iban logrando en los talleres semanales anteriores, llegamos a la conclusión de que, una clave concreta en este contexto es tratar de no distanciar más de una semana entre uno y otro taller. Con esto no queremos decir que sea una cuestión de ciencia exacta, ya que cada espacio y cada taller o actividad tienen sus tiempos, pero esta es la clave que pudimos construir en nuestra experiencia. 
Para el sexto taller planificamos dejar un espacio para la escritura individual: trabajar con "mensajes en botellas". Ambientamos y preparamos en función a eso, la sala de visitas:

Del registro de campo:

Unos minutos después de Joaquín llegó Renato, que era la primera vez que participaba, habíamos estado esperándolo en los otros talleres. Letizia había insistido mucho en que él participara.

En la sala pusimos un video del mar en la computadora, con olas llegando a la playa, además las poesías sobre un papel azul en el piso y una botella de plástico con un papel enrollado, como mensaje. Había café y una torta. Hablamos sobre el mar, ellos no lo conocían. Joaquín vio la botella con el mensaje y nos contó que había visto un documental con una historia de un soldado de las islas Malvinas que escribió un mensaje para su madre, y el mensaje apareció unos años después. Renato comentó que vio una película de un náufrago, Joaquín un poco irritado le resaltó que lo que él vio era VERDAD, que era REAL, que no eran pavadas, que había pasado, era real, resalta: REAL. (Aparece de nuevo la cuestión de la realidad como un valor por encima de la ficción)

Se leyó la letra de Mensaje en una Botella de The Police, y un poema de Ismael Serrano, el cantante español. Les dijimos que hiciéramos de cuenta que, como un náufrago, queríamos escribir un mensaje a alguien para pedir ayuda, para que nos rescaten. Los chicos se pusieron a escribir, y luego vimos como arrancaban una hoja del cuaderno, hacían un rollito con su escrito y lo ponían en la botella: la interpretación era literal. Cuando terminamos respetamos su decisión de mantener en privado lo que escribieron.

Luego de este "ritual" en el que se destacó la condición de la privacidad de algunos textos, continuamos con la escritura de la novela grupal

\footnotetext{
Del registro de campo:

Le explicamos a Renato que se trataba de un proyecto, un proceso de escritura, Joaquín insistió en que no se puede publicar así, que escribieron demasiadas estupideces, pavadas, para reírse entre ellos, Letizia le respondió que por supuesto que la vamos a revisar y mejorar, pero también le aclaró que no tiene nada de malo escribir algo que sea gracioso (Joaquín parecía darle mucha importancia al hecho de que la novela sea publicada). Renato la había leído apenas llegó, porque estaban los 5 "capítulos" pegados en la pared. Luego renarramos la novela oralmente, en partes leímos, nos reímos, observamos cómo cada parte continuaba donde se dejó en el taller anterior.
} 
Prestamos atención sobre que en este momento del relato teníamos que tomar decisiones importantes ¿Yandel cayó "de garrón"76 o cometió un delito? ¿Quedó detenido o salió pronto en libertad? Los chicos daban distintas posibilidades, se pusieron de acuerdo en que como era la primera vez, cayó "de garrón", en este caso era Letizia la que iba escribiendo y ellos iban dictando, prestando mucha atención a las palabras, usando el lenguaje jurídico con pertinencia. Utilizando la ironía, el humor.

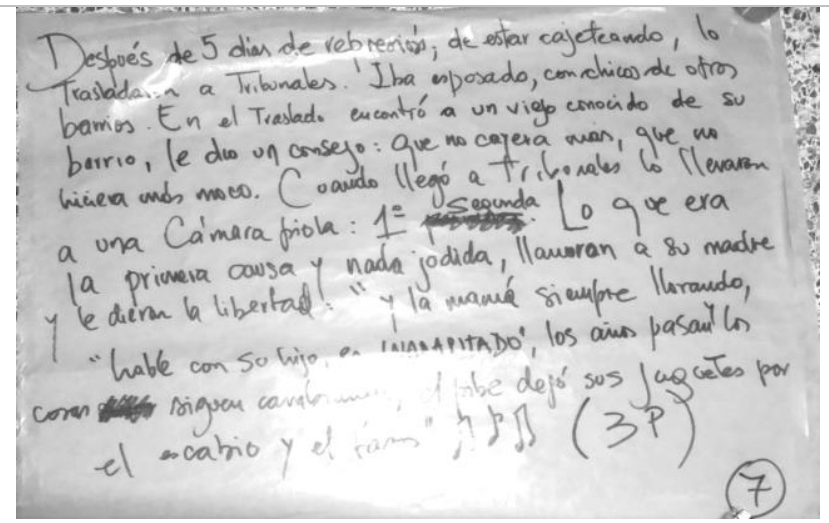

Después de cinco días de represión... de estar cajeteando, lo trasladaron a Tribunales. Iba esposado con chicos de otros barrios. En el traslado encontró un viejo conocido de su barrio, que le dio un consejo:

Que no cayera más, que no hiciera más moco.

Cuando llegó a Tribunales lo llevaron a una cámara piola: Primera Segunda. Lo que era la primera causa y nada jodida le dieron la libertad

Ya terminando el taller Renato nos expresó su necesidad de seguir escribiendo:

Del registro de campo:

Finalizado el taller, Renato nos pide un cuaderno, dice que hace "bocha" que no escribe, que tiene ganas de escribir, que ellos escriben de todo, "canciones", acota Joaquín. Sabemos que la guardia les saca los cuadernos, les decimos que igual el próximo martes le traeremos uno para que se lo lleven. Es la hora de irnos, nos abren la puerta, nos queda la imagen de los chicos: nos saludan, quedan parados y encerrados en el medio del salón

Aquí reaparece una cuestión: las posibilidades u oportunidades de escribir en el encierro, que ya desarrollamos en el capítulo "El encierro: las oportunidades, posibilidades y prohibiciones de la escritura".

\section{9 de septiembre/ SÉPTIMO TALLER "Día complicado"}

Del registro de campo

Llegamos al Horizontes sabiendo que el día iba a ser complicado, Graciela nos había dicho que Joaquín estaba castigado (porque participó en una pelea a la mañana), y que

\footnotetext{
${ }^{76}$ Caer de garrón: ir preso siendo inocente
} 
Alejandro había salido de permiso y había vuelto "muy drogado" (es secreto a voces que los chicos salen de permiso y se ponen "de la cabeza" y que además traen "algo" para los compañeros). Los guardias, como siempre, nos advierten que los chicos estaban durmiendo la siesta. Así y todo, traen a Enzo, y a Ariel, un chico al que no conocíamos pero que ya nos habían dicho que tenía "problemas de conducta". Después llegó Leandro, otro chico también nuevo, que nos contó que lo habían traído los guardias, pero no tenía ni idea de donde estaba, ni de que se trataba el taller.

Solo vinieron Enzo y los dos chicos nuevos. Dada esa situación se improvisó un taller inicial para los chicos que recién empezaban y no conocíamos, darles la oportunidad de presentarse y de informarse sobre la actividad que propone el taller. Luego se trabajó con la novela

Del registro de campo

Luego de las presentaciones, leímos en voz alta la novela completa, las siete hojas que los chicos habían escrito hasta ahora. Escucharon atentos, les gustó la historia, Ariel se entusiasmó con continuarla. Leandro mientras tanto empezó a mirar y leer los libros de César González que habíamos traído.

Ariel, quería participar en el proyecto de la novela, se mostraba ansioso, y sin ningún tipo de consigna empezó a inventar y a dictarle a Letizia:

Se puso a pensar y "tirar" ideas para la historia, iba inventando, iba dando razones, dictándole a Letizia, que trataba de escribir todo lo que Ariel proponía. Enzo participaba, pero de una manera no tan protagónica como Ariel, que parado al lado de los afiches leía, pensaba, corregía sus propias ideas. Ariel pensaba en voz alta "es que por momentos se me mezcla con mi vida, me pongo a pensar en mi mamá, que la mamá es mi mamá y que Yandel soy yo". Llegó a escribir dos hojas, junto con Enzo y Leandro, que de vez en cuando participaban. Escribieron sobre la vuelta a la casa, las andanzas y su primera novia.

Fragmento de la novela:

Él la buscaba todas las tardes en su moto, y ella contenta, porque él llegaba. Un día Yandel la llevó a su casa a cenar y ese día ella se dio cuenta de que él vivía en un barrio bajo. Vio otro mundo, un mundo que no conocía, muy distinto al de su ambiente. 
6 de octubre/ OCTAVO TALLER: "Aladino"

Como todos sabemos, Scherezade logró, a fuerza de cuentos, demorar su muerte durante mil y una noches y luego, como consecuencia de esa demora, demorarla aún más, sine die, es decir, sin día de plazo fijo, con plazo azaroso, que es la mejor moratoria que, hasta ahora hemos conseguido los humanos en la tarima del destino. (Montes, Graciela, 1999)

En el taller del seis de octubre, octavo taller, se trabajó sobre la historia de "Las mil y una noches", en particular la historia central de Scherezade y Schariar, y la de Aladino, en la versión de Graciela Montes. El epígrafe con el que comenzamos, de la misma autora de la versión leída, da cuenta del significado y la profundidad que esta historia puede connotar, y del poder que pueden llegar a tener las historias. Para este taller se puso especial cuidado en la ambientación:

Del registro de campo:

Llegamos al Horizontes, con música árabe, una pava vieja a modo de "lámpara", café, y mantecol para los chicos. Preparamos toda la ambientación, la línea de tiempo, los afiches para escribir, etc. Como siempre "pedimos" a los chicos del sector D. Luego de un rato los guardias abrieron las puertas, y llegaron Joaquín, Jerónimo, Alejandro, Enzo y Valentín por primera vez (hermano menor de Bruno, que hoy salió de permiso a ver a su padre preso). Nos alegramos de ver esa llegada masiva, nos saludamos con todos los chicos. Les llamó la atención la "decoración". Letizia le contó a Valentín sobre el proyecto de la novela, de paso, todos repasamos la historia una vez más.

La decisión de leer un cuento fue muy importante en este momento, ya que no se había partido de la estructura tradicional de un proyecto de escritura: primero la lectura del género, y luego la escritura. Se estaba escribiendo una novela, y se había leído sobre todo poesía. Se estaba inventando una secuencia de talleres en circunstancias particulares y sobre la marcha se tomaban decisiones.

Primero se narró la historia principal de Las mil y una noches y luego se leyó el cuento de Aladino en voz alta.

Del registro de campo: 
Los chicos escuchan muy atentos, por momentos se ríen, les dan gracia los nombres árabes, Joaquín y Jerónimo van siguiendo de cerca la lectura y mirando algunas ilustraciones del libro.

Se realizó luego un momento de escritura individual, la consigna era escribir deseos ¿Qué harían si se les apareciera un genio? ¿Qué deseos pedirían?

Del registro de campo:

Los chicos se quedan bastante callados pensando. Jerónimo dice "ir a mi casa, comprarme un cero y estar con mi guacha". Los otros se ríen y asienten. Letizia le comenta que justamente el primer deseo de él es el mismo de Aladino: volver a su casa.

Luego se pasó a la escritura del nuevo capítulo de la novela, se presentaron unos fragmentos del libro de Aladino: se echó a correr, se sentó a pensar, a ver pasar la vida, y otros, de la línea de tiempo como: consiguió su primer trabajo, el primer hecho, decidió volver a la escuela, probó la droga.

Del registro de campo:

Le dijimos a Jerónimo que escriba, le insistimos, al final aceptó, agarró el fibrón y empezó. El ritual era el de siempre, el afiche en la pared, las tiras con las frases/sugerencias en la tarima de cemento. Joaquín y Valentín estaban interesados en participar, lo llamaban a Alejandro, que estaba mirando fotos y buscando música en la computadora. Le decían "vení que tenemos que escribir sobre el primer hecho". Eligieron entonces "consiguió su primer trabajo", a lo que agregaron "un caño", (o sea el primer trabajo era un robo "de caño", con revolver). Apareció entonces en la novela un nuevo personaje, amigo de Yandel, un rastafari: el wacho Mustafá (como el padre del cuento de Aladino). En este tema todos participan, se preocupan por qué términos utilizar, si "robó" o "delinquió". Jerónimo toma las decisiones rápidamente, hace chistes todo el tiempo, escribe con algunos errores de ortografía, que Joaquín le corrige. Valentín hace aportes todo el tiempo, que siempre son con rima, está participando, le proponemos que el siguiente capítulo sea él, el que escribe. Acepta con cierta timidez. En el siguiente capítulo los chicos dicen que Yandel "se mareó": que le robó la novia a Mustafá, le vendió la pistola (o sea traicionó a su amigo), y riéndose agarran la tira de "volvió a la escuela" y "¡volvió a la escuela!", dicen y se ríen, finalmente prefieren continuar con que siguió robando $24 \times 7$, o sea las 24 horas del día de los 7 días de la semana". 


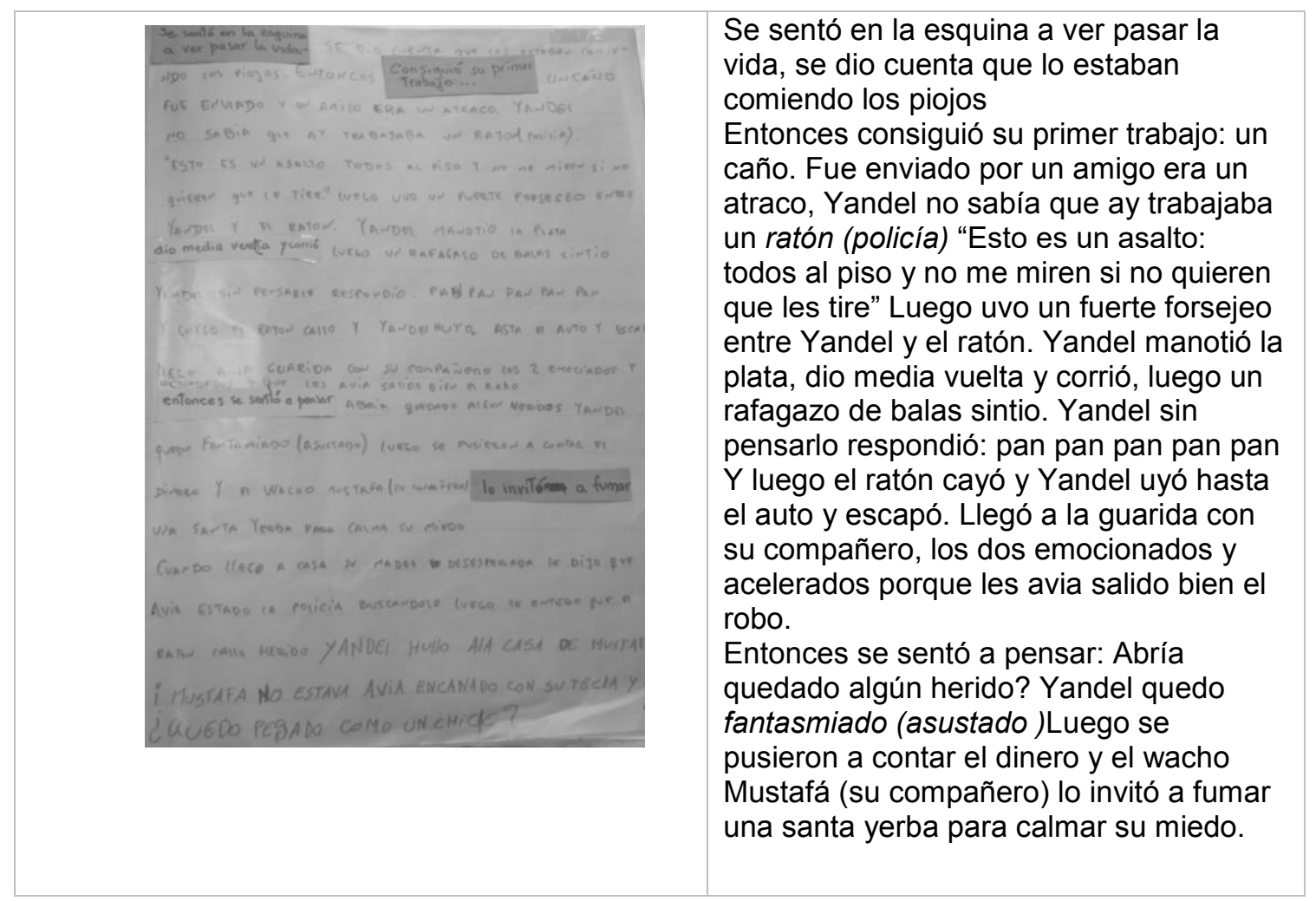

Yandel "se marea" y traiciona a su amigo: le roba la pistola, la novia, y "vuelve a la escuela”. Volver a la escuela ¿Una traición más en la lista? Por algún motivo les causó gracia y decidieron continuar con que Yandel se dedicó a partir de ahí a robar noche y día. A esta altura de la novela Yandel parecía uno más entre ellos, como consta en el siguiente registro, en el momento que estaba escribiendo Valentín:

Del registro de campo

Valentín se preocupa por la escritura y no le parece bien que se rían tanto de Yandel, dice: "estamos "fantasmeando" (imaginando) demasiado", les señala a los chicos que se están burlando de Yandel, y les remarca que lo están tratando como a un "gil".

En el momento final del taller, Joaquín insistía en llevarse el cuaderno para poder escribir en el sector $\mathrm{D}$, donde viven; le preguntamos si los guardias se lo van a permitir, y nos responde irónicamente:

Del registro de campo

"mirá vos, ¿nos dejan entrar con droga y no nos van a dejar entrar con cuadernos?". Finalmente se lleva cada uno un cuaderno y también lapiceras, les recomendamos que por favor no hagan nada malo y que traten de escribir algo y que si quieren pueden traerlo al próximo taller. 


\section{3 de octubre/ NOVENO TALLER: "El encierro"}

Para el trece de octubre se volvió a estabilizar la asistencia de los talleres. Se volvió a la regularidad de todos los martes/uno en la semana. Creemos que esa regularidad ayudó -como mencionamos antes- a que los chicos incorporen esta actividad en su rutina, y los guardias también, quienes poco a poco fueran aceptando la presencia de las talleristas y actividades en el lugar, que en un comienzo nos pareció que percibían como una invasión a "su" territorio.

Ya se llevaban escritas once hojas de la novela. Hasta el momento se iban pegando como "capítulos" en la pared, pero el taller anterior, se había hecho un "encuadernado" de estos papeles de gran tamaño en una suerte de libro gigante, con tapas de cartón. A partir de allí, cuando se repasaba la lectura iban desplegando las hojas, una a una, como en un libro "real"

Se planificó para trabajar sobre un tema difícil: las sensaciones del encierro. La actividad consistió en trabajar en forma individual en los cuadernos, en un cuadro con una lista de títulos como: sonidos/ olores/ tiempo/colores, a las que los jóvenes debían completar con palabras, frases o versos, sobre sensaciones concretas

Del registro de campo

Les repartimos los cuadernos, ya que allí tienen escrita la consigna, los chicos se dispersan por el perímetro de la sala, para escribir sobre la tarima y se ponen a escribir en silencio. Valentín no tiene cuaderno, le damos una hoja, está un poco trabado, no arranca. Bruno escribe. A Alejandro y Renato se los ve concentrados escribiendo, sobre todo Alejandro, que cuando empezamos la puesta en común todavía seguía escribiendo. En la puesta en común todos leen, y Letizia va tomando nota, va anotando las palabras o frases que los chicos van leyendo en tarjetas de cartulina. Bruno, además de leer lo que escribió, va "tirando" otras frases a Letizia.

Luego leemos poesías de autores que escribieron desde/sobre el encierro: Miguel Hernández, Cesar González, Armando Tejada Gómez y Paco Urondo, los chicos escuchan atentos, tomamos nota también de algunas frases de los poemas leídos.

A esta altura cuando se pasaba al momento de la escritura grupal, ya estaba instalada una rutina: el afiche sobre la pared, los papelitos con las palabras o frases en la tarima, y todos los chicos parados alrededor: 


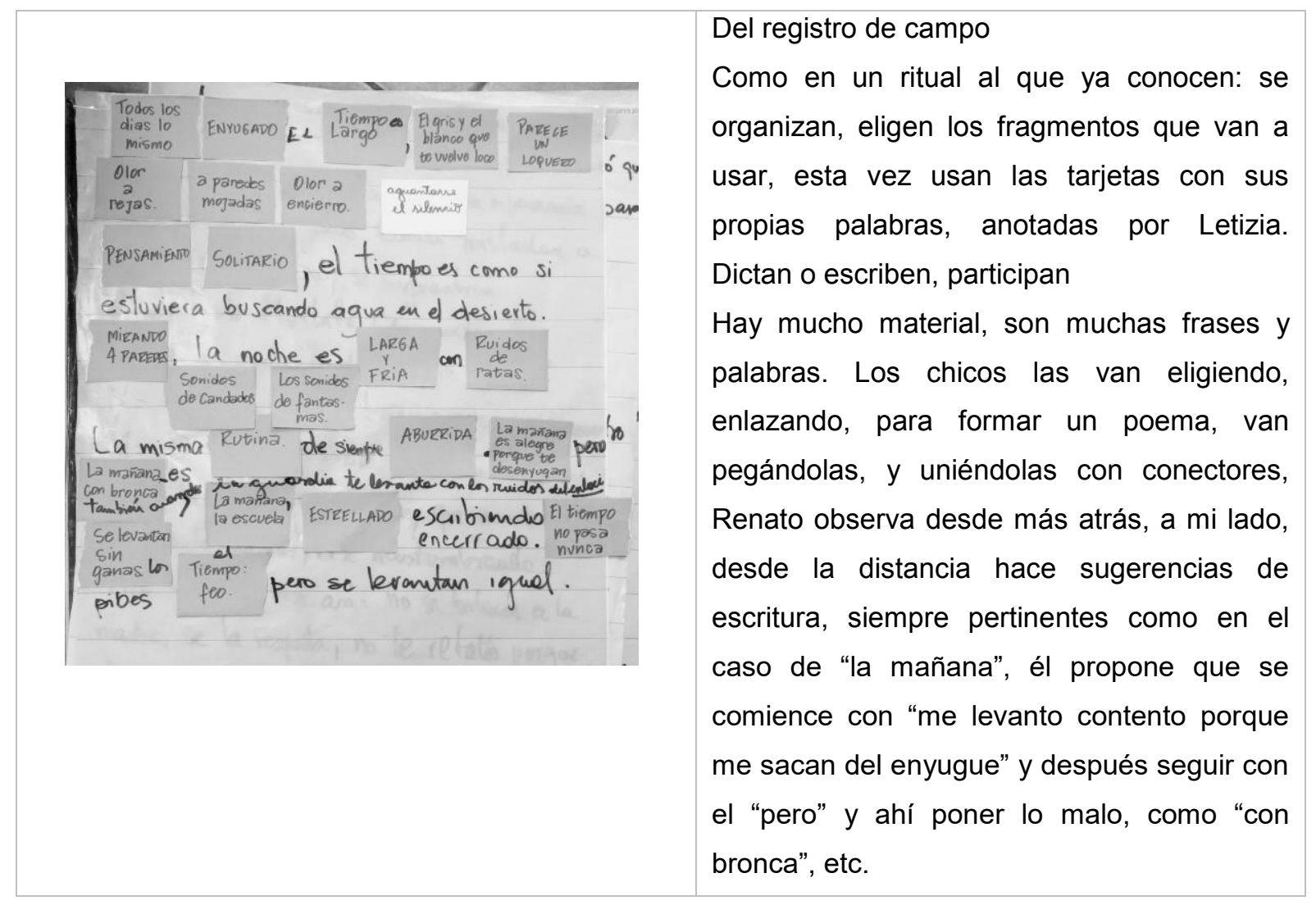

El segundo texto propuesto es un diálogo entre los dos amigos: Yandel y Mustafá, que se encuentran estando los dos presos.

Del registro de campo

Renato propone que Mustafá lo estaba esperando para "cumplir juntos la condena", hacemos esa introducción y escriben un texto, en el que participan todos muy activamente, se suman con entusiasmo Alejandro y Bruno. El diálogo de la novela empieza con cierta violencia mezclada con humor y termina en un motín.

No se había escrito hasta el momento ningún diálogo. Se pudieron corroborar a partir de aquí las enormes posibilidades de este formato textual. El formato diálogo favoreció a la espontaneidad, la incorporación de sus formas propias de hablar, y sus modismos. Lo interesante también en este caso es que incorporaron el humor y la ironía, siempre presentes en su comunicación oral, en la vida cotidiana.

Terminado el taller queda "en el aire" la minuciosa descripción que realizaron los jóvenes sobre el motín que organizan los protagonistas de la novela:

Del registro de campo

Después que se llevan a los chicos, quedamos en la sala de visitas, esta vez encerradas nosotras, con Graciela. La observo a Letizia preocupada, escuchando y mirando por la 
pequeña ventana de rejas, con intranquilidad. Me dice que está impresionada por la descripción del motín, como si esa escritura tan detallada (sobre un motín) fuera un anuncio de algo que estuviesen por hacer y fuese a pasar a corto o largo plazo. Se escuchan ruidos y voces, gritos de los chicos, pero son difíciles de percibir, después todo vuelve a la tranquilidad.

Surge en este momento una inquietud que acompañó a las talleristas en mayor o menor medida en todo el proceso. Si bien estaba claro que la novela estaba siendo escrita por los jóvenes, quienes habían decidido hablar sobre su realidad, al finalizar cada taller, en particular en algunos capítulos, aparecía con fuerza la crudeza del relato, y la sinceridad de los jóvenes. Surgían las dudas respecto a cuál debía ser la intervención -o no- del tallerista en los contenidos. Por ejemplo, como en la temática del motín, aparecía el relato de un hecho real y posible. ¿Podía interpretarse de alguna manera como una “apología”? ¿Podía esta experiencia de escritura lúdica "construir" un hecho a tal punto de proponer un hecho real? O ¿Podía la escritura tener "el poder" de construir la realidad? La decisión fue priorizar la expresión de los jóvenes, el relato de lo que viven, continuar conversando y problematizando, evitar en todo momento algún tipo de censura

20 de octubre/ DÉCIMO TALLER: "El final de la novela"

Ya en el décimo taller, se propuso pensar la escritura de "el final". El entusiasmo a esta altura era contagioso. Los chicos que faltaban un día al taller se interesaban por la continuidad de la historia, e incluso, las socio-educadoras nos comentaron que, en el otro sector del instituto, el sector $\mathrm{C}$, los jóvenes reclamaban tener su taller de escritura, que querían escribir su novela, que ellos querían y podían hacer "una mejor". En ese momento tratamos de organizar la realización de algún taller en el sector $\mathrm{C}$, pero no se pudo concretar.

Del registro de campo

Llegan los chicos, entran todos de golpe: Enzo, Alejandro, Bruno, Renato, Valentín y Joaquín, que no había venido la última vez, y quiere saber qué escribimos. Curiosean la novela así que abrimos "el libro" y leemos lo escrito, esta vez leemos solo lo del último día, el poema sobre el encierro, la charla de Yandel con Mustafá, y el motín. Explicamos brevemente que ya estamos llegando al último taller de la novela, que tenemos que ir 
cerrando el final, que hay muchas opciones, y que si a ellos les parece bien podemos escribir uno dos o más finales.

Luego de los diez talleres transcurridos, y habiendo participado en casi todos, por primera vez Joaquín acepta escribir:

Del registro de campo

Proponemos empezar a escribir, le ofrecemos el fibrón: Joaquín acepta y empieza a escribir él, por primera vez. La consigna inicial era "Después del motín Yandel estuvo..." Joaquín empieza a escribir el relato de los castigos sufridos después del motín. Es muy minucioso, de cerca lo acompañan Valentín y Bruno, van pensando cada palabra y corrigen cuando no les parece bien, unos a otros se corrigen sin problemas ni ofensas.

Fragmento de la novela:

Después del motín Yandel estuvo un tiempo en el aislado, estuvo una semana encerrado en una pieza sufriendo hambre, frío, sed y falta de higiene, pensando, cajeteando al borde de la locura, sintiendo el dolor de los golpes por la verdugueada de la yuta ortiva

Es el momento de las decisiones finales, tienen que decidir quién es la primera persona que visita a Yandel estando preso: "la primer visita":

Del registro de campo:

Hay que elegir, nos reunimos todos en ronda, leemos las posibilidades, les proponemos que elijan dos. Hay acuerdo general porque sea el padre quien lo visita (Juancho) (Alejandro había preguntado ¿qué onda Juancho? en general parece que a los chicos este personaje les simpatiza) El encuentro del padre y el hijo es muy amoroso. Algunos chicos, como Bruno, hacen comentarios escépticos, dicen que nunca podría ser real esa situación (recordemos que Bruno tiene si padre preso).

Queremos prestar atención al siguiente fragmento del registro de campo, allí se percibe claramente la dinámica de la escritura grupal y cómo los jóvenes a esta altura la han incorporado, escribiendo y tomando decisiones cada vez con menos intervención de las talleristas:

Del registro de campo:

Siguen escribiendo y avanzando en la historia, todos participan. Está escribiendo Joaquín, algunos chicos están dispersos, pero cuando hay que tomar decisiones, se 
reúnen un momento todos en ronda, leen las posibilidades, eligen. Luego se dispersan nuevamente, unos escriben, Ramón y Enzo mientras tanto ven videos y escuchan música en la computadora, pero asombrosamente ninguno de ellos deja de estar atento a lo que se está escribiendo, van participando con sus ideas, por momentos se acercan y escuchan las consignas para tomar decisiones sobre la novela, incluso, van rotando los "escribientes". Ahora deben decidir qué es lo primero que hace Yandel cuando sale de permiso: "ir a ver a su madre" dice Enzo. Todos acuerdan totalmente, expresan que no puede ser de otra manera. A esta altura Letizia y yo solo acompañamos desde un lugar auxiliar lo que ellos ya resuelven solos, alcanzamos fibrón, plasticola o cinta, damos alguna sugerencia, pero ellos son los que llevan la batuta en la escritura. En un momento están todos parados escribiendo en los afiches pegados en la pared, ya sin consignas, escriben solos, que Juancho muere en un asalto, que Yandel sufre muchísimo y piensa en matarse, pero piensa en su amor y su hijo... después se les ocurre la idea de que se reencuentra con Gaby, su maestra jardinera mencionada en los primeros capítulos, se ríen, proponen que Yandel y Gaby se enamoran, tienen un hijo y que ella lo acompaña y lo ayuda, y él siempre la amó. Finalizan la novela con un tema que Yandel compone para su hijo Juancho (el nombre de su padre): "Son las 12 de la noche/ y te estoy viendo/ te estoy mirando mi angelito/ y estas durmiendo/ Me asombra ver lo rápido que estas creciendo/ si parece que fue ayer cuando estabas naciendo/ me causa tanta ternura tu tranquilidad/ que me llena el alma esa expresión de paz..." Son varias las canciones incorporadas al relato y con este tema de Fuerte Apache adaptado por ellos deciden el final de la novela.

El recurso de las canciones o versiones adaptadas aparece a todo lo largo de la novela, se trata justamente de una de las experiencias de escritura cotidiana.

Cuando se les pregunta a los jóvenes sobre qué escriben en la cotidianeidad del encierro, algunos cuentan que cuando pueden acceder a cuadernos $u$ hojas escriben cartas o letras de canciones, o sino, lo hacen en la pared, como veremos en el próximo capítulo sobre la escritura cotidiana.

Del registro de campo:

Cuando terminamos la escritura damos un gran aplauso, felicitamos a los chicos, quedamos en que la próxima seguimos con la revisión final. Alejandro ayuda a pegar las hojas al libro, con sumo cuidado y prolijidad. Joaquín propone que cuando ellos estén en la calle nos sigamos viendo, les comentamos que nos imaginamos presentando el libro en la Feria del libro, están muy entusiasmados, se los ve contentos. Cuando nos vamos los guardias nos miran serios, como enojados y sin entender 
27 de octubre/ UNDÉCIMO TALLER: "Revisión de la novela"

Del registro de campo:

Cuando llegamos en el hall de entrada del Horizontes, lo vemos llegar a Enzo, esposado junto a otro chico, esposados entre ellos, están como atados. Enzo nos saluda con total naturalidad, enseguida viene un guardia y le saca las esposas. Enzo nos dice que se va a bañar y enseguida va al taller.

La escena de la llegada de Enzo con las esposas puestas nos reafirmaba, como para que no perdiéramos de vista, que estábamos en un lugar donde los jóvenes se ven violentados y vulnerados en sus derechos en forma cotidiana.

La novela grupal se encontraba en su tramo final, por eso la planificación del taller se planteó resolver el problema de la revisión. Se propuso entonces hacerlo en forma grupal, como había sido todo el proceso de escritura. La idea fue proyectar en una pantalla la novela transcripta en un documento de texto de Word, para leer y realizar las correcciones entre todos. Parecía importante que los jóvenes participaran de estas últimas decisiones y de esta manera tomaran contacto con una parte fundamental del proceso de escritura: la revisión.

El proceso de revisión de un texto es un trabajo minucioso, como Joaquim Dolz y Bernard Schneuwly lo explican:

"en la mayoría de casos que se trata de un proceso lento, laborioso, lleno de idas y venidas, a lo largo del cual el texto escrito es objeto de reescrituras constantes. Cada palabra, cada frase, cada párrafo es re-interrogado, sopesado e incluso reorganizado de forma más o menos decisiva. Según el propósito perseguido, el hilo conductor del texto puede ser revisado y la organización modificada. En función de una imagen más precisa del público destinatario, los recursos lingüísticos y las estrategias aplicadas pueden modificarse considerablemente. Es un poco como si en el texto ya escrito, el borrador, el primer intento, no fuera más que un punto de partida que permite ir más allá en la elaboración del pensamiento y en la precisión de la comunicación" (Dolz y Schneuwly, 2011, pág. 3)

Si bien se fueron realizando revisiones durante el proceso de escritura, fue necesaria una revisión final. Se tuvieron en cuenta diferentes aspectos, y se conversó sobre cada problema que se presentaba en el texto. Se fue realizando con cierta 
minuciosidad, pero a la vez hubo que ir resolviendo y tomando decisiones en forma rápida acomodándose a los tiempos del taller y del lugar. Se había podido lograr un proceso de escritura con un grupo estable de jóvenes, la realidad era que peligraba la estabilidad del grupo. Ya cerca del fin de año había posibilidades de que algunos de ellos salieran en libertad. De hecho, la mayor de las ilusiones de los jóvenes era irse pronto a su casa, sin duda esa era la prioridad número uno para ellos. Era necesario entonces que todo el grupo pudiera de alguna manera cerrar el proceso de escritura con un producto terminado.

La propuesta del taller literario no se planteó como enseñanza de la escritura, pero sin pretenderlo, la enseñanza y el aprendizaje formaron parte de cada experiencia, porque, tomando las palabras de Emilia Ferreiro, estos jóvenes -como los niños- no pueden evitar aprender, porque "aprender es su oficio" (Ferreiro, Emilia, 2001). Si hablamos de escritura, la oportunidad de aprender se presenta en el ejercicio de los quehaceres del escritor: la planificación, la textualización y en este caso, la revisión. Todo ocurre, además, y fundamentalmente, en el marco de la experiencia de una escritura grupal, y como sostienen Lerner y Kaufman (2015) "Escribir con otros obliga a debatir para tomar decisiones consensuadas acerca de los múltiples problemas que plantea la escritura y de este modo se constituyen en objeto de reflexión cuestiones que pueden permanecer implícitas cuando se escribe en soledad" (Lerner y Kaufman, 2015, Pág. 12)

Del registro de campo:

Llegamos más temprano a la sala de visitas. De los sectores se escuchan los gritos de los chicos: - ¡Letizia! ¡Letizia! - Después de un rato llegan Joaquín, Alejandro, Enzo, Braian y Valentín. Alejandro tiene un ojo morado, le preguntamos qué pasó, nos dice que se peleó con otro chico. Les proponemos, como habíamos planeado, empezar con la revisión de la novela, los chicos habían expresado e insistido en que, en el caso de publicarla, querían que estuviera "bien", que no fuera "al bardo" ... "cualquier cosa". Les contamos que la ortografía ya está en parte revisada y les proponemos que ellos den sugerencias, propongan cambios, o agregados, en cuanto al contenido de cada capítulo, cada párrafo y en general. Para revisar proyectamos el documento Word en la pared, la novela ya está transcripta. Me siento en un pequeño pupitre con mesa con la computadora, y voy tipeando y agregando las correcciones que los chicos proponen. Los chicos se entusiasman con este nuevo formato de la novela en el procesador de texto. Letizia dirige la actividad, va leyendo por párrafos en voz alta. Los jóvenes conocen la historia casi de memoria, dado que ya la leímos muchísimas veces, e incluso ya hicimos pequeñas correcciones en el manuscrito original en los grandes afiches. Vamos revisando el contenido, las palabras, el sentido de las frases. Los chicos señalan con 
mucha minuciosidad las correcciones, proponen recortar o completar las frases que no están tan claras, o cambiar frases por otras, por ejemplo: proponen sacar la palabra "papá", porque Yandel no le diría "papá" a Juancho, "no sería real", de manera que donde decía "Bueno, te escucho, papá" queda solo "Bueno, te escucho". Se les ocurre, por ejemplo, agregar a Mustafá -el compañero de su primer robo- como su compañerito de jardín, y agregar a Mordelón -su compañerito del jardín- en el atraco final, en el que muere. Mientras van leyendo el diálogo, lo van representando, actuando, y van agregando detalles de la conversación. Se preocupan también porque las letras de las canciones sean las correctas. Es un trabajo de mucha concentración, también revisamos puntuación. Finalmente quedan conformes y todos aplaudimos. Se pasa rápido la hora esta vez. Al final les pedimos sugerencias para el título, pero como se acabó el tiempo decidimos hacer un taller más para ese tema la próxima semana

3 de noviembre/ DECIMOSEGUNDO TALLER: "El título"

En los dos últimos talleres se trabajó sobre el título de la novela y se realizó la producción de fotos para la tapa y diferentes capítulos.

En cuanto al trabajo con el título, se partió de los libros de la biblioteca. Primero se leyeron y analizaron títulos de libros de la biblioteca, se observaron los distintos tipos de título y se conversó sobre el significado y la elección de un título en una obra literaria. Luego, se propuso empezar "a jugar": Se les presentó una cantidad de frases extraídas de la novela y recortadas en palabras sueltas para que ellos vayan pensando combinaciones posibles, pegándolas en tarjetas. Les explicamos entonces que de ahí podía llegar a salir el título de la novela.

Del registro de campo

Los chicos andaban dispersos por la sala, hasta que se acercaron a la tarima donde estaban apoyadas todas las palabras, les explicamos que las palabras son todas sacadas de la novela, que son SUS palabras. De a poco se fueron sumando y fueron armando frases, llegó un momento en el que estaban todos amontonados frente a las palabras, iban agarrando algunas, se iban sentando e iban armando las frases:

Ratas y pistolas / Pasos a vicios / Sin destino / Guachines estrellados/ Guachos retobados/ Loquitos pegadasos/ Chabones encerrados/ Presos tirados/ Altos hermanos/ Verdugueada del encierro/ Mundo de corazones quebrados por la soledad/ Pibes que sufren condenas/Vidas de pistoleros/ Fue historia 
Del registro de campo

Hacemos una puesta en común, se van mostrando entre ellos lo que hicieron. Luego vemos la exposición y leemos los títulos posibles, tratamos de combinarlos entre sí. Uno de los chicos dice: "la vida de los pibes pistoleros", Renato agrega: la "otra" vida. Remarca: "La OTRA vida de los pibes pistoleros". Les gusta. Nos gusta a todos, votamos por ese título. Luego de compartir unas bebidas con galletitas, damos por finalizado el taller

Al proponer Renato "LA OTRA vida de los pibes pistoleros" estaba haciendo referencia explícita y clara a la idea de alteridad, probablemente sin conocerla teóricamente: "La otra vida", y no la que todo el mundo supuestamente conoce. Por un lado: un otro, que serían ellos mismos a partir del estigma y la criminalización social, y del otro lado el otro que son y no se conoce, el que no aparece en las noticias sensacionalistas y medios de comunicación masivos. Ellos conocen muy bien esa imagen, ese estigma social.

En referencia a esa OTRA parte que no se conoce sobre ellos, transcribiremos aquí un texto escrito por los jóvenes: una carta abierta a la sociedad. En oportunidad del Encuentro interprovincial de proyectos de comunicación en contexto de encierro77, realizado en el mes de mayo del año 2015, la escuela recibió un contingente del Instituto Almafuerte de Buenos Aires. Alumnos y profesores locales y visitantes, en una propuesta de taller de comunicación social, trabajaron sobre vivencias y percepciones juveniles, sobre cómo los ve, los etiqueta y nombra la sociedad, en particular la imagen que se difunde a través de los medios de comunicación masivos y alternativos. A partir de lo trabajado en ese encuentro se elaboró una carta abierta que luego fue leída en la Audiencia Pública de la Defensoría del Público de Servicios de Comunicación Audiovisual, en Paraná/junio 2015 y publicada en la revista Tumbando Rejas/8. Copiamos:

Buenas tardes, somos jóvenes alumnos del Centro Educativo Complejo Esperanza de Córdoba, nos encontramos privados de nuestra libertad por estar en conflicto con la ley. Nosotros pensamos que los medios de comunicación en general discriminan a los jóvenes que cometemos delitos, sólo se habla de nosotros en las noticias y todas las noticias que hablan de nosotros son malas.

Nos muestran como delincuentes, ladrones, ratas, malandras, maleducados, drogadictos y vagos, atorrantes, peligrosos, negros de villa, brasas. Nos etiquetan como malvivientes

\footnotetext{
77 Proyectos de comunicación: Revistas: Tumbando Rejas (Complejo Esperanza/ Córdoba) y Seguir Soñando (Instituto Almafuerte/ Buenos Aires)
} 
y peligrosos, nos discriminan por nuestra forma de ser, de vestir, por nuestra cultura, nuestro color de piel, nuestros barrios y villas.

No nos conocen.

Cuando hablan de nosotros sólo dan a conocer los delitos, nunca se habla de las causas que nos llevan a eso, de las necesidades que tenemos, la falta de asistencia real.

No nos conocen ni les interesa conocernos.

La mayoría de los medios de comunicación nos muestran como malas personas, ya estamos marcados, por más que intentemos rescatarnos, ya estamos marcados.

Pensamos que los medios lo hacen por razones económicas, porque es un negocio. Vende más la mala noticia, y nosotros siempre somos mala noticia.

Sobre el Complejo Esperanza, la mayoría de las veces se conocen las cosas malas que ocurren, como motines, fugas, muertes, tomas por reclamos gremiales de los guardias, pero pocas veces muestran las cosas buenas que pasan acá, que vamos a la escuela, que hacemos una revista, que aprendemos oficios, deportes, que nos esforzamos por aprender.

Tampoco se habla de que nosotros sabemos ser solidarios, compartimos, somos compañeros, que cuidamos a nuestros hermanitos.

No nos preguntan qué sentimos ni qué pensamos. Dicen que no tenemos futuro porque somos marginados, pero nosotros sí pensamos en tener un futuro mejor, en progresar en la vida.

No nos conocen.

Somos estudiantes, trabajadores, hijos, padres, hermanos, tíos, deportistas, artistas, ni totalmente buenos ni totalmente malos. Somos personas y tenemos códigos. Somos pibes normales.

Cuando matan a un chico, cometiendo un delito o no, los medios justifican su muerte diciendo que tenía antecedentes penales. Les cabe por choros, dicen. Nunca nos muestran como víctimas de la violencia de otros. No muestran el dolor de las familias de esos chicos.

Nosotros pensamos que ninguna cosa material vale más que la vida de una persona. La sociedad y los medios hablan de nosotros como violentos, pero la violencia también se genera por la aprobación y el silencio ante estas muertes.

Queremos cerrar esta presentación con un rap que creamos entre todos en un taller de nuestra revista:

"Viviendo en esta moraleja.

Fuimos tumbando las rejas

venciendo la poderosa mordaza

y desatando el nudo que está en nuestra garganta

Seguimos improvisando 


$$
\begin{gathered}
\text { todo piola } \\
\text { soñando en seguir } \\
\text { para poder sobrevivir } \\
\text { fuimos volteando rotas cadenas } \\
\text { para salir de esta mierda" } \\
\text { Si callamos, seremos olvidados. }
\end{gathered}
$$

"No nos conocen", dicen y repiten los jóvenes. Para la novela grupal Renato propuso un título en coincidencia con esa idea, ya que nace de la necesidad de mostrar su otra parte, su parte desconocida. Un título que habla de la alteridad y el desconocimiento del otro diferente: lo mismo que dicen los jóvenes en el taller de comunicación que produjo la carta abierta. Tomamos palabras de Carlos Skliar, quien acerca alteridad a esta idea de desconocimiento de la que venimos hablando: "Alteridad significa extrañamiento, perturbación, alteración. Y desconocimiento. Pero no el desconocimiento que está a punto de saberse, de entumecerse, de sumergirse, de ahogarse. El desconocimiento es el estado permanente del desconocido. No es un límite, es una interioridad" (Skliar, 2015, pág. 158)

\section{0 de noviembre DECIMOTERCER TALLER "Producción de fotos"}

El siguiente y último taller fue de producción de fotos para la novela. Se había pensado en la posibilidad de acompañar la historia con dibujos o fotos y los jóvenes eligieron la producción de fotos. Se llevaron "disfraces" para representar los personajes, lentes y pañuelos, en especial, porque por su condición de "menores" no se puede exponer su rostro en una publicación. Se realizó una nueva lectura completa, y se propuso una foto para cada capítulo. Los jóvenes, una vez más jugaron como niños, y en función a cada capítulo armaron escenas donde representaban a los personajes y situaciones.

5.2.3. Lo que los chicos dicen sobre la experiencia de escritura en los talleres

En las entrevistas personales se conversó con los jóvenes sobre la experiencia del taller de escritura. En nuestra necesidad de conocer, indagamos sobre el significado de estas experiencias para ellos. Como acabamos de describir, la biblioteca realizó 
diferentes propuestas de talleres literarios de acuerdo a las posibilidades materiales, institucionales, e infinidad de otros factores. Para presentar la palabra de los jóvenes, lo haremos también en orden cronológico: primero las apreciaciones del año 2014 y luego las del 2015. No es una decisión arbitraria o meramente organizativa, sino que como venimos viendo, las propuestas del taller literario en los respectivos años tuvieron grandes diferencias.

\section{Año 2014:}

Entrevista a Daniel:

Me gustó y espero salir devuelta, espero que me saquen devuelta. Me gusta, acá estar con los libros... Tranquilo, nada que ver con estar en otro lugar donde te sentís medio incómodo...

Entrevista a Facundo:

Yo vengo por...son dos o tres razones: porque me gusta, paso el tiempo, para no estar encerrado ahí adentro, y aparte como que me despabila, así, me puedo desahogar, puedo hablar con ustedes, y aparte a mí, como me gusta hacer cartas, y esas cosas y en taller hacemos muchas cartas, por todo eso, todo eso, me gusta escribir y todas esas cosas

Para Daniel la experiencia del taller va claramente articulada a la idea de salir o de que lo saquen, pero también, a la importancia de poder sentirse cómodo -o dejar de sentirse incómodo- en un ambiente tranquilo y rodeado de libros. Salir del encierro es el primer argumento de los jóvenes, aparece en forma constante, y es comprensible por propia fuerza. Daniel le da importancia a sentirse cómodo en un lugar rodeado de libros. Facundo agrega otras razones: desahogarse, despejarse, despabilarse, hablar, y ya directamente relacionado a la escritura: escribir cartas, para él, una práctica cotidiana.

Los jóvenes entrevistados durante el año 2014, en general destacaron que la experiencia de la escritura en los talleres literarios los ayudó - además de lo fundamental: salir del encierro- a hablar con los compañeros de "otros temas", poder tomar aire, despejarse. Valoraron el hecho de despejar la mente, desahogarse, "despabilarse".

Despabilarse, para el Diccionario de la R.A.E es salir de un estado de modorra y de letargo $^{78}$. Buscamos los orígenes ${ }^{79}$ de este término, y encontramos que deriva de espabilar "quitar la parte carbonizada de la mecha de una vela o una lámpara, con lo que la llama se aviva, y usado en sentido figurado, adquiere pues el sentido de avivar o azuzar

\footnotetext{
78 D.R.A.E.

${ }^{79}$ Diccionario Etimológico de Chile http://etimologias.dechile.net/?espabilar
} 
a alguien para que salga del sueño, para que se apresure o para que agudice el entendimiento". Resulta curioso analizar los términos usados por los jóvenes, que lejos de la idea de "déficit" lingüístico, poseen un amplio bagaje que incluye lengua estándar, los términos regionales, la jerga de los jóvenes y los códigos "tumberos". Como podemos apreciar en la novela grupal, además, en su forma de expresarse aparece con frecuencia el lenguaje figurado y la metáfora. Despabilarse, una expresión que junto a la sensación de "despejar la mente", al "salir del encierro", resulta una salida que da vida, que re-aviva. Creemos que esta sensación tiene que ver con el poder de la palabra creativa y expresiva

Desahogarse, en este contexto adquiere una densidad y un peso especial, porque el encierro ahoga y oprime. Estar privados de la libertad, aislados de sus afectos, vulnerados en sus libertades elementales, genera en los jóvenes una sensación de asfixia, les "falta de aire". Este ahogo muchas veces termina en depresión o autoagresiones. El taller se constituye, en palabras de los jóvenes, en un espacio en el que se puede respirar y sacar lo que tienen adentro.

Michèle Petit (2003), sobre este espacio respirable que para los jóvenes es el taller literario, agrega a sus palabras: "es un espacio para tomar un nuevo aire, para reconstruirse, para rehacerse. Allí se perfila otra representación de sí mismo" (Petit, 2003, pág. 8,). Petit resalta que las actividades creativas con el lenguaje (y una cantidad de actividades culturales) permiten sobrellevar la angustia de la separación:

“... integrar - un poco- la ausencia, la falta, la pérdida, el exilio - de la misma manera en que la historia que se lee al niño antes de que se duerma le permite atravesar la noche, soportar la separación de sus padres. Dicho de manera más general, la cultura nos protege un poco de la angustia de la separación, de la muerte, nos distancia de nuestros sufrimientos. Hace que el mundo sea más habitable. (Petit, 2003, pág. 23).

Los jóvenes valoraron estar rodeados de libros, el taller literario aparece como actividad cultural:

Del texto autobiográfico de Facundo:

"conocimos poemas de afuera, palabras que nunca antes habíamos escuchado"

La oportunidad de participar en el taller lo puso en contacto con otras palabras, conoció palabras nuevas; Facundo dice que eran palabras "de afuera", no las de adentro 
del encierro, las que se van aprendiendo a lo largo de la carrera de pibes presos, o de pibes chorros. Palabras nuevas, una experiencia cultural distinta a la experiencia cultural de todos los días - de adentro o afuera- lo que tiene que ver con una posibilidad concreta que habilita el derecho de acceso a otros bienes culturales.

Le preguntamos a Facundo sobre la experiencia particular de la escritura de poesías con versos prestados:

Entrevista a Facundo:

"Recortar las palabras de una poesía y armar la propia poesía... jamás lo hice....Me gustó hacerlo porque...que se yo...lo hice... y al principio parecía que no formaban nada las palabras y después cuando los leímos, quedó como una poesía de verdad, que NOSOTROS hicimos la poesía, que la armamos NOSOTROS"

Lo que Facundo resalta es que lo que empezó como un juego o una construcción caótica, terminó siendo una poesía, resultó un producto cultural digno: "quedó como una poesía de verdad", una construcción propia, resaltó el "nosotros" en "nosotros hicimos la poesía”. Petit (2009) cita a Marie-Claude Penloup, quien desde su experiencia en talleres de escritura afirma que "bajo el cobijo de las palabras de otro, la sintaxis de otro, incluso el formato de otro, el sujeto que escribe se construye, imitándolo, con una dedicación a otra persona más autorizada que la de él, copiándoles su virtuosismo, pero también si legitimidad" (pág. 227). Bajo el cobijo de los versos de los poetas, cuyas poesías habían leído o escuchado atentamente, surgieron palabras nuevas, poemas nuevos, poemas "de verdad", nuevas construcciones legitimadas, pero, sobre todo, propias y originales.

Le preguntamos luego si alguna vez se había aburrido en los talleres literarios Entrevista a Facundo:

No me aburrí nunca en los talleres, lo que me gustaba era así, porque hablábamos, todo eso...nos contábamos cosas entre todos, así, por ahí teníamos un tiempo libre, un tiempo nuestro, podíamos hacer lo que a nosotros nos gustara, nosotros queríamos escribir cartas, a mi mamá, a mi novia, y aprovechábamos...

Facundo deja ver que los talleres no son solo "la escritura" ¿o son la escritura y mucho más? ¿O es la escritura tal vez todo eso? La escritura en el taller incluye siempre y necesariamente hablar, contar cosas, conversar. $Y$ aparece en escena otro tema: la posibilidad de vivir el tiempo de otra forma "un tiempo libre, un tiempo nuestro". En la vida 
del encierro: "un tiempo libre", siendo la libertad un valor primordial (el más importante y anhelado), "un tiempo nuestro", habiendo perdido toda posibilidad de propiedad y privacidad. Surge la dimensión tiempo, el doloroso tiempo que en el encierro, no pasa: "cuatro paredes oscuras,/ un reloj que nunca avanza,/ una cortina de hojas,/ aquí la vida no pasa,/ el tiempo detenido/ del amor y la nostalgia..."

En palabras de Petit, el acercamiento de los jóvenes a la lectura habilita otro tiempo, "otra manera de habitar el tiempo" (Petit, 2003, pág. 9). Los talleres facilitaron la posibilidad de habitar el tiempo de otra forma, tal vez como un avance en el ritmo del reloj del joven privado de la libertad o al menos un movimiento en ese tiempo detenido del encierro.

Conocer palabras nuevas, habitar otros ambientes, hablar de otros temas, vivir otro tiempo, son expresiones con las que los jóvenes describen su interés por los talleres de escritura, o en palabras de César González: "ahora quiero escribir / letras que te muestren otros ambientes/ no simplemente el que inventaron no sé dónde"81

\section{Año 2015:}

Entrevista a Joaquín:

E: ¿Qué experiencia de la escuela de este año fue importante para vos?

J: La novela que escribimos... el taller de la biblioteca... estuvo piola, aprendí a trabajar en grupo, a compartir con otras personas... Nunca me imaginé que iba a escribir "de flash", encima fue así. Porque si uno se enfoca, así, se pueden escribir un montón de cosas, y se pueden hacer un montón de cosas con la imaginación. Y eso que fue como decir... por decir... hacer bardo, podríamos haberla hecho más piola todavía, hasta una película pueden hacer los guachines ahora, ya que están al pedo, encerrados

La escritura de la novela grupal fue para algunos jóvenes lo más relevante de su experiencia en la escuela. Joaquín lo calificó como "lo más importante" de su experiencia escolar, a pesar de ser trabajada dentro el Instituto, en un ambiente y formato no tradicionalmente escolar, él la asoció con la escuela. Destacó la importancia de compartir con los otros, trabajar en grupo. Valoró la posibilidad de enfocarse para lograr un objetivo, y mencionó a posibles destinatarios, lectores de la novela: los guachines, los jóvenes más

\footnotetext{
80 Poema "Mi mundo" de Víctor Hugo L. publicado en la revista Tumbando Rejas 8

81 Fragmento de "Interrogantes" de César González
} 
pequeños privados de la libertad, los "niños presos" en el Complejo Esperanza. Él piensa que puede ser bueno para ellos leer la novela, conocer la experiencia que él vivió con su grupo de compañeros. Además, como los jóvenes en el 2014, expresó que los talleres le sirvieron para despejar la mente, y además ponerse en contacto con esas cosas que le gustan:

Entrevista a Joaquín:

Uno acá adentro vive desahuciado, está mucho tiempo, tiene muchos problemas en la cabeza que no puede solucionar porque está preso, por ahí de vez en cuando, reírse un rato, despejar un poco la mente... está piola... porque además aprendés cosas, como que por ahí te inspiras más... por ahí cuando estas así, ves un par de cosas... leyendo, escribiendo. Aparte te ponés en contacto con eso que a vos te gusta... a veces estás de mal humor y no se te da, pero sí, te gusta... a mí me gusta leer, escribir cosas, también las cosas que trae Letizia: las gaseosas, galletitas, las películas, el pururú"

Jerónimo, por su parte, nos dijo que para él fue importante hacer algo distinto, que le sirvió para hablar de otros temas y como Daniel, para ponerse en contacto con los libros. La entrevista fue realizada apenas comenzó a participar, su experiencia coincide con algunas expresiones de los jóvenes del año anterior:

Entrevista a Jerónimo

Los vinieron a buscar a los otros chicos... “¿qué taller? "... "de literatura" me dicen, tiene que ver con lengua?... quiero ir, díganle que me saquen, y se ve que dijeron, porque me sacaron los maestros ... y estuvo piola, fue algo distinto... porque estábamos hablando de cosas diferentes, sentí que estábamos hablando de otros temas... ¡Y los libros! ¡ Eso! Me daban ganas de pedir un par de libros, pero no me gusta pedir.

Enzo, que hizo una experiencia personal en su alfabetización inicial como ya relatamos, admitió que los días martes esperaba los talleres para salir del "enyugue": estar encerrado en su pieza/celda. La salida a la sala de visitas no los sacaba materialmente del encierro, como expresaban los jóvenes que participaron en los talleres de la biblioteca, en la escuela -el afuera del adentro- en el año 2014, pero les permitió por lo menos- salir del encierro máximo de la pieza, encontrarse con sus compañeros:

Entrevista a Enzo

Siempre las espero....sabe ser martes...las dos de la tarde y pienso "ahí vienen en camino" ... ya son las tres de la tarde...ayer eran las tres y media y no venían...nos estaban desenyugando... ¿está el taller? si ...jmientras más temprano mejor! porque nos sacan de la 
pieza... ¿Ves? nosotros a la una de la tarde ya estamos enyugados... hasta las cuatro de la tarde...si ustedes vienen a las dos nos sacan...y estamos desenyugados todo el día...

Cuando seguimos a indagando a lo largo de los meses, acerca de la decisión de participar en los talleres del año 2015, ya no aparecía en primer plano la idea de salir del encierro: es que estos talleres fueron desarrollados dentro del encierro, en la sala de visitas del instituto de máxima seguridad. La salida del enyugue a la que se refiere Enzo, es la salida del encierro solitario en una pieza, a la sala de visitas, con sus compañeros, pero dentro del encierro del instituto.

Joaquín expresaba que el taller lo puso en contacto con eso que a él le gusta. Una característica del proceso de escritura del año 2105, fue la presencia del componente lúdico: desde la experiencia directa con los juguetes y juegos de la infancia, hasta el juego y la risa presentes en la elección de una palabra $u$ otra, una frase $u$ otra en la escritura grupal.

Es que como dice Petit, estas experiencias culturales son juego: una extensión de los primeros juegos, son recreación de la vida creadora, de la emancipación: "durante toda la vida, pueden ser vías privilegiadas para hacernos recuperar, tanto ese espacio apacible como la experiencia del niño que, a partir de ese espacio tranquilo, protector, estético, entre su madre y él, se rehace y se vuelve autónomo" (Petit, 2003, pág. 8,).

Renato por su parte reconoce que la cuestión de la novela era un tema de charla entre ellos en "el sector", en su cotidianeidad en el encierro: "por ahí adentro del sector nos ponemos a hablar de la novela", y reconoce que la historia que construyeron tiene que ver con su vida:

\section{Entrevista a Renato:}

Lo que escribíamos por ahí... era lo mismo que a mí me estaba pasando.

Petit manifiesta sobre la lectura -y lo tomamos también para la experiencia de la escritura- que "incluso a los más golpeados, una narración, una metáfora poética, pueden ofrecer un eco de su propia situación, bajo una forma transpuesta. Un eco de lo que pasa en uno mismo, en las regiones de uno que no pueden ser nombrada”. (Petit, 2003, Pág. 4).

Entrevista a Renato:

Puedo pensar con la palabra de otro chico... y la puedo escribir 
Pensar con la palabra de otro chico... y poder escribirlo. En las palabras de Renato entra en escena y con fuerza lo particular de la experiencia de lo grupal, lo colectivo: la parte de lo colectivo que no está en el trabajo individual. Creemos que la escritura grupal de la novela pudo haber significado para los jóvenes, en principio, una forma de eco, de nombrar lo que les está pasando, a uno y a la vez todos, lo que no siempre puede ser nombrado. Pero creemos que, además, y en particular, en esta posibilidad de la escritura grupal, lo que se posibilitó fue pensar en plural, pensar con las palabras de los otros. Esto significó que ese eco fuera elaborado entre todos, que en esos ecos de historias compartidas se entretejieran nuevas historias, y que el poder escribirlas diera materialidad a esa red de historias y pensamientos.

Cuando Aidan Chambers, en Dime (2007) explica el significado de hablar juntos, manifiesta que, en la conversación, las ideas que surgen "exceden ampliamente lo que cada uno de los miembros del grupo podría haber logrado solo. Cada uno sabe una parte, pero ninguno sabe todo" (Chambers, 2007, pág. 34). Explica que una comunidad cooperativa de lectores descubre cosas sobre el texto que no se lograrían de otra manera. Nosotros, a partir de la experiencia de la escritura de la novela y de las palabras de los jóvenes que participaron, pensamos en una comunidad de escritura, en una escritura conversada, en la que se pueden descubrir nuevas cosas. Creemos que, a través de la escritura compartida, se puede llegar a otra cosa: una experiencia y una escritura diferente de lo que cada uno viviría o haría individualmente, de la misma forma que Chambers describe las particularidades de la comunidad de lectura y la conversación literaria.

Creemos necesario acompañar todo lo dicho por los jóvenes en las entrevistas -en referencia a las posibilidades de la experiencia del taller literario- con lo que hemos observado en conversaciones cotidianas en los talleres. Allí queda más claro que no es fácil para ellos reconocer que, en este momento particular de sus vidas, y en este lugar en el que se encuentran encerrados -privados de la libertad- pueda haber alguna experiencia que pueda remotamente llegar a ser positiva o constructiva. No se resignan a aceptar que en el encierro - "esta bosta"- pueda haber algo que mínimamente pueda ser bueno para su vida presente o futura. En ese marco, el taller literario -por bueno que sea- sucede dentro de la privación de la libertad. Ellos reconocen que el taller es un alivio momentáneo, reconocen -y en eso todos coinciden- que se habilita un espacio personal, 
una posibilidad de respirar, de despejar la mente: una experiencia de supervivencia que hace un poco más respirable el encierro.

Presentamos, como ejemplo, cierto conflicto que surgió cuando se trabajó con las entrevistas a César González, que acompañaron la lectura de los poemas. Los jóvenes son lectores y seguidores de la obra de César González, sus libros de poemas son bienes muy apreciados y circulan en las piezas de los sectores, en ocasiones fotocopiados, en otras arrebatados, además muchos vieron sus películas. Por tanto, se muestran siempre muy interesados por conocer su vida: es un referente para ellos. Incluso, en diciembre del año 2015, César los visitó personalmente en la escuela del Complejo Esperanza, en una charla organizada por la Biblioteca Abierta, en la que los jóvenes conversaron a solas con él y le mostraron la novela.

En este marco, en uno de los talleres iniciales se leyó una entrevista que le realizó un medio gráfico. Allí el poeta cuenta cómo fue su acercamiento a la literatura, y cómo fue que -estando encerrado- tuvo contacto con los primeros libros y escrituras, gracias a un profesor de un taller de magia: "Al principio no le di mucha importancia, 'este loco de mierda, qué me importa lo que dice, si total a mí me quedan un montón de años'. Pero venía en serio, con pureza, para ayudar." Sobre el libro De Ernesto al Che, de Calica Ferrer, agrega: "Ese libro me sirvió para darme cuenta de que uno puede hacer un click en la vida, como lo hizo el Che. Y comenzaron las preguntas, aparecieron los porqué: por qué nací en una villa, por qué tuve que ser pobre, por qué tuve que nacer en un contexto de mierda, por qué tuve que saber a los 7, 8 años que existe la cocaína, el porro y que vivo en un barrio donde eso es frecuente y la cultura es ésa." ${ }^{22}$

Al leer la entrevista y el relato sobre su acercamiento a la literatura -y el alejamiento de la delincuencia- algunos jóvenes que asistían al taller parecían entrar en un conflicto: "se rescató" ... "le hicieron mal las rejas", murmuraban tristemente. El problema los interpelaba y parecía centrarse en dos cuestiones: una, que César dejara la vida de delincuente y otra, que es la que más nos interesa: la posibilidad de sacar "algo bueno" del encierro. Estos planteos habilitaron charlas que problematizaban los estereotipos carcelarios impuestos, los códigos y los prejuicios dentro del encierro. Son las formas en las que la poesía y los poetas pueden interpelar el sentido común de la vida cotidiana de los jóvenes.

Tanto en sus poemas como en las entrevistas, Cesar González plantea las posibilidades de la poesía -y el arte en general- como arma, como una forma de enfrentar

82 https://www.pagina12.com.ar/diario/suplementos/espectaculos/4-19641-2004-01-02.html 
al sistema. Pero la poesía no siempre llega sola, en la entrevista destaca la importante presencia de un mediador, que "con pureza" le acercó un libro. En el mismo sentido que Michèle Petit insiste en la importancia de los mediadores, de los lazos y la confianza, de cuando el acercamiento -en palabras de César- "viene en serio", y sobre el impacto de "esos momentos de encuentro, de esa posibilidad de ser escuchado, a veces a media voz" (Petit, 2013, pág. 17).

Creemos que la experiencia del taller pudo ayudarlos a crear un espacio propio, personal y grupal, de confianza, de conversación y escritura, "allí donde ningún margen de maniobra, ningún territorio personal parece ser permitido. (Petit, 2003, pág. 7). En la novela grupal, ese espacio fue nombrado en plural, como un espacio construido por todos. 


\subsection{Conclusión provisoria: "Un tiempo libre, un tiempo nuestro"}

"escribir ¿y no hacer literatura?

iy qué más da!

hay demasiado dolor

en el pozo de este cuerpo

para que me resulte importante

una cuestión de este tipo.

Escribo

para que el agua envenenada

pueda beberse."

Chantall Maillard (Fragmento de Escribir)

En este capítulo se describió la experiencia de la escritura en los talleres literarios que se propusieron durante los años 2014 y 2015. Nuestro rol como investigadores, a lo largo de todo el proceso, fue ser parte del equipo que llevó a cabo los talleres, lo que permitió realizar los registros, acceder a las escrituras, acordar las entrevistas a los jóvenes, y lograr luego el permiso para entrar a diferentes sectores donde viven, para posteriormente registrar las escrituras en las paredes, tema que desarrollaremos en los próximos capítulos.

Durante el año 2014, las actividades se concentraron en el espacio de la Biblioteca Abierta de la escuela en contexto de encierro. En el año 2015 los talleres se "trasladaron" a la sala de visitas del Instituto Horizontes, de máxima seguridad. En los talleres iniciales la mayoría dentro de la biblioteca de la escuela- aparecieron las dificultades cotidianas de una escuela en el encierro, específicamente las que tienen que ver con la institución punitiva y con la problemática penal juvenil, entre ellas: la estadía incierta de jóvenes privados de la libertad, las salidas a tribunales, cuestiones de salud, conflictos entre pares, vínculo difícil con los guardias o castigos.

Esta realidad dificultó pensar en procesos a largo plazo, por lo que se planificaron para ese año ciclos de tres talleres unitarios por grupo de jóvenes. Si bien cada taller tuvo su singularidad, y sus particularidades, todos tuvieron aspectos en común. Tomando las palabras de los jóvenes, podemos decir que la experiencia de estos talleres los ayudó a 
contar lo que les pasa y a hacer respirable el encierro: "despejar la mente", conocer "otros ambientes", integrar otro tiempo "un tiempo libre, un tiempo nuestro", hablar de "otros temas" y encontrar otras palabras, "palabras nuevas" "palabras de afuera". La coincidencia general fue que -a través del taller- podían salir del ahogo del encierro, tomar aire: despejarse, desahogarse. En palabras de Petit: reconstruirse, rehacerse, integrar la ausencia, la falta, la pérdida, romper el silencio, incorporar otros sonidos en los sonidos del encierro, ingresar a otros lugares, sobrevivir al aislamiento, la soledad, y la opresión. O, en palabras de César González, poder "camuflar este martirio". Creemos que esta experiencia habilitó derechos vulnerados y posibilitó el acercamiento a los bienes culturales negados: el acceso a los libros, a la lectura, y a la escritura de literatura, "el derecho al extrañamiento, al desvío, a la metáfora, a la ampliación de su universo cultural" (Petit, 2003, pág. 19).

El taller de escritura que observamos -y en el que participamos- adquirió un valor especial en el contexto en el que hizo la propuesta la Biblioteca Abierta: un espacio de encierro. Ese "saltar del otro lado" (Petit, 2003, pág. 6) que ofrece la literatura se resignificó aquí: porque saltar afuera puede representar aquí nada menos que saltar las rejas, los altos muros, saltar hacia la libertad, fugarse a otros lugares. El taller se presentó como una oportunidad para fugarse simbólicamente a otros mundos posibles, y también desde una mirada más amplia, sobrepasar el muro de la identidad "asignada" en el tablero social y asumida desde la autopercepción: el estereotipo impuesto por el encierro y por el estigma.

En el año 2015, a partir del mes de agosto, los talleres tuvieron otras características y otras problemáticas. Se ganó un espacio dentro de uno de los institutos: la sala de visitas del Instituto Horizontes, y un horario fijo: los martes por la tarde. Luego de los permisos y las negociaciones necesarias realizadas por el coordinador de la escuela, y a partir de la entrada en escena de las socio-educadoras ${ }^{83}$ y su colaboración en la mediación, se realizaron los talleres semanalmente, con un grupo de jóvenes estable, y con un proyecto de escritura concreto: la novela grupal.

Nos detendremos en especial en esta experiencia de la escritura grupal.

Los talleres literarios, -como dijimos- ayudan a integrar la ausencia, sobrevivir y hacer respirable la opresión del encierro, en este caso, dentro del mismo encierro, ya que 
la sala de visitas se encuentra dentro del instituto al lado de las piezas donde los jóvenes viven privados de la libertad. La apuesta del año 2015 fue la construcción de un proyecto de escritura grupal; se visualizó la posibilidad de formar un grupo estable de jóvenes que tuviera un proyecto de escritura propio y situado. Para las talleristas el desafío fue, a partir de las condiciones inhóspitas del lugar, la necesidad de invención y reinvención constante de estrategias que pudieran adaptarse a la realidad material, de recursos, y a las posibilidades de escritura de los jóvenes: algunos escribían, otros no. La propuesta del taller fue generar un proyecto que finalmente llegara a concretar un producto escrito digno, de posible circulación social. Posteriormente se desarrollaron los trece talleres que acabamos de describir. En ellos se compartieron los pequeños avances y logros y se sortearon las dificultades juntos, en un dispositivo formado por las talleristas, los socioeducadores, la coordinación de la escuela y los jóvenes.

Prólogo de la novela "La otra vida de los pibes pistoleros", escrito por las talleristas (fragmento):

Con sólo algunos libros, un fibrón y un afiche se creó esta novela. Porque la hicieron un grupo de jóvenes que, pese a lo inhumano del encierro y las inapropiadas condiciones, pusieron pasión, humor, creatividad y sus propias historias sobre esos papeles.

Esta novela se escribió sobre un muro, el mismo que separa el encierro de la libertad, el adentro del afuera. Sobre un muro que encierra los cuerpos, palabras que liberan los sueños. Porque siempre y pese a todo...hay quienes abren una ventana en medio del paredón ${ }^{84}$

Nos atrevemos a reformular a Jorge Larrosa (2006), sobre la narrativa en los talleres: escribimos para nosotros y para los demás y sobre todo escribimos de, y desde nosotros, para contar lo que nos pasa, lo que sufrimos en el encierro, para ser leídos-escuchados. Petit (2009) sobre la escritura en los talleres literarios, afirma que a veces se escribe "bajo el cobijo de las palabras de otro", esto sucedió y fue necesario porque a veces las palabras de otros son "un eco de lo que pasa en uno mismo, en las regiones de uno que no pueden ser nombradas".

${ }^{84}$ Prólogo de la novela La otra vida de los pibes pistoleros, 2016 
Los jóvenes reconocieron que la historia que construyeron tiene que ver con su vida: "lo que escribiamos, por ahí era lo mismo que a mí me estaba pasando". A la vez la propia historia fue enredada con la vida de los otros. Se empezó por la confección de línea de tiempo grupal, se sumaron las poesías, las historias del rap, pasando por la narrativa y la articulación, por ejemplo, con el cuento Aladino, de Las mil y una noches, en un ida y vuelta permanente con la propia biografía, hasta llegar a construir un personaje y una vida, la vida de Yandel, el protagonista de la novela, quien poco a poco fue teniendo vida propia como un miembro más del grupo.

La novela fue un eco de la propia vida: mi vida, pero también fue algo más. Fue más bien el eco de un nosotros: nuestras vidas. Ese nosotros fue el eje de la escritura grupal. Escribir con otros, necesariamente los obligó a tomar decisiones, generar acuerdos no solo acerca de los problemas que plantea la escritura, sino especialmente decisiones sobre la historia, sobre qué es lo que querian contar sobre sí mismos. La línea de tiempo expresaba materialmente que eran un nosotros que en la novela se expresaba en uno: Yandel. Lo que quedó claro en este proceso, es que hubo una experiencia de escritura diferente a la experiencia de la escritura en soledad: se conformó una comunidad de escritura, se produjo una escritura conversada.

No jerarquizamos una escritura sobre la otra, pero sí queremos dejar en claro que la escritura grupal es un proceso diferente, y que ese proceso de construcción colectivo pareció tener un peso especial en el interés por la escritura, y en el interés de los jóvenes por seguir participando en los talleres.

Hubo dos características que en este punto queremos desarrollar brevemente, y tienen que ver con la relación entre esta experiencia en el taller del año 2015 y la escritura cotidiana de los jóvenes en el encierro (la que desarrollaremos más ampliamente, más adelante):

- La escritura grupal: Cuando los jóvenes escriben en la soledad de los sectores, frecuentemente comparten con otros sus experiencias de escritura; comparten la escritura de canciones, de cartas. Aparecen como describimos antes las redes solidarias de escritura: los que saben un poco más ayudan a los que saben un poco menos. Es decir, la escritura con los otros forma parte de las prácticas sociales de escritura en el encierro.

- La escritura en la pared: A falta de mesas y sillas, los talleres se desarrollaron a partir de las estrategias que iban resolviendo las dificultades: así aparece el recurso de los afiches pegados en la pared. Toda la escritura de la novela se hizo 
sobre la pared, justamente la pared, el soporte que los jóvenes usan para escribir en el encierro, al no poder contar por lo general con hojas ni lápices, como ya explicamos en el capítulo sobre las oportunidades y posibilidades de escribir.

Sin haber sido planificado directamente, la necesidad de adaptación del taller a las circunstancias materiales del encierro del instituto, reprodujo cierta correspondencia con las prácticas sociales cotidianas de escritura de los jóvenes en los sectores donde viven. Esto, creemos, tuvo que ver también con que luego valoraran el ponerse en contacto con eso que conocen y les gusta, como expresaron, pero que a la vez se encontraran usando otras palabras, hablando de otros temas. Renato nos contaba que "por ahí adentro del sector nos ponemos a hablar de la novela". Las prácticas sociales recuperadas, resignificadas, se pusieron en valor para generar un producto escrito grupal y de valor social.

Creemos que un proyecto como una novela, es una producción de valor cultural y social, Que posteriormente fuera publicada y presentada a la sociedad, fue otro punto importante para los jóvenes ${ }^{85}$. Les brindó la oportunidad de tener un proyecto de escritura propio, posibilitó verse capaces de reconstruir su historia. Y comunicar la otra parte de su historia, de la que no se habla en los medios hegemónicos de comunicación. Posibilitó que, desde allí, de su propia historia, saliera un producto concreto y digno de ser presentado, producto material de su escritura, a partir de su creatividad, su esfuerzo y su constancia: un libro, con su forma, sus tapas, sus palabras y sus nombres.

En el fragmento del poema "escribir" con el que empezamos este capítulo, Chantall Maillard se pregunta: “escribir/ ¿y no hacer literatura? / y qué más da! ...”. Luego agrega "escribir para rebelarse/ sin provecho/ a pesar de la derrota ya prevista..." (Fragmento de Escribir). En el mismo sentido, pero desde otro punto de vista, Víctor Moreno Bedoya (2008) duda sobre los mitos y poderes atribuidos a la literatura y advierte:

"Hay problemas que ninguna literatura de este mundo, la escriba Auster, Cervantes o Joyce, será capaz de solucionar. En especial, los que produce el Fondo Monetario Internacional y la Deuda Externa Mundial. Así que demos a la literatura lo que es de la literatura, y a la realidad real lo que es de ella. Especialmente, cuando nada tiene que ver con la ficción." (Moreno Bedoya, pág. 23).

${ }^{85}$ Desarrollaremos este punto en el post-scriptum 
La advertencia de Moreno Bedoya (2008) nos es pertinente, este autor desarrolla el concepto de fundamentalismo lector, que nosotros podríamos parafrasear como "fundamentalismo escritor". Moreno Bedoya sostiene que es posible que la literatura alivie ciertos problemas de algunas personas, pero "también lo hacían los confesionarios", dice. El plantea: "dudo mucho que la literatura cure problemas cuyo origen no está en ella, ni los ha creado" (Moreno Bedoya, pág. 23).

Con esto queremos aclarar que no somos ingenuos: la literatura -leída o escritano es un elixir que soluciona mágicamente la vida de las personas que sufren día a día la vulneración de sus derechos más elementales. Pero también sabemos que la escritura es a veces un arma, y muchas veces la única, contra la ausencia, la soledad y el ahogo del encierro: "Los golpes van dejando de doler para empezar a quemar/ Rezo: que se hayan cansado de pegar/Quieren hacerme un monstruo pero yo soy poeta/ Podría ansiar matarlos, pero prefiero escribir" (César González, Buzones)

Decíamos al comenzar la descripción de los talleres que existe un cierto mito romántico acerca de la "poética villera". Julián Axat advierte sobre un "mito etnocentrista", construido desde la exterioridad, lo caracteriza como un mito burgués al que denomina "el mito de los pibes chorros poetas" (Axat, pág. 177). Sabemos que puede existir una romantización burguesa sobre las producciones de los poetas marginales, y sobre el poder de la literatura, que sin duda se potencia cuando hablamos de jóvenes pobres, excluidos, o privados de su libertad. En este punto debemos reconocer que la producción de poetas o intelectuales consagrados también adquirió un valor diferente cuando esa surgió desde la prisión: desde el Marqués de Sade, Miguel Hernández, hasta Antonio Gramsci o Paco Urondo: "Del otro lado de la reja está la realidad,/ de este lado de la reja también está la realidad;/ la única irreal es la reja"86

Pero el objeto de estudio de este trabajo es la experiencia de escritura de los jóvenes privados de la libertad: ni la escritura literaria, ni la escritura de los escritores consagrados, sino la escritura ordinaria, la escritura de la gente común. Por eso volvemos a aclarar, que por lo menos aquí y en este momento no nos interesa entrar en el campo de la discusión literaria. Y para complejizar esta aclaración, retomamos a Daniel Fabre y nos preguntamos: “...acaso la literatura moderna, la concepción moderna de la escritura

${ }^{86}$ Cárcel de Villa Devoto, abril de 1973 
literaria y sus usos ordinarios no son, muy a menudo, la misma cosa?" (Fabre, 2008, pág. 7).

Podríamos continuar con una enorme cantidad de preguntas e intentos de respuestas respecto a la escritura literaria y la vida de los jóvenes. Pero debemos dar un cierre a esta conclusión, siempre provisoria, y para eso elegimos un fragmento de la reflexión publicada por César González (2016) en su cuenta de Facebook, el 22 de octubre de 2016:

"Quiero que sepan que hago arte a partir de esa resignación, de la certeza inmensa que la muerte no dejará de venir a la Gardel y a todas las villas de Argentina a llevarse hermanos. El arte no es más que un miserable consuelo y si hacemos películas o lo que fuese, solo es para rellenar con algo los huecos de los balazos que llevo y que llevan los niños veteranos que me acompañan. Pero, sobre todo, para tratar de lograr que los pibes dejen de morir y matar. Tienen tanto para decir con el horror que han vivido como para desbordar de letras miles de libros, guiones, películas, canciones, etc... En su cuero llevan tantas marcas y pueden reciclarlo en tantas obras maestras, que hoy mismo deberían retirarse unos cuantos chantas del arte. Por eso se necesita tanto mantenerlos en silencio y apichonados, si el preso realmente hablara con su dolor no habría oídos preparados para escuchar y soportar esos testimonios." 87

${ }^{87}$ https://www.facebook.com/cesar.gonzalez.poetavillero/posts/1328140443877121 


\title{
6. La escritura cotidiana en el encierro
}

\author{
"escribir \\ para arquear el espinazo de las letras \\ a imagen del dolor \\ para trazar las líneas de la vida \\ líneas que se encogen \\ líneas retráctiles \\ como nervios apresados en la carne \\ como venas quebradizas \\ venenos infiltrados \\ en las arterias, líneas \\ que merodean en torno al corazón \\ calado por la angustia \\ y el cansancio" \\ Chantal Maillard (Fragmento de Escribir)
}

\subsection{Introducción}

"Henos aquí inmersos en lo banal y lo diverso, en busca de un objeto sin contornos, evanescente, imposible tal vez."

(Daniel Fabre, 2008, pág. 4)

La cuestión de la escritura cotidiana surgió en las primeras conversaciones informales en los talleres propuestos por la biblioteca, en los que iniciamos el vínculo con los jóvenes. Allí, espontáneamente, y luego en las entrevistas etnográficas, fue apareciendo el tema de la relación de los jóvenes con la escritura en la vida de todos los días en el encierro. Para poder acercarnos a este objeto efímero, evanescente, que es la escritura de todos los días, lo fuimos haciendo sigilosamente.

Proponemos para explicarlo una mirada en planos, a modo de los planos del lenguaje visual: como cortes o puntos de vista. Primero enfocaremos en una perspectiva amplia -a modo de plano panorámico- sobre la escritura cotidiana en el encierro: allí aparecen las cartas, la escritura en el cuerpo y la escritura en la pared. Luego, como en un plano 
medio, pondremos el objetivo sobre la escritura en la pared, donde registramos escrituras concretas en los sectores donde los jóvenes viven. Finalmente, sobre la escritura en la pared haremos un zoom sobre una escritura particular: el nombre en la pared, y los relatos de los jóvenes acerca de una creencia: "la pared te llama".

Hasta aquí, recapitulando lo dicho y hecho, partimos de las biografías de los jóvenes y las trayectorias escolares, indagamos sobre las posibilidades de apropiación de la escritura, y sobre las oportunidades y prohibiciones de escribir; luego abordamos la escritura en los talleres literarios. Ahora nos centraremos en la experiencia concreta de la escritura cotidiana de los jóvenes en la situación del encierro.

\subsection{Lo que los chicos escriben en la vida cotidiana.}

\subsubsection{Escritura de cartas}

E: ¿Pensás si en algo tu vida podría mejorar si sabés leer y escribir?

Enzo: Y... calculo que sí

E: ¿Y qué cosa sería lo primero que escribirías?

Enzo: Una carta

(Entrevista a Enzo)

La carta es el texto que más usualmente aparece en las entrevistas como el de mayor circulación e importancia en la cotidianeidad del encierro, relacionado a la necesidad de contacto con la familia, el afuera y la posibilidad de libertad. No contamos con las cartas concretas por pertenecer éstas al campo de la privacidad, pero sí con un interesante bagaje de testimonios surgidos de las entrevistas. Nuestra descripción sobre la escritura de cartas se basa en lo que los jóvenes mismos describen y explican.

Roger Chartier afirma que la correspondencia es una forma de la escritura ordinaria "en el doble sentido de una escritura producida por los hombres y mujeres sin título ni calidad, y de una escritura estrechamente dependiente de la existencia cotidiana, sin finalidad estética ni otro destinatario que quién escribe y aquellos a los que está estrechamente ligado" (Chartier \& Madero, 2001)

En Me alegraré que al recibo de ésta.... Cuatrocientos años de prácticas epistolares, Antonio Castillo Gómez desarrolla la cuestión de las "situaciones 
propiciatorias de los intercambios epistolares", allí menciona tres circunstancias: la guerra, la emigración y la cárcel. En coincidencia con esta idea, los chicos entrevistados, reconocieron que la escritura de cartas comenzó o se vio propiciada en el momento en que empezaron a vivir situaciones de privación de la libertad, así lo reconocen Facundo, Renato o Jerónimo, en sus respectivas entrevistas:

Entrevista a Facundo:

...sinceramente, desde que empecé a caer ${ }^{88}$, a los trece años, empecé a escribir cartas: a mi mamá, para Navidad, para los cumpleaños, para todas esas fechas importantes, le hacía cartas... y bueno, y desde los trece años, voy a cumplir dieciocho y desde esa vez...

\section{Entrevista a Renato:}

...la carta por ahí es para cuando estás en un lugar como acá, cuando estás lejos y no te tienen todos los días...

\section{Entrevista a Jerónimo:}

...acá estás solo, te podés poner a pensar tranquilo, cuando estás afuera andás todo el tiempo activo... estando acá, así... estando así... solo... sin que nadie mire y vea lo que estoy escribiendo... yo acá adentro empecé a escribir y a leer, en la calle...estaba re loco...

Aunque no es así la experiencia de Nicolás, quien ya intercambiaba cartas con su novia antes de estar preso:

\section{Entrevista a Nicolás:}

...siempre fuimos re unidos, y era que ya a lo último éramos re chiquilines, así, porque nos mandábamos cartas siempre, a lo mejor nos teníamos así de frente y yo le hacia una carta lo mismo, siempre todo así, re romántico, re piola...

A diferencia de lo que sucede con otros textos, como los que se produjeron en el taller literario, no accedimos -como ya dijimos- a las cartas escritas, por ser textos personales, privados. Se trata de una privacidad que los entrevistados valoraron y prefirieron preservar, tanto respecto a nosotros, como en relación a sus compañeros:

Entrevista a Joaquín:

Le escribo a mi mamá... o a mi guacha ${ }^{89} \ldots$ y no tienen por qué leerla los otros si es una carta personal... acá a la familia la respetamos...

\footnotetext{
${ }^{88}$ Caer preso
} 
Entrevista a Jerónimo

...no, no es que me moleste que las lean, pero... me da vergüenza... Igual acá nadie va a tocar las cosas de uno: “¿Me dejás leer?”... “Y bueno, leelo”. Si querés sí, pero si no querés, no...

Entrevista a Enzo

"E: ¿Entonces para vos es importante aprender?

Enzo: Si. Es lo más importante, es lo que más quiero...

E: ¿Por qué?

Enzo: Y sí, y que se yo... si yo un día quiero escribirle un mensaje a mi mamá, o una carta a mi familia, yo no voy a saber, y no quiero decirle a otro que me escriba una carta, si yo quiero poner algo importante, yo no quiero que lo sepan todos, es una carta a mi familia...

Verónica Sierra Blas, en el artículo Autobiografías en miniatura. Apuntes y reflexiones sobre la correspondencia infantil (2015) aborda las cartas de niños y su uso pedagógico entre mediados del siglo XIX y mediados del siglo XX. Sostiene que las cartas ofrecen a los niños una oportunidad de expresarse, de hacerse entender, y son un reflejo de sí mismos. Y aclara que, aunque sea sabido que están influidas por un sinnúmero de agentes externos, no lo son menos que las cartas de los adultos, ya que tampoco los adultos estamos libres de ser condicionados por múltiples factores:

Siempre fronterizas, liminares, híbridas, en las cartas de los niños existe una tensión natural, inherente y constante entre lo permitido y lo desaconsejado, entre lo espontáneo y lo vigilado, entre la libertad y el control, entre el juego y el deber, entre la inocencia y la manipulación, entre lo público y lo privado, y es precisamente en esa tensión donde reside su verdadera riqueza. (Sierra Blas, 2015, pág. 64)

Sierra Blas explica que, desde la casa o desde la escuela "la correspondencia infantil respondía, por lo general, a una necesidad comunicativa generada por el alejamiento de los hijos del núcleo familiar, como queda reflejado en muchos de los epistolarios familiares conservados y el significativo predominio de modelos de esta

${ }^{89}$ Forma de referirse a la novia 
tipología epistolar en los manuales destinados tanto a niños como a adultos (Chartier, 1991)" (Sierra Blas, 2015). En el caso de su investigación, los motivos de la separación son muy diversos, Sierra Blas diferencia la distancia geográfica de la distancia afectiva, y sostiene que "las cartas resultaron ser el medio más idóneo para superar la primera y calmar la segunda". La autora toma de Claudio Guillén la idea de que "una carta suponía, por otro lado, desarrollar todo un ejercicio de definición y auto representación, e invitaba a conocerse mejor a uno mismo, dado que quien escribía no hacía sino autorretratarse sobre el papel, fabricar una imagen de sí para su destinatario, dotando a la carta de un carácter referencial o autobiográfico que hacía posible cumplir con el "pacto epistolar" (Guillén, 1998)." (Sierra Blas, 2015)

En nuestra indagación aparece la escritura de un tipo de cartas con función pedagógica, de contención, control, o como parte del tratamiento de los diversos profesionales. Joaquín, como mencionamos al comenzar, cita las palabras de su asistente social, que cuando él se hace cortes en los brazos, le aconseja: "agarrá un cuaderno, una lapicera y ponete a escribir, una carta, algo". Braian, un joven al que tuvimos oportunidad de entrevistar a fines del año 2015, nos explica:

\section{Entrevista a Braian:}

Me han pedido... así... que escriba, ponele, una carta: como me levanté hoy día, si me levanté de buen humor... de mal humor. Me pedían las educadoras sociales que escribiera así, y que con todo lo que iba escribiendo yo... después se podría hacer un libro... Yo muchas veces me he levantado de mal humor, he renegado, he discutido, he peleado y nunca escribí nada yo... No!... camino por el pasillo... me fumo un pucho, voy y vuelvo, cambio el aire... y me tranquilizo

Ahora que me acuerdo tengo un cuaderno, ahí hago el borrador, después pido una hoja y... lo saben tener las chicas, las socio-educadoras, yo se los sé dejar a ellas. Como ser... el profesor del taller de sensibilización me pidió que escriba una carta sobre lo que me daña... las consecuencias que causa el consumo de la marihuana y yo le hice...con dos hojas... o tres hojas!... y mañana se lo tengo que entregar...

En relación al tema de la escritura de cartas y la necesidad de privacidad; apareció, fuera de nuestras previsiones, un nuevo elemento: los sobres. Una vez finalizado el primer taller literario del año 2014, observamos que los jóvenes habían preservado sus escrituras: las habían guardado haciendo un plegado con el papel, 
quedando así resguardadas sobre sí mismas. Si bien fue parte de la escritura del taller, se estaba reproduciendo una práctica cotidiana:

Del Registro de campo del primer taller/ primer grupo, 28 de junio de 2014:

"Una vez en la biblioteca decidimos mostrarle a Diego, el coordinador, las producciones escritas: al abrir los grandes sobres de papel madera nos sorprendimos al encontrarnos en su interior con una especie de "sobres" pequeños hechos con las escrituras del taller: estas habían sido dobladas varias veces hasta llegar a un tamaño pequeño, el doblez era algo sofisticado, a modo de un pequeño origami, que terminaba en un cuadrado de unos $3 \mathrm{~cm}$. por $3 \mathrm{~cm}$. No nos habíamos dado cuenta en el taller, no supimos en qué momento los doblaron. Diego nos explicó entonces que es una práctica muy "tumbera" 90 , muy común en la cárcel, que "así doblan por lo general los presos las cartas que escriben a su familia para preservar la privacidad", por medio del sobre protegen la privacidad y pueden corroborar que nadie lea lo que escribieron (ya que sería muy difícil desdoblar y volver a hacer el mismo doblez)."

Cuando le preguntamos a la mayoría de los chicos sobre el tema, fue Renato, quien sobre la confección de estos "sobres", ratificó lo que nos había dicho el coordinador de la escuela: "Lo hacen porque puede ser algo personal que no les gusta que lo lean" (Entrevista a Renato). Similares respuestas tuvimos en otras entrevistas, pero no volvió a suceder que en los talleres literarios los jóvenes hicieran sobres con las escrituras del taller.

La confección de estos sobres tiene características de protección y en su plegado encripta la escritura. La carta es doblada a mano con técnicas de doblado de papel al estilo "origami", lo que forma una especie de "cubierta" que oculta la escritura de la carta, la que queda del lado de adentro. El origami es una actividad manual cotidiana muy apreciada por los jóvenes en el encierro, y siempre que pueden tratan de conseguir cartulinas $u$ otros papeles de colores para realizar distintas artesanías -flores, estrellas, barquitos, cisnes- sobre todo para regalarle a la familia en los días de visita. En los días de visita también entregan las cartas a sus familiares, estas tienen generalmente este "plegado especial" cuyo objetivo es claramente que nadie que no sea el destinatario pueda abrirlas. Estos sobres aparecen como una táctica de los jóvenes que surge de la necesidad explícita, de preservar un mínimo espacio de protección de la intimidad. Aunque el sobre sea una necesidad que aparece en la cuestión de las cartas en general, ya que el sobre es el medio material que protege la carta, en la situación de privación de

${ }^{90}$ carcelaria 
la libertad se convierte en una táctica que nace en un escenario donde los espacios de intimidad escasean.

Viviendo en una institución total todo se convierte en público, se borran los atributos individualizantes, se producen el cese de la propiedad personal y el impedimento sistemático de la intimidad, a lo que se suman degradaciones y humillaciones: "profanaciones del yo". Caracterizamos institución total como la que se caracteriza por una tendencia totalizadora, tomamos el concepto del sociólogo Erving Goffman que las designa como un "lugar de residencia o trabajo, donde un gran número de individuos en igual situación, aislados de la sociedad por un periodo apreciable de tiempo, comparten en su encierro una rutina diaria, administrada formalmente" (Goffman, 1961, pág. 13). Esta experiencia en la institución total es característicamente desindividualizante y "conlleva un efecto nocivo sobre la subjetividad de las personas que viven en estas instituciones, en tanto todas las prácticas apuntan a moldear las subjetividades" (Ferjtman \& Herrera, 2010, pág. 124).

Por todo lo dicho, y retomando la cuestión de la confección de los sobres, creemos que estos pueden considerarse una táctica, en el sentido de táctica de De Certeau, como artimaña para esquivar la vigilancia del panóptico que sirve para sortear la lógica desindividualizante-totalizante de la institución, la seguridad y el control. En este sentido la confección de los sobres se puede considerar como un ejemplo de escritura contrapanóptico, categoría que tomamos del trabajo Voces en cautiverio, de Lelia Gándara, la define como "una estrategia comunicativa que se enfrenta al panóptico y crea grietas en ese aislamiento".

La protección del contenido de la carta, además de representar la protección de un espacio propio de intimidad y una artimaña de escape a la vigilancia, dimensiona el valor, la fuerza de la palabra escrita, y la necesidad de su preservación. Sobre esta fuerza nos detendremos particularmente más adelante, en la experiencia de escritura del nombre en la pared.

Pondremos el foco ahora en algunas cartas concretas que los jóvenes escriben, y las presentamos ordenadas de acuerdo a lo que ellos mismos nos fueron describiendo, de acuerdo a sus destinatarios, o a sus fines, sin pretender ser una clasificación ni un catálogo exhaustivo:

Cartas a la familia, a la novia, a amigos: 
Lo más común es que para los días de visita los jóvenes preparen cartas y tarjetas para darle en mano a la madre, a la novia, o para ser enviada a algún otro miembro de la familia. Estas son cartas que los visitantes se llevan, para sí mismos, para leer y guardar luego de la visita, o para ser entregadas a alguna persona.

En algunas oportunidades se escriben cartas para chicas y chicos de otras escuelas con quienes intercambian la correspondencia a través de algún profesor.

Entrevista a Joaquín

...estábamos haciendo una carta para las chicas ahí del $\mathrm{CECAM}^{91}$, porque habíamos mandado fotos, todo, que nos sacó una profesora para las chicas, siempre preguntaban por nosotros y bueno hicimos unas cartas

\title{
Cartas para desahogarse
}

Algunos jóvenes escriben cartas de modo catártico, como una forma de desahogo, tal como ellos lo expresan, como una manera de "sacar afuera" la angustia o la bronca. Muchas veces esas escrituras son cartas dirigidas a alguien, aunque a veces no tienen un destinatario definido. De los jóvenes entrevistados, Facundo y Joaquín lo expresaron así:

\author{
Entrevista a Facundo \\ Cuando tengo muchas cosas en la cabeza y las quiero contar a alguien y bueno, por ahí \\ no tenés a quien contarle las cosas acá adentro, ponele la noticia que me dio mi mamá \\ por teléfono de tribunales, o algo que pasó afuera y no las puedo contar con nadie y \\ bueno, y agarro una hoja y empiezo... Cuando estoy mal y así, para sacarme un poco la \\ bronca me pongo a escribir, corte como una carta... \\ Entrevista a Joaquín \\ Joaquín: cuando tengo ganas de escribir algo así... \\ E: ¿Y siempre escribís solo o a veces escribís con algún amigo? \\ Joaquín: No, siempre solo, me gusta escribir así porque puedo pensar. A la hora que me \\ pinte, y más acá adentro que siempre que estoy al pedo, me pinta escribir una canción, \\ una carta, inventar algo... algo voy a hacer para pasar el tiempo. \\ E: ¿Y a quien le escribís o a quien le escribirías? ... \\ Joaquín: Para mí... que se yo...únicamente para mi vieja un par de veces
}

\section{Cartas para peticionar o resolver cuestiones de la realidad}

${ }^{91}$ Centro Socio Educativo Módulo de Mujeres Adolescentes (ex CECAM) 
En las entrevistas con los jóvenes, a nuestra pregunta respecto si a través de la escritura -en general- ellos pensaban que podían cambiar algún aspecto de su realidad, la respuesta en casi todos los casos, fue la escritura de una carta a un juez, a otras autoridades de la justicia, o autoridades del Complejo Esperanza para reclamar por sus derechos dentro del encierro o su situación judicial, pero - fundamentalmente- para lograr o acercar la salida hacia la libertad:

\author{
Entrevista a Jerónimo: \\ "Jerónimo: Escribiría a Tribunales \\ $\mathrm{E}:$ ¿Alguna vez escribiste a Tribunales? \\ Jerónimo: No, pero lo haría \\ $\mathrm{E}:$...y que cosa le pondrías? \\ Jerónimo: Que se les paga muy bien acá a los guardias y todo, y a veces hay mucho \\ abandono de persona acá, porque te sentís mal pedís que te saquen o algo así y no te \\ dan bola, no te dan cabida... \\ Entrevista a Joaquín \\ El otro día estábamos haciendo una carta para que lean los fiscales, todo eso, los \\ jueces... para que autoricen la visita privada92, escribimos una carta entre todos. Porque \\ acá hay chicos que tienen pareja, hijos, familia, y bueno, necesitan tener relaciones con \\ su pareja, están mucho tiempo acá adentro...
}

\title{
Cartas por encargo
}

Los que saben escribir "aunque sea un poco más" son en general los escritores del grupo y ayudan o directamente escriben las cartas de los que menos saben, como mencionamos en el apartado sobre apropiación de la escritura:

\author{
Entrevista a Nicolás \\ E: ¿y alguna vez un chico te pidió que escribieras algo especial, por ejemplo, una \\ carta... alguna vez escribiste algo para otros? \\ Nicolás: Sí, una banda de veces me pidieron que los ayude, para la madre me pidieron, \\ yo le dije que yo no tengo a mi vieja, que esos son los sentimientos que tiene él por \\ dentro...y bueno... pero me sentí bien, y a la vez me sentí mal, me hubiera gustado \\ escribirle a mi mamá
}

\footnotetext{
${ }^{92}$ La cuestión del derecho a la visita privada es un tema que están trabajando en la escuela como parte de los talleres de Educación Sexual Integral
} 


\section{Cartas a un ser querido fallecido:}

Aparecen en los relatos de los jóvenes algunas cartas, como la que le escribe Facundo a su abuelo, Joaquín a su hermanito. Jonathan escribió varias cartas a su madre, luego supimos que había fallecido hacía poco. Son escritas a un ser querido que ya no está, como en el caso de Facundo, su abuelo falleció estando él privado de la libertad. Como ya aclaramos, no insistimos sobre el acceso a esas cartas para la lectura, registro o publicación ya que sobre todo fueron los chicos los que pusieron un límite en ese punto, en todos los casos.

\footnotetext{
Entrevista a Facundo

...le escribí una carta a mi abuelo. Vino mi papá al otro día que falleció y me contó, y bueno, ahí me acuerdo que me puse re mal y me fui al sector y agarré y me acosté a dormir, al otro día me levanté pensando en eso, y había soñado con él, y me puse a escribir el sueño que soñé con él y todas las cosas que me hubiera gustado hacer a mí, si cuando yo salía él estaba

Entrevista a Joaquín

...en el cuaderno había escrito una carta para mi hermano que falleció... un montón de cosas...
}

Para finalizar este apartado, nos es útil el concepto de escritura necesaria de Antonio Castillo Gómez (2002), en De la suscripción a la necesidad de escribir. Allí Castillo Gómez aborda, como ya señalamos, las escrituras populares de las clases subalternas. De todas ellas, aquí nos interesa la cuestión de las cartas y en particular las de las personas que habitan los umbrales de la sociedad, que sufren las situaciones de emigración, exilio, reclusión o la guerra. Castillo Gómez analiza la necesidad de escribir en estas situaciones, y concibe a estas escrituras -tanto las cartas como las autobiografías- como escrituras necesarias "según se ha dicho, sus autores no son escritores ni escribientes de oficio, pero sus testimonios dan fe de la práctica de una escritura necesaria, sobre todo en algunas circunstancias” (Castillo Gómez, pág. 36).

Estas escrituras necesarias están ligadas a experiencias de distanciamiento forzado y de la separación. Con este concepto cerramos este acercamiento a la experiencia de los jóvenes sobre la escritura de cartas en el encierro: 
"Arrancan de una necesidad más personal e íntima, y a menudo están ligadas a vivencias dolorosas y a las zozobras interiores de la persona, lo que no significa que dichas escrituras sirvan solo para superar las distancias y para dar señales de vida. Van mucho más allá $y$, de facto, como sucede con los epistolarios de guerra, responden a motivaciones más hondas, que implican la defensa de la identidad, el refugio frente a un ambiente hostil o la búsqueda de una evasión (Castillo Gómez, 2002, pág. 35)

\subsubsection{Escritura en el cuerpo}

Ocurren cosas terribles en mis ilustraciones. Cada una es un cuento. Si usted las mira atentamente unos pocos minutos, le contarán una historia.

Ray Bradbury, El hombre ilustrado

El tatuaje es una escritura que se lleva en el cuerpo, siempre presente, ya sea en la libertad como en el encierro. Esta escritura pertenece como las cartas a un ámbito privado: el propio cuerpo de los jóvenes. No se trata de un ejercicio de escritura dentro del encierro, como puede ser el caso de los tatuajes en adultos presos, ya que son pocos los jóvenes que se realizan los tatuajes en el momento de la privación de la libertad.

Vimos que Giorgio Cardona, en Antropología de la escritura concibe a la escritura, desde una perspectiva antropológica, como "el uso y la producción de sistemas gráficos con fines comunicativos" (Cardona, pág. 24). Como señalamos antes, Cardona diferencia escritura de lengua escrita. Desde esta mirada, la escritura es una manifestación gráfica que excede a la "lengua escrita". Este autor explica que "muchos, pero no todos los fenómenos de la comunicación tienen una correspondencia de escritura y muchos, pero no todos, los fenómenos de la escritura tienen una correspondencia oral' (Cardona, pág. 88).

En el marco de este concepto amplio de escritura, nos acercaremos a un tipo de escritura cotidiana: los tatuajes, y de manera más amplia, también, a otras marcas en el cuerpo. Unas y otras marcas forman parte de una historia que los jóvenes quieren contar, una afirmación de los jóvenes: "este soy yo, y tengo ésta marca en mi cuerpo". Cada 
marca forma parte de una historia que se puede narrar, cada una es un cuento, como en el fragmento inicial de Ray Bradbury.

Cardona analiza el significado del cuerpo escrito y señala algunas características: "las inscripciones puestas en el cuerpo sirven para indicar el estado social de quien las lleva dentro del grupo". Explica que estas marcas, en las sociedades primitivas subrayaban una afiliación común, se aplicaban en correspondencia de etapas de la vida, relacionadas a ritos de iniciación "prevén que de las duras pruebas físicas por las que deben pasar los iniciados, quede una señal tangible, indeleble” (Cardona, pág. 188). Esta cuestión de afiliación común, aparece como marca que da cuenta de pertenecer a un grupo, de haber pasado por las pruebas iniciales.

Philippe Artiéres estudia la escritura, y la cárcel como "máquina grafómana" a finales del S.XIX (Artiéres, 2005). En referencia a los tatuajes, explica que estas escrituras comenzaron a llamar la atención a la medicina forense desde 1880, y que a partir de allí se iniciaron una serie de investigaciones de carácter en general cuantitativo, a partir de encuestas y muestras de micro sociedades, como la prisión. Estos trabajos sirvieron de referencia a estudios posteriores. Su importancia radicó en que empezaron a configurar un objeto de estudio particular que interesó a varias disciplinas como la historia de la escritura y la antropología, ya que encerraba "un resto de primitivismo en el hombre moderno, se convierte por esa razón en objeto privilegiado de estudio a la hora de esbozar una antropología del hombre occidental" (Artiéres, 2005, pág. 141). Los primeros estudios sobre los tatuajes hechos por los forenses, se centraban en sus aspectos materiales, como el tipo de figura y la temática; los posteriores análisis se fueron centrando en otros aspectos, como sus posibilidades como práctica de escritura, o las condiciones de producción.

Artiéres señala que los reclusos conseguían escribir sus cuerpos a diario, a pesar de estar prohibido en prisión, por eso "las condiciones en que se realizaba eran especialmente precarias" (pág. 142). Los describe como "una especie de diario donde el individuo narraba su vida" (pág. 143): en los cuerpos de los detenidos se podía conocer la vida del sujeto delincuente, seguir su trayectoria, identificar sus prácticas sexuales o aislar los grandes acontecimientos de su vida (pág. 144).

Sobre estas escrituras en el cuerpo, y en particular sobre los tatuajes, indagamos en las entrevistas a los jóvenes. Pudimos corroborar que los tatuajes que "llevan en su 
cuerpo" durante el encierro, no son generalmente realizados allí, sino que en general se tatúan, como en el caso de Facundo, en sus breves períodos de libertad.

Le preguntamos a Facundo sobre sus tatuajes, nos contó que lleva los nombres de sus seres queridos:

Facundo: Tengo tres: tengo el nombre de mi mamá acá en el brazo, este: Claudia. Tengo la W acá, la letra de mi papá: Walter (se señala la parte derecha del pecho). Y la letra de mi abuelo, que falleció: Cacho (se señala la parte izquierda del pecho): la C E: ¿Qué sentiste al escribirte el nombre de tu mamá en el brazo?

Facundo: ...era lo primero que me quería hacer...era eso ...para tener siempre, siempre un recuerdo, siempre... en mi cuerpo, para llevarla siempre conmigo, aparte de pensarla, todo, tenerla yo, en mi cuerpo (Entrevista a Facundo)

En Escrito en prisión. Las escrituras carcelarias en los siglos XVI y XVII (Castillo Gómez, 2002) menciona las escrituras de la ausencia (pág. 160). La escritura del nombre de la madre, para Facundo, significa para él "llevarla siempre" con él, en su cuerpo. La ausencia es reparada a través de la escritura del nombre, y así logra una presencia imperecedera de su madre, logra "tenerla" todo el tiempo con él, en una presencia física y viva.

En el año 2014, se realizó en el Complejo Esperanza un Taller sobre Derechos Humanos ${ }^{93}$, de allí surgió "Enderechados. El misterio de la libertad" (Burchardt, Bartolacci, Giorgis, 2014). Creemos que es relevante tomar parte de este trabajo como fuente en este tema, ya que es contemporáneo en tiempo y espacio con nuestro trabajo de campo y porque se indagó en particular sobre la escritura en el cuerpo en el capítulo El niño ilustrado. Alli se hace referencia específica a las marcas en el cuerpo de los jóvenes, a través de un registro fotográfico y de los relatos de los jóvenes, que cuentan sus historias:

"Hace cuatro años que nació, es la inicial de mi mamá. Ha andado por todos lados y somos compañeros. (Javier)" (pág. 54)

"Me lo hice a los 13 años porque casi falleció mi hermanita cuando nació. Ahora tiene dos años ella y le diría que la quiero un montonazo. (Marcelo)" (pág. 55)

"Este me lo hice a los ocho años, es el símbolo del bien y el mal. Me lo hice porque yo estaba así, a veces venía bien, a veces para atrás... (Denis)" (pág. 55)

\footnotetext{
93 La intervención surge del Proyecto "Componiendo Experiencias" , becado por la Secretaría de Extensión Universitaria de la Universidad Nacional de Córdoba
} 
"Este ahora está encerrado, pero quiere libertad y andar mostrándose por todos lados. Son las iniciales de mi abuelo. (Maico)" (pág. 57)

"Tengo las marcas de las esposas. Fue así esa noche. Me cagaron a golpes a mí solo. La policía fue. No me acuerdo bien. Estuve esposado toda la noche. Fue hace como un año, tenía calambres en las manos. Me las apretaron tan fuerte que no sentía los dedos ya del dolor, no daba más (Axel)" (Pág. 58)

"Yo me levanté una mañanita y me lo hice...me lo hice de cara...me lo hice por mi papá cuando tenía catorce años, cuando salí de acá...mi papá se murió en la cárcel cuando yo tenía cinco años...Lo mató la policía cuando se iba del penal... ipum pum pum! (Jeremías)" (Pág.59)

Las autoras concluyen: “¿Cómo llevar estas marcas en el cuerpo que se enlazan a experiencias de muerte y soledad? Estos tatuajes y cicatrices traen consigo historias de amor, de muerte, de afectos, de dolor y sufrimiento. Quizás es por eso que cuesta tanto verlas. Debemos verlas. Son niños ilustrados, niños que narran historias dolorosas a través de la piel" (pág. 60)

Claramente aparecen como marcas en el cuerpo la escritura, las ilustraciones y también las cicatrices, que aparecen con fuerza también en nuestra indagación. Para los jóvenes estas marcas forman parte de su vida, "las llevan" como Facundo al nombre de su madre, las personalizan: "somos compañeros", son parte de ellos mismos: "quiere libertad y andar mostrándose"

En las conversaciones habituales con los jóvenes, a partir de los relatos cotidianos en charlas informales, surgen estas otras marcas, visibles e indelebles: las cicatrices. Cicatrices que dejan huella, como prueba de "las duras pruebas físicas" que debieron pasar "los iniciados" en las primitivas ceremonias: "en el rito de iniciación, la sociedad imprime su marca en el cuerpo de los jóvenes. Y esa marca nunca se olvidará" (Cardona, pág. 189).

Las mostraron espontáneamente, son sus propias marcas. Hablaron sobre ellas, y contaron su historia, tal vez como prueba de esas duras pruebas iniciales, y como muestra de haber superado esos momentos difíciles:

Registro de campo. 4 de agosto. Taller de presentación

"Una vez terminado el taller, nos quedamos un rato conversando, todos contaban cosas de su vida, Alejandro nos contó que es papá, y que extrañaba a su hija, Joaquín, siguió dándonos detalles sobre las secuelas de la pelea y el problema de su mandíbula, 
finalmente Braian nos contó que una vez estuvo "ahí" de morirse, entonces se levantó la remera y nos mostró una cicatriz que le atravesaba todo el abdomen, una cicatriz grande y gruesa. Nos contó que fue un balazo, y nos detalló el incidente: lo que sintió cuando estaba tirado en el piso, que se sentía "irse", hasta que quedó inconsciente, que después lo operaron, y que estuvo en terapia intensiva dos meses. Nos mostraba orgulloso la cicatriz, parecía importante para él, parecía parte de su presentación personal"

\footnotetext{
Entrevista a Joaquín

Apenas comenzábamos con la entrevista personal, estábamos conversando antes de empezar con las preguntas... le estaba pidiendo algunos datos concretos: la edad, de qué barrio era, etc... y en eso Joaquín se levanta las mangas de la remera y me muestra unas marcas gruesas de cortes en los brazos: muchas cicatrices, varias en cada antebrazo.

-Son cortes... cuando me agarra la locura... para no desquitármela con los guardias, con los otros.... O sino me quemo con el cigarrillo (muestra otras cicatrices), soy un enfermo... es el encierro, te vuelve loco...
}

Las cicatrices de Joaquín y Braian son distintas. Las de Joaquín, autoinfligidas en la "locura" del encierro, forman parte de la escritura del encierro. A lo largo de nuestro trabajo pudimos observar que los cortes en los brazos son además la marca de haber estado allí, y forma parte de la cotidianeidad que uno u otro joven acceda a un elemento cortante y se lastime. La cicatriz de Braian, es una marca de un enfrentamiento con la policía en la calle. Otra marca, marca tal vez de una prueba más dura. Pero ambas son escritura en el cuerpo, ambas cuentan una historia: en el cuerpo de ambos quedó grabada la marca de una historia y un sufrimiento, ya sea una marca del encierro o la marca de la persecución de la policía, en los dos casos las cicatrices narran historias de las duras pruebas por las que habían tenido que pasar. $Y$ ambas, sobre todo, fueron puestas en valor por ellos al mostrarlas como parte de su presentación personal.

Artiéres plantea que la cárcel es una máquina grafómana, donde los tatuajes conviven con otra cantidad de escrituras. La escritura en prisión produce para él una inversión de la sociedad disciplinaria. Los infames ordinarios acceden a la escritura, dejan de estar confinados a la oralidad (Artiéres, pág. 146) y van construyendo estos "palimpsestos de la prisión". Estas huellas prefigurarían características de las sociedades de control contemporáneas: 
“Estas grafías anuncian, pues, la creación de las propias señas de identidad por parte de individuos y grupos que va a caracterizar a las sociedades del siglo $X X$, así como las diversas maneras de declinar la propia identidad que van a convertir al individuo en el actor de su propia vigilancia” (Artiéres, Philippe, 2005, pág. 146)

Para seguir indagando sobre este palimpsesto en el que conviven una cantidad y variedad de escrituras en la cotidianeidad del encierro, pasamos a abordar otra clase de marcas: la escritura en la pared

\subsubsection{Escrituras en la pared: antes de llegar a ellas}

No para todos... No a todos les da igual escribir la pared.

(Entrevista a Braian)

La escritura sobre las paredes ocupa por lo general un espacio público, se desarrolla con grandes limitaciones y prohibiciones, más aún y en particular en el espacio del encierro. Es una escritura trasgresora en sí misma.

Contamos aquí con un abundante registro y con el testimonio de los jóvenes. Explicaremos en este punto cómo pudimos acceder al registro de algunas de las escrituras expuestas en los muros del encierro, para describirlas y analizarlas en el próximo capítulo.

Estas escrituras forman parte de las escrituras populares. Los diferentes autores las llaman: graffiti, escritura mural, o escritura expuesta. Cada denominación pone atención en alguna particularidad. Desde el concepto de "escritura pública, expuesta" Fabre retoma a Petrucci, y la contrapone con la escritura del poder "tan completamente identificada con la regla, portadora de la lengua y de las formas tipográficas del poder". La escritura del poder contrasta con esta otra escritura, que funcionaría como una reacción, como una "contra-escritura" que Armando Petrucci vincula a una ocupación violenta de los espacios prohibidos:

Graffitis, murales espontáneos, incisos pintados o dibujados, representan un tipo de expresión gráfica habitualmente caracterizado por formas expresivas 
innovadoras y llamativas que responden a una clara voluntad política de ocupación violenta de espacios prohibidos. (Petrucci, A. 2002)

La escritura en la pared -pública, expuesta- es una contra-escritura, que en el encierro forma parte de la escritura cotidiana. En su análisis se hacen presentes las múltiples complejidades del objeto escritura a las que se suman las contradicciones propias del contexto de encierro, más aún, si como afirma Braian en la entrevista: "No a todos les da igual escribir la pared"

Partimos, desde el comienzo de este trabajo, del reconocimiento de la real dificultad que significaría acceder a la escritura de las paredes en los sectores donde los jóvenes viven. Comenzamos indagando sobre el tema, y preguntando al respecto en las entrevistas personales a los jóvenes:

Entrevista A Facundo:

E: ¿En los sectores hay escritos en las paredes, graffitis, esas cosas?

Facundo: ¡Sí! todos escriben las paredes, cada uno su mambo, cada uno pone ahí, algo que cree... tienen sus creencias, y escriben sobre lo que ellos creen, hay otros que escriben para la familia, que le piden perdón... otras cosas de dios, que le de otra oportunidad. Rayan o raspan la pared...

La primera entrevista, realizada a Facundo, nos adelantaba una valiosa información sobre lo que queríamos saber, nos dijo sobre la escritura: que los chicos escriben, y que "todos escriben". Sobre las temáticas: que escriben sobre sus creencias, sobre la familia, y que piden perdón. También habló sobre las técnicas de escritura "Rayan o raspan la pared". Aparecía desde su relato una presencia fuerte de la escritura en las paredes del encierro.

Antonio Castillo Gómez desarrolla parte de su análisis en relación a las escrituras realizadas sobre las paredes. Sostiene que estas escrituras, concebidas como una necesidad, tal como las cartas "constituyen otras tantas de las posibilidades de un escribir desde abajo ejercido a lo largo de la historia, según acredita la condición subalterna, social y gráfica” (Castillo Gómez, pág. 41). Una escritura desde abajo, como también sostiene Diego Navarro Bonilla, quien también concibe que la escritura -como cualquier otra experiencia de la prisión, de la historia, o de la sociedad- puede ser observada, desde "arriba” o desde "abajo". Las personas que allí escriben, para desarrollar su escritura 
deben sortear "las dificultades y restricciones impuestos por la vida privada de libertad" (Navarro Bonilla, pág. 19)

Seguimos indagando en la entrevista a Nicolás sobre la misma cuestión:

Entrevista a Nicolás

$\mathrm{E}:$ ¿Escriben en las paredes?

Nicolás: Una banda de versos... escribimos una banda de dichos, así... hay mucho, pero por ahí queda feo, queda muy cachivache, pero son como poemas. Van quedando cosas, porque caen banda de chicos, entran y salen a cada rato, por ahí uno escribe algo, para la familia, que la quiere a la madre, todo... Yo la otra vez me puse a escribir y puse todo así: "Padre nuestro que estas en los cielos..." en un pedazo de la pared...

Aún no contábamos con las escrituras, pero seguíamos buscando información. Retomando lo dicho por Franco, y que Nicolás nos reafirmó: nos dijeron que había mucha escritura en las paredes, que se escribe a la familia, a la madre y además Nicolás nos contó que él mismo escribió un "Padre Nuestro". Aunque aclara que queda "muy cachivache". Pero igual escriben.

Entrevista a Enzo:

“E: Y la pared... ¿Para qué se escribe?

Enzo: Para escrachar"

Enzo fue conciso, la pared se escribe "para escrachar". Nos llamó la atención el término. Para el diccionario de la RAE, escrachar es un modismo de Argentina que significa "decir algo de una persona que la perjudica o la deja mal vista ante otras personas". Lo cierto es que en los últimos años, en nuestro país, "escrache" tiene claras connotaciones políticas. "Escrache", en los años 80, fue una forma de señalar en forma pública, por medio de una manifestación popular -ya sea en la calle o frente a su viviendaa militares vinculados a los crímenes de lesa humanidad, es decir, una forma de denuncia pública. Esta práctica del escrache en nuestro país comenzó justamente con H.I.J.O.S., una agrupación de jóvenes, hijos de desaparecidos, que reclamaban juicio y castigo: jóvenes que pedían justicia. 
Que Enzo se refiera a "escrache" tiene valor para nosotros por dos razones, porque se trata de un tipo de escritura mural -que después desarrollaremos- destinada muchas veces a denunciar o difamar, y porque en el registro que realizamos posteriormente pudimos corroborar que es así, y en una gran cantidad de escrituras. Luego pudimos confirmar que la denominación "escrache" estaría generalizada entre los jóvenes como la mención de toda escritura en la pared.

Es interesante observar aquí que de alguna manera estas escrituras en la pared, se relacionan a aquellos escraches de H.I.J.O.S., y en sentido más general, como denuncia de un grupo de jóvenes y pedido de justicia.

Sobre su experiencia de escritura en la pared, seguimos conversando con Enzo ${ }^{94}$

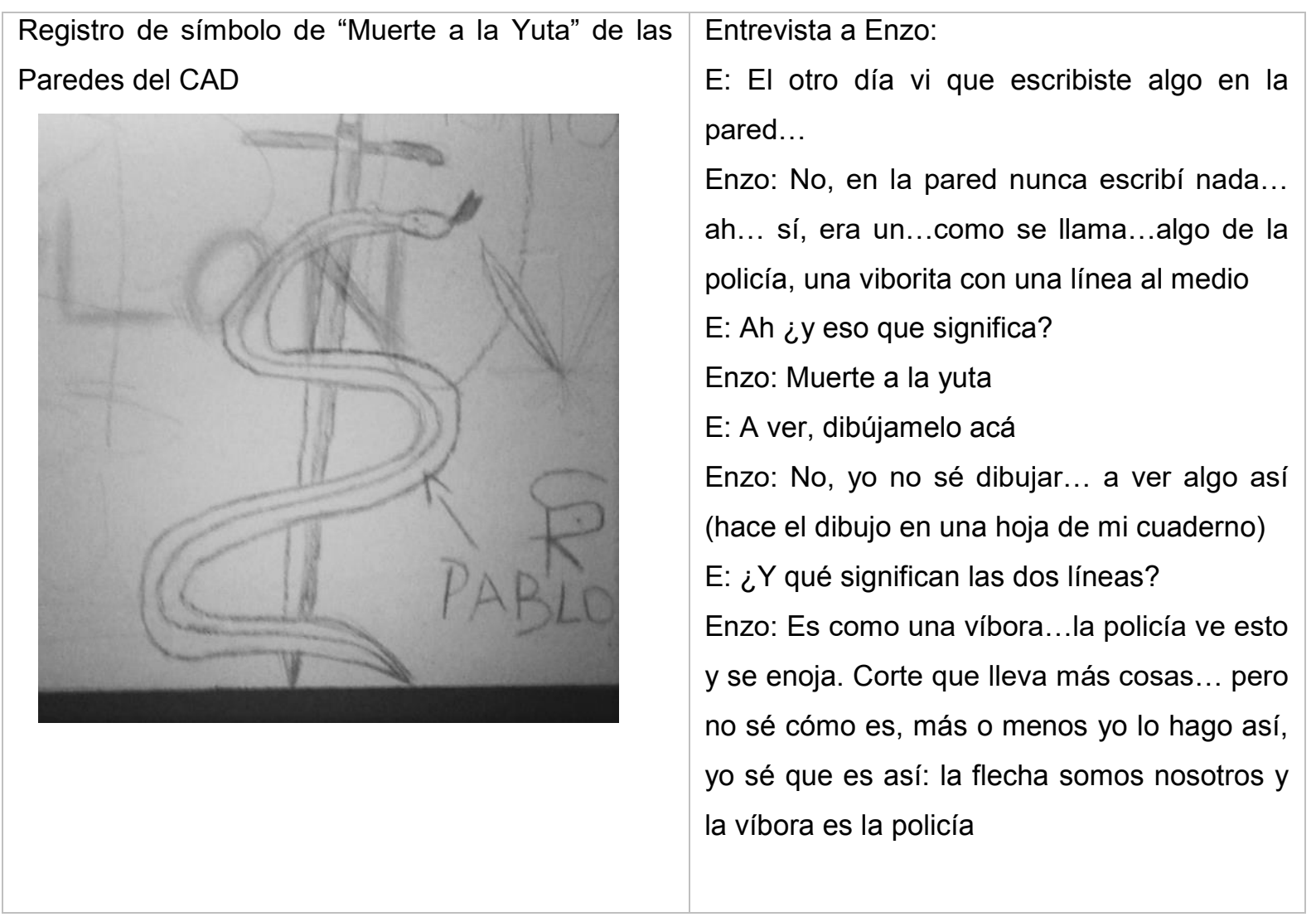

En este diálogo con Enzo se reconoce el concepto amplio de escritura diferente a lengua escrita, al que se refiere Giorgio Cardona, con el que comenzamos el apartado

${ }^{94}$ Recordemos que Enzo es el joven que en su ingreso a los talleres aclara que "no sabe escribir" 
anterior sobre los tatuajes: escritura como toda manifestación gráfica con intención comunicativa, en ese sentido el dibujo de la espada y la víbora es escritura.

Navarro Bonilla (2002), sobre la escritura en la pared complementa lo que venimos diciendo a partir de las palabras de los jóvenes:

"En cualquiera de las épocas, las escrituras murales han estado motivadas por las razones más diversas: unas, de contenido crítico y contestatario; otras, más ligadas a la manifestación de un sentimiento personal; algunas, para insultar o difamar; otras, en fin, seguramente sin más trascendencia que la de pasar un rato. Pero cualquiera que sea el motivo, lo destacable es que asumamos la necesidad de mirar las paredes y dar cuenta de lo que en ellas se ha escrito, máxime cuando se trata de sacar a la superficie las maneras, los gestos y los espacios donde se ha manifestado la palabra escrita de las clases subalternas." (Navarro Bonilla, 2002, pág. 19)

En función a lo dicho por los jóvenes, respecto a la cantidad de escrituras que abundan en las paredes de los sectores donde ellos viven, tuvimos un especial interés en seguir buscando y acercarnos a esas manifestaciones concretas de escritura. Sabíamos que no sería sencillo, y no lo fue, como ya lo desarrollaremos.

En la entrevista personal, sobre este tipo de escrituras, Joaquín nos orientó:

Entrevista a Joaquín:

Acá al lado en el Centro de Admisión está todo escrachado, como hay ingresos todos los días...ahí entran y se van, pueden estar como máximo una semana, escriben su nombre, el barrio, escriben... que se yo... "mamá perdoname porque hice..." se ponen a cajetear los giles, los pibes se ponen a escribir...

Nos proponemos entonces en el próximo capítulo, observar, leer y analizar a algunas de estas escrituras murales, asumimos la tarea y la necesidad de mirar las paredes y dar cuenta de lo que en ellas se ha escrito (Navarro Bonilla, pág. 19), con la ayuda de los jóvenes, que, en el grupo de discusión, en las entrevistas y en los comentarios en los talleres, nos ayudaron a comprenderlas. 


\title{
6.4. La escritura en la pared: los registros, la escritura y lo que dicen sobre la escritura
}

\subsubsection{Sobre el ingreso al campo}

\begin{abstract}
"Nos adentramos en el estrecho pasillo, a través del agujero de apertura de las celdas, caras pálidas y ojos húmedos y asustados; sentí como una mano de hierro en el corazón. Junto al número 5, el guardián introdujo la inmensa llave en la cerradura, la giró y abrió de par en par la puerta pequeña, haciéndome con la mano gestos que decían que tenía que entrar, que era mi vivienda. A la vista de esa pocilga, de ese inmundo habitáculo, de donde emanaba un olor inmundo, lloré" (David Albertario, en Caffarena, Fabio, pág. 112)
\end{abstract}

Nos ocuparemos aquí de describir el ingreso -o el intento de ingreso- a algunos espacios para encontrarnos con la escritura de los jóvenes en las paredes.

De distintas maneras, con mayor o menor cercanía, se tuvo acceso a ciertos sectores donde los jóvenes viven. Se lograron registrar escrituras de cuatro espacios: el Instituto San Jorge (2014), el patio del Instituto Horizontes (2015), el CAD -Centro de Admisión y Diagnóstico- (2015), y la escritura cotidiana de la escuela (2015).

Transcribiremos, explicaremos y comentaremos fragmentos de los registros de las situaciones de entrada a los espacios, primero, y más adelante nos dedicaremos a presentar y analizar lo registrado: las escrituras en sí.

La descripción que realiza David Albertario ${ }^{95}$ nos sirvió de epígrafe, fue seleccionada del trabajo de Fabio Caffarena Condenados a escribir. Cartas y recuerdos del establecimiento penitenciario de Finale Ligure (1864-1965). Allí Albertario describe en forma minuciosa la sensación de la entrada a la celda. La elegimos por su cercanía a las propias percepciones, en particular, en la entrada a las piezas del CAD, salvando una gran distancia: nuestra entrada fue transitoria, y a sabiendas de que permaneceríamos allí por un tiempo muy corto y bien determinado, muy lejos de la incertidumbre y la angustia de una entrada real a la reclusión.

\footnotetext{
${ }^{95}$ periodista católico comprometido con la doctrina social de la iglesia, preso por tres años por publicar artículos que incitan "el odio entre clases sociales" y "poner en peligro la tranquilidad pública", en 1898
} 
Se trata de percepciones, que suponemos puede experimentar cualquier persona con solo ingresar a un espacio de este tipo. Creemos que es significativo para la mayor comprensión de lo que venimos a describir.

\section{Paredes Instituto San Jorge/ 2014}

El registro de las paredes del Instituto San Jorge fue realizado en octubre del 2014. Apenas entregamos el pedido de permiso para el registro fotográfico, el coordinador de la escuela nos sugirió que podíamos hacerlo acompañados de algún profesor, un preceptor, o él mismo. Edgardo, tutor y profesor de Tecnología, se ofreció entonces a acompañarnos. La concreción de este registro se hizo finalmente muy difícil en la práctica. Por distintos motivos institucionales no se encontraba el día propicio para acordar la realización de la actividad. Al poco tiempo, y ante la prioridad de registrar la escritura en la pared, Edgardo, que como tutor tenía la oportunidad de ingresar a los sectores donde los chicos viven, fue quien finalmente encontró una ocasión y realizó personalmente el registro. Tomó en total 100 fotos del Instituto San Jorge, que nos entregó para este trabajo. Luego lo entrevistamos para que nos ayudara a interpretar y comprender las escrituras registradas fotográficamente.

\section{Paredes Instituto Horizontes/patio 2015}

Para el próximo registro, de las paredes del Instituto Horizontes, hubo que esperar al año 2015. Se concretó finalmente, y luego de varias gestiones, un día y una hora para ingresar, y se haría en compañía de un preceptor o el coordinador. El 24 de abril era la fecha indicada. Pero nos encontraríamos con un imprevisto que nos iba a complicar la tarea, aunque de todas formas nos daría cuenta de una valiosa información respecto a la experiencia de la escritura en la pared:

Registro de campo 24 de abril de 2015

El viernes fuimos a la mañana, finalmente, para sacar personalmente las fotos a las paredes del Instituto Horizontes (de máxima seguridad), fuimos al instituto atravesando el parque, me acompañó un preceptor de la escuela, íbamos con cámara en mano, los permisos, todo lo necesario. Nos recibieron los guardias, y nos hicieron pasar a hablar con el jefe, el jefe nos recibió, dijo que no habría problema, que podríamos ingresar, pero advirtió que "la novedad" era un pequeño detalle: que habían pintado las paredes de todo el instituto hacía pocos días atrás ¿Todo? Sí, todo, recién pintado (la gran "novela 
colectiva" escrita en las paredes del Horizontes había sido tapada por la pintura) ... Salí de la oficina del jefe, casi derrotada, miré los pasillos oscuros, y vi con mis propios ojos todo impecablemente pintado en dos tonos de gris, la mesa de los guardias antes de ingresar, un pasillo largo que lleva a los sectores, era la primera vez que entraba, la arquitectura no tenía diferencia con una cárcel de adultos. Les pregunté entonces a los guardias si los sectores donde viven los chicos estaban todos pintados también, me reiteraron que sí, que pintaron todo. Insistente, les pregunté entonces por el patio, y me respondieron que... podía ser que el patio no estuviera pintado... Entonces allí fuimos, logramos entrar al patio, con tres o cuatro guardias de escolta. El lugar estaba sucio, con basura y botellas de plástico en los rincones, dos arcos de fútbol. De las pequeñas ventanitas con rejas de los sectores se veía alguna ropa colgada, se oía la música de cuarteto cordobés, ruido de agua, las voces y gritos de los chicos que parecía que cantaban bajo la ducha. En las paredes había algunas escrituras, estaban escritas en letra bastante grande muy borroneada, muchas tachadas, la escritura parecía hecha con lápiz negro o carbón, con alguna pintura blanca en otras partes. La más visible era una enorme frase de Don Bosco en la base de un antiguo mural tapado por la humedad, con imágenes de niños y el cura, al menos eso me parece. También aparecían en la parte inferior grandes inscripciones semi borradas con marcas deportivas: Adidas, Puma, etc. Saqué las fotos, registré, bajo la mirada de los guardias. En ese momento caí en la cuenta de que toda escritura en la pared era, es o sería sancionada.

"En ese momento caí en la cuenta de que toda escritura en la pared era, es o sería sancionada." Hasta ese momento sabíamos que la escritura en la pared formaba parte de la escritura cotidiana, habíamos naturalizado su realización, desconociendo las tensiones que se generaban alrededor, partiendo de la necesidad de escribir, pasando por sus posibilidades, sus restricciones y sus prohibiciones. Tampoco los jóvenes en las entrevistas hechas hasta el momento, nos habían advertido acerca de tal censura sobre la escritura. Pensamos que para ellos probablemente fuera una obviedad. En el fragor de nuestro afán por llegar a conocer estas escrituras no tuvimos en cuenta que tal como puede pasar en una casa o en la calle, la escritura en la pared, casi siempre se hace en forma furtiva. Fue a partir de este primer fracaso que caímos en la cuenta entonces de que toda escritura en la pared era una escritura furtiva y una trasgresión.

Indagamos a partir de aquí con las autoridades, preceptores, guardias del lugar sobre la existencia de normas o reglas respecto a la escritura en la pared. Nos encontramos con algunas ideas que surgían del sentido común, basadas, por ejemplo, en 
la necesidad del mantenimiento e higiene del lugar, y se daba por hecho que la escritura en la pared formaba parte de una falta menor. Pero tal como ya describimos no encontramos ninguna reglamentación escrita que en forma concreta sancionara la escritura en la pared. Menos aún nos encontramos con ningún tipo de valoración o registro de dichas escrituras, excepto algún registro esporádico de algún profesor.

En conversaciones posteriores con los jóvenes ellos confirmaron que era una obviedad, que no se podía escribir la pared, y que ahora menos, ya "que está todo recién pintado", y que serían sancionados con más razón si lo hacían; además expresaban que les gustaba conservar sus espacios sin escrituras porque si no quedaba todo "muy escrachado" "muy cárcel", pero que igual, curiosamente, escribían. O lógicamente, escribían. Como señala Emilio de Ípola, en relación al rumor carcelario, los mensajes en la cárcel circulan inevitablemente y proliferan a pesar de las restricciones del sistema:

"Curiosamente (o, mejor dicho, lógicamente) en ese ámbito cerrado que lleva hasta el paroxismo las medidas para asegurar el desconocimiento y la desinformación más integrales, los mensajes proliferan. En este mundo, donde los signos están prohibidos o rigurosamente controlados, todo es signo y mensaje, todo es inevitable y enfáticamente significante" (Ípola, 2005, pág. 29)

Sobre la escritura en la pared de grupos subalternos y en particular, en situación de encierro, resulta imprescindible volver a la referencia de Antonio Castillo Gómez.

En su extenso trabajo sobre historia y escritura este autor da cuenta de una mayor presencia en los archivos históricos de las escrituras del poder; vs. los pocos o a veces ausentes registros de la escritura popular, en general.

Castillo Gómez toma prestado el término memoricidio de Goytisolo en referencia al abandono, desvalorización, desconocimiento y olvido de los documentos escritos de escrituras populares "Ios testimonios que han sobrevivido «no son, como algunos creen, una muestra accidental de lo que originalmente existía», sino que "han sido escogidos para que prevalecieran normalmente por miembros de los grupos sociales políticos o instruidos, al suponérseles significativos»; de tal suerte que la memoria escrita preservada es, sin duda, el mejor espejo de la estructura del poder y de los prejuicios establecidos en cada época” (Castillo Gómez, 2002 , pág. 44). La pintura de las paredes del Instituto Horizontes, sin el lugar ni el tiempo para un registro previo, nos resulta un memoricidio, tomando las palabras de Goytisolo. A partir de esta idea necesitamos destacar y ratificar que las escrituras que intentamos registrar y en este caso fueron cubiertas por la pintura, 
en su condición de escrituras populares, fueron claramente desvalorizadas, consideradas irrelevantes e insignificantes cuando no rechazadas y censuradas.

Pedro Javier Cruz Sánchez (2011), en uno de sus trabajos sobre escrituras expuestas, advierte sobre la fragilidad de su permanencia por distintos motivos, uno de ellos es la acción destructora del hombre: "Todos estos escritos y símbolos se encuentran en grave peligro de destrucción a causa de la fragilidad de sus soportes, por lo común al aire libre, en viejos edificios, casi siempre en ruinas, o en espacios públicos expuestos a la degradación por motivo de la climatología y de la acción destructora del hombre" (Cruz Sánchez, 2011, pág. 86)

Las escrituras murales, podrían entrar también en la categoría de escritura efímera que propone Cardona a las escrituras que "no están hechas para durar" (Cardona, pág. 52), como la escritura en la arena, o en el polvo. Estas pueden expresar la voluntad de dejar un rastro más que momentáneo. Cardona hace referencia a estas escrituras en el mundo antiguo, cuyo ejemplo más conocido es el episodio evangélico cuando Jesús frente a los fariseos, escribe en el suelo " $E$ El que esté sin pecado entre vosotros que arroje la primera piedra!" (pág. 53). El acto de escribir no era allí un hecho narrativo ni comunicativo:

"era algo que se concebía como una actividad enderezada a uno mismo, en la que no se prevé que ningún otro pueda intervenir; no está dirigida a comunicarse, antes bien es señal de que se excluye toda interacción. Pero al mismo tiempo no es un despropósito, o escribir inútil; cuando se quiere aludir a una escritura verdaderamente lábil, poco estable (es decir lo que hoy llamaríamos "letras en la arena")" (Cardona, pág. 54)

Dentro de estas escrituras efímeras -en mayor o menor medida todas pueden serlo- encontramos, por ejemplo, la escritura con jabón que nos describía Leandro: "escribo con jabón blanco, para que los guardias no vean". La escritura es efímera de un modo más evidente, pero todas las otras, también lo son al estar siempre en posibilidad de ser borradas, ya sea por la pintura, por la limpieza de la pared, o por el tiempo. Braian nos cuenta que los guardias lo mandaron a limpiar una pared en la que habían escrito un insulto: 
Entrevista a Braian:

El otro día habían escrito la pared a la orilla de la reja... y decía...estaban insultando a un maestro ${ }^{96}$ y hace mucho está... y me pidieron "por favor" a mí si podía borrarlo... yo no lo había escrito...

En este breve relato de Braian niega haber escrito el insulto y cuenta que le hicieron lavar la pared, se trasluce una sanción que él aparentemente minimiza: el pedido de "por favor" deja algunas dudas, dado el tono ante una supuesta infracción, en este contexto. De una u otra forma el escrito debía ser borrado.

Queremos para finalizar este punto, aclarar, retomando a Castillo Gómez, que las escrituras de las paredes de los sectores donde los jóvenes se encuentran alojados, son testimonios relevantes: "no se trata de textos sin importancia, sino de auténticos objetosmemoria" (Castillo Gómez, pág. 44) y compartimos la preocupación por su fragilidad y fácil destrucción, lo que, además, nos consta. Creemos por todo esto, que es significativo salvaguardar estas escrituras, estos fragmentos de la memoria escrita del presente, en coincidencia con lo que propone Castillo Gómez: "por lo que atañe al presente y al futuro, la creación de centros y acervos que se afanen en estos menesteres de la salvaguarda, conservación y estudio del legado escrito de las clases subalternas." (Castillo Gómez, 2002, pág. 44)

\section{Paredes CAD /2015 (registro a mano)}

La entrada al Centro de Admisión y Diagnóstico -CAD- se tramitó a partir de la sugerencia que realizó uno de los jóvenes -Joaquín- en la entrevista personal. Se trata del Instituto, dentro del Complejo Esperanza, donde los jóvenes hacen el ingreso al encierro. Quedan internados allí por varios días hasta que se resuelve su situación legal, pueden pasar por diferentes entrevistas con equipos técnicos, y en la mayoría de los casos, ingresan a una etapa de privación de la libertad en alguno de los tres institutos restantes. Volvemos a la descripción de Joaquín respecto a las paredes del CAD: "está todo escrachado, como hay ingresos todos los días...ahí entran y se van, pueden estar como máximo una semana, escriben su nombre, el barrio, escriben... que se yo... "mamá perdoname porque hice..." se ponen a cajetear los giles, los pibes se ponen a escribir..."

La descripción del ingreso al CAD, vamos a dividirla en dos partes: una primera parte, previa al ingreso; y la segunda, el ingreso en sí mismo. La primera parte no brinda

\footnotetext{
${ }^{96}$ Se refiere a un guardia. Los llaman maestros como una continuidad de la figura de los maestros en la época del patronato.
} 
información específica sobre la escritura, pero sí describe una interesante información sobre el contexto. Este ingreso lo realizamos acompañados de uno de los coordinadores:

Primera parte: Previo al ingreso al CAD:

Registro de campo 14 de octubre 2015 -CAD- Primera parte-

Entramos con Carlos por una pequeña puerta al costado del edificio donde nos atiende el guardia de turno. Carlos le explica que tenemos autorización para ingresar y otro guardia nos acompaña a hablar con la autoridad del lugar, Díaz. Pasamos por un pasillo, atravesando puertas de rejas y saludamos a los diferentes guardias. Llegamos a un sector de oficinas (al fondo está la oficina del jefe: Díaz). Carlos entra y el jefe grita, "pero pedí permiso, che, no ves que estoy ocupado!". Carlos sonríe y vuelve a salir, y en el mismo momento Díaz accede "bueno, pasá", de manera que Carlos vuelve a pasar, y yo decido quedarme afuera. Escucho que se saludan y conversan, me invitan a pasar haciendo entender que lo anterior había sido solo una broma (yo paso con confianza, sé que Carlos está acostumbrado a negociar en este tipo de situaciones). El escenario es bizarro: el escritorio es enorme y están sentados el jefe y una persona de los equipos técnicos de salud; Díaz es un hombre de contextura grande, está sentado, más bien echado en su silla, su remera tiene una inscripción en inglés "Welcome Las Vegas", el escritorio está abarrotado de papeles y distintos elementos: útiles, tazas de café, mate y criollos. Apenas entro Carlos me presenta "mirá lo que te traigo" ... Díaz se ríe, e insiste en que me siente. Disimulando mi incomodidad me siento y le cuento al jefe el motivo del pedido, y muy brevemente de que se trata el trabajo de investigación. Díaz asiente, dice que por supuesto, que está todo bien, que no va a haber ningún problema, que él nos autoriza a pasar, y resalta que lo hace solo porque él aprecia mucho a Carlos. También bromea respecto a otro coordinador, y pregunta por qué no fue, según él porque "le tiene miedo", los otros se ríen. Luego de un rato de charla, decidimos partir hacia los sectores, Díaz, accede "Ok, vayan" pero apenas salimos en voz fuerte advierte "¡Pero no! ¡Si yo no lo autoricé!", a lo que Carlos le responde en voz firme "vamos a ir igual", y le aclara que tenemos permiso de $M$. que es autoridad mayor. Yo observo en silencio, en ningún momento sé si hablan en serio o en broma, pero se ve claramente que el jefe quiere en todo momento remarcar su autoridad y bromea con respecto a eso y hace ver la arbitrariedad con la que puede actuar y tomar decisiones. Finalmente nos dirigimos a los sectores de las piezas del CAD

Decidimos no omitir el anterior registro por dos razones: en primer lugar, por su relevancia al ser el CAD un lugar al cual, como queda claro, es difícil de acceder: espacio dentro del instituto donde los jóvenes están alojados al ingresar, espacio que en la jerga 
del lugar es "territorio de los guardias"; en segundo lugar, porque da cuenta del autoritarismo, la arbitrariedad, y los códigos con los que toman las decisiones quienes ejercen el poder. Nos desconcierta que se manejen de esta forma entre personas adultas. Nos quedan a partir de aquí muchas dudas e inquietudes respecto el ambiente institucional y en particular al trato a los jóvenes.

Segunda parte: Ingreso al CAD:

Pasamos ahora a la descripción del ingreso al sector donde los jóvenes están internados y de donde pudimos registrar las escrituras:

Registro de campo 14 de octubre 2015 -CAD- Segunda parte-

Llegamos a un pasillo largo con dos entradas, una para cada sector de piezas. Frente a cada entrada hay una puerta de rejas, y un escritorio con tres guardias en cada uno. Los guardias nos miran en silencio, uno de ellos nos pide que esperemos un momento para entrar al sector y avisar a los chicos que vamos a ir. Luego nos acercamos a la puerta de uno de los sectores, el más próximo. Nos acompaña un guardia. Frente al escritorio de la guardia está el portón de rejas que tiene apoyados rollos de papel higiénico, y algunas tazas vacías, lo abren y entramos. Allí comienza un pasillo angosto y largo, de unos 25 metros, con aproximadamente diez piezas individuales de mano izquierda, todas con puertas de hierro y una pared de mano derecha del pasillo. Las puertas de hierro están despintadas, y tienen una pequeña ventanita con rejas y una especie de plancha de hierro con pequeños agujeros. El lugar está todo pintado de gris. La primera celda se ve más grande que las otras, ahí hay dos chicos encerrados, que saludan desde adentro a Carlos, y le dan la mano a través de la reja. El resto de las celdas están abiertas y vemos las pertenencias de los chicos, algún buzo, o algún pantalón, pero los jóvenes no están en este momento, los llevaron al patio. Las celdas son todas parecidas: la puerta de hierro, con una pequeña ventanita con rejas a la altura de los ojos que tiene solo un espacio abierto ( $1 / 4$ de la ventanita), como para pasar algún elemento (me imagino un vaso por ejemplo). Del contorno de la ventana se ven puerta y pared manchadas de humo, indicio de que alguna vez hubo fuego en el lugar. Una vez adentro, la celda es un espacio cuadrado de aproximadamente dos metros con cincuenta por dos metros con cincuenta, pintado de gris oscuro abajo y gris claro arriba, de paredes muy altas. Tiene una tarima de cemento como cama, una pequeña tarima para apoyar cosas, colchones y frazadas viejos. Se siente olor "a encierro". Las paredes están repletas de escrituras y están manchadas de agua con tierra a la altura del piso como si el lugar hubiese estado inundado. La parte inferior de la pared está pintada de color gris oscuro, de pintura lavable, como esmalte sintético, es de aproximadamente un metro y medio, y tiene las escrituras grabadas, 
horadadas con algún elemento punzante. En la parte superior, por arriba de un metro cincuenta, la pared es blanca/gris y las escrituras son casi todas hechas aparentemente en lápiz negro, excepto algunas que están marcadas con los dedos con algún líquido que parece café. No teníamos autorización oficial para sacar fotos, de manera que había que anotar todo lo que veíamos. Como era mucho el material que registrar, Carlos se ofreció a ayudar, y nos repartimos: él copiaba algunas escrituras. Él pidió permiso y sacó algunas fotos que luego me entregó, conversábamos sobre las escrituras o dibujos que nos llamaban la atención por diferentes motivos, observamos muchas escrituras para la madre, muchas cruces, pedidos de perdón y súplicas, algunas horadaciones muy profundas"

Sobre este recorrido del ingreso a los sectores donde los jóvenes viven, podemos en primer lugar destacar la dificultad inicial y general para ingresar, pero a la vez cierto progreso en las posibilidades: desde la imposibilidad de entrar -como pasó en el Instituto San Jorge-, a la posibilidad fallida -el Instituto Horizontes-, a un registro mínimo -el patio-, al ingreso a las piezas y un posible registro -el CAD-. En cuanto a la escritura: su labilidad, su fragilidad y la tensión entre carácter de escritura efímera de algunas, la permanencia de otras.

Sin dudas esta complicación para la entrada y el registro tiene que ver con las características generales de acceso a una institución de encierro. A estos problemas, que podemos llamar generales, se suma el hecho de que, en el Complejo Esperanza, durante los últimos años se realizaron graves denuncias judiciales y periodísticas sobre las malas condiciones de vida de los jóvenes internados, a partir justamente, de registros fotográficos "furtivos" de los sectores donde viven los jóvenes.

Los registros de campo precedentes nos sirven de marco para una mejor comprensión del contexto, de las posibilidades y condiciones de producción de las escrituras que a continuación vamos a presentar.

\subsubsection{La escritura en las paredes: Descripción- Posible catalogación ${ }^{97}$}

A lo largo de los dos años de trabajo, ya atravesado el proceso de ingreso a los diferentes sectores -y el consiguiente acceso a las escrituras- pudimos realizar los siguientes registros:

\footnotetext{
${ }^{97}$ En el Anexo 2 se incluye el registro de toda la escritura en la pared: las escrituras transcriptas y una selección fotográfica
} 
- Registro de escrituras de las paredes del Instituto San Jorge: 100 escrituras. Contamos con fotos de las escrituras. Sobre algunas de ellas, la explicación de los jóvenes en el grupo de discusión

- Registro de escrituras de las paredes del CAD: 66 escritos transcriptos a mano. Contamos con 28 fotos. Sobre algunas de ellas, la explicación de los jóvenes en el grupo de discusión

- Registro de escrituras de las mesas de la escuela: 64 escritos. Contamos con las fotos de las escrituras

- Registro de escrituras de las paredes del patio del Instituto Horizontes: 17 escritos. Contamos con las fotos de las escrituras

El problema que se nos presentó a partir de aquí es encontrar la forma de presentación de este conjunto de escrituras. La decisión se complejiza dada la cantidad y la variedad del material. Contamos, sumando los tres institutos, con unos 200 registros de escritura, más los 64 de la escuela.

Priorizamos, en primer lugar, las que tuvimos la oportunidad de poner en cuestión en el grupo de discusión, siendo los jóvenes quienes nos ayudaron a comprenderlas.

El punto en el que todas las escrituras confluyen y no podemos escindir, es que se trata de escritura en los muros del encierro. En esta búsqueda de encontrar un criterio adecuado de presentación y clasificación, podemos observar las escrituras desde diferentes criterios: de acuerdo a los espacios donde fueron registradas, a las edades de sus escribientes, a la temática, al dominio, al ámbito, a las condiciones de producción, a los usos ¿o la combinación de algunos de estos criterios?

Daniel Fabre caracteriza el graffiti en la ciudad moderna, y aunque no se trate de un contexto de encierro, ni de un momento histórico cercano, su descripción se acerca a las escrituras en la pared que pudimos observar, registrar, y sobre las que pudimos indagar, por su carácter de escrituras furtivas, transgresivas y siempre fuera de lugar:

Furtiva, nocturna, atormentada en su grafismo, poco sumisa a la ortografía, siempre fuera de lugar, invade los muros de la ciudad. Esos graffitis bien conocidos en las ciudades italianas del Renacimiento son escritos transgresivos, criminales, más por el lugar que ocupan, que por su contenido, que suscitan una vigilancia activa de la escritura." (Fabre, 1991, Pág. 14) 
Empecemos por el comienzo: la entrevista personal a Joaquín. Ésta comenzó con una conversación informal sobre la escritura en la pared del espacio que ocupábamos:

Del registro etnográfico:

"Esta entrevista la realizo dentro del Instituto Horizontes, porque Joaquín no puede salir por estar con "medida cautelar". Lo espero en un pequeño cuarto que tiene un cartel "REQUISAS A MENORES", el cuarto será de 3 x 2 m., es un espacio totalmente cerrado, con el techo alto, como unos 4 metros y una rejilla de ventilación arriba, la puerta está golpeada, algo quebrada a la altura de la cerradura como si le hubieran dado patadas. El cuarto tiene dos pequeños pupitres escolares. Las paredes están todas horadadas con rayas hechas con algún material punzante, y otras rayas. Observo y me llama la atención que está todo lleno de grupos de rayas, como garabatos hechos con lápiz, además arriba de los bancos se ven unas manchas como huellas de manos con tinta. Llega Joaquín con el guardia, lo saludo, nos ponemos a conversar, y sale el tema de las paredes rayadas":

Entrevista a Joaquín:

E: ¿y estas cosas...? (Señalo la pared)

Joaquín: (mira la pared y pregunta) ¿qué es lo que es eso?

E: No sé... son como rayitas...

Joaquín: Rasguñado es, acá verduguean a lo choros, los hacían cagar tanto que rasguñaron las paredes los choros, ja.

$\mathrm{E}:$ ¿A vos te parece?...

Joaquín: Naaa, son mentiras que dicen (se ríe) ... que rasguñaban los chicos acá, que les pegaban... dicen... ¿Sabés lo que quiere decir?: que acá uno ha estado al pedo y se ha puesto a rayar"

Del registro etnográfico:

"Me costaba diferenciar entre lo dicho en serio y lo dicho en broma por Joaquín, trataba de comprender, pero me costaba... y me venía a la mente la letra de la canción de Sui Géneris, Rasguña las Piedras: "Detrás de las paredes/ que ayer te han levantado/ te ruego que respires todavía...". El entorno de esta sala de requisas, y la conversación con Joaquín me dejaron muy impresionada"

De cada entrevista con los jóvenes, van quedado nuevas preguntas, nuevas dudas, la necesidad de buscar nuevas explicaciones, de seguir indagando, preguntando, registrando. La entrevista con Joaquín fue una de las más largas y nos orientó respecto a 
la escritura de las paredes, nos indicó específicamente que fuéramos a ver las paredes del CAD, nos dio herramientas para seguir indagando, pero, sobre todo, como para que no lo perdamos de vista, nos advirtió sobre la dura realidad que viven los jóvenes en el lugar donde estamos trabajando.

Daremos cuenta ahora de las escrituras en las paredes. Nos basaremos en las explicaciones que los jóvenes hacen de ellas. Para eso contamos, como mencionamos, con entrevistas personales, registros de conversaciones, y la entrevista grupal -grupo de discusión- sobre estas escrituras. Esta descripción de los jóvenes será cruzada -como venimos haciendo- con aportes del marco teórico y el propio análisis.

Giorgio R. Cardona, en Antropología de la escritura, desarrolla los conceptos de dominio, situación y evento de escritura. Como dominio define a "un conjunto de situaciones sociales tipificadas y reguladas por normas de conducta". Cardona aclara que en sociolingüística se habla de cinco dominios: familia, amistad, instrucción, religión y empleo. Él propone para la escritura los siguientes dominios: de lo magisacro, de las transacciones económicas, de la instrucción formal y la producción literaria, y del poder político y las leyes. Cardona resume estos cuatro dominios propuestos, en cuatro espacios que son sede de cuatro tipos de situaciones: el templo, el mercado, la escuela y el palacio. (Cardona, 95, 1991). La cuestión es que Cardona en esta clasificación se refiere especialmente a situaciones de escritura de las expresiones de poder. Más adelante, el mismo Cardona, cuando describe los factores de distribución del uso de la escritura, menciona otra clase de dominio, el dominio profano, contraponiéndolo al dominio religioso. Lo religioso "exige productos preparados con cuidado, sin ahorro de tiempo", en cambio las escrituras profanas, asociadas a la práctica cotidiana "deben poder realizarse con rapidez y con materiales fácilmente accesibles, con frecuencia en condiciones que no son perfectas" (Cardona, pág. 107). Agrega que en la escritura se puede determinar un tono del evento "se trata también aquí del tono musical extendido a la comunicación (y por lo demás, también en el lenguaje corriente se dice "en clave de broma", etc.)" (Cardona, pág. 97). La clave del tono puede sugerirse en lo escrito mediante elementos gráficos: como el color, el subrayado, elementos de demarcación, etc. 
Podremos observar más adelante estos distintos aspectos en los diferentes tipos de escrituras, más cercanas a lo religioso o lo profano; y los distintos tonos que aparecen a la vista desde los aspectos gráficos de lo escrito.

En su trabajo Una primera catalogación de las escrituras expuestas del medio rural en Castilla y León de la Red de Archivos, sobre las escrituras populares, Pedro Javier Cruz Sánchez analiza las relaciones entre escritura y espacio/soporte. Hace su observación a partir de escrituras del siglo XVI y describe a las escrituras expuestas como "un fenómeno acumulativo de grafías que favoreció la creación de un palimpsesto en el que se entremezclan escrituras piadosas, escrituras civiles, escritos de quintos, pastores o de emigrantes, símbolos religiosos con otros que no lo son, decoraciones alegóricas, etc.".

Cruz Sánchez, junto a Monteagudo Robledo, en Las escrituras expuestas populares: un patrimonio olvidado (2011), presentan algunos criterios para una posible clasificación, proponen lo que ellos denominan ámbitos de escritura. Creemos que la idea de "ámbito" de Cruz Sánchez y Monteagudo, puede coincidir en algún punto con lo que Giorgio Cardona denomina "dominio". Estos autores separan medio urbano de medio rural, y dentro de estos, los ámbitos ${ }^{98}$ : público/ privado/ de lo sagrado/ etc. Los mismos autores proponen otras posibles clasificaciones, como la que atiende a sus propósitos y usos: escrituras espontáneas, escrituras planificadas, escrituras copiadas, escrituras ocasionales, escrituras rituales y escrituras estacionales; todas estas posibilidades aparecen en nuestra indagación. Propósitos y usos nos resulta un criterio interesante, aunque, como vemos, los criterios pueden cambiar de acuerdo a lo que se quiera estudiar.

Para el análisis del graffiti carcelario en particular, encontramos orientación en el trabajo de Diego Navarro Bonilla Archivos y cultura escrita carcelaria: escribir y documentar la prisión desde el siglo XVI (2005). Allí se sostiene que si bien debemos analizar la tipología de lo que se escribe, en la escritura carcelaria debemos observar en primer lugar que el acto físico de la escritura está ceñido a un espacio, un tiempo y una motivación particulares. Navarro Bonilla propone las preguntas primordiales: “¿dónde y

\footnotetext{
${ }^{98}$ Dentro del medio urbano:

-Escritos en el ámbito de lo público y de lo privado (Letreros y placas, Fechas, iniciales, números o símbolos grabados. Vítores. Reinterpretaciones populares de los esgrafiados de tipo culto. Letreros, frases, fechas, iniciales y símbolos protectores. Escritura de emigrantes. Escritos de quintos. Tejas escritas.) / Escritura en el ámbito de lo sagrado/ Escritura en la cultura material.

Dentro del medio rural: Escritos de pastores. (Frases, fechas y nombres. Dibujos)/Escritos de molineros.

(Nombres y letras. Cuentas)/ Símbolos protectores en el campo/ Escritos para tiempos de guerra.
} 
cómo se escribe?, ¿qué instrumentos se utilizan?, ¿la escasez de elementos sustentantes y sustentados propició una gran variedad de soportes de escritura carcelaria?" Este autor advierte que las respuestas a estas preguntas quedan mediatizadas por el propio discurso del poder.

Para nuestra presentación de las escrituras decidimos tomar en cuenta, para empezar, algunas preguntas esenciales que presenta Navarro Bonilla, sobre dónde, cómo y con qué se escribe. Creemos que el análisis debe situar las escrituras en su espacio y en su tiempo concreto, poniendo en primer lugar sus condiciones y posibilidades de producción, lo que condiciona los demás aspectos.

\subsection{3. ¿Dónde, cómo y con qué se escribe?}

Si preguntamos ¿dónde se escribe? sabemos que se trata de las paredes dentro de una institución donde los jóvenes viven privados de la libertad por haber cometido delitos. Un espacio de encierro, vigilado, y compartido con otros jóvenes, territorio a la vez compartido solo con los guardias, quienes ejercen el control y la autoridad. Se trata de un soporte público sobre el cual, si bien no hay claridad sobre su permiso-sanción para ser escrito, podríamos caracterizarlo como un soporte clandestino, que produce una escritura a veces efímera y siempre trasgresora

Sobre cómo se escribe y qué instrumentos se utilizan, pudimos indagar en base a las escrituras registradas y en el grupo de discusión y las entrevistas. Queda claro que los elementos utilizados son sumamente restringidos a las posibilidades del contexto de encierro y generalmente clandestinos. Las formas de escritura que aparecen son: horadaciones en la pared, siempre con elementos alternativos que encuentran en el espacio, en algunos casos, materiales no permitidos, recolectados del suelo o algún material escolar de la escuela del encierro. Las condiciones son siempre precarias, se escribe con lo que se tiene "a mano", y "como se puede", hasta un pedazo de jabón puede ser un elemento de escritura.

Ya hechas en capítulos anteriores las descripciones del contexto donde se escribe, seleccionamos algunos ejemplos para describir cómo y con qué instrumentos se escribe: 


\section{Horadaciones:}

Aparecen sobre todo en la parte inferior de la pared, más oscura y rugosa. Los elementos de horadación pueden ser: un botón, un cierre, un pedazo de vidrio o de hierro, u otro elemento duro. Son tallados sobre la pared, algunos muy profundos, son escrituras hechas, como describe Cardona, con cuidado, sin ahorro de tiempo. Las temáticas que aparecen son en su mayoría religiosas, o familiares. En cuanto a los propósitos y usos: son escrituras más bien planificadas y cercanas a lo ritual.

\begin{tabular}{|c|c|}
\hline \multirow{2}{*}{\multicolumn{2}{|c|}{ Foto 1/paredes: CAD }} \\
\hline & \\
\hline & $\begin{array}{l}\text { E: les quiero preguntar... ven que ese está } \\
\text { grabado en la pared... ¿con que escriben en } \\
\text { la pared eso? } \\
\text { Ch1: Con un botón } \\
\text { Ch2: Con un cierre } \\
\text { Ch3: Con algo duro } \\
\text { Renato: Con un cierre, un cierre de una } \\
\text { campera. (Lo afirma con seguridad, hablando } \\
\text { en serio) } \\
\text { Ch: y si estás ahí cinco horas ahí, } \\
\text { enyugado... la cajeta... }\end{array}$ \\
\hline
\end{tabular}

\section{Símil "lápiz negro"}

Estas escrituras están en la mitad superior de la pared, de color gris claro, el trazo es rápido y en general menos cuidado que en las horadaciones. Son escrituras más espontáneas, u ocasionales. Los elementos con los que escriben son pedazos de baldosas, de ladrillos, y ocasionalmente algún lápiz que -como describía Leandropuedan tener escondido. La temática tiene en general más relación con la delincuencia, la policía, cercana a la escritura "profana", aunque también aparece el tema religioso.

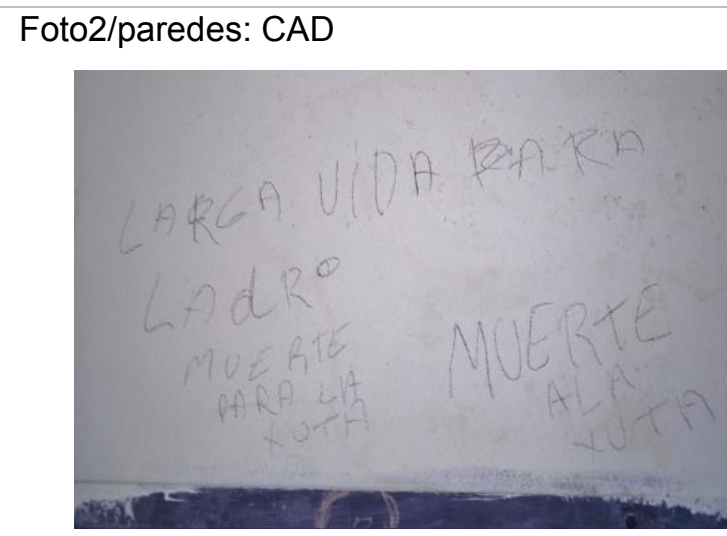

Grupo de discusión:

E: Yo observé, no sé ustedes, que en la parte blanca está escrito con lápiz negro...

Alan: Usted "se cree" que es lápiz negro...

Ch1: No es lápiz negro

Ch2: ¿¿¿de dónde va a sacar un lápiz negro???

Alan: ¿Sabe que es lo que es? ¿Vio la junta que le ponen a la baldosa, eso negro? Con eso escriben

Chs: (todos a Alan) ¡Ahhh! ¿Qué haces vos? ¡Escritor! ¡Qué hacés, escritor! Mc Giver!!! (Se ríen burlándolo) 


\section{Materiales escolares:}

Aparecen escrituras con materiales de la escuela. Sobre todo, en los Institutos donde se comparte espacio con la escuela. Se trata de material didáctico escolar que los jóvenes consiguen o acceden de diferentes maneras: pidiéndole a algún docente, a un guardia o entrándolos "de contrabando" al sector. A partir de estos materiales escolares surgen escrituras murales, muchas de ellas parecen ser cuidadas, planificadas.
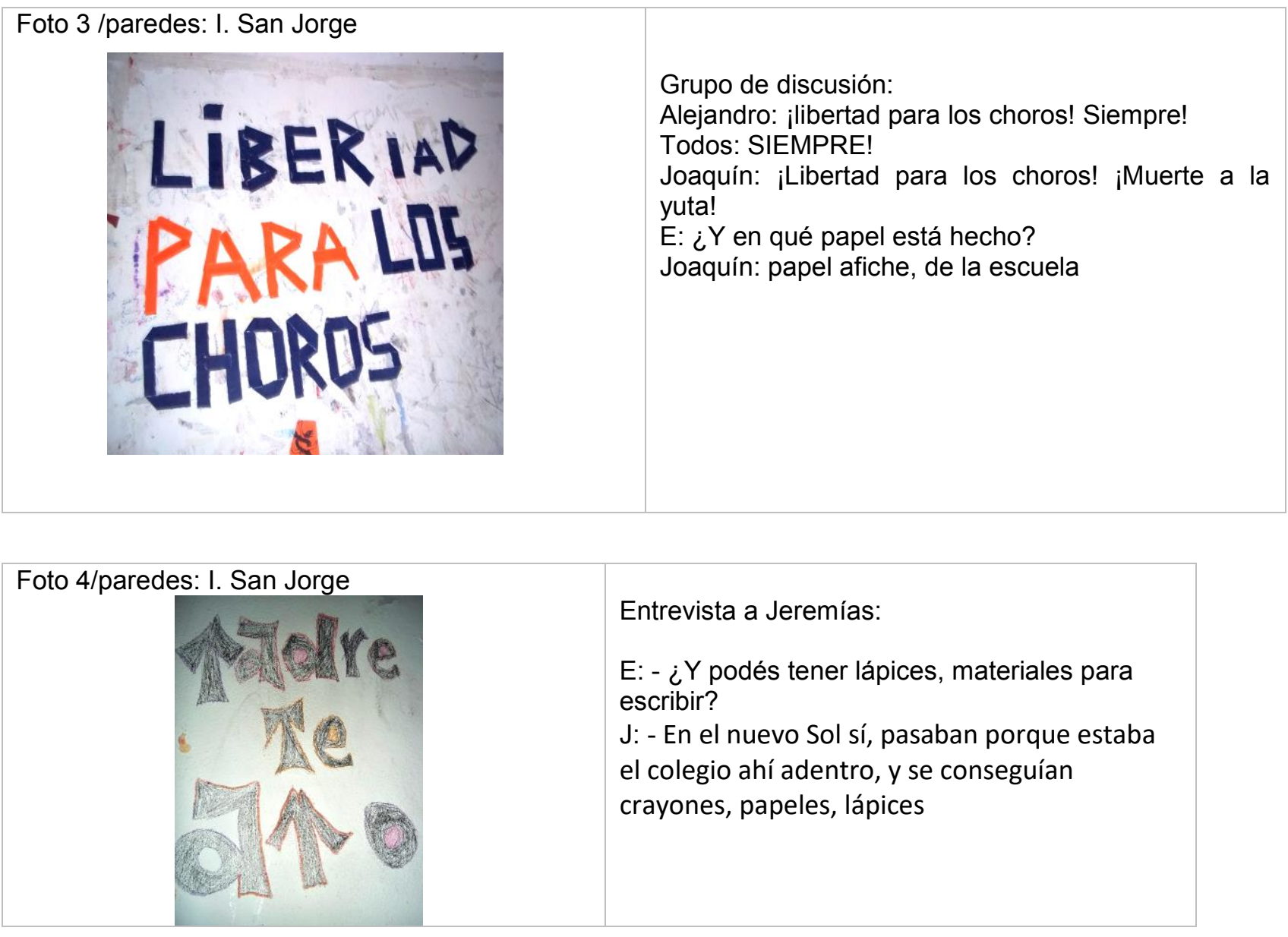

Podemos ver que ni las posibles sanciones de los guardias ni la escasez de elementos, cercenan la producción de escritura en la pared, sino que aparecen, por el contrario, una gran variedad de instrumentos alternativos de escritura: desde las horadaciones con cualquier elemento duro que pueda raspar el muro, hasta partes de baldosa, ladrillo, junta de baldosas, u otros elementos que sirvan para marcar, todos con un único soporte: la pared.

Dijimos que Cardona diferencia escrituras del dominio profano y del dominio religioso, y a la vez su relación con los elementos, el tiempo y la labor de escritura, más 
cuidado en lo religioso, más rápido en lo profano. Hasta aquí venimos describiendo el dónde, el cómo y con qué escriben, o tienen la posibilidad de escribir. Vamos observando distinto tipo de formas de escrituras en relación a distintos ámbitos. Ensayaremos la cuestión de los ámbitos de escritura -específicamente para nuestro trabajo- para un análisis de la relación de otros aspectos: el qué, y el para qué.

\subsection{4. Ámbitos de la escritura: ¿qué y para qué escriben?}

En el marco de una investigación cualitativa -basada en los datos- nos propusimos construir categorías de acuerdo a nuestro campo, es decir, categorías que surgen a partir de los datos. Los antecedentes y premisas teóricas de las que venimos hablando nos sirven de base y nos ayudan a orientarnos para construir nuestros propios criterios,

Toda esta escritura mural pertenece en sí misma al ámbito de lo público, por el solo hecho de estar expuestas en los muros: "el concepto de escritura expuesta se ha de relacionar con aquella que se encuentra localizada en el espacio público como expresión de determinadas prácticas sociales" (Cruz Sánchez, Monteagudo Robledo, 2011, pág. 2). Es particular la situación de las escrituras que analizamos, por encontrarse en los muros de una institución de encierro, donde como dijimos, por un lado, todo se vuelve público, pero a su vez se trata de un público restringido a los actores del encierro: los propios jóvenes encerrados y los guardias que ejercen la vigilancia.

En base a nuestra observación y registros proponemos una posible clasificación de las escrituras que los jóvenes escriben/tallan/horadan en la pared en la cotidianeidad del encierro, de acuerdo a ámbitos de escritura, en un acercamiento a la respuesta a la pregunta ¿qué escriben?:

- El ámbito personal- lo legal: Este ámbito incluye los nombres propios, la madre, la familia, los barrios, el fútbol. Tiene que ver con la vida familiar antes del encierro, los vínculos más cercanos, el barrio: todas las actividades legales de su vida en libertad.

- El ámbito religioso- las súplicas/las cruces: aquí aparecen tanto escrituras como dibujos religiosos, súplicas, pedidos de perdón, las creencias: Dios, el gauchito Gil. 
- El ámbito de la temática de lo ilegal: todo lo relacionado a lo ilegal dentro y fuera del encierro. Aparecen temas como la delincuencia, la droga, la policía, el encierro, el "verdugueo", y los códigos y símbolos "tumberos".

- El ámbito de la libertad: colocamos a la libertad como un ámbito propio, la libertad como necesidad urgente, incluye todas las escrituras de la palabra libertad, los dibujos, los calendarios.

6.4.4.1. Sobre lo registrado en cada espacio en cruce con los ámbitos de escritura99:

La primera mirada que proponemos, es una presentación de todas las escrituras en cada espacio, y los ámbitos que aparecen en cada uno de ellos:

- Instituto San Jorge (100 escrituras)

- 44 del ámbito personal - legal: los barrios (9), nombres solos (14), madre (16), madre y padre (3), hijo (1), amor (1),

- 34 del ámbito de lo ilegal: marihuana (2), escraches e insultos (5), delincuencia (4), muerte a la yuta (12), signos tumberos (2), tumberos (1), dibujos (3), letras de canciones (6)

- 12 del ámbito de la libertad: libertad (6), calendarios (4), dibujos (2)

- 9 del ámbito religioso: dios (8), un dibujo (cruz)

En este Instituto se encuentran los más jóvenes del Complejo Esperanza: niños desde 11 años hasta los 14 o 15 años. Vemos que, dentro de todos los ámbitos, el que más frecuentemente aparece es el ámbito personal: el tema de la madre aparece como el tema principal, luego el nombre y el barrio. El nombre de los barrios se repite junto con la firma en muchos casos, como por ejemplo "El Wacho Dani de Bialet”. Dentro del ámbito de la delincuencia, que ocupa un segundo lugar, la escritura que predomina es: "muerte a la yuta". De todas las escrituras el total de firmas y escrituras firmadas es de 26 , o sea un $28 \%$ aproximadamente: nos interesa ir prestando atención al tema de las firmas ya que más adelante dedicaremos un capítulo especial a la cuestión de la escritura del nombre en la pared.

\footnotetext{
${ }^{99}$ En el anexo final adjuntamos el inventario del total de las escrituras registradas.
} 
- Paredes CAD (71):

- 36 del ámbito personal- legal: nombres (6), madre (11), papi mami (2), papá (2), familia-abuela hijos-(5), novia (8), barrios (2)

- 15 del ámbito de lo ilegal: delincuencia (2), muerte a la yuta/guardia/policía (8), muerte (5)

- 15 del ámbito religioso: dios (7), gauchito Gil(2) madre/dios (1), cruces (5)

- 5 del ámbito de la libertad: libertad (5)

De las paredes del CAD, como consta en la descripción de entrada, se registraron abundantes escrituras, la mayoría copiadas a mano, y algunas fotográficamente. No pudimos cuantificar los dibujos, pero observamos en especial la abundante cantidad de cruces.

Respecto al anterior - el San Jorge- se ve una fuerte presencia del ámbito familiar, aparecen además de la madre: padres, abuelas, novias. Encontramos dentro de lo escrito solo diez firmas, un $15 \%$, menos que en el anterior. En el ámbito religioso aparecen los pedidos a Dios y la devoción al Gauchito Gil.

- Escuela -mesas, paredes- (64):

- 32 del ámbito personal: nombres (17), barrio (10), novia (1), madre (1), fútbol (1) otros (2)

- 29 del ámbito de lo ilegal: insultos -perro/ tu mamá- (5), muerte a la yuta (5), marihuana (1), otros (2), símbolos (11), dibujos (5)

- 3 del ámbito de la libertad: libertad (1), dibujos (2)

- 0 del ámbito religioso: ninguno

Del total de 64 registros en las mesas y paredes de la escuela, el ámbito personal y los nombres en particular es el más frecuente, encontramos 20 firmas, o sea un $37 \%$. Aparecen aquí muchos dibujos y símbolos, en general relacionados a la temática de la delincuencia (como los 5 puntos) y lo curioso es que directamente no aparece el ámbito religioso. 


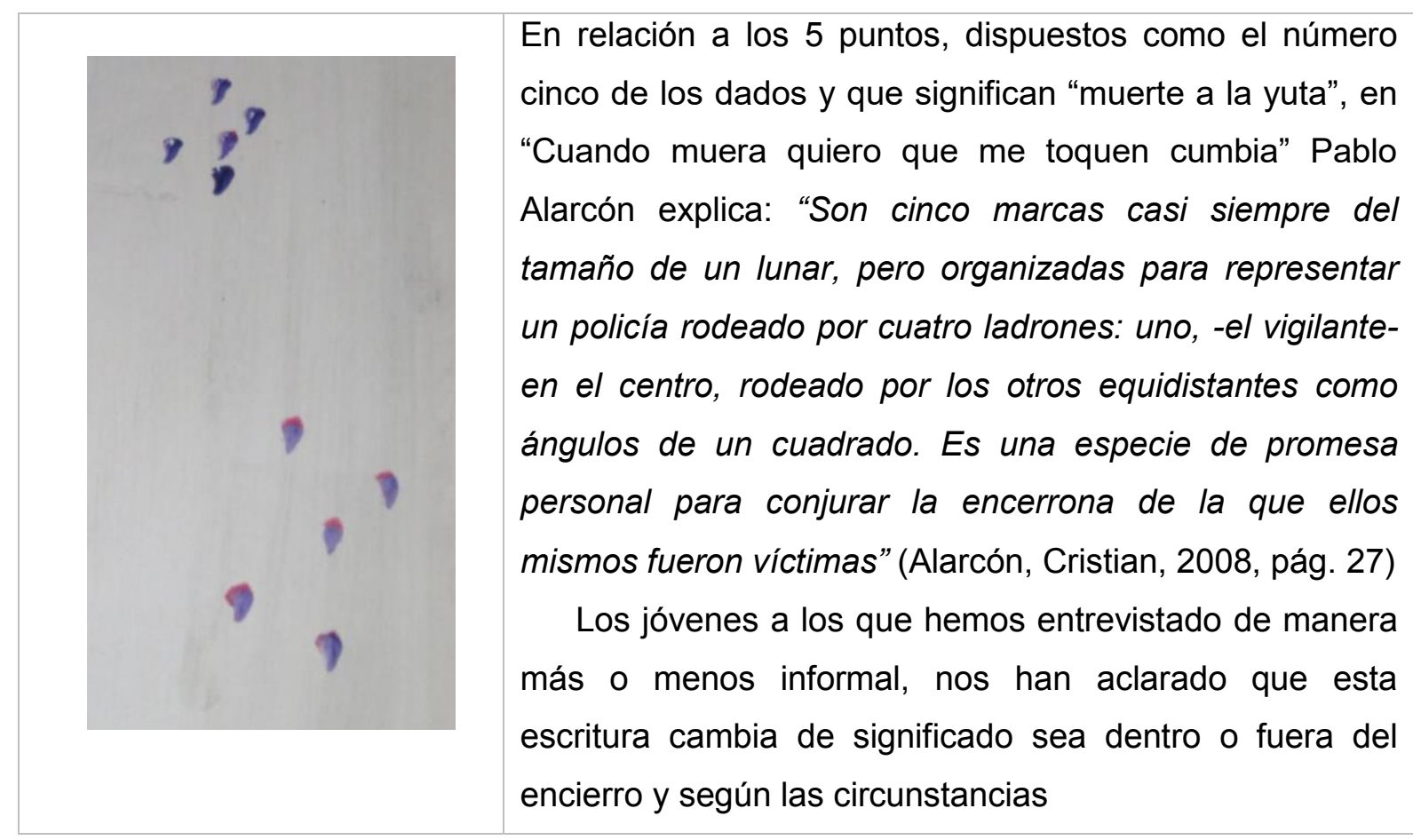

Decidimos incorporar estas escrituras cotidianas en la escuela porque, a pesar de no estar ubicadas en los sectores donde los jóvenes viven, la escuela también forma parte del espacio del encierro, aunque como nos expresa el coordinador, sea "el afuera del adentro". Este registro nos permite apreciar algunas rupturas y continuidades de la escuela respecto al "adentro" de los institutos.

- Patio del Instituto Horizontes (14):

- 3 del ámbito personal-legal (no nombres propios)

- 9 del ámbito de lo ilegal: insultos (7), delincuencia -símbolos- (2)

- 1 del ámbito de la libertad:

- 0 del ámbito religioso.

El patio del Instituto Horizontes no tiene escritos nombres, los que están escritos están escritos por otro a modo de insulto, por ejemplo "Diego perro ${ }^{100 " . ~ A p a r e c e ~ u n a ~ f r a s e ~ s o b r e ~}$ la libertad y no aparecen escrituras del ámbito religioso.

\footnotetext{
100 "Perro" es un insulto carcelario frecuente. La revista Tumbando rejas en su diccionario lo define como: Joven que realiza lo que le ordenen hacer
} 
Lo que aparece como "telón de fondo", es un gran mural con un dibujo y una frase de Don Bosco en la base cuyo principio está borroso: “...de las alegrías de los jóvenes. Ellos son dóciles cuando están convencidos de que se los ama", se trata claramente de una escritura desde la institución / el poder, que hace alusión a los jóvenes y la necesidad de su docilidad. Imposible no relacionarlo con la idea de una sociedad disciplinada en la que se busca formar individuos dóciles y útiles, de Foucault: "Una "anatomía política", que es igualmente una "mecánica del poder", está naciendo; define cómo se puede hacer presa en el cuerpo de los demás, no simplemente para que ellos hagan lo que se desea, sino para que operen como se quiere, con las técnicas, según la rapidez y la eficacia que se determina. La disciplina fabrica así cuerpos sometidos y ejercitados, cuerpos "dóciles". (Foucault, 2001, pág. 142)

6.4.5. Presentación de las escrituras por ámbitos, en cruce con entrevistas a los jóvenes.

Haremos ahora una presentación de algunas de las escrituras concretas registradas en los diferentes espacios que venimos describiendo. Presentaremos una selección, analizándolas por ámbitos, a la luz de las palabras de los jóvenes en el grupo de discusión y clasificándolas, sobre todo por una necesidad organizativa, como venimos haciendo, en relación a cada ámbito:

- Del ámbito personal- legal:

En el Instituto San Jorge se destaca el nombre de los barrios, y los nombres propios, y aparece el nombre y el barrio como parte de la firma de otras escrituras. Como dijimos, la escritura para la madre ocupa el segundo lugar. $O$ sea que casi la mitad de las escrituras pertenecen a este ámbito. En el CAD, predominan en primer lugar las escrituras para la madre y la familia, y los dibujos religiosos. En relación al Instituto San Jorge, el CAD tiene una cantidad mayor de escrituras para la familia y aparecen las novias y los abuelos que en el anterior no aparecían. Es en la escuela donde encontramos mayor cantidad de nombres propios, y en el patio del Instituto Horizontes, ninguno.

Foto 5 /paredes: I. San Jorge 


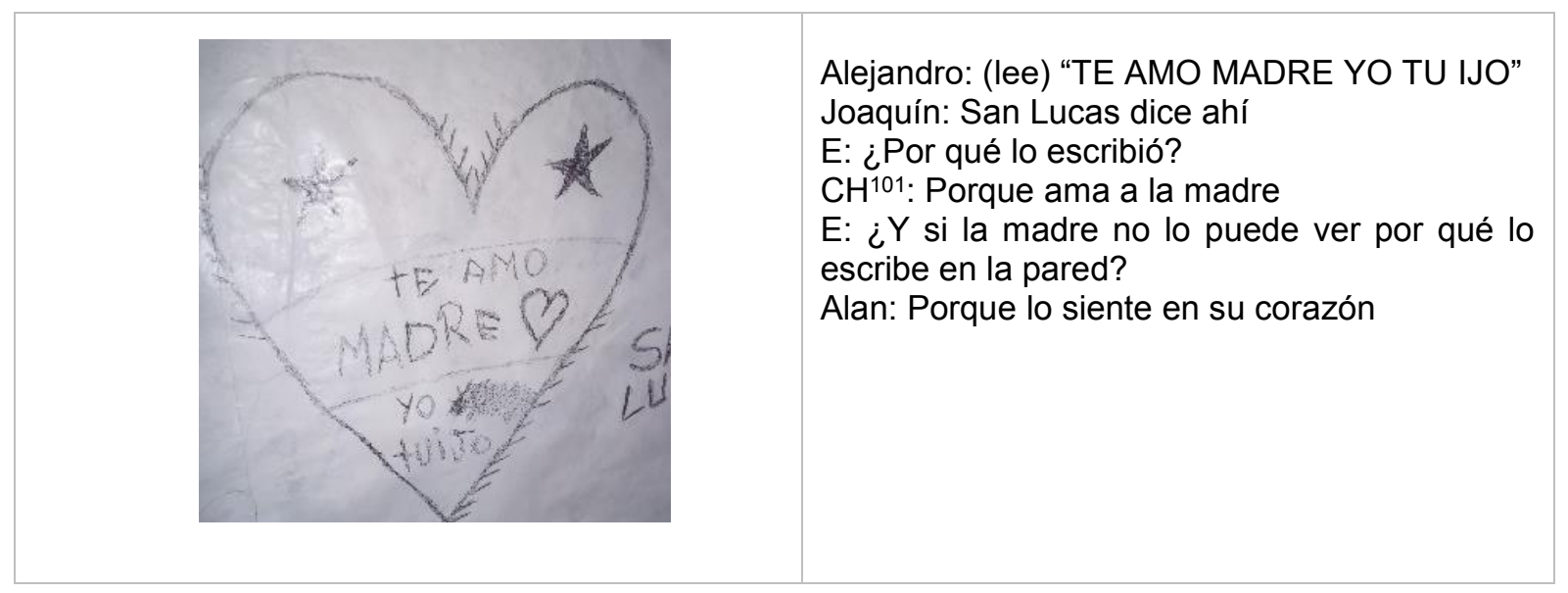

Fotos 6 y 7 /paredes: CAD

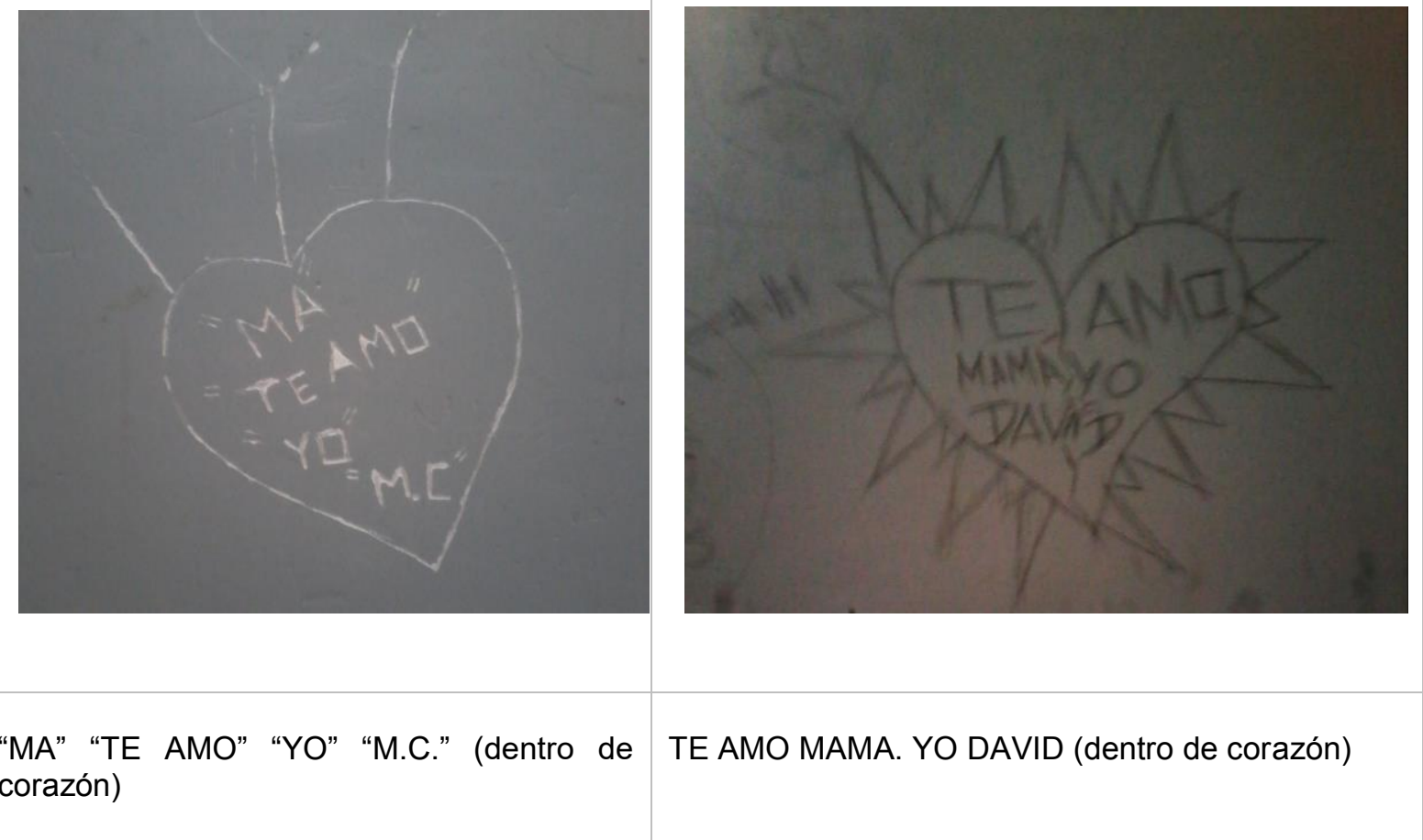

- Del ámbito religioso: las súplicas/las cruces

¿Qué es el texto cuando se trata de solicitar lo invisible, de ponerlo en escena, de usarlo para curar el cuerpo y el espíritu? Aunque este invisible esté fuera de nosotros, en nosotros o pasando de uno al otro, no dejamos de señalarlo, de esperar que dé una señal, de solicitarlo por escrito. (Fabre, 1993)

${ }^{101} \mathrm{CH}$ : Chico 
En el Instituto San Jorge y en el CAD encontramos una cantidad de escritura religiosa y sobre todo en el CAD, cruces horadadas en la pared que no llegamos a cuantificar. En el patio del Instituto Horizontes no aparece escritura religiosa, como así tampoco en la escuela.

Foto 8/paredes: I. San Jorge

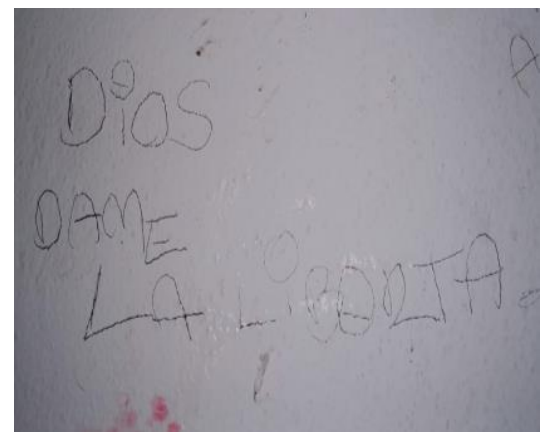

Ch: (lee) "DIOS DAME LA LIBERTA"

Alejandro: "Calla ladrón en tu silencio está tu libertad"

Joaquín: Esta en todos lados

$\mathrm{E}:$ ¿Y de dónde sacaron esa frase?

Alejandro: de acá adentro

Renato: Es vieja esa frase, es como "una rosa dura un día el amor de una madre dura toda la vida", está escrito por todos lados... ayer vi uno que lo tiene tatuao...

Fotos 9 y 10/paredes: I. San Jorge

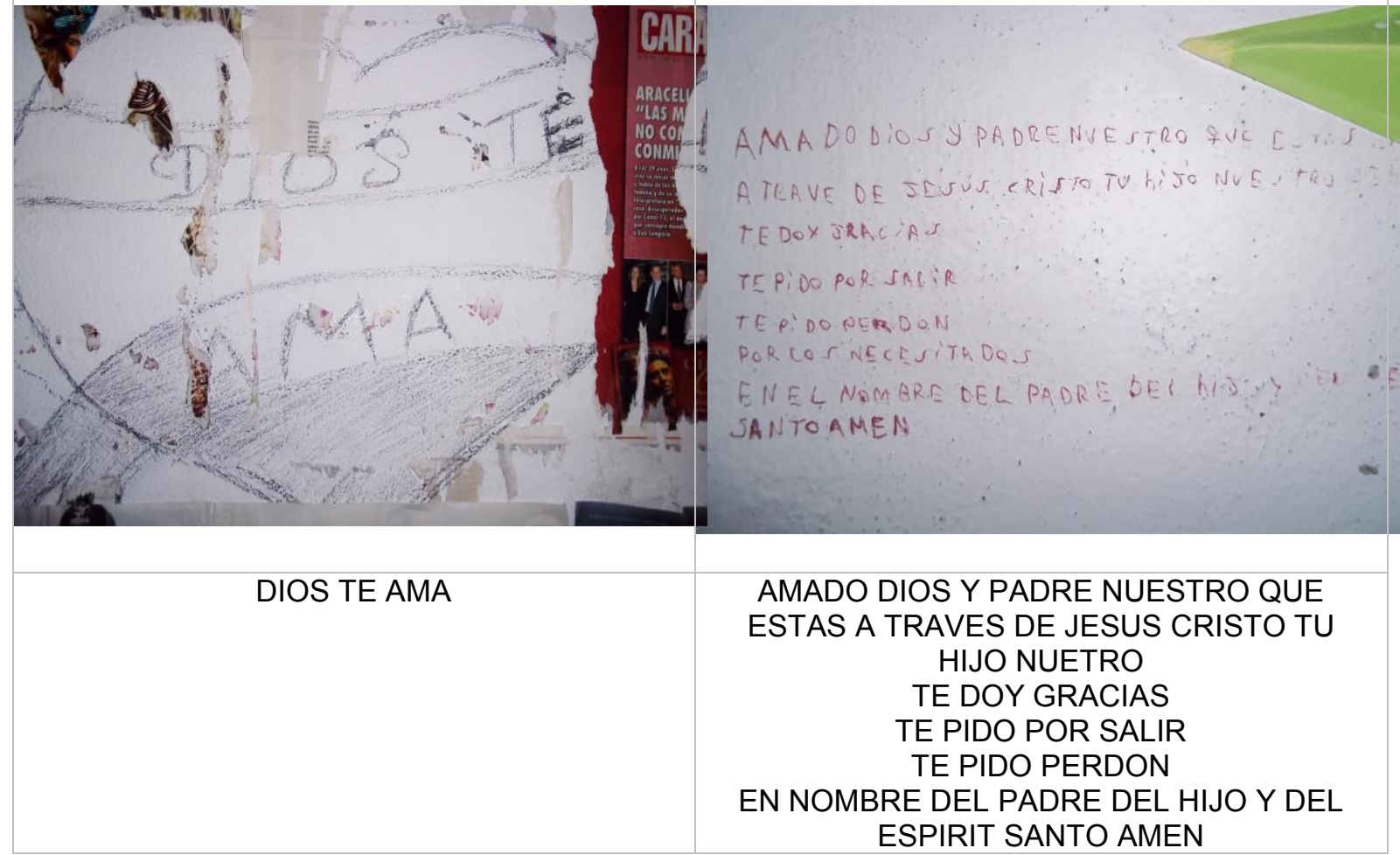


- Del ámbito de lo ilegal:

La letra se instala en la pared en busca de trascendencia y como denuncia. En efecto, a lo largo de la historia, el graffiti ha funcionado en diversos contextos como una estrategia contra el silencio: en este caso el que impone la institución carcelaria (Gándara, 2005)

En el registro del Instituto San Jorge, abunda la escritura a favor de la delincuencia y en contra de la policía. De la misma manera, en el CAD registramos una cantidad de escrituras con la leyenda "muerte a la yuta/guardia/policía", varias sobre el deseo de libertad y algunas a favor de la delincuencia, como "viva la delincuencia" o "larga vida al ladrón". Pero en proporción, donde mayor cantidad de insultos relacionados al encierro encontramos es en el patio del Instituto Horizontes. La frase que se repite en la mayoría de las escrituras es "muerte a la yuta", Joaquín aclara que esa frase "es la religión de los choros". Por su carácter de súplica y de escritura ritual se acerca en algún punto a la escritura religiosa

Foto 11 /paredes: I. San Jorge

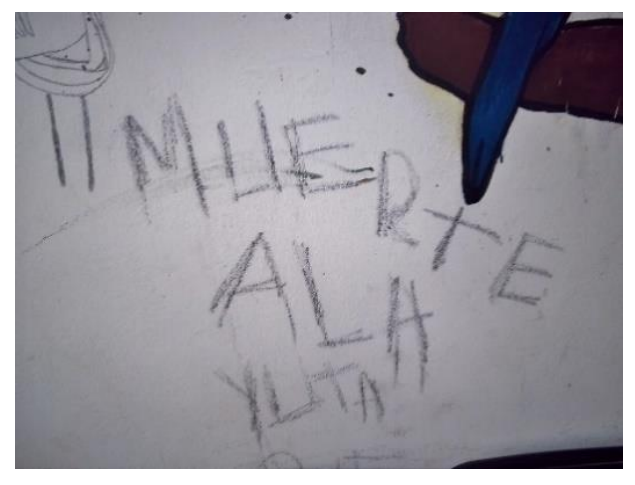

Joaquín: "Muerte a la yuta"

Renato: que se muera...

Alan: muerte a la policía

Alejandro: iiiMuerte a la Yuta!!!

Todos: Muerte! (suena como un ritual)

Joaquín: Esa es la religión de los choros:

muerte a la yuta.

Alejandro: ahhhhh!!!

Foto 12 /paredes: I. San Jorge

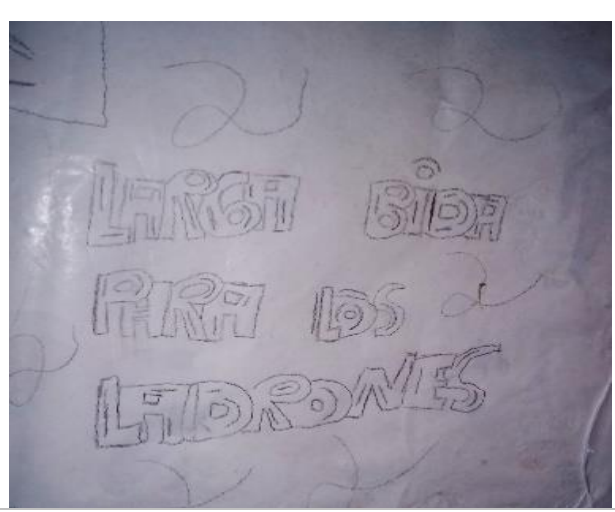

Alejandro: "Larga vida para el ladrón"

Renato: Muerte a la policía!!

$\mathrm{E}: \mathrm{Y}$ estos cositos...?

Renato: ¡Son detalles!

Joaquín: El moñito de la muerte.

naaaa 
Foto 13 /patio Instituto Horizontes

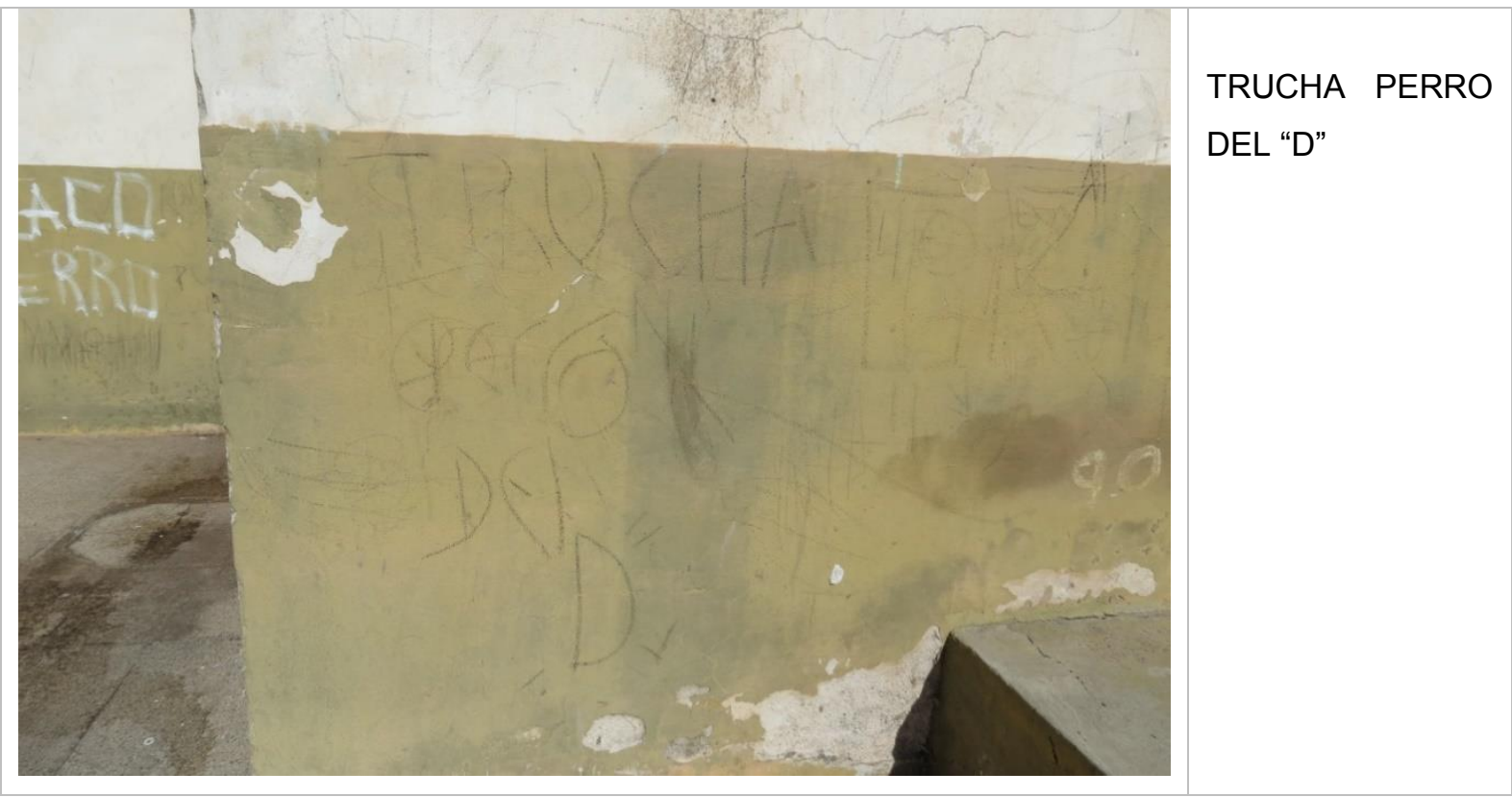

Repetidas veces, en las paredes del patio del Instituto Horizontes, aparece el insulto "perro". Para los jóvenes "perro" es quien, dentro del sector, obedece las órdenes de los demás.

También aparecen letras de canciones relacionadas al ámbito de lo ilegal: las registramos en el Instituto San Jorge y en el CAD. En general son letras de cuarteto, cumbia o rap que hacen referencia al tema de la delincuencia o la vida en el encierro:

Foto 14 /paredes: I. San Jorge 


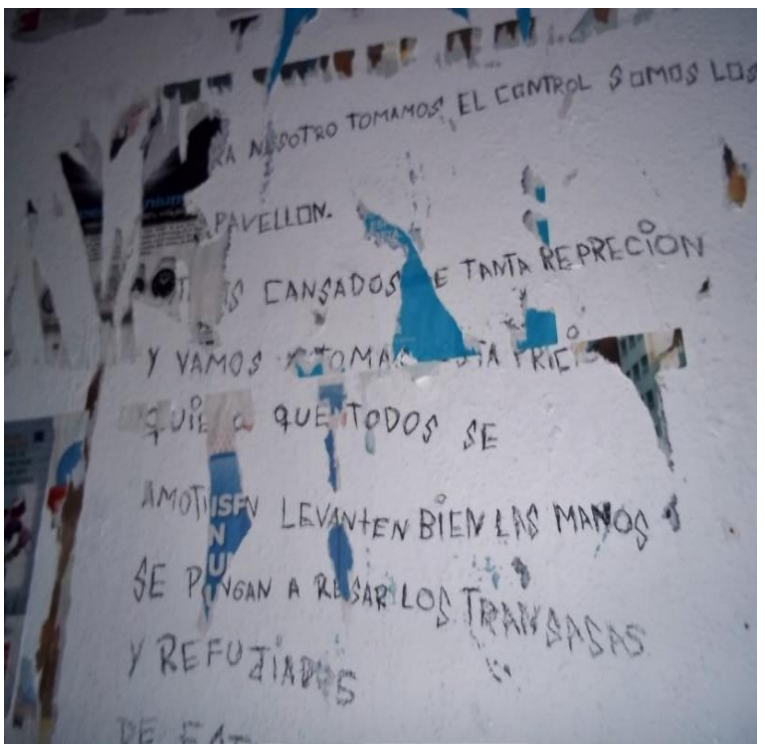

Alan: Es un tema de...los Pibes Chorros Todos: (Leen, cantan y aplauden) "Ahora nosotros tomamos el control somos los dueños del pabellón estamos cansados de tanta represión y vamos a tomar esta prisión Quiero que todos se amotinen levanten bien las manos que se pongan a rezar los guardias y refugiados"

Letizia: ¿Que son los refugiados? Joaquín: Los transas Ch: los que están con la yuta Todos: (siguen leyendo) E: ¿y esto lo escribieron porque iba a haber un motín o algo así? Alejandro: No, estaban fumados...

"Muerte a la yuta", "muerte a la policía": la escritura más repetida. Trataremos de explicar la compleja y conflictiva relación de los jóvenes y la policía. Para empezar, como ya mencionamos, los jóvenes vienen siendo víctimas de la violencia institucional, y en particular, de la violencia policial. Esteban Rodríguez Alzueta en su trabajo, hace un análisis minucioso de la violencia por la que pasan los jóvenes, que coincide con los relatos de los jóvenes entrevistados por nosotros. Este autor hace una enumeración de experiencias, "prácticas menores" generalmente invisibilizadas -incluso para sus propios destinatarios- por las que pasa un joven, antes de ser víctima del "gatillo fácil":

"Para cuando a un pibe lo gatillaron seguramente ese mismo pibe antes fue demorado en la comisaría varias veces, lo pasearon en el patrullero, lo detuvieron por averiguación de identidad sesenta veces en un año, lo cachearon en la vía pública de manera humillante varias veces... Entonces de lo que se trata es de referenciar estas "prácticas menores" como violentas porque son las que habilitan o van creando condiciones para esas otras prácticas." (Rodríguez Alzueta, 2016)

Rodríguez Alzueta explica que en la violencia policial -más allá del objetivo de reducir a una persona o de obtener información sobre determinados hechos- existe una dimensión expresiva que no hay que perder de vista: cuando un policía ejerce violencia sobre un joven le está marcando el territorio, está queriendo comunicar algo y se sirve del cuerpo de ese joven para utilizarlo como una suerte de bastidor donde inscribe mensajes (Rodríguez Alzueta, 2016) 
"Cuando hablamos de violencia policial, no estamos pensando en una "política de estado" sino en prácticas políticas. Esto significa que no se trata de una política decidida en las más altas esferas, sino que forma parte de las rutinas cotidianas, institucionales, con las que se mueve la policía" (Rodríguez Alzueta, 2016)

Estas prácticas policiales violentas cotidianas hacia el joven, en la provincia de Córdoba están en cierta forma habilitadas por el Código de Faltas, y de hecho denunciadas año a año en la Marcha de la Gorra (que mencionamos en la primera parte). Creemos que estas prácticas violentas convierten a la policía en el enemigo número uno del joven, quien, como señala Kessler, percibe a la policía como "una banda más", enfrentada a muerte con él (Kessler, 2004). Así lo expresan las escrituras de las paredes: Muerte a la yuta es "la religión de los choros", como nos explica Joaquín.

- Del ámbito de la libertad:

"La libertad, Sancho, es uno de los más preciosos dones que a los hombres dieron los cielos; con ella no pueden igualarse los tesoros que encierra la tierra ni el mar encubre; por la libertad, así como por la honra se puede y debe aventurar la vida, $y$, por el contrario, el cautiverio es el mayor mal que puede venir a los hombres"

Don Quijote, Segunda Parte, Capítulo LVIII

La palabra Libertad aparece en todos los registros, su escritura es una práctica casi ritual, es un pedido o una súplica. Por eso también podemos decir que se acerca al ámbito religioso. La libertad representa sin dudas el valor más alto dentro del encierro "un don precioso". Es todo lo que desean. Es tan obvio el deseo y su valor por su oposición al cautiverio "el mayor mal", que cuesta explicarlo: "La libertad es algo muy valioso para uno, es lo más valioso.", expresa Joaquín.

Agustín, en una escritura en la escuela del encierro, ensaya una prosa sobre la libertad:

Al no tenerla te ponés a pensar en el sol que te esté dando en la cara, el canto de los pájaros, hasta te ponés a oler ese olor al aire libre al lado de una ventana con rejas con huecos muy chicos. (Agustín) 
En un terreno cargado de contradicciones la escritura reiterada de la palabra libertad se presenta como un desafío a la prohibición (prohibición de escribir). La trasgresión que es la escritura, su poder y sus contradicciones se pueden ver representadas en la palabra libertad escrita una y mil veces sobre la pared del encierro

Foto 15 /paredes: I. San Jorge

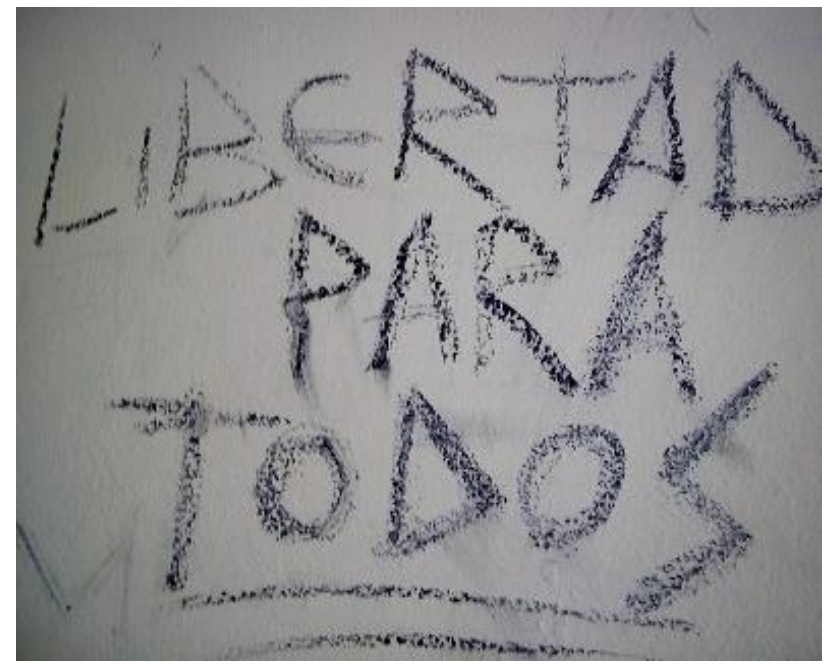

Joaquín: (lee) "Libertad para todos" $\mathrm{E}:$ ¿con que está escrito?

Alan: Con lo negro que te digo yo...

Ch: (todos) no...nooo...

Alan: con eso es... ¡si yo lo he visto!

Ch: calmateeee! Que te interesaaaa!

Alejandro: ¿adónde viste eso??

Alan: $\mathrm{Si}$, yo le he visto...que escriben con eso ipor eso lo digo!

Todos: (los chicos lo burlan)

$\mathrm{E}$ : ¿para qué lo escribió? Con qué sentido hizo esta escritura?

Joaquín: Pidió libertad para todos los

delincuentes, lo que dice

Alejandro: libertad para todos los choros

Foto 15/ Patio Instituto Horizontes

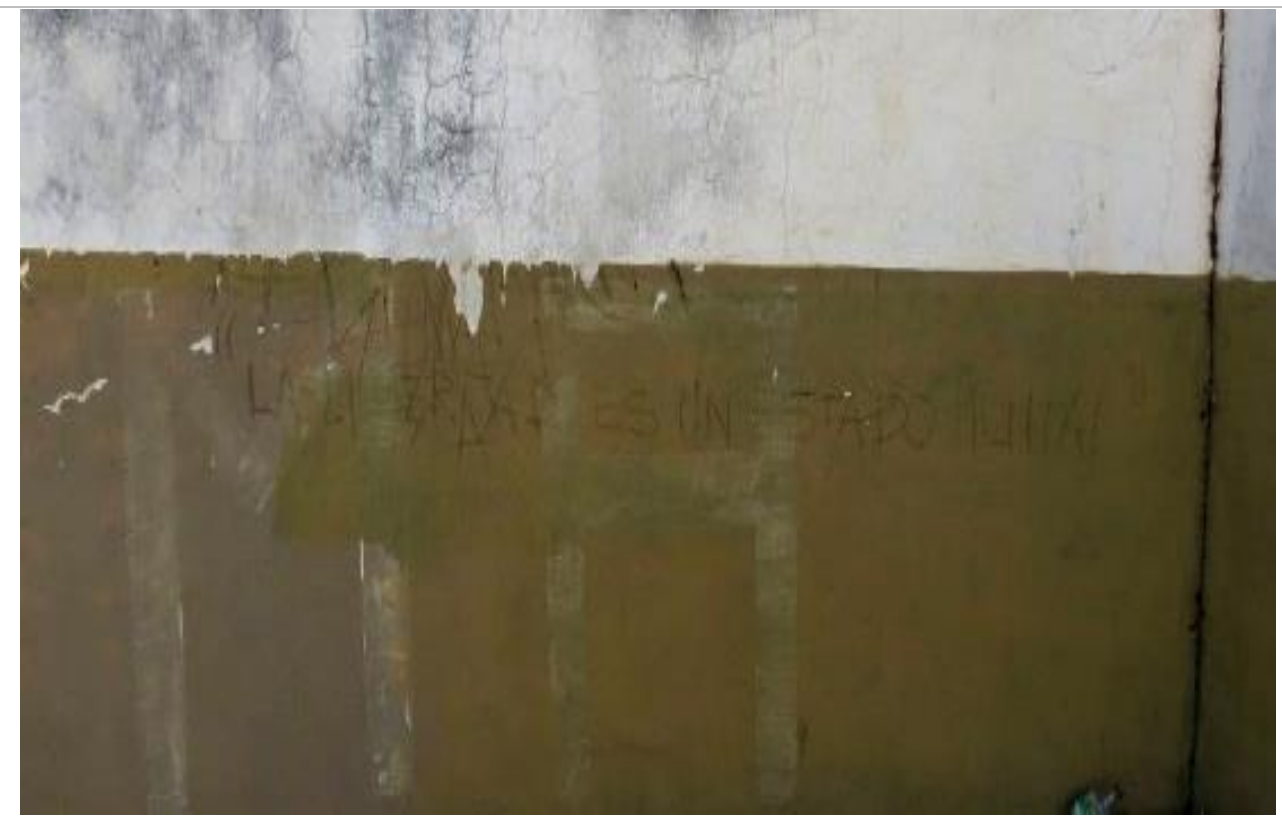

LA LIBERTAD ES UN ESTADO MENTAL

6.4.6. Breve cierre y apertura: 
Queremos cerrar este apartado como una apertura a seguir investigando. Nos propusimos aquí, como dijimos, una presentación y descripción de las escrituras, como parte de un capítulo de esta tesis sobre la experiencia cotidiana de escritura de los jóvenes privados de la libertad. No pretendemos haber hecho un análisis exhaustivo, creemos que esta indagación puede hacer un aporte para generar nuevas preguntas y problematizaciones. El asunto es suficientemente complejo, por lo que consideramos a esta parte de nuestro trabajo como una primera aproximación al tema que, creemos, amerita continuar y profundizar. A continuación pondremos foco sobre una escritura en particular: el nombre en la pared.

\subsection{El nombre en la pared: La pared te llama}

"Pero ignoras que fuiste tú, con tus invocaciones inoportunas pronunciando el Nombre, quien me precipitaste de lo alto contra mi voluntad. ¡El Nombre produce ese efecto en todos nosotros! ¡Por eso no lo pronunciamos jamás!" Entonces yo, para que me sacara de aquella montaña, le dije: ¡Perdona y no me riñas; pues, en verdad, yo no podía adivinar las consecuencias funestas de mi homenaje al Nombre! ¡Te prometo no volverlo a pronunciar durante el trayecto, si quieres transportarme ahora a mi casa!"

Fragmento de Simbad el Marino, Las mil y una noches

En el último viaje de Simbad el Marino, el hombre volátil le advierte: ¡El Nombre produce ese efecto en todos nosotros! $!^{102}$ El nombre propio no es nunca una designación arbitraria o un simple grupo de sonidos, el nombre expresa la naturaleza y la historia de aquel que es designado con él. desarrollar

Vamos a analizar ahora el significado de la "impronunciabilidad" del nombre, esta vez, la del nombre escrito en la pared del encierro. Transcribimos a continuación fragmentos de entrevistas y registros que dan cuenta de la forma en que este tema irrumpe:

${ }^{102}$ El fragmento de Simbad el Marino está relacionado al pensamiento judío de que el nombre de Dios es impronunciable. Dios le dice a Moisés en la Biblia: "Yo soy el que soy" (Éxodo 3-14). 
Registro taller 4 de agosto

"Ya casi finalizando el taller Alejandro fue corriendo a escribir en la pared: "muerte a la yuta", era la segunda vez que lo hacía...les pregunté después a Braian y a Joaquín si ellos escribían las paredes, dijeron que no, que después que pintaron el sector, menos, y que además no está bueno escribir el nombre en ese lugar, porque "dicen que si escribís el nombre, el nombre te llama para volver a ese lugar"

\section{Entrevista a Enzo:}

"E: ¿Y si escribís tu nombre?

Enzo: No... Te llama... Cuando salís, te llama. Eso es lo que dicen...

E: ¿Vos nunca escribiste tu nombre?

Enzo: No... Y si lo he escrito me he arrepentido. Ya queda acá."

\section{Entrevista a Renato:}

"E: ¿Y qué se te dio por escribir tu nombre?

Renato: Lo que era la primera causa, no se... escribí mi nombre en el CAD, y después había escrito mi nombre acá, en el Nuevo Sol. Después me fui en libertad y me dijeron que nunca lo tendría que haber hecho eso... porque es la pared, que te llama, y a lo mejor fue por eso que volví a caer ahora la segunda vez...

$\mathrm{E}$ : O sea que es verdad eso que...

Renato: Sí, para mí sí, es verdad."

\section{Grupo de discusión}

"Un chico: (lee) "Vieja te amo una banda yo Nero"

E: Vieron que unos firman y otros no ¿Por qué pasa eso?

Alejandro: Porque muchas veces cuando pones el nombre, te llama...

Un chico: ii Eso "dicen"!!!...eso "dicen"...

Letizia: Que si pones el nombre... ¿Qué?

Alejandro: Te llama, la pared...te llama"

\section{"Entrevista a Braian:}

B: Yo escribo la pared, escribo mi nombre...mi apodo: Noncho. Dicen que te llama la pared por escribir el nombre. Ponele: yo escribo acá... y cuando me voy en libertad, como que me va a llamar...porque mi nombre ya queda acá, que me llaman las rejas... pero es mentira eso! Si vos haces las cosas bien en la calle no volvés más acá 
E: ¿Y por qué lo escribís?

Braian: Es un recordatorio. Yo me voy de acá y pasan muchos amigos míos por acá. Después me los cruzo en la calle y me dicen: mirá ahí está tu nombre...un suponer: en la esquina de mi casa hay un paredón, cuando era chico escribí Noncho, hasta el día de hoy voy a comprar pan...verdura... y ahí está todavía"

¿Qué puede representar la simple escritura del nombre, la aposición de una firma en las paredes del encierro? Parecería ser que entre escribir el nombre en la pared y no escribirlo se presentara nada más y nada menos que la alternativa entre un destino de encierro y uno de libertad. Pudimos corroborar que es una creencia muy difundida entre los jóvenes, que impone un código: no escribir el nombre en la pared. Pero observamos a la vez que este código es muchas veces trasgredido, ya que -como vimos en los registros de la escritura en la pared- los nombres y las firmas están presentes en un gran número de escrituras.

Entramos aquí al ámbito de las creencias de los jóvenes privados de la libertad, las que emergen en un determinado contexto y momento biográfico. Daniel Miguez (2012) considera que dentro del encierro se enfatizan algunas creencias y devociones "disponibles", muchas de ellas cercanas a la religiosidad popular, a veces en una recurrencia de prácticas religiosas que él llama "minimalistas":

“...el panteón espiritual que surge de esta variedad de alternativas religiosas pone a disposición de los marginados fuerzas espirituales que pueden colaborar en ese inestable y cambiante mundo social en el que habitan". (Miguez, 2012, pág. 61)

Miguez reconoce que junto a estas prácticas religiosas minimalistas se crean otras creencias y prácticas con características muy especiales (Miguez, 2012, pág. 49). Aldo Rubén Ameigeiras las denomina prácticas mágico-religiosas o el "universo simbólico mágico-religioso implícito en el mismo como su vinculación con las creencias y la dimensión espacio-temporal que las conforma" (Ameigeiras, 2015, pág. 372). Este autor se detiene en el análisis de la frase "creer o reventar" de un chofer de colectivo, con el que él entabla un diálogo, y analiza su creencia sobre una virgen que lo protege de sufrir un accidente. El reventar no aparece allí como una mera advertencia extrema:

"Es la expresión de una certeza fatal ante la cual se instalan salidas no pensables en otras circunstancias, pero, sobre todo, momentos en los que está en juego la habilitación de una dimensión del creer, que sin objeto definido en sí misma, 
emerge como significativa y potente para brindar respuesta ante el fenómeno". (Ameigeiras, 2015, pág. 376)

Para el colectivero existe un peligro cierto: un accidente. Para los jóvenes, el peligro es volver a perder la libertad, lo que se observa como un acontecer probable. Estos peligros obligan a tomar la decisión de creer: es un recurso extraordinario.

Los fenómenos de la vida diaria aparecen como imprevisibles: "explicitan la desnudez, el desamparo del individuo frente a la emergencia, el accidente, la violencia. Situaciones de enorme densidad vital ante las cuales se produce la irrupción de lo supra racional”. (Ameigeiras, 2015, pág. 376). El lugar puede ser también interpretado como una accidentalidad: "El lugar adquiere una significación propia que interactúa directamente con los ocupantes del espacio, transformándose en las coordenadas temporales de lo cotidiano donde el aquí es precisamente el ahora." (Ameigeiras, 2015, pág. 378)

Se trata entonces de una habilitación a la dimensión del creer que "la pared te llama", ante el peligro de "volver a caer". Se crea la necesidad de protegerse -la no escritura del nombre en la pared- para no volver a este lugar. Volver a estar preso es una situación de enorme densidad vital que en toda su dimensión se convierte en posible pero imprevisible y mágica a la vez.

Sobre esta creencia que une nombre y pared, podemos en principio decir, que puede tratarse de una práctica religiosa minimalista, como menciona Miguez (2012), o una creencia de tipo extraordinario, como denomina Ameigeiras (2015).

Si determinadas creencias -como la que hace referencia a que "la pared te llama"aparecen en este tiempo, y en este lugar como un recurso extraordinario, si son estas creencias que el mismo encierro habilita, nos preguntamos entonces aquí si la escritura en sí misma no puede llegar a aparecer también como recurso extraordinario que pueda ayudar a sobrevivir en ese inestable y cambiante mundo que habitan. Esta escritura ordinaria -en el sentido que las describe Fabre- puede emerger en forma significativa y potente como una salida no pensable en otras circunstancias y aparecer entonces como una escritura extraordinaria.

Esta creencia conjuga la fuerza de la escritura con dos fuerzas: la fuerza de la pared del encierro, que no es en absoluto cualquier pared, y la fuerza del nombre propio, que no es una palabra cualquiera. ¿Cómo se articulan estos elementos en una cuestión 
mágica o religiosa? ¿Puede la escritura del nombre en la pared del encierro, por sí sola y sin intervención de otros, desencadenar la acción de retener a la persona en el lugar?

Porque "la pared llama", como afirman los jóvenes en nuestra indagación, a quien escribe su nombre, y no otra escritura. Parecería que la pared tomara una fuerza, de forma mágico-sinérgica, a través del nombre inscripto, y a través de esa fuerza "reforzada", la escritura llama o retiene al nombrado.

La escritura, la pared del encierro, y el nombre, en una alquimia de significaciones cruzadas se potencian y adquieren ese poder que los jóvenes nos presentan como creencia, recurso extraordinario, que a la vez se convierte en norma: no se debe escribir el nombre propio en la pared.

Pero el nombre propio no solo designa una persona: promueve su singularidad. Como ya señalamos, el nombre cumple una función muy especial y privilegiada "es a partir del nombre que un hombre o una mujer se inscriben como individuos, como sujetos de derecho y como parte activa de su comunidad y su cultura." (Castedo, 2014, pág. 15)

Escribir el nombre es, con frecuencia, poner la firma. "Firma" deriva de la palabra latina firmāre, 'afirmar', 'dar fuerza', la fuerza de la firma. A lo que se suma lo que Fabre nos recuerda: la firma con frecuencia implica una conformidad. ¿En una pared del encierro la firma señalaría la conformidad con ese encierro, o sea, todo lo contrario, al anhelo de libertad? Nos preguntarnos si este nombre en la pared no podría estar señalando algún tipo de conformidad inscripta involuntariamente, que se estaría expresando como un efecto secundario de la necesidad imperiosa de la escritura del nombre.

Por otro lado, dice Fabre, sobre quien inscribe la firma, "se trata siempre de un sujeto que escribe por su propia mano. Este simple gesto lo califica como único, le confiere al menos la autonomía de un nombre propio" (Fabre, Pág. 19). Pensamos que puede ser que de esa cualidad del nombre propio nazca, la necesidad de escribirlo, e inscribirlo, más aún en un momento es que todo es totalizante y desindividualizante.

Indagamos además sobre las implicancias mágicas que por sí mismo pueda tener el nombre propio. Ya mencionamos el poder del nombre y su "impronunciabilidad". Sobre esta cuestión, Lorena Amaro (2010) describe las relaciones "mágicas" que se establecen con el nombre propio:

"cualquier daño o cambio hecho a un nombre, afecta a quien lo detenta. Los ejemplos son muchos, y se pueden perseguir en el campo de la antropología como 
también en el estudio de la cábala y las corrientes gnósticas del lenguaje” (Amaro, 2010, pág. 230)

Y más allá de la magia, la autora explica cómo, en referencia al mundo clásico, por ejemplo, sólo los nobles tenían un nombre propio. El resto eran los "proletarios", una vasta masa de "sujetos innominados" cuya única posesión era su prole. "La heredad del nombre, por tanto, conlleva una historia de exclusiones, censuras y desgarros". (Amaro, 2010, pág. 232)

La autora agrega que la atávica conexión con el nombre propio se proyecta de alguna manera en las costumbres actuales, como el hecho de castigar los delitos de calumnias e injurias, daños realizados contra el nombre de una persona (Amaro, 2010, pág. 230). Para su análisis Amaro retoma a Roland Barthes, quien respecto a la relación nombre-autor señala: "En el fondo, el escritor tiene siempre la creencia de que los signos son arbitrarios y que el nombre es una propiedad natural de la cosa (Barthes, 1981: 54)"

Relación, creencia religiosa o pensamiento mágico, el poder del nombre en la pared, más que protección o "efecto benéfico", produce un peligro, efecto mágico de retención, diferente a otras creencias, como las devociones a San La Muerte o al Gauchito $\mathrm{Gil}^{103}$, de protección.

Respecto al significado de las paredes del encierro, nos encontramos con otro código o creencia carcelaria que involucra a la pared: "no debe pintarse la celda". Este tema aparece en el testimonio de Rodolfo C., un ex interno del penal de San Martin (Córdoba), en el documental audiovisual "59"104. Este documental narra desde la voz de sus protagonistas uno de los motines más importantes en cárceles de la provincia de Córdoba, en el año 2005. Describe cómo luego de este motín fueron procesados 59 internos (y ningún penitenciario). Rodolfo C., explica ${ }^{105}$ que "ese día" -el día del motín y de su posterior doble condena- él estaba pintando la celda, lo que él consideró una ruptura con los códigos carcelarios y una marca para su destino:

\footnotetext{
103 Santos de veneración popular, en particular en la cárceles de Argentina.

104 "59" narra e indaga sobre cómo se desencadenaron los hechos que en febrero de 2005 derivaron en una de las tragedias carcelarias más recordadas de Córdoba: el motín en el penal de San Martín, por el que fueron juzgados luego 59 internos.

${ }^{105}$ http://vos.lavoz.com.ar/cine/la-historia-detras-del-motin-del-penal-de-san-martin-mira-aca-elestreno-exclusivo-de-la?cx level=player home Ivi extendido minuto 15:15
} 
"La celda no se pinta...eso es un código viejísimo...eso es de la yuta: no se pinta... Pintar la celda es como... que te estas apoderando... como que estas... ya te entra un sentido de propiedad ¿me entendés?...es un lugar transitorio por más que estés un montón de años...hoy estás acá... mañana estás allá... ¿Vos podés creer que me puse a pintar ese día?"

Parecería que no es conveniente apropiarse justamente de "esa pared", y pintarla sería una forma de hacerla propia. Esta apropiación que significa la pintura le correspondería siempre a la institución penitenciaria. Como sucedió con las paredes del Instituto Horizontes, tal como antes describimos: a pesar de que esa pintura "encierre", sepulte bajo ella lo que esté escrito allí. El portador "pared" en un lugar de encierro está sin duda fuertemente cargado de significados. No pintar la pared se relaciona con la necesidad del privado de la libertad de no aceptar ese espacio como propio, de no conformarse nunca con estar ahí, de no olvidarse de buscar y anhelar siempre la libertad. La pared, justamente, que es a la vez muro que separa el encierro de la libertad.

Como dijimos, las creencias y los códigos existen, pero usualmente se trasgreden. Rodolfo se arrepiente de pintar la celda. Enzo reconoce -respecto al nombre en la pared-: "si lo he escrito me he arrepentido".

La creencia sobre la no-escritura del nombre, puede revelar la necesidad de no dejar inscripta esa parte tan propia, justamente en esa pared que es tan ajena, y que debe seguir manteniéndose ajena: es la pared del encierro. Porque como dijimos, el nombre es la palabra que nos inscribe, como personas, como individuos y como parte de una comunidad. Por eso a pesar de la fuerza de esta creencia, no es suficiente para que los jóvenes no sigan escribiendo, grabando y horadando una y otra vez su nombre en la pared

Uno de los primeros contactos que tuvimos con la problemática de la escritura del nombre en la pared, fue en el año 2014, cuando se registraron las paredes del Instituto San Jorge. Este registro fue hecho, como dijimos, por un profesor de la escuela que tenía acceso a los sectores de los institutos. Aparecieron entonces dos fotos de escrituras de nombres que nos llamaron la atención:

Registro 5 de diciembre de 2014

Nos pusimos a mirar en la computadora las fotos que tomó Edgrado de las paredes del instituto San Jorge, estábamos en la cocina que oficia de sala de profesores con Letizia y el coordinador. Entre las 90 fotos que empezábamos a mirar y comentar, a Letizia le habían llamado la atención dos fotos con listas de nombres, las buscamos. Lo llamativo 
era que en esas listas había dos nombres tachados. Letizia estaba impresionada, alguien le había dicho que los nombres que estaban tachados era un registro de los chicos muertos por la policía, el coordinador comentó también que podía ser que simplemente no quisieran que estuviera su nombre escrito en la pared.

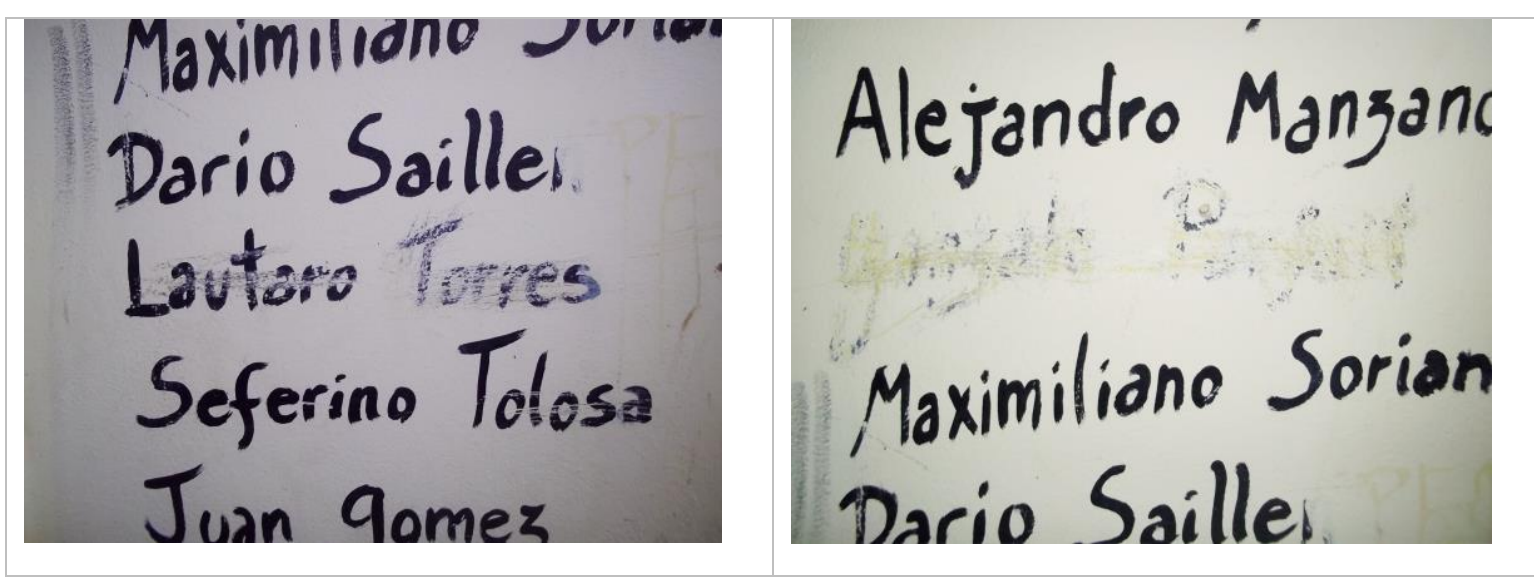

Para poder comprender el sentido de estas listas de nombres y sus tachaduras, estas escrituras fueron puestas a consideración de los jóvenes en el grupo de discusión:

Grupo de discusión:

"Joaquín: ah hace cuanto.... eso... fue del 2013...

$\mathrm{E}$ : ¿y por qué borraron el nombre?

Joaquín: no quería que estuviera ahí...

Ch: No le daba

Ch1: Saillen...

Joaquín: ahora está en la cárcel el loco

Renato: Es del año cero que está eso

E: A mí me habían dicho una vez que capaz eran chicos que los mató la policía...

A: No, no los borran por eso...

$\mathrm{CH}$ : no, eso por ahí uno lo escribe y después se arrepiente "uh, cierto que me llama la pared" y lo borra

Ch: en un taller lo escribieron, en un taller

$\mathrm{E}$ : ah, claro, esto no lo han escrito los chicos...

Ch: Debe ser la firma del mural"

En el módulo número 9 del Postítulo en contexto de encierro Bibliotecas abiertas en contexto de encierro, se desarrolla un capítulo sobre escritura "Escribir y ser escrito". Allí se explica: "En una cárcel, la escritura de listas, la escritura que ordena, está casi 
siempre en las manos de otros. Los internos son escritos en esas listas, raras veces tienen la posibilidad de ser ellos quienes escriban.” (pág. 130). Allí explica también como el poder se ejerce sobre un plano subjetivo:

“Una planilla de asistencia es una lista de nombres. En la que una persona, representada en una, dos o tres palabras, es inscripta. Alguien deja una marca, en forma de categoría, en forma de concepto, en forma de sobrenombre, sobre un sujeto que desborda cualquiera de esas formas de ser escrito. Cuando ese alguien es siempre otro, el quedar escrito de una u otra forma puede reforzar el sentimiento de captura, exclusión y encierro." (Módulo 9, Postítulo en contexto de encierro, pág. 129)

Se agrega, entonces, más información: la escritura del nombre puede reforzar el sentimiento de captura, de exclusión. Las explicaciones de los jóvenes, sumadas a la cuestión de la escritura de listas de nombres en este contexto, nos advierten una vez más sobre la singularidad de cada escritura y la importancia de no perder nunca de vista la mirada de los actores, y el contexto social, cultural e histórico.

La lista registrada había sido escrita en el contexto de la realización de un mural, y los nombres, escritos por los talleristas, seguramente para dejar registro de los autores que habían participado en su realización. En otro contexto la inscripción del nombre de los autores es un registro y hasta una valoración de la obra. En este contexto, es diferente, pensamos que probablemente no se tuvieron en cuenta las connotaciones que puede llegar tener el nombre propio en la pared para los jóvenes privados de la libertad.

Los nombres tachados dentro de una lista tienen entonces otro sentido, tal vez junto con la creencia de que "la pared te llama", se pueden relacionar aquí con este sentimiento de la inscripción, de la marca de la captura, de la exclusión. Estos sujetos, los jóvenes, tachan su nombre de la lista, escrita por otros, por negarse a ser parte de esa representación.

Sobre el significado y las profundas huellas de la escritura del nombre, Carlos Skliar, en el capítulo El lenguaje deportado de Desobedecer al Lenguaje (2015), recrea un 
fragmento de la biografía de Anna Lárina Lo que no puedo olvidar (2006) ${ }^{106}$ Allí Skliar reescribe el relato de su traslado en tren:

Escribe Anna y no se encuentra. No hay luz. Está todo cerrado. El olor no se huele. Es una fiera que la atrapa y la corroe, era ajeno y es suyo. Es el olor de otros que estuvieron aquí encerrados. ¿Se llamarían fácil? ¿Con nombres que se pronuncian sin esfuerzo? ¿También escribirían sus nombres, sin poder ver en la madera putrefacta del vagón? Donde quieran que estén sepan que Anna ha leído sus nombres. No sobrepuso su nombre a ninguno de los suyos. Puede tocar la madera y darse cuenta donde está lisa, donde es posible seguir escribiendo y donde quedaron las uñas de los otros viajantes funestos. (Skliar, 2015, pág.31)

Como Anna tal vez, en la reclusión, los jóvenes escriben su nombre, en esa suerte de palimpsesto de nombres escritos, a pesar de las creencias y de todo. Se encuentran encerrados y sin luz. Solo huelen el encierro o el olor no se huele: "si acá no se siente nada" dice Enzo. Ellos tampoco superponen su nombre a ninguno de los otros, porque allí también escribieron sus nombres otros jóvenes y allí, donde quieran que estén hoy, otros jóvenes leerán sus nombres, como explica Braian, su nombre escrito es para él "un recordatorio".

Aparece claramente la tensión entre la creencia que aconseja no escribir el nombre, y la necesidad de escribirlo. Por un lado, para quien vive en el encierro, la necesidad elemental de grabar el nombre propio, de dejar la marca propia "su" marca. A la necesidad de inscribirse, de ser uno "único" y singular, se suma la fuerza de la escritura, su poder de dejar una huella, de mitigar la ausencia y la soledad. Por otro lado, la necesidad de no dejar su nombre inscripto, atado a esa pared, la necesidad de salir de allí, la necesidad primordial de la libertad

\footnotetext{
${ }^{106}$ Anna Lárina se convirtió en víctima de la tragedia soviética. Cuando su marido Bujarin fue arrestado, en marzo de 1937, Anna tenía tan veintitrés años y un hijo de diez meses. Al primero ya no volvería a verle con vida, y con el segundo se reencontraría en 1956. Entre esas dos fechas, Anna cumplió una condena inexplicable e inhumana dominada por la incertidumbre sobre su futuro y sobre el de todas las personas de las que había sido separada. Sinopsis de su autobiografía. Lo que no puedo olvidar: http://www.galaxiagutenberg.com/libros/lo-que-no-puedo-olvidar.aspx
} 
Porque, a pesar de todo, a pesar de que "la pared los llama", los jóvenes insisten, escriben e inscriben una y otra vez sus nombres en las paredes del encierro. Necesitan afirmar su singularidad, preservar la autonomía de un nombre propio, dejar su marca: por encima de todo, tal vez como una forma de hacerse presentes, de estar vivos, de ser visibles, de decir "acá estoy yo", en una institución donde como dijimos se borra lo propio, lo singular, se pierde toda intimidad, donde todo se totaliza y se des-individualiza., en el medio de un encierro que los vuelve locos, los oprime, los invisibiliza,

\subsection{Conclusión provisoria}

"Cuando alguien es desposeído de todo, cuando pierde el control sobre el propio espacio y sobre el tiempo propio, cuando se ve reducido a la indignidad sólo queda la dignidad de la propia conciencia: sólo queda la memoria. Escribir y leer como formas de combatir esa anulación, de trascender el cautiverio y resistir" (Castillo Gómez, 2003, pág. 21)

Los chicos en el encierro, escriben. No tienen materiales, elementos, ni condiciones para escribir. Por circunstancias impuestas en la vida privada de libertad pierden el control sobre el propio espacio y sobre el tiempo propio, nada les pertenece. Pierden la intimidad, su vida transcurre en una institución donde todo se convierte en público, previa decisión o disposición de alguna autoridad. La escritura se desarrolla con una cantidad de limitaciones, dificultades y restricciones que los jóvenes deben sortear.

Pero a pesar de todo, escriben.

Escrituras efímeras, evanescentes, casi siempre clandestinas, furtivas y poco dóciles a la ortografía, "escrituras brutas": "las únicas en deshacerse, sin saberlo ni quererlo, de las leyes de bronce de la letra." (Fabre, 2008, pág. 6). El problema parece ser que los infames ordinarios, cuando se apropian de la escritura, dejan de estar confinados a la oralidad (Artiéres, 2005, pág. 146). Pero además, los jóvenes llevan en sus cuerpos otras escrituras: tatuajes y cicatrices que narran sus vidas y las duras pruebas por las que tuvieron que pasar. Ellos los muestran y cuentan sus historias. 
El encierro es una de las circunstancias extremas que propician la escritura, junto a las guerras y a las emigraciones. Los jóvenes escriben cartas: la escritura se convierte en una fuerte necesidad que generan la ausencia, el aislamiento, el alejamiento, o la separación de la familia y los afectos. La escritura "resuelve" la ausencia. Lahire sostiene que la escritura posee el "don de ubicuidad" ya que lo escrito "continúa marcando nuestra presencia mientras nuestro cuerpo está ausente. Compensa la ausencia corporal para continuar ejercitando una acción (Lahire, 2005, p. 11). La ausencia intenta ser reparada a través de la escritura, por eso escriben cartas y confeccionan sobres para preservar un mínimo espacio de protección de la intimidad.

En el encierro escriben donde pueden, utilizan un espacio público: la pared, el graffiti carcelario implica siempre una ocupación violenta del espacio. $Y$ aparecen las escrituras. Lo que escriben. Los "pibes chorros” necesitan escribir, y van construyendo en los muros los "palimpsestos de la prisión".

Se trata de escrituras furtivas, transgresivas y siempre fuera de lugar: muchas veces una súplica, o solo una palabra: "libertad" o "madre". Otras veces un nombre el nombre propio, otras, la manifestación de un sentimiento personal; y otras tantas: una difamación o un insulto. "líneas/ que merodean en torno al corazón/calado por la angustia/y el cansancio" (Chantal Maillard)

Escribir puede cumplir la función de construir un "otro" que se constituye como destinatario y que se materializa en la escritura: "Posibilita la construcción de un otro a distancia, diferido en el espacio y en el tiempo, pero presente. Un otro potencial, que puede llegar a leernos alguna vez, o que quizás no nos lea nunca, pero si pudiera lo haría” (Módulo 9 Postítulo, pág. 127)

La escritura visibiliza a los niños y jóvenes privados de libertad en el Complejo Esperanza, los que son casi siempre invisibles, ciudadanos "de segunda", y cuando se vuelven visibles es a través del rechazo y el estigma social, de las noticias policiales o del expediente judicial, casualmente escritos por otros.

Los jóvenes escriben su nombre en la pared, pero no deben escribirlo, porque el nombre en la pared posee "un poder": los puede llevar de nuevo a ese lugar. El nombre en la pared "los llama". "La pared te llama". La creencia surge como necesidad extraordinaria de preservar lo que para ellos es imprevisible: la futura libertad. Pero igual lo escriben. La escritura del nombre puede ser en palabras de Castillo Gómez una forma de escribir para no morir, porque "La escritura se conecta íntimamente a la vida por cuanto el prisionero vive en la medida que escribe y escribe en cuanto vive" (Castillo 
Gómez, 2003, pág. 21) Es que, como Castillo Gómez afirma, necesitan escribirlo para vivir: superar de alguna manera la invisibilidad y la anulación del encierro, y recuperar la dignidad de tener un nombre.

Analizar determinada creencia en relación a la escritura en el encierro nos interpela y nos hace pensar que la escritura de los jóvenes privados de la libertad puede convertirse en un recurso extraordinario que ayuda a sobrevivir en el mundo de la prisión. La escritura ordinaria aparece aquí como una salida posible y se convierte así en una escritura extraordinaria. El sentido que adquiere la escritura en la privación de la libertad como forma de expresión, como forma de dejar huella, como inscripción de sí mismo, puede no tener el mismo sentido ni urgencia cuando los jóvenes vuelvan "a la calle" y vivan la libertad. 


\section{Conclusión final}

Este trabajo de investigación se propuso conocer, documentar, describir y analizar la experiencia de la escritura en jóvenes privados de la libertad, en particular, en un grupo de jóvenes varones de 14 a 18 años, alojados en el Complejo Esperanza ${ }^{107}$, en Córdoba, por encontrarse en situación de conflicto con la ley penal.

Al iniciar este trabajo de tesis desarrollamos algunos conceptos teóricos desde donde partíamos, en relación a tres categorías que guiaron esta investigación: jóvenes, escritura y experiencia. También planteamos la información contextual sobre diversas cuestiones como el régimen penal juvenil o la educación en contexto de privación de la libertad. Durante los casi tres años de trabajo, la realidad nos fue interpelando, y la indagación se fue complejizando y ramificando en una sucesión de mínimos descubrimientos, pequeños fracasos, nuevos problemas y preguntas. La descripción de la cotidianeidad y el rescate de los datos mínimos, se constituyeron en resultados que creemos significantes en sí mismos. Podemos decir que la tarea no se encuentra terminada -como en casi ninguna investigación- y que esta conclusión no pretende ser un cierre sino más bien una apertura a seguir indagando.

En el desarrollo de la investigación, el marco teórico y los datos del contexto se fueron entrelazando en el tejido de la experiencia, que como expresa Jorge Larrosa, siempre es contextual, provisional, y tiene un componente de desorden, como la vida misma. (Larrosa, 2006). La materia prima de la experiencia -define Scott- es la historia del sujeto y el lenguaje es el sitio donde se representa esa historia (Scott, 1992). Por eso, para hacerla visible prestamos especial atención a los relatos de los jóvenes respecto a sus experiencias de escritura y a sus escrituras actuales, realizadas con mínimos recursos, sorteando las prohibiciones, a veces desde un precario contacto con la cultura escrita.

Llegar hasta aquí requirió una cuidada planificación de la metodología. "Estar alli" demandó para empezar una serie de permisos y autorizaciones propias de la administración penitenciaria. Ingresamos a un campo, como mínimo, complejo: un espacio de encierro punitivo, en el que se presenta un conjunto de ambivalencias que

107 El Complejo Esperanza es el "Centro Socio-educativo" que concentra a todos los jóvenes varones privados de la libertad de la provincia de Córdoba 
parten no solo de la institución sino de todos los actores involucrados (Giuseppe Mosconi, 2006).

La institución de encierro -Complejo Esperanza- aparece como un campo sembrado de tensiones y contradicciones, como las que se presentan entre su compromiso de brindar protección y asistencia integral como centro socioeducativo, y la contracara que se pone de manifiesto en las denuncias de diferentes organismos sobre el encierro, las malas condiciones de vida o los malos tratos que sufren los jóvenes presos. Las contradicciones están presentes ya desde el marco legal: un régimen penal juvenil de la época de la última dictadura argentina, y vigente hoy, que se contradice con diferentes leyes, como la de protección a niños y adolescentes. La tensión se presenta en sus dos extremos: ¿Los jóvenes, son objetos de tutela-represión o son sujetos de derechos? Pudimos observar en el momento de nuestro trabajo que estas contradicciones y tensiones macro, se presentan en la mirada micro de la cotidianeidad de los institutos, además de la ausencia de un reglamento interno que determine reglas claras de convivencia, derechos y deberes de los jóvenes y los adultos que los tienen a su cargo.

Para el ingreso al campo propusimos un dispositivo que permitió nuestra presencia como investigadores: la participación en los talleres de escritura creativa que empezaban a planificarse y realizarse desde la biblioteca escolar. Nos basamos en la premisa de que la participación es la condición sine qua non del conocimiento cultural, y que la voz del investigador no pretende presentar una "realidad objetiva" sino que siempre implica un posicionamiento (Guber, 2011). Propusimos entonces una observación participante concebida no como una captación inmediata de lo real, sino como "una elaboración reflexiva teórico-empírica que emprende el investigador en el seno de relaciones con sus informantes." (Guber, 2004).

La entrada al campo, la participación en los talleres de la biblioteca, las primeras entrevistas a los jóvenes, y las conversaciones con diferentes actores institucionales, generaban nuevos problemas y preguntas: en particular la necesidad de indagar sobre la experiencia cotidiana de escritura de los jóvenes. Se planteó primero (y se negoció después) la posibilidad del ingreso a los sectores donde los jóvenes viven. Finalmente, luego de obtener los permisos pertinentes y vencer algunas resistencias, se logró ingresar a algunos espacios y registrar una cantidad de escrituras de las paredes, sobre las que luego, para una mejor comprensión, se preguntó a los jóvenes en un grupo de discusión. 
Nos planteamos comenzar la presentación de esta conclusión en un punteo de temas en respuesta a los interrogantes de investigación iniciales. Primero, desde una recapitulación y análisis de lo hecho. Luego, con el planteo de una seria serie de cuestiones y preguntas para seguir indagando y profundizando.

Las preguntas iniciales del proyecto fueron:

- ¿Cuál es la experiencia de escritura de los jóvenes privados de la libertad, desde su apropiación hasta la experiencia actual en el encierro?

- ¿Cómo es la experiencia de escritura en los talleres literarios que propone la Biblioteca de la escuela? ¿Qué, cómo, para quién y para qué escriben estos jóvenes en los talleres literarios?

- ¿Qué escriben los jóvenes en la cotidianeidad del encierro? ¿Dónde, cómo y con qué escriben? ¿Para quién y para qué lo hacen?

- ¿Cómo funcionan estas experiencias de escritura, entre las posibilidades y las imposibilidades de la institución de encierro?

- ¿Qué experiencias y qué significados personales, sociales, religiosos, políticos u otros, se encuentran asociados a la escritura de los jóvenes en situación de encierro?

Para buscar respuestas exploramos la cuestión de la experiencia de escribir, en primer lugar, a partir de los relatos de los jóvenes. Sus experiencias escolares, la cuestión de la alfabetización y su experiencia actual en el encierro se fueron entrelazando con las situaciones contextuales, sociales, legales, históricas y políticas en toda su densidad y complejidad.

La exploración estuvo especialmente centrada en siete jóvenes: Facundo, Daniel, Nicolás, Jerónimo, Joaquín, Renato y Enzo, con los cuales tuvimos la oportunidad de conversar en profundidad en las entrevistas personales. Pero además, obtuvimos información de otra cantidad de jóvenes que participaron en los diversos talleres, eventos y jornadas de los que fuimos parte. En los relatos de sus historias pudimos observar que cada experiencia es singular, pero también sus narraciones dan cuenta de que los jóvenes comparten experiencias de vida: en especial la vulnerabilidad social que los atravesó desde pequeños y que los atraviesa en una forma decisiva hoy, en el presente, en su vida en el encierro. 
Todos ellos nacieron y se criaron en el contexto de la crisis política, social y económica desatada en Argentina alrededor del año 2001. Hoy, más de una década después, forman parte del grupo más proclive a la criminalización social y el más estigmatizado por los medios masivos de comunicación. Desde muy pequeños son vistos como una "amenaza" para la sociedad, y ellos asumen este estereotipo en su autopercepción. Casi todos provienen de los llamados por ellos mismos "barrios bajos" o "villas", también fuertemente marcados por el estigma social.

Sus trayectorias escolares, de mayor o menor intensidad, se desarrollan generalmente de maneras fragmentadas y la mayoría de las veces han sido interrumpidas. Cada uno ha vivido, de diferentes formas, experiencias de abandono o exclusión. De hecho, casi todos habían dejado de asistir a la escuela al momento de caer presos. Son varones jóvenes, de "barrios bajos" de origen; el bajo nivel de escolarización completa el cuadro de la estigmatización y la criminalización.

En relación a la escritura, el dato fue contundente: algunos jóvenes no sabían leer y escribir. Unos cuantos expresaron que no sabían escribir bien, otros, que escribían solo en el marco de las exigencias de la escuela del encierro, y algunos pocos expresaban disfrutar cotidianamente de la escritura (en especial, la escritura de cartas y canciones).

Pensamos entonces, que si el contrato fundacional de la escolaridad primaria es justamente enseñar a leer y escribir (Emilia Ferreiro, 2001), éste parece no haberse cumplido. En primer lugar, desde la exclusión, al dejarlos afuera del sistema educativo, pero tampoco fue cumplido desde la inclusión ya que, algunos chicos, habiendo cursado la escolaridad primaria completa, como hemos visto con Enzo, no sabían leer y escribir.

Tuvimos la oportunidad de conversar con Enzo sobre la apropiación de la escritura, y observar un proceso de alfabetización que se reiniciaba en el encierro. Pudimos entonces visibilizar las marcas de las que hablan Kurlat y Perelman (Kurlat y Perelman, 2013) en referencia a la alfabetización de jóvenes y adultos. Observamos en Enzo algunas de ellas "marcadas a fuego": las marcas de la enseñanza, como el intento de deletreo y el reconocimiento de las letra; las marcas de la exclusión, el permanente y repetitivo "no sé"; y los niveles de conceptualización, posiblemente transitando la etapa silábica. Todas estas fuertemente enredadas en una trenza, a veces, difícil de desanudar. Finalizando el año 2015 , nos sorprendió observar que este joven, que asistió a los talleres 
literarios y participó en la escritura grupal, comenzaba a leer y escribir algunas palabras y textos por sí mismo.

En este contexto de diversas experiencias de apropiación y acercamiento a la escritura, y con algunos jóvenes no alfabetizados, descubrimos en nuestra indagación una experiencia de alfabetización no-escolar que nos sorprendió: la enseñanza de la escritura entre pares, unas ciertas "redes solidarias" de alfabetización colaborativa. El relato del acercamiento de Enzo a la escritura y el de Renato como alfabetizador, sumados a la observación participante, nos permitieron acercarnos al conocimiento de cómo funcionan estas redes de alfabetización en el interior de las piezas del encierro de los distintos sectores de los institutos: los que saben un poco más ofician de maestros de sus compañeros.

Pero podemos afirmar que estas redes no funcionan totalmente aisladas, sino que muchas veces se combinan con otras acciones educativas más o menos formalizadas. Como lo observamos en el proceso vivido por Enzo, desde su conflicto inicial en el repetitivo "no sé escribir", hasta el inicio de un proceso de apropiación de la escritura que combinó la tarea alfabetizadora de su compañero, con la experiencia de escritura grupal en los talleres literarios y la tarea cotidiana de su maestra, en la escuela primaria del encierro.

Hasta aquí, una primera confirmación se hace visible: no nos encontramos ante un escenario de alfabetización generalizada, y esto se corresponde con trayectorias escolares a veces de baja intensidad, fragmentadas, casi siempre de exclusión, lo que revela, además, condiciones de vulneración de derechos.

Sobre el plano de los derechos, las oportunidades, posibilidades y prohibiciones de la escritura dentro del encierro, podemos decir que, al momento de llevar a cabo este trabajo de campo, los jóvenes no contaban con materiales ni tenían posibilidades de escribir en los sectores donde viven. Los lápices y lapiceras estaban prohibidos por ser potencialmente peligrosos, y la escritura en la pared, por cierto, tampoco estaba permitida. Esta situación se expresaba de manera más o menos rígida de acuerdo a las características de cada Instituto.

Observamos que en este punto la institución punitiva presenta un doble discurso respecto de la escritura: desde las intenciones se propone la promoción a la escritura y la 
lectura, pero no se habilitan los medios para que esto ocurra en la vida cotidiana en los sectores donde los jóvenes viven, de esta manera se ve vulnerado su derecho a acceder a la práctica de la escritura cotidiana y a la experiencia de la escritura creativa.

Creemos importante aclarar que, a pesar de las descripciones iniciales, en la interacción observamos que la mayoría de los jóvenes le da importancia a la escritura, y que, de diversas maneras y con escasos recursos, practican la escritura cotidianamente en el encierro. A pesar de las prohibiciones, o la alfabetización incipiente, los jóvenes no solo expresan la necesidad de escribir, sino que de hecho lo hacen: escriben como pueden y con los materiales que tienen cerca o pueden conseguir. De formas más o menos precarias, la escritura es parte de sus vidas en el encierro, con frecuencia a través de las cartas, de manera más o menos furtiva, o en la transgresiva escritura en la pared.

En este marco se propusieron los talleres literarios durante los años 2014 y 2015 , con propuestas de trabajo diferentes.

En el año 2014, las actividades se concentraron en el espacio de la Biblioteca Abierta de la escuela en contexto de encierro, desde allí se propusieron ciclos de tres talleres a distintos grupos de jóvenes a modo de invitación a la Biblioteca. En ese marco, se plantearon las actividades y los momentos que puede ofrecer en general un taller de escritura creativa: ambientación, lectura grupal, escritura individual o en parejas, puesta en común. En el inicio, en la organización de los grupos, aparecieron algunas dificultades parecidas a las que cotidianamente debe resolver la escuela en el encierro, como, por ejemplo: la estadía incierta de los jóvenes privados de la libertad en la institución, las salidas a Tribunales, cuestiones de salud, conflictos entre pares, el vínculo difícil con los guardias, los castigos, etc. Aun así, se conformaron cuatro grupos en los que se leyeron y escribieron poesías, acrósticos, narrativas, con consignas precisas, adaptándolas a las situaciones y al contexto.

A partir de las entrevistas realizadas a los jóvenes que participaron durante el año 2014 podemos decir que la experiencia de estos talleres los ayudó, trayendo aquí sus palabras: a contar "lo que les pasa", a hacer respirable el encierro: "desahogarse", "despejar la mente", a conocer "otros ambientes", integrar otro tiempo: "un tiempo libre, un tiempo nuestro", hablar de "otros temas" y encontrar otras palabras, "palabras nuevas", "palabras de afuera".

¿Qué escribieron? Partiendo de lo que ya conocían: letras de canciones, poesías, acrósticos, a veces intercalando sus palabras con las palabras de otros, "los poetas", 
tomando sus versos prestados. En forma a veces minuciosa y cuidada, otras en forma caótica, lúdica, azarosa y sin enormes pretensiones literarias. Una de las producciones de estos talleres, escrita tomando versos prestados, es esta poesía de Nahuel:

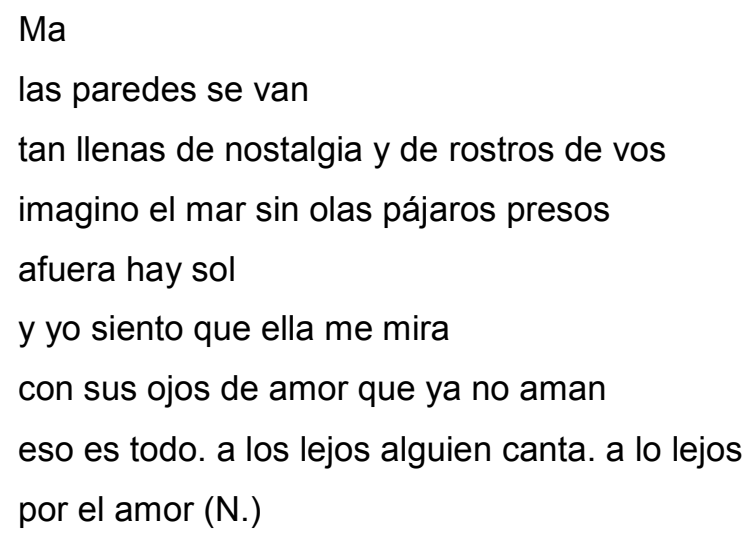

También escriben relatos breves y cartas, se trata de escrituras la mayoría de las veces autorreferenciales, expresiones cargadas de deseos, de pedidos, de disculpas, de necesidad de "sacar afuera" algo que les pasa, algo que los ahoga. Aquí un fragmento de uno de estos relatos, una carta escrita por Nahuel a su familia:

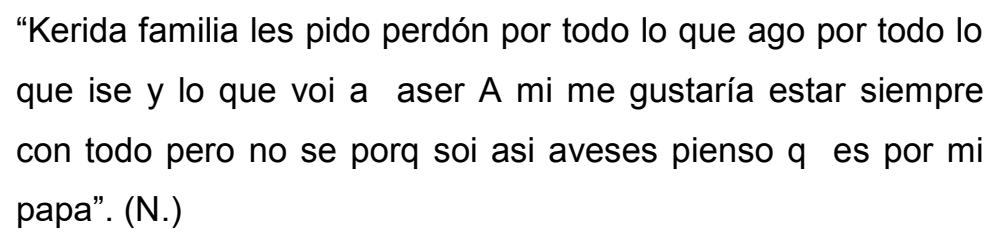

¿Cómo escriben? En el marco de los talleres escriben a mano y en hojas sueltas, con materiales escolares, muchas veces preocupados por su caligrafía, más permisivos con la ortografía. Escriben sentados alrededor de una mesa cargada de libros, de poemas, de palabras recortadas. Los escritos son colocados luego en un sobre cerrado, previamente preparado con su nombre, escrito y decorado por ellos mismos. Finalmente todo queda guardado en la biblioteca para ser retirado cuando salgan en libertad o entregado a su familia.

¿Para qué y para quién escriben? En primer lugar, escriben para sí mismos, como una forma de superar la ausencia y la opresión del encierro. El destinatario es a menudo una persona real: una carta a la madre, a la novia, a la familia; a quienes les escriben para pedir perdón, o para expresar sus sentimientos y su sufrimiento en el encierro. Otras veces, a la sociedad, a través de la revista Tumbando Rejas, que publica algunos de los 
escritos. Se trata de destinatarios inciertos: escriben para "los otros", los que puedan llegar a leerlos, los que no los conocen y los ven solo como chicos peligrosos, "choros" o "ratas", los que piden la baja de edad de imputabilidad y más cárcel, e incluso a veces pena de muerte; y también, para los que los ven desde una mirada compasiva. Quieren escribir para contar lo que les pasa y mostrarse como "pibes normales".

Podemos afirmar que el taller de escritura que observamos del que participamos en el año 2014, adquiere un valor especial en la institución de encierro. El taller en la biblioteca - ubicada en el espacio físico de la escuela, por fuera de los institutos- le dio un significado casi literal al "saltar del otro lado", una posibilidad que de por sí ofrece la literatura (Petit, 2003). Aquí, "saltar afuera" puede representar salir del aislamiento, del encierro total, saltar los altos muros de los institutos, hacia un ambiente real de un poco más de libertad. Pero también -en el mismo sentido que adopta Michèle Petit- el taller se presenta como una oportunidad de saltar para fugarse simbólicamente a otros mundos posibles, y sobrepasar por un momento otro muro: el muro del destino prescripto.

En el año 2015 los talleres se trasladaron de la escuela a la sala de visitas del Instituto Horizontes, de máxima seguridad. Se presentaron, por lo tanto, otras problemáticas que tienen otras características. Se ganó un espacio: la sala de visitas, y un horario fijo por la tarde: un día en la semana. Fueron necesarios nuevos permisos, negociaciones, el aval de la coordinación de la escuela y la mediación de las socioeducadoras.

Se desarrollaron a partir de allí trece talleres en un equipo formado por las talleristas, las socio-educadoras y los jóvenes. Se logró formar un grupo estable de jóvenes y se propuso un proyecto de escritura que culminó en la novela grupal. Poder concretar una propuesta de escritura creativa en un espacio como el que describimos, en condiciones inhóspitas, se convirtió en un verdadero desafío. Pero, paradójicamente, estas condiciones adversas generaron un margen de creatividad extraordinario, de invención y reinvención constante de estrategias que pudieran adaptarse a esa realidad material, a los muy limitados recursos, y a las posibilidades de escritura de los jóvenes. Como dijimos, algunos admitían escribir más y otros menos. En este contexto, la escritura grupal posibilitó que los que escribían más, tomaran la posta, y los que escribían menos, pudieran hacerlo a través de los otros: proponiendo ideas, debatiendo, tomando decisiones de forma y contenido, dictando a sus compañeros. 
Algo particular de esta experiencia de escritura colectiva merece destacarse: la forma en que las propias historias se fueron enredando con las historias de los otros. Una de las primeras actividades que se propuso fue la confección de la línea de tiempo grupal (que representaba sus biografías), en tres septenios en los que se fueron incorporando palabras o fragmentos de sus historias de vida, de los momentos intensos que cada uno recordaba. Más tarde esta línea de tiempo fue formando los núcleos narrativos de la historia, en combinación con poesías de diferentes autores, especialmente las de César González, las letras del rap y la narrativa literaria, y se fueron generando pequeños capítulos/ relatos. En este proceso se llegó a construir un personaje: Yandel, y una vida: su vida, con la mezcla de las vivencias de todos los chicos.

La novela es un eco de la propia vida, pero también es algo más: el eco de un nosotros, que es el eje de la escritura grupal. El nosotros, el hilo conductor de la narración; y la experiencia, el material del relato. Es importante aquí destacar que la densidad de la experiencia común es la materia prima que fue construyendo una historia que por decisión de los jóvenes debía ser realista, autorreferencial. Ellos manifestaron la primordial necesidad de escribir sobre y desde ellos, de contar lo que les pasa y les pasó, lo que sufren en el encierro, y valoraron sobre todo la posibilidad de ser leídosescuchados.

Escribir con otros genera una experiencia muy diferente de la escritura en soledad: se conforma una comunidad de escritura, una escritura permanentemente conversada. Hay que tomar decisiones y llegar a acuerdos: en especial sobre qué es lo se quiere contar de sí mismos. Cabe señalar que participar en este proceso de construcción de un relato grupal tuvo un peso especial en el interés de los jóvenes por continuar con la escritura y seguir participando en los talleres.

Esta novela, escrita en forma grupal y sobre los afiches pegados en las paredes de la sala de visitas. sin habérselo propuesto, replica dos características de la escritura cotidiana de los jóvenes en el encierro. Una, es la experiencia de escritura grupal, ya que cuando los jóvenes escriben en los sectores de los institutos, frecuentemente comparten con otros sus experiencias de escritura: canciones, cartas o escritura en la pared. La escritura con los otros, forma parte también de las prácticas sociales de escritura en el encierro. 
Otra particularidad que se reedita es el soporte pared. Este soporte surge como una estrategia de resolución a las dificultades de un espacio sin sillas y sin mesa, y es justamente el que los jóvenes usan para escribir cotidianamente en el encierro, al no poder contar -por lo general- con hojas ni lápices. Sin haberlo planificado directamente, la necesidad de adaptación del taller a las circunstancias materiales del encierro del instituto, reprodujo -en una cierta correspondencia- las prácticas sociales cotidianas de escritura de los jóvenes en los sectores donde viven y donde el único soporte material con el que cuentan para escribir es la pared. El taller literario, sin habérselo propuesto, replicaba el mismo tipo de escritura que el elaborado por los jóvenes en la vida cotidiana. Esto nos hace pensar que probablemente, la apertura del dispositivo propuesto, puede haber posibilitado una co-gestión de estrategias y actividades puestas en marcha.

Ya dejamos en claro que el objeto de estudio de este trabajo de investigación es la experiencia de escritura de los jóvenes privados de la libertad, más allá de la discusión sobre si es o no escritura literaria, o si es alta o baja literatura, o si es literatura urbana o "de los márgenes"108. No entramos en ese debate, y menos nos interesa emitir algún juicio de valor sobre lo que los jóvenes escriben. Lo que sí podemos decir es que su escritura deja una huella y da un testimonio de lo vivido. Cuenta una parte de la historia -la otra parte de la historia muchas veces es silenciada- bajo el manto benévolo de la ficción.

Nos interesa decir que esta escritura es una escritura necesaria, porque escribir los ayuda a respirar, desahogarse, superar la ausencia, la distancia, la soledad y la opresión del encierro. El analizar el sentido de la experiencia de escribir en los talleres, nos hace pensar que esta experiencia rehabilita el sentido de la escritura que de hecho sucede cotidianamente en el encierro, como veremos más adelante.

La novela grupal además tiene otro sentido: ofrece a los jóvenes la oportunidad de participar en un proyecto colectivo. La posible publicación los coloca en el lugar de autores/ escritores, pero no en el lugar del escritor como un héroe individual, sino como miembro de una experiencia de autoría colectiva, alejada del individualismo, en un trabajoso proceso que requiere constancia, compañerismo, y una suma de acuerdos y solidaridades.

108 http://www.revistaanfibia.com/ensayo/intelectuales-de-los-suburbios/ 
El capítulo que desarrolla la escritura cotidiana comienza con una cita de Antonio Castillo Gómez, que describe cómo, cuando se está desposeído de todo, del propio espacio y del tiempo propio, el escribir aparece como una forma de combatir la anulación, como una manera de trascender el cautiverio y resistir (Castillo Gómez, 2003). Dijimos que los jóvenes escriben cotidianamente, a pesar de una cantidad de limitaciones, dificultades y restricciones, sin materiales, elementos, ni condiciones.

El encierro es una circunstancia extrema que propicia la escritura, como recurso extraordinario para sobrevivir. La escritura de cartas surge de la fuerte necesidad que genera el aislamiento, la separación de la familia y los afectos. La escritura resuelve la ausencia, es reparadora. Los jóvenes escriben cartas y confeccionan sobres con papel plegado para preservar un mínimo espacio de protección de la intimidad. Son minúsculos espacios donde el "panóptico" no llega, son tácticas, pequeñas astucias del "débil" en el orden construido por el "fuerte" (De Certeau y Giard, 1996)

Los jóvenes a veces llegan al encierro con escrituras en sus cuerpos: tatuajes y cicatrices, escrituras que narran historias y dan testimonio de las duras pruebas por las que tuvieron que pasar. Ya en el encierro escriben donde pueden, pero sobre todo utilizan la pared, en una ocupación violenta del espacio y así van construyendo los "palimpsestos de la prisión". Se trata de escrituras furtivas, transgresivas, siempre fuera de lugar: una súplica, la palabra "libertad" o la palabra "madre", un nombre -el nombre propio-, la manifestación de un sentimiento personal, una denuncia, un deseo o una escritura ritual. "Muerte a la yuta" "es la religión de los choros", recalcan los jóvenes en el grupo de discusión.

Escrituras de por sí efímeras y casi siempre clandestinas. Palimpsestos que van formando estratos: los jóvenes presos escriben, la institución penitenciaria los limpia, los tapa, pero algunas escrituras reaparecen, se suman otras nuevas, y luego la historia se repite: escritura- pintura. A pesar de todo, el palimpsesto sigue creciendo. Si se pudiera recuperar una a una de esas capas de escritura de las paredes una y mil veces grabadas, probablemente se podría escribir la historia del encierro punitivo de los jóvenes.

Los jóvenes escriben la pared, y escriben su nombre, aunque saben que no deben hacerlo. Creencia, o pensamiento mágico, lo importante es que en los pasillos del encierro se dice que si se escribe el nombre en la pared "la pared te llama". Esa escritura 
/inscripción /huella de sí mismos, puede convertirse en una fuerza que los hace volver al encierro. Enzo dice "si lo he escrito me he arrepentido", y como él, a pesar de todo, a pesar del peligro, casi todos los jóvenes siguen escribiéndolo. Es que la escritura del nombre tiene un fuerte significado de afirmación de sí mismos; tal vez los jóvenes necesitan escribirlo para sobrevivir, superar de alguna manera la invisibilidad y la anulación del encierro, y recuperar la dignidad de tener un nombre.

Escribir es dejar huella, testimonio, es inscripción de sí mismos. Pero además escribir es un derecho y una marca de ciudadanía. Las biografías y trayectorias educativas de los jóvenes daban cuenta de una sucesión de derechos vulnerados. Aquí aparece un eslabón más en una cadena de vulneraciones, marginaciones y exclusiones históricas. Escribir es un derecho que creemos, la institución de encierro debería garantizar y también promover si se supone que su objetivo central es socioeducativo.

Aunque pueda parecer obvio, necesitamos aclarar que para nosotros la escritura no es por sí misma la panacea o la solución frente a las complejas situaciones y vulneraciones de la vida de los jóvenes. En cierta coincidencia con las aserciones que realiza Víctor Moreno Bedoya sobre el fundamentalismo lector, creemos que algunos problemas exceden al poder que puede tener la escritura, como los que dependen de las decisiones de determinadas políticas públicas que generan desigualdades sociales, económicas, educativas y de seguridad.

Tampoco pensamos que el hecho de haber participado en un taller de escritura literaria estando privados de la libertad convierta llanamente a los jóvenes en poetas, novelistas, escritores o artistas, aunque seguramente se produzcan hechos creativos y artísticos. Pero, además ¿quién define quien es un artista o un escritor? Lo que sí podemos afirmar es que la expresión creativa a través de la literatura, la liberación de la palabra desde un pequeño relato, una poesía o una novela, surge en un momento particular de su vida: la reclusión forzada por haber cometido un delito. Y esa experiencia, esa práctica de expresión social y cultural adquiere también un significado y un valor particular.

Creemos que, para los jóvenes, la escritura en el encierro tiene un significado que probablemente será diferente a la experiencia de la escritura una vez que salgan en libertad.

La escritura creativa se presenta como una práctica de expresión social y cultural en un momento de sus vidas en una institución total, en la anulación de toda privacidad, 
en la opresión del encierro, en la ausencia de sus afectos, en el que la circulación de la palabra está restringida. La escritura creativa aparece como posibilidad de hacer libre la palabra. Por eso, la existencia de estos talleres en una institución de reclusión, con fines claramente contrarios a esa institución, se presenta como una propuesta contracultural a la propuesta institucional del encierro.

Para concluir, podemos decir que, para los jóvenes privados de la libertad, la experiencia de la escritura aparece como una posibilidad de sobrevivir al encierro, y resolver por lo menos mínimamente la ausencia y la separación. Por algo los jóvenes cotidianamente escriben cartas, o escriben sobre la pared, a un destinatario cierto o incierto, desafiando los peligros y las prohibiciones. Escribir en este lugar puede llegar a construir un "otro", un destinatario, que se materializa en la escritura.

Los jóvenes escriben, y mucho, a pesar de que a veces apenas saben escribir, a pesar de las limitaciones del encierro. Pero además escriben con otros jóvenes, escriben juntos, solidariamente. Pueden participar en proyectos colectivos de escritura, y a pesar de la individualización y las resistencias de la institución de encierro, generar una escritura colectiva, porque necesitan hacer saber lo que les pasa, contar su historia, lo que son.

Podemos decir que la escritura aparece como un recurso extraordinario. Son por una parte escrituras ordinarias -retomando a Daniel Fabre-, porque son escrituras de gente común. Pero también son escrituras extraordinarias, porque pueden estar añadidas a lo ordinario, porque pueden estar apareciendo fuera del orden o regla, o porque pueden ser vistas como una escritura mayor o mejor que lo ordinario. La polisemia de la palabra extraordinario nos ayuda a pensar y plasmar esta complejidad.

Pero sobre todo creemos que son escrituras extraordinarias porque para los jóvenes, la experiencia de la escritura se convierte en un recurso extraordinario que adquiere una significación propia y única en la opresión del encierro. En un momento y un entorno en los que las posibilidades de expresión están anuladas, la escritura habilita una posibilidad. Es en este lugar y en este instante que necesitan escribir: necesitan dejar una huella, dejar un testimonio propio, estar presentes, estar vivos, ser visibles, justamente en un momento de su vida donde se borró todo lo propio, lo singular, y hasta la dignidad; en un encierro que los invisibiliza, los vuelve locos, los ahoga, y hasta los mata. Escribir: un 
recurso extraordinario, que los desahoga y los visibiliza, en el momento en que son, más que nunca, invisibles.

Damos un cierre a esta conclusión con un comentario final en tono de reflexión e invitación:

Si la experiencia de la escritura para los jóvenes que están viviendo en situación de encierro punitivo significa un recurso extraordinario que los ayuda a sobrevivir la opresión del encierro, la ausencia, la distancia y la soledad; si la inscripción /huella de sí mismos que es la escritura se puede convertir en una práctica de expresión social y cultural; si el escribir puede habilitar por lo menos un derecho vulnerado dentro de una cadena de vulneraciones; entonces, creemos que es importante que alguien les ofrezca esa posibilidad.

Cuando los jóvenes son invitados a escribir, no solo se restituye un derecho, también se produce una propuesta contracultural a la cotidianeidad ordinaria de la institución de encierro, una invitación extraordinaria, una oportunidad. Sabemos que cuando existe esta posibilidad, los que aceptan la invitación asumen un compromiso y se les va la vida que tienen en ese momento en lo que escriben. La experiencia del taller de escritura, como fue la escritura de la novela colectiva en el taller de la Biblioteca Abierta, dentro de la sala de visitas, y sobre papeles pegados en las paredes, se convierte en una experiencia extraordinaria a la rutina del encierro. Es una gran oportunidad que, en este contexto, alguien se ocupe de la escritura -e incluso de la apropiación de la escritura-, e invite a los jóvenes a escribir. Es de gran importancia que en medio de la soledad, la deshumanización y la rutina del encierro existan experiencias humanas extraordinarias. 


\section{POST SCRIPTUM}

\section{AÑO 2016}

El año 2016, no forma parte del trabajo de campo de esta tesis. Pero tuvimos la oportunidad de seguir participando de determinadas actividades y permanecer en contacto con algunos temas, en particular, el recorrido de la novela "La otra vida de los pibes pistoleros" y con algunos de los jóvenes autores de ésta. Este es un conocimiento que consideramos valioso, que no queremos pasar por alto, por eso proponemos describir brevemente aquí algunas cuestiones puntuales.

Los talleres literarios del Instituto Horizontes, continuaron en el año 2016 con un grupo nuevo de jóvenes y tres jóvenes del año anterior. Se leyó la novela "La otra vida de los pibes pistoleros" y los jóvenes se mostraron muy interesados. A partir de allí de planificó para este año la escritura de una nueva novela, objetivo que se inició en el mes de abril y se culminó en diciembre, no sin dificultades de todo tipo, ya que se trató de un año sumamente conflictivo en el Complejo Esperanza. El título provisorio de la nueva novela es: "Hermanos, siempre"

Se realizó un taller de encuadernación de la novela del 2015, en la que el grupo de jóvenes participantes de los talleres literarios del 2016, aprendieron el oficio de encuadernador, cosieron y pegaron 100 libros. Un joven participante de estos talleres se quitó la vida al poco tiempo de salir en libertad.

La novela fue presentada públicamente en por lo menos cuatro ocasiones:

- En la Feria del Libro de Córdoba, en el mes de junio, junto a la revista Tumbando Rejas, con la lectura completa a cargo de diez lectores: referentes artísticos, culturales y sociales de la lucha de los derechos de los jóvenes

- En El III Encuentro Nacional de Escritura en la Cárcel, en el mes de octubre, en el Centro Cultural Paco Urondo, organizado por la UBA. Se participó de una mesa de lectura, y uno de los lectores fue Jerónimo, como autor, ya en libertad 
- En el Museo de Antropología de Córdoba, en el mes de noviembre, en el marco de la Marcha de la Gorra: "La Gorra Literaria" con el mismo grupo de lectores de la Feria del Libro, a los que se sumaron Jerónimo y Joaquín, como autores, ambos en libertad.

- En la Cárcel de Adultos de Bouwer, la leyeron completa y en voz alta los propios internos, quienes luego escribieron cartas para los jóvenes del taller literario del Complejo Esperanza

Paralelamente, en el año 2016, fue creada la Asociación Civil Libertando, una idea finalmente concretada por un grupo de docentes de la escuela del Complejo Esperanza. El objetivo de la asociación civil es el acompañamiento de los jóvenes cuando salen en libertad: en lo escolar, laboral, social, salud, judicial, etc. De los cinco jóvenes participantes de la Asociación dos de ellos son Jeremías y Joaquín, quienes a través de la asociación están siendo acompañados en la continuidad de la escuela, capacitación laboral y a través de ella, se encuentran trabajando. De los once autores de la novela "La otra vida de los pibes pistoleros", cinco están en libertad, de ellos son dos los que continúan en involucrados como autores de la novela, como mencionamos. Tres jóvenes siguen privados de la libertad en el Complejo Esperanza y dos de ellos participan activamente de los talleres, incluso como autores de la novela del año 2016. Dos jóvenes están privados de la libertad en la cárcel de adultos. Con uno de ellos perdimos contacto al salir en libertad en el año 2015.

Sin pretender una estadística, lo que queremos señalar aquí, es que de los casi 1200 jóvenes que pasan por el Complejo Esperanza en un año, son cinco los que siguieron en contacto a través de la asociación Libertando, recién creada. Dos de ellos Joaquín y Jeremías- participaron en los talleres literarios como autores de la novela y son además parte de esta tesis a través de las entrevistas en profundidad. En su participación en la presentación de la novela, ambos respondieron preguntas, destacaron el valor de haberse convertido en autores del relato de sus propias vidas, pero aclararon que no continuaron escribiendo una vez que salieron en libertad. En este sentido corroboramos la cuestión de que el valor de la experiencia de la escritura estando presos no es necesariamente el mismo en la vida en la libertad, cuando se presentan otras posibilidades de expresión. 
PARA SEGUIR INDAGANDO...

Como dijimos al iniciar la conclusión, este trabajo no pretende ser un cierre a un tema tan amplio y complejo, pero la presentamos como un paso necesario desde nuestro trabajo de investigación y en el plano institucional. Presentamos y analizamos lo hecho hasta aquí, pero asimismo pensamos que queda mucho para seguir conociendo, comprendiendo, profundizando, y analizando desde distintos puntos de vista. A lo largo de la indagación nuestros propios significados se fueron complejizando, la realidad nos fue interpelando y surgieron nuevos problemas y preguntas. Plantearemos aquí solo algunas de las posibles cuestiones e interrogantes a seguir indagando:

- Sobre la escritura en la escuela, creemos que sería interesante conocer qué, cómo, para qué, y para quien escriben en la escuela en contexto de encierro. Asimismo, podríamos indagar sobre la escritura en su biografía escolar, tema al que solo nos acercamos tangencialmente para dar un marco a su experiencia de escritura actual.

- Sobre la escritura en los muros del encierro realizamos un abordaje principalmente descriptivo, valoramos la posibilidad de acercamiento al tema, y el haber logrado el acceso y conocimiento primario de estas escrituras. Queda mucho por analizar sobre su significado, desde distintos puntos de vista y desde diferentes posibles categorías de análisis.

- Sobre los talleres literarios: la experiencia de escritura colectiva en el año 2015, la novela grupal, podemos seguir preguntándonos sobre el sentido de esa experiencia para los jóvenes, no solo en la vida en el encierro, sino lo que puede llegar a generar una experiencia de este tipo en su vida en libertad. Respecto a este tema haremos una breve reseña de la experiencia del año 2016 en este postscriptum.

- Sobre los talleres literarios: la experiencia de equipo docente, la planificación y coordinación colectiva, creemos que también es un punto interesante para indagar ya sea desde la etnografía, la investigación-acción o la investigación didáctica 


\section{BIBLIOGRAFÍA}

Alarcón, C. (2008). Cuando me muera, quiero que me toquen cumbia: vidas de pibes chorros. Buenos Aires: Grupo Editorial Norma.

Amaro, L. (2010). Poética, erótica y políticas del nombre propio: de la magia a la autobiografía. AISTHESIS, 47, 229-246.

Ameigeiras, A. (2001). Una Aproximación Etnográfica. Simbolismo Mágico-religioso y Vida Cotidiana o cuando más vale "Creer que reventar..." Sociedad y Religión, (20) en Sociedad y Religión/edición $30^{\circ}$ aniversario: "30 artículos, 30 AÑOS" (2015)

Andruetto, M. T. \& Lardone, L. (2011). El taller de escritura creativa en la escuela, la biblioteca, el club. Córdoba: Comunicarte.

Artieres, P. La prisión a finales del S XIX: Una máquina grafómana. Centre Nationale de la Recherche Scientifique, París, p.147-163, en Castillo Gomez, A. , \& Sierra Blas, Verónica (2005) Letras bajo sospecha. Guijón, Asturias: Ediciones Trea.

Auyero, J. (2001). La política de los pobres: las prácticas clientelistas del peronismo (1. ed). Buenos Aires: Manantial.

Auyero, J., \& Berti, M. F. (2013). La violencia en los márgenes: una maestra y un sociólogo en el conurbano bonaerense (1. ed., 2. reimpr). Buenos Aires: Katz.

Axat, J.; Rodríguez Alzueta, E. (2013). Los pibes chorros. En Tonkonoff, S., Blanco, A. B., \& Sánchez, M. S. (Eds.). (2014). Violencia y cultura: reflexiones contemporáneas sobre Argentina (Primera edición). Ciudad de Buenos Aires, Argentina: CLACSO: Instituto de Investigaciones Gino Germani, Facultad de Ciencias Sociales, Universidad de Buenos Aires.

Azeñas Mallea, V. T. Una experiencia de educación no formal por medio del arte en contexto de encierro y su relación con acciones de resistencia por parte de los sujetos privados de libertad (2012), Director: Daniel Fridman, Universidad Nacional De San 
Martín. "Maestría En Derechos Humanos Y Democratización Para América Latina Y El Caribe"

Barbero L. (2011) Análisis de la experiencia “Tumbando Rejas". Especialización Docente de Nivel Superior en Educación en Contextos de Encierro

Burchardt, I., Bartolacci, V, Giorgis, L (2014) Enderechados. El Misterio de la Libertad. Córdoba. Editorial Brujas

Blajaquis, C. (2010) La venganza del cordero atado. Buenos Aires. Ediciones Continente

Bourdieu, P., \& Kauf, T. (1999). Razones prácticas: sobre la teoría de la acción. Barcelona: Anagrama.

Buenfil Burgos, N. R., Navarrete Cazales, Zaira (2011) Discursos educativos, identidades y Formación Profesional. México. Editoral Plaza y Valdés, pp 11-28

Cardona, G. R, (1994) Antropología de la escritura, Barcelona. Editorial Gedisa

Castedo, M. (coord.). (2015). Lecturas y escrituras cotidianas - Alfabetización para la Unidad Pedagógica. Ministerio de Educación de la Nación Argentina. Recuperado a partir de http://universidadesup.fahce.unlp.edu.ar/materiales/materiales-delpostitulo/Modulo\%202\%20Completo VF.pdf/view

Castillo Gómez, A. (2002) De la suscripción a la necesidad de escribir, en Antonio Castillo Gómez (coord.): La conquista del alfabeto. Escritura y clases populares, Gijón: Trea, 2002, pp. 21-51.

Castillo Gómez, A., \& Sierra Blas, V. (2005) Letras bajo sospecha. Guijón, Asturias: Ediciones Trea.

Castillo Gómez, A. (2003) Escrito en prisión. Las escrituras carcelarias en los siglos XVI y XVII Península. Revista de Estudios Ibéricos | n. ${ }^{\circ} 0$ | : 147-170 
Castillo Gómez, A. (2005). El mejor retrato de cada uno. La materialidad de la escritura epistolar en la sociedad hispana de los Siglos XVI Y XV. Hispania, LXV/3(221), 847-876.

Castillo Gómez, A. (2003). Escribir para no morir. La escritura en las cárceles franquistas. En Franquismo y memoria popular. Escrituras, voces y representaciones (pp. 17-53). Madrid: Siete Mares.

Ceballos, Diego (2011). Implementación del uso del timbre como elemento instituyente. Especialización Docente de Nivel Superior en Educación en Contextos de Encierro

Certeau, M. de, \& Giard, L. (1996). La invención de lo cotidiano. I, I,. México: Universidad Iberoamericana, departamento de historia: Instituto tecnológico y de estudios superiores de occidente : Centro francés de estudios mexicanos y centroamericanos.

Chambers, A. (2007). Dime. Los niños, la lectura y la conversación. México: FCE

Chartier, R., \& Madero, M.. (2001). Poderes de la escritura, escrituras del poder. Anales de historia antigua, medieval y moderna, 34, 145-162.

Chaves, M. (2006). Investigaciones sobre juventudes en Argentina: estado del arte en Ciencias Sociales. La Plata. Universidad Nacional de La Plata.

Chaves, M. (2005) Juventud negada y negativizada: Representaciones y formaciones discursivas vigentes en la Argentina contemporánea. Valparaíso. Ultima década №23, CIDPA, pp 9-32

Colectivo de Jóvenes por nuestros derechos. (2016). Ni código de faltas ni código de convivencia. Kit de resistencia al código de convivencia. Recuperado a partir de http://marchadelagorra.org/wp-content/uploads/2016/03/Kit-Resistencia-2016.pdf

Collin, F. (1994). Espacio doméstico, Madrid: Seminario Permanente: Ciudad espacio público. In: Cuidad y Muje. p.231-237 
Comisión Provincial de la Memoria de Córdoba (Ed.). (2014). Mirar tras los muros: situación de los derechos humanos de las personas privadas de libertad en Córdoba: informe provincial 2013 (1. ed). Córdoba: UniRo Ed., Ed. de la Univ. Nacional de Río Cuarto.

Cruz Sánchez, P. J. (2011). Una primera catalogación de las escrituras expuestas del medio rural en Castilla y León. Stvdia Zamorensia, X, 85-106.

Cruz Sánchez, P. J.; Monteagudo Robledo, J. I. (2011): Las escrituras expuestas populares: un patrimonio olvidado. Proyecto de catalogación y estudio. Comunicación presentada en las Quintas Jornadas de Archivo y Memoria. Extraordinarios y fuera de serie: formación, conservación y gestión de archivos personales. Madrid, 17-18 febrero

Cucuzza, H. R., \& Spregelburd, R. P. (2012). Historia de la lectura en la Argentina: del catecismo Letizianial a las netbooks estatales. Buenos Aires: Editoras del Calderón.

De Laurentis, Teresa. (1989). Technologies of Gender. Essays on Theory, Film and Fiction, London, Macmillan Press (La tecnología del género. Traducción de Ana María Bach y Margarita Roulet) 1-30.

Daroqui, A., Cesaroni, C., Maggio, N., Mouzo, K., Rangugni, V., \& Angilesi, C. (2006). Voces del encierro. Mujeres y jóvenes encarceladas en Argentina. Una investigación socio-jurídica. Buenos Aires: Omar Favale Ediciones Jurídicas.

Daroqui, A. (2002). La cárcel del presente, su «sentido» como práctica de secuestro institucional. En Violencias, delitos y justicias en la Argentina (Manantial).

Devetach, L. (2008). La construcción del camino lector (1. ed). Córdoba: Comunicarte.

Dolz, J. y Schneuwly B. (2011) Escribir es reescribir. La reescritura en las secuencias didácticas para la expresión escrita. Leer.es. En

http://leer.es/documents/235507/242734/art prof ep eso escribiresreescribir dolz schen euwly.pdf/af6797dd-50a8-4ca6-bd72-f6fdd8ff218c 
Dubet, F., Martuccelli, D., \& Gudiño Kieffer, E. (1998). En la escuela: sociología de la experiencia escolar. Buenos Aires: Losada.

Dayrell, Juarez (2003) Cultura e identidades juveniles. Última Década №18, Cidpa Viña Del Mar, pp. 69-91.

Ferreiro, E (2007). Las inscripciones de la escritura. La Plata: Edulp. (Honoris causa). En Memoria Académica. Disponible en:

http://www.memoria.fahce.unlp.edu.ar/libros/pm.409/pm.409.pdf

Ferreiro, E. (2001). Pasado y presente de los verbos leer y escribir (1st ed.). México: Fondo de Cultura Económica.

Ferreiro, E., \& Gómez Palacio, M. (Eds.). (2013). Nuevas perspectivas sobre los procesos de lectura y escritura (1. ed., 19. reimpresión). Madrid [etc.]: Siglo XXI.

Fabre, D. (1993) Écritures Ordinaries. POL/PPI Centre Georges Pompidou

Fabre, D. (2008, enero-junio). Introducción (al libro Escrituras ordinarias). CPU-e, Revista de Investigación Educativa, 6.

Florio, A., \& Educación en Contextos de Encierro (Argentina). (2010). Sujetos educativos en contextos institucionales complejos: contexto sociocultural y alternativas pedagógicas. Buenos Aires: Ministerio de Educación, Presidencia de la Nación: Educación en Contextos de Encierro, Coordinación de Modalidad.

Foucault, M. (2002). Vigilar y castigar: nacimiento de la prisión. Buenos Aires: Siglo Veintiuno.

Freire, P. (1993). “Alfabetización y ciudadanía” en: Gadotti, M.; Torres, C.; Puiggros, A.; (Comp.) Educación popular. Crisis y perspectivas (pp. 95-104). Argentina: Edit. Miño y Dávila. 
Frejtman, V., Herrera, P. Educación en Contextos de Encierro (Argentina). (2010). Pensar la Educación en Contextos de Encierro: primeras aproximaciones a un campo de tensión. Buenos Aires: Ministerio de Educación, Presidencia de la Nación: Educación en Contextos de Encierro, Coordinación de Modalidad.

Gándara, L. (2005) Voces en cautiverio: un estudio discursivo de graffiti carcelario. Universidad de Buenos Aires, p. 237-255, en Castillo Gomez, A., \& Sierra Blas, Verónica (2005) Letras bajo sospecha. Guijón, Asturias: Ediciones Trea

Gil Flores, J. (1992) La metodología de investigación mediante grupos de discusión. En revista Enseñanza \& Teaching Revista interuniversitaria de didáctica N 10-11. Pag 199214

Goffman, E. (1995). Estigma: la identidad deteriorada. Buenos Aires, Amorrortu.

Goody, J., Dauzat, P.-E., \& Formentor, M. B. (1996). El Hombre, la escritura y la muerte: conversación con Pierre-Emmanuel Dauzat. Barcelona: Península.

Guber, R. (2004) El Salvaje Metropolitano: Reconstrucción Del Conocimiento Social En El Trabajo de Campo. 1a. ed. en Editorial Paidós. Paidós Estudios de Comunicación, 19. Buenos Aires: Paidós.

Guber, R. (2011) La etnografía: método, campo y reflexividad. 1. ed. Mínima. Buenos Aires: Siglo XXI Ed.

Ginzburg, C., Martín, F., \& Cuartero, F. (1997). El queso y los gusanos: el cosmos, según un molinero del siglo XVI. Barcelona: Muchnik.

Hall, S. (1996) ¿Quién necesita «identidad»? En Cuestiones de identidad cultural, Buenos Aires- Madrid. Amorrortu editores pp 13-40

Harris, R. (1999). Signos de escritura. Barcelona: Gedisa Editorial. 
Kalman, J. (2003). Cultura escrita el aprendizaje de la lectura y la escritura para su uso en la vida cotidiana. CREFAL. Decisio, 3-9.

Kalman, J. (2004). Saber lo que es la letra: una experiencia de lectoescritura con mujeres de Mixquic. Mexico: Siglo XXI : UNESCO Institute for Education.

Kaufman, A. M., Wuthenau, C. von, Marguery, M., \& Zaidenband, A. (Eds.). (2010). Leer y escribir: el día a día en las aulas (1. ed., 2. reimpr). Buenos Aires: Aique Grupo Ed. http://www.crefal.edu.mx/decisio/images/pdf/decisio 6/decisio6 saber1.pdf

Kessler, G. (2004). Sociología del Delito Amateur, Buenos Aires. Paidós

Kessler, G. (2004). Trayectorias Escolares de Jóvenes que Cometieron Delitos Contra La Propiedad con uso de Violencia. Conferencia en Seminario Permanente de Investigación de la Maestría En Educación De La UdeSA. Publicado en Documento de Trabajo N 13. Serie "Documento de Trabajo" Escuela de Educación Universidad de San Andrés

Kessler, G. \& Tizziani, A. (2014). Repensando las desigualdades sociales en América Latina. Revista Ensambles, 1, 6-10.

Kurlat, M. (2014). El «culto a las letras» en los procesos de alfabetización inicial de personas jóvenes y adultas Un obstáculo en los caminos de escritura. Revista Interamericana de Educación de Adultos, 36, pp. 59- 90.

Kurlat, M., \& Perleman, F. (2013). Procesos de alfabetización inicial en personas jóvenes y adultas: ¿hacia una historia de inclusión? Revista del IICE, 32, pp. 55-72.

Lahire, B. (1995). Escrituras domésticas. La domesticación de lo domesticado.

Larrosa, J. (2006) Sobre la experiencia en Aloma N 19, Universitat de Barcelona, pp. 87112

Larrosa, J. (1995) Escuela, poder y subjetivación. Madrid: La Piqueta, pp. 259-329. 
Larrosa, J. (2006) Una invitación a la escritura. FLACSO. Buenos Aires.

Larrosa, J. (2003) La experiencia y sus lenguajes. Conferencia dictada en Serie

Encuentros y Seminarios, Barcelona, Departamento de Teoría e Historia de la Educación, Universidad de Barcelona, Disponible en la Web:

http://www.me.gov.ar/curriform/publica/oei20031128/ponencia larrosa.pdf

Lejeune, P. (1991). El pacto autobiográfico. Suplementos Anthropos 29, 49-87.

Lerner, D. (2001). Leer y escribir en la escuela: lo real, lo posible y lo necesario. México:

Fondo de Cultura Económica.

Lerner, D. \& Kaufman, A. M. (2015). Documento transversal 1, la alfabetización inicial.

Ministerio de Educación de la Nación Argentina.

Mazzola, R. (2011, 10). Un nuevo paradigma. Página 12. Buenos Aires.

Míguez, D. (2004) Los pibes chorros. Buenos Aires: Capital Intelectual

Míguez, D. (2012) Los universos morales en el mundo del delito. Las lógicas de reconversión en contextos de institucionalización, Revista de Ciencias Sociales, segunda época, año 4, № 22, Bernal, Universidad Nacional de Quilmes pp. 45-63.

Moreno Haro, Y. (2009). CORRESPONDENCIA PRIVADA. En ESOS PAPELES TAN

LLENOS DE VIDA... Materiales para el estudio y edición de documentos personales.

Girona: CCG Edicions.

Mosconi, G. (2006) Mujeres y jóvenes encarceladas en Argentina. Una investigación socio-jurídica. En Voces del encierro. Buenos Aires: Omar Favale Ediciones Jurídicas.

Ministerio de Educación de la Nación. (N.D.). Blog Oficial de la Coordinación Nacional de Modalidad "Educación en Contextos de Privación de la Libertad". Retrieved from http://bibliotecasabiertas.wordpress.com/ 
Ministerio de Educación de la Nación, Observatorio Argentino de Violencia en las Escuelas, \& Miradas interdisciplinarias sobre la violencia en las escuelas. (2006). Miradas interdisciplinarias sobre la violencia en las escuelas. Buenos Aires: Ministerio de Educación, Ciencia y Tecnología de la Nación. Recuperado a partir de http://www.me.gov.ar/observatorio/pdf/violencia.pdf

Ministerio de Educación de la Nación (2010) Pensar la educación en contextos de encierro: primeras aproximaciones a un campo en tensión 1a ed. - Buenos Aires: Ministerio de Educación de la Nación (Pensar y hacer educación en contextos de encierro; 1)

Montes, G. (2004, marzo). La literatura, la infancia, el arte [Punto de partida]. Recuperado a partir de https://issuu.com/bibliotecaaleer/docs/la literatura la infancia el arte

Montes, G. (1999) "Scherezada o la construcción de la libertad" en "La frontera indómita", FCE, pp. 15-31

Moreno Bayona, V. (1997). Jóvenes y lectura. Peonza: Revista de literatura infantil y juvenil, (42-43), pp. 6-9.

Moreno Bayona, V. (2008). Sarcasmo. Pido la Palabra, 166(20), 22-23.

Navarro Bonilla, D. (2005) Archivos y cultura escrita carcelaria: escribir y documentar la prisión desde el siglo XVI. En Castillo Gómez, A. \& Sierra Blas, Verónica (2005) Letras bajo sospecha. Guijón, Asturias: Ediciones Trea, pp. 17-41

Ocaña Arias, A. (2010). La escritura autobiográfica y su repercusión en el ámbito educativo: Josefina Aldecoa como ejemplo de autobiografía y docencia (Doctorado Filología Hispánica). Universidad de Granada.

Olaeta, H., Fernández, D., Müller, C., Reyes, F., \& Vasile, V. (2013, febrero). Niños, niñas $y$ adolescentes en conflicto con la ley penal. Editorial Ministerio de Justicia y Derechos Humanos de la Nación. 
Olson, D. R., \& Wilson, P. (1998). El mundo sobre el papel: el impacto de la escritura y la lectura en la estructura del conocimiento. Barcelona: Gedisa.

Petit, M. (1999). Nuevos acercamientos a los jóvenes y la lectura. México, D.F.: Fondo de Cultura Económica.

Petit, M. (2003). La lectura, intima y compartida. Presented at the Lectura y desarrollo social, Ballobar - I Jornadas Aragonesas de Bibliotecas Escolares y Promoción de la Lectura.

Petit, M. (2007). La lectura como constructora de sujeto -Entrevista exclusiva con Michèle Petit. Impronta Boletín de Novedades Editoriales Editorial Pontificia Universidad Javeriana, 1(3), 8-14.

Petit, M. (2012). La literatura, parte integrante del arte de habitar. En La literatura que acoge: inmigración y lectura de álbumes (1. ${ }^{a}$ ed., pp. 263-281). Banco del Libro; Gretel.

Petit. M. (2009). El arte de la lectura en tiempos de crisis. Océano-Travesía.

Petit. M. (2009, mayo 11). «Transmitir el hábito de la lectura es una tarea sutil» [Página 12].

Ortiz Bergia, M. J. (2012) Historia Los menores abandonados y la tutela estatal en Córdoba, cambios y continuidades en un período de transición, 1930-1943. Revista Síntesis $n^{\circ} 3$

Petrucci, A. (2000). Marginales y escribientes subalternos, «SIGNO. Revista de Historia de la Cultura Escrita» 7, Universidad de Alcalá, pp. 67-75.

Petrucci, A., \& Castillo Gómez, A. (2002). Un paseo por los bosques de la escritura [Litterae. Cuadernos sobre cultura escrita] pp. 9-37 
Procuración Penitenciaria de la Nación. (2013) Colectivos Vulnerables/ Adolescentes y Jóvenes. Recuperado a partir de http://www.ppn.gov.ar/?q=node/1749

Reguillo Cruz, R. (2002) Emergencia de culturas juveniles. Estrategias del desencanto. Buenos Aires. Grupo Editorial Norma

Rockwell, E. (2005). Del campo al texto. Reflexiones sobre el trabajo etnográfico Conferencia en Sesión Plenaria Primer Congreso de Etnología y Educación, Universidad Castilla-La Mancha, Talavera la Reina- Centro de Investigación y de Estudios Avanzados del IPN

Rockewll, E. (2000). La otra diversidad: historias múltiples de apropiación de la escritura. Diverscité Langues. En ligne. Vol. V. Disponible àhttp://www.teluq.uquebec.ca/diverscite

Rockwell, E. (2005) La apropiación, un proceso entre muchos que ocurren en los ámbitos escolares. En: Memoria, conocimiento y utopía México. Anuario de la Sociedad Mexicana de Historia de la Educación No. 1, Ediciones Pomares

Rockwell, E. (2001) La lectura como práctica cultural: conceptos para el estudio de los libros escolares Educação e Pesquisa, vol. 27, núm. 1, enero-junio, 2001, pp. 11-26 Universidade de São Paulo São Paulo, Brasil

Rodari, Gianni. (1997) Gramática de la Fantasía, Introducción al arte de inventar historias. Buenos Aires. Ed Colihue

Scott, J. W. (1992) Experiencia. En Feminists Theorize the Political, traducción de Moisés Silva, Routledge, Inc.

Sierra Blas, V. (2015). Autobiografías en miniatura. Apuntes y reflexiones sobre la correspondencia infantil. Tempo e Argumento, Florianópolis, v. 7, n.15, pp. 42 - 70.

Sierra Blas, V., Martínez Martín, L., \& Monteagudo, J. I. (2009). Esos papeles tan llenos de vida_: materiales para el estudio y edición de documentos personales. Girona: CCG. 
Skliar, C. (2015). Desobedecer el lenguaje: alteridad, lectura y escritura. Madrid: Miño y Dávila.

Skliar, C. (2010). Los sentidos implicados en el estar-juntos de la educación. Revista Educación y Pedagogía, 22(56).

Terigi, F. (2009). Las trayectorias escolares: del problema individual al desafío de política educativa. Ministerio de Educación de la Nación Argentina.

Tumbando Rejas. (2008) Revista del Centro Educativo Complejo Esperanza - Año 1 Número 1/ septiembre 2008

Vasile, V. (2012) Niños, niñas y adolescentes en conflicto con la ley penal / Virginia Vasile y Fabiana Reyes. - 1a ed. - Buenos Aires: Infojus,

Villa, A.; Barletta, C. (2014): Niños Criminales: intervenciones pedagógicas sobre "otras" infancias y juventudes en Relaciones escolares y diferencias culturales: la educación en perspectiva intercultural. Alicia Inés Villa y María Elena Martínez (comps.), Buenos Aires, Novedades Educativas

Wacquant, L. J. D. (2001). Parias urbanos: marginalidad en la ciudad a comienzos del milenio. Buenos Aires: Manantial.

Zaffaroni, E. R., Rep, M., \& Vattimo, G. (2013). La cuestión criminal (5. Ed.). Buenos Aires: Planeta.

Zaffaroni, E. (1991). La filosofía del Sistema penitenciario en el mundo contemporáneo. Cuadernos de la Cárcel. Buenos Aires: Editorial La Galera.

Zapiola, M. C. (2010) La Ley de Patronato de Menores de 1919: ¿una bisagra histórica? en Lionetti, Lucía y Míguez, Daniel (comp.), Las infancias en la historia argentina. Intersecciones entre prácticas, discursos e instituciones (1890 1960), Prohistoria, Buenos Aires, pp. 117-132. 
ANEXOS 


\section{ANEXO 1: PLANES TALLERES 2015}

4 de agosto $1^{\circ}$ TALLER INSTITUTO HORIZONTES

PLAN $1^{\circ}$ TALLER

"PRESENTACIÓN / LA ESCRITURA EN EL ENCIERRO/ CÉSAR GONZÁLEZ"

Ambientación: una mesa con libros, poesías y canciones

$1^{\circ}$ MOMENTO:

Presentación del taller y talleristas.

Presentación de los chicos: escriben una parte de la letra de una canción para presentarse y tres razones por las que eligieron esa canción. Puesta en común

$2^{\circ}$ MOMENTO: Lectura en voz alta de poemas de Cesar González (Camilo Blajaquis): Poema Candado, y otros, comentamos sobre la vida de César, su obra y vemos videos (fragmentos) de entrevistas

$3^{\circ}$ MOMENTO: Lectura de Gracias a la Vida (Violeta Parra) y Gratitud (Girondo) Escribimos poemas cortos diciendo gracias a algo Se pone música mientras escriben, se asigna un tiempo/ Lectura de lo escrito

FINAL: Ponen su nombre y decoran el cuaderno del taller: con fibrones, papeles de colores, recortes de revistas

11 de agosto $2^{\circ}$ TALLER INSTITUTO HORIZONTES

PLAN $2^{\circ}$ TALLER

"LA LINEA DE TIEMPO/ LA NIÑEZ Y LOS JUEGOS"

Ambientación: algunos libros (en el piso), letras de canciones, caramelos

$1^{\circ}$ MOMENTO: Lectura de letras de canciones de Esteban el As, poemas sobre la infancia, poemas de Cesar González, vemos un video de Esteban el As.

$2^{\circ}$ MOMENTO:

Propuesta del proyecto de la novela grupal: escribir una historia que refleja la vida de ellos, puede ser la vida real de cada uno, o puede ser la vida de un amigo

Propuesta de armar una línea de tiempo con los hechos más importantes de cada etapa, en forma grupal en un afiche (tres afiches pegados con una línea central el primero de los 0 a los 7 años, de los 7 a los 14 años, de os 14 a los 21 años)

Colocar en la línea cartelitos con nombre de cosas importantes que les pasaron en cada etapa, todo lo que se les ocurra, cosas buenas como malas, las tarjetas están vacías (ellos los completan). "Hoy vamos a poner solo los títulos, eso luego se va a ir completando" $3^{\circ}$ MOMENTO: 
Caja con juguetes: cada uno elige algo que le recuerde su infancia explica por qué lo eligió. Proponemos un momento de escritura en lo que cada uno empiece en forma automática a escribir algún recuerdo de su infancia

Se comparte una merienda (gaseosa y galletitas) Se pone música mientras escriben

LECTURA DE LO ESCRITO

18 de agosto $3^{\circ}$ TALLER INSTITUTO HORIZONTES

PLAN $3^{\circ}$ TALLER

"EL COMIENZO DE LA HISTORIA"

PRIMER MOMENTO: Lectura del cuento "Cambios" de Anthony Brown.

Retomar la idea de la "línea de la vida", (dejar claro que en nuestras historias de vida somos singulares y a la vez tenemos cosas en común)

SEGUNDO MOMENTO:

Escritura Grupal: presentar distintos comienzos para la historia escritos en tarjetas “¿Cómo puede empezar la historia?" Presentamos tarjetas con opciones, por ejemplo: "Nunca había imaginado que" o "Fue el día más bonito porque", "Decidió nacer cuando", "Llegó al mundo un día”, etc. Dejamos tarjetas vacías para completar por si se les ocurren otras opciones. En la pared pegado uno o dos papeles afiche con renglones. Uno de los chicos u otro adulto escribe las ideas que surgen del grupo en común acuerdo. Terminamos con "en su casa había una mesa" y lo dejamos pendiente

TERCER MOMENTO:

Escritura individual: lectura de "La mesa" de Grippo y "Oda a la mesa" de Neruda

Recordamos alguna mesa que estuvo presente en la vida de cada uno de los participantes traen de la memoria alguna mesa que recuerden. Proponemos escribir algo sobre esa mesa ¿Qué recuerdan? ¿Cómo era? ¿Color? ¿Forma? ¿Tamaño? ¿Quién estaba alrededor? ¿O estábamos solos? ¿Se reunía otra gente? ¿Para qué se usaba? ¿Recuerdan algunas otras mesas? En que los hace pensar el recuerdo de la mesa?

Proponemos un ejercicio de escritura automática: escribir tal cual surgen las ideas de la mente, sin reflexionarlas y sin tener un tema preciso, plasmarlas sin pensar ni revisar,

Se dan unos diez minutos para la escritura, luego leemos en voz alta

25 de agosto $4^{\circ}$ TALLER INSTITUTO HORIZONTES

PLAN $4^{\circ}$ TALLER:

"JORNADA de ESCRITURA Y PELÍCULAS"

PRIMER MOMENTO: Escritura Grupal: a partir de dos ítems de la línea de tiempo "a los 5 años se entera que su padre estaba preso" y "iba al jardín de la mano de..." (Sacadas de la línea de tiempo) 
SEGUNDO MOMENTO: Escritura individual: El barrio. Lectura de varios textos de la revista Seguir Soñando (escrito por chicos del Almafuerte) les proponemos que escriban en su cuaderno sobre el barrio: qué fotos sacarían, qué fotos no sacarían, y cuál es la seña o marca de su barrio.

TERCER MOMENTO: PELÍCULA: 7 CAJAS

1 de septiembre $5^{\circ}$ TALLER INSTITUTO HORIZONTES

PLAN $5^{\circ}$ TALLER

"LA ESQUINA/EL BARRIO"

PRIMER MOMENTO: presentamos tarjetas en blanco para la línea de tiempo: proponemos completar de los 7 a los 14 años

SEGUNDO MOMENTO: Escritura individual. Lectura de la letra de canciones: Barrio Bajo (Esteban el As) y la canción "Como que no" de La Liga/Onda Vaga. Vemos los videos (varias versiones) Conversamos sobre la esquina, experiencias de cada uno, proponemos que escriban en forma individual sobre su barrio, o la esquina.

TERCER MOMENTO: Escritura grupal. Con fragmentos recortados de las letras de las canciones, proponemos continuar la novela grupal

22 de septiembre $6^{\circ}$ TALLER INSTITUTO HORIZONTES

\section{PLAN $6^{\circ}$ TALLER}

"MENSAJES EN BOTELLAS"

Ambientación: una tela celeste, arriba botellas con papeles enrollados adentro, en la computadora un video con el sonido y las olas del mar

PRIMER MOMENTO: Les preguntamos si saben lo que significan los mensajes en la botella, Y qué es un náufrago. Leemos algunos poemas y letras de canciones que se refieren a mensajes en una botella (anexo) (podemos ver el video del tema de The Police)

SEGUNDO MOMENTO: Escritura individual: Les proponemos que imaginen que este lugar es una isla rodeada de mar, y que pueden escribir un mensaje para que alguien los ayude. Diez minutos para la escritura. Puesta en común (cada uno puede poner su mensaje en una botella, simbólicamente)

TERCER MOMENTO: Escritura grupal: Continuamos con la novela grupal:

Yandel queda preso por primera vez ...(relato de su primer día preso)

Por fin llega el día tan esperado... (relato de la salida permiso/ o libertad

29 de septiembre SÉPTIMO TALLER INSTITUTO HORIZONTES

PLAN: dada la situación que se presentó, solo vinieron Renzo y dos chicos nuevos, no se dio el taller que estaba planificado, que pasó al próximo, y improvisamos un taller inicial 
6 de octubre $8^{\circ}$ TALLER INSTITUTO HORIZONTES

PLAN $8^{\circ}$ TALLER

"ALADINO"

Ambientación: una manta (a modo de "alfombra persa") con libros de cuentos orientales (de la Biblioteca Abierta) y música árabe

PRIMER MOMENTO: Lectura del cuento Aladino

SEGUNDO MOMENTO: Escritura individual: que tres deseos le pedirías al genio? Escribirlos

TERCER MOMENTO: Escritura grupal a partir de frases del cuento

13 de octubre $9^{\circ}$ TALLER INSTITUTO HORIZONTES

PLAN $9^{\circ}$ TALLER

"EL ENCIERRO"

Ambientación: una manta en el piso con libros y poesías de escritores que escribieron desde el encierro

PRIMER MOMENTO: escritura individual: sensaciones y palabras del encierro y la libertad: cuadro de dos columnas LIBERTAD/ENCIERRO, y opciones para describir o poner palabras sueltas: NOCHE, MAÑANA, SUEÑOS, OLORES, SONIDOS. Puesta en común (se tomarán estas palabras para la escritura grupal)

SEGUNDO MOMENTO: Lectura de poesías de Miguel Hernández, Paco Urondo, César González, Armando Tejada Gomez.

TERCER MOMENTO: Escritura grupal 1: Descripción: tomando las palabras que escribieron hacemos una descripción del encierro, la escribimos en primera persona, es Yandel el que describe. Escritura grupal 2: Diálogo. Imaginamos una situación en la que Yandel se encuentra con Mustafá, utilizando su lenguaje como espontáneamente hablan

20 de octubre $10^{\circ}$ TALLER INSTITUTO HORIZONTES

PLAN $10^{\circ}$ TALLER: "EL FINAL"

Continuación/finalización de la novela: proponemos distintas consignas y opciones en tarjetas para cada página

Página 15: Después del motín Yandel estuvo un tiempo... (continuar)

Hasta que por fin llegó el día de visita y tuvo una gran sorpresa...

ELEGIR:

Su madre, Angélica le trae una gran noticia...

Entre medio de las familias, vio llegar a quien menos esperaba: Yesi, ella....

Conoce a la hermana de Mustafá, Julieta, una hermosa...

Reconoce a Gaby su maestra de Jardín de Infantes, que se había enterado que...

Ve llegar a un hombre de unos 40 años, muy parecido a él, era... 
Página 16: En su primer permiso lo primero que hizo fue...

ELEGIR

Volver a la maldita eskina

Visitar al amor de su vida

Volver a su casa y abrazar a su madre

Encontrarse con su padre

Ir a la biblioteca de su barrio donde trabajaba....

27 de octubre $11^{\circ}$ TALLER INSTITUTO HORIZONTES

PLAN UNDÉCIMO TALLER: 27 de octubre

REVISIÓN DE LA NOVELA:

Proceso de revisión de un texto. Trabajo grupal de revisión, pero esta vez en una pantalla.

Elementos: Proyector y notebook para revisar en equipo, con toda la novela transcripta en Word Elección del título: llevamos libros/distintos tipos de títulos: cortos, largos, extraídos del texto, con nombre propio, insólitos.

3 de noviembre $12^{\circ}$ TALLER INSTITUTO HORIZONTES

PLAN $12^{\circ}$ TALLER: EL TÍTULO

Consigna para armar título de la novela

- Explicamos el sentido del título, los distintos tipo de títulos, los vemos en ejemplos de libros de la biblioteca

- Presentamos las palabras sueltas recortadas

- Les proponemos que con las palabras propuestas armen frases cortas al azar.

- Pueden o no agregar palabras nuevas

- La consigna es usar todas las palabras y armar todas las frases posibles

- Luego en la puesta en común vemos si alguna puede ser el título de la novela, tal vez puedan rearmarse uniendo dos frases, cortándolas, etc.

- Podemos elegir dos o tres posibles, fundamentar por qué los elegimos y después votar

10 de noviembre $13^{\circ}$ TALLER PRODUCCIÓN DE FOTOS 


\section{ANEXO 2: NOVELA GRUPAL}

\section{LA OTRA VIDA DE LOS PIBES PISTOLEROS}

\section{El día más bonito}

Fue el día más bonito: se enteró que iba a nacer su primer bebé.

Angélica tenía 18 años y vivía en Buenos Aires en la Villa 31.

Un día fue al Luna Park a ver a Carlitos La Mona Jiménez, ahí fue donde conoció a Juancho, un cordobés de 21 años que la invitó a tomar algo y a bailar. Se empezaron a conocer y se enamoraron.

Angélica se fue a vivir a Córdoba, a la Villa El Tiradero, era un barrio donde había mucha droga, delincuencia y necesidades

Ese día él le dio la plata para comprar un Evatest. Cuando Angélica le dio la noticia de que estaba embarazada Juancho se fue a buscar trabajo y como no encontró se mandó de caño a un Súper, sin querer mató una persona y perdió su libertad, su mujer y su pequeño bebé.

\section{Se quedó sola}

Angélica se quedó sola, sin plata, embarazada.

Decidió llamar a su hijo Yandel Santino.

Yandel llegó al mundo un día cálido y húmedo de octubre. Nació en la Maternidad. Estuvo tres días. Las enfermeras la ayudaron porque estaba sola.

Estaban todos tan felices, pero faltaba Juancho, que estaba privado de su libertad en Bouwer. Yandel era un bebé gordito y sano, había nacido con 3 kilos y medio. Se alimentaba de pecho y mamadera, porque Angélica tenía que salir a trabajar y lo cuidaba su abuela, la mamá de Juan.

\section{El tiempo es veloz}

El tiempo es veloz y Yandel ya sabe dar sus primeros pasos, decir mamá, y papá a la nueva pareja de Angélica, Roberto, que es peón de peón de peón de albañil, es un cabezón de turcón. Angélica en esa época trabajaba en una empresa de alimentos, pero esa altura ya la habían echado de su trabajo.

La mamá de Juan los había volado de la casa y ahora vivían en la Villa La Tablita.

En la plaza del barrio se veían chicos jugando, abundaban las mujeres hermosas, los transas, y la policía patrullaba por sus calles rotas.

\section{Su padre era Juan y estaba preso}

Su madre le contó que su padre era choro cuando tenía cinco años. Le contó que Juancho andaba robando bien hasta que perdió. 
Se perdió en el MD1, un módulo de la cárcel de Bouwer, porque había matado al chino. Su madre no se lo había contado porque era muy chico.

Angélica había recibido una carta de Juancho pidiéndole ver a su hijo.

Yandel se quería morir porque pensaba que su padre era Roberto y ahora se enteraba que su verdadero padre era Juan y estaba preso.

Angélica no lo quiso llevar a conocer a su padre a la cárcel, porque no quería que su hijo conociera ese lugar.

\section{Al jardín de la mano de la madre.}

lba al jardín de la mano de la madre. Allí jugaba con los amiguitos y las amiguitas al papá y a la mamá en el rincón de la casita. En el patio jugaban al futbol y al ladrón y al policía. La seño Gaby era tan linda y buena, era la más linda del jardín (para lambearla como una paleta).

Su compañerito se llamaba Mordelón porque en las peleas mordía. Su otro amigo era Mustafá, que ya en el jardín le enseñó a defenderse y a no tenerle miedo a nadie. Anduvieron juntos ambientando por el jardín y por el barrio, hasta conocieron una comisaría por primera vez por andar a los gomerazos por todos lados

\section{Se activan las esquinas}

Cae la noche y se activan las esquinas: los pibes altas pistolas, las pibas altas colas -ando buscando alguna que no quiera estar sola-, fumando un fasito, una macumba, un porro, una rocha (una 542)...tomando un tereré...

Las chicas atrevidas provocan a la batucada, fuman y beben un poco y después se descontrolan... al otro día ya no se acuerdan qué hicieron.

Una noche sin luna el barrio se ilumina con los disparos de la policía.

Los pibes salen corriendo como ratas de alcantarilla.

Las chichas salen a chusmear a ver qué ratas se llevan

Las madres tienen la valentía de hacer guerra a la policía.

El sol sale y corre la noticia que al guacho Yandel lo llevo la yuta.

En la comisaria encontró paredes escritas:

"Que se haga verdadera mi ilusión: conocer a mi hijo Yandel. Juancho"

\section{Preso de garrón}

Cayó preso de garrón, pasó toda la noche entera tirado y reventado por la policía. No pudo dormir en esa cama de cemento, pensando toda la noche en aquella frase que su padre preso escribió cuando encanó. Se quebró como una galleta de agua. 
Al otro día lo derivaron a un instituto de menores: lo trasladaron al Complejo Esperanza en un patrullero.

Apenas ingresó era toda una señorita, se la aplicó un chuncano y le choreó las zapatillas. Yandel no sabía cómo reaccionar, y batió la cana a un guardia, al chuncano lo trasladaron a otro instituto.

\section{Tribunales}

Después de cinco días de represión... de estar cajeteando, lo trasladaron a Tribunales. Iba esposado con chicos de otros barrios. En el traslado encontró un viejo conocido de su barrio, que le dio un consejo:

Que no cayera más, que no hiciera más moco.

Cuando llegó a Tribunales lo llevaron a una cámara piola: Primera Segunda. Lo que era la primera causa y nada jodida le dieron la libertad

$$
\begin{gathered}
\text { "y la mamá siempre llorando... } \\
\text {-Hable con su hijo es un inadaptado- } \\
\text { Los años pasan y las cosas siguen cambiando } \\
\text { El pibe dejó sus juguetes } \\
\text { por el escabio y el faso" }
\end{gathered}
$$

\section{Hacer las cosas que no tenía que hacer}

Yandel volvió a su casa, estuvo toda la tarde con su familia y salió a ver a sus amigos en la esquina. Lo invitaron a fumar y él no dijo que no (si estaba en la esquina, no estaba en la escuela)

"Le daban todos los gustos sin saber, sin entender que lo mal enseñaban.

Usaba zapatillas de primer nivel, No iba nunca a la escuela, a los doce ya fumaba, se descarrilaba"

Andaba con la mala junta y empezó a hacer cosas que no tenía que hacer: le empezó a gustar la plata fácil y hacer daño a los demás.

Pobre madre, había sufrido mucho por la requisa de la policía en los allanamientos, y él le pagaba mal con las cosas que hacía. Pero la mamá es la mamá y siempre va a estar. ¿Tenés que tropezarte muchas veces para darte cuenta de las cosas? ¡No da!

\section{Su primer amor}

Yandel era chico todavía, tenía 15 años, cuando encontró su primer amor: Yesi. Ella lo hizo feliz hasta que lo dejó el día en que cayó preso. 
Se conocieron en Patio Olmos (se habían conocido por el Facebook y tuvieron una cita) ese día se amaron hasta que llegó el otro día.

Yesi era una chica buena y estudiosa, iba al colegio, era una rubia bien bonita, y vivía en un barrio careta: el Cerro. Ella no sabía lo que hacía él porque él le decía que trabajaba y estudiaba, y ella por amor estuvo a su lado.

Él la buscaba todas las tardes en su moto, y ella contenta, porque él llegaba.

Un día Yandel la llevó a su casa a cenar y ese día ella se dio cuenta de que él vivía en un barrio bajo. Vio otro mundo, un mundo que no conocía, muy distinto al de su ambiente.

A ella no lo importó, lo que a ella le importaba era el amor que sentía ella por él y él por ella

\section{TE AMO YANDEL <3 (notita de Yesi)}

\section{Su primer trabajo: un caño}

Una mañana Yandel se sentó en la esquina a ver pasar la vida, se prendió un porro y se dio cuenta que lo estaban comiendo los piojos

Ese mismo día consiguió su primer trabajo: un caño. Fue enviado por un amigo a un atraco, pero no sabía que ahí trabajaba un ratón

"Esto es un asalto: todos al piso y no me miren si no quieren que les tire"

Luego hubo un fuerte forcejeo entre Yandel y el ratón. Yandel manoteó la plata, dio media vuelta y corrió, luego un rafagazo de balas sintió. Yandel sin pensar respondió: pam pam pam pam pam!

Luego el ratón cayó y Yandel huyó hasta el auto y escapó.

Llegó a la guarida con su compañero, los dos emocionados y acelerados porque el robo les había salido bien.

Entonces Yandel se sentó a pensar: ¿Habría quedado algún herido?

Quedó fantasmiado

Luego se pusieron a contar el dinero y el guacho Mustafá, su compañero, lo invitó a fumar una santa hierba para calmar su miedo.

Cuando llegó a su casa, la madre desesperada le dijo que la policía lo estaba buscando, que el ratón había caído herido y Yandel huyó a la casa de Mustafá.

Pero Mustafá no estaba, había encanado con su tecla. Había quedado pegado como un chicle.

\section{Lo que tenía que suceder}

Mientras en cana Mustafá jugaba a las cartas con las arañas, Yandel en la calle seguía delinquiendo $24 \times 7$.

Estaba fugado porque lo andaban buscando por lesiones graves en ocasión de robo. 
Entonces sucedió lo que tenía que suceder: en medio de un atraco cuatro balazos le dieron, cayó muerto un policía y también su compañero Mordelón. Se había acabado su vida de pistolero en la calle. Logró recuperarse de los balazos, pero encerrado otra vez en el Complejo Esperanza.

Ahora camina solo en la pieza del CAD, acusado de homicidio en ocasión de robo.

\section{El encierro}

Todos los días lo mismo, enyugado, el tiempo largo

El gris y el blanco que te vuelve loco

Parece un loquero

Olor a rejas, a paredes mojadas

Olor a encierro

Aguantarse el silencio

Pensamiento solitario

El tiempo es como si estuvieras buscando

agua en el desierto

Mirando cuatro paredes

La noche es larga y fría

Con ruidos de ratas

Sonidos de candados

Sonidos de fantasmas

La misma rutina siempre

Aburrida

La alegría de la mañana porque te desenyugan

La mañana es con bronca también

cuando el guardia te levanta con los ruidos del enlace

la mañana, la escuela, estrellados

escribiendo encerrados

el tiempo no pasa nunca

se levantan sin ganas los pibes

el tiempo es feo

pero se levantan igual

\section{Hacer la condena juntos}

Mustafá estaba en el Nuevo Sol y se enteró que Yandel había caído preso. Lo estaba esperando para hacer la condena juntos. Cuando trasladan a Yandel al Nuevo Sol se encuentran:

Y: Hola Mustafá como andas?

M: Qué onda Yandel? ahora vos acá... 
Y: por una boleta y lesiones graves, por lo nuestro

M: que otario que sos! como vas a encanar pedazo de logi!

Y: Bueno guacho vos sabés cómo es esto...

M: Bueno guacho, ahora vamos a tener que hacer la condena juntos, hay que mandarle para adelante nomás, irse acostumbrando... Acá las cosas son así: no se bolacea a la madre, se la respeta, no te refalés porque te podés golpear, no te retobés...

Y: Vos no te retobés... de cuándo vos Mustafá, no te juna ni una, pedazo de pancho, salchicha humana, que es lo que te pasa a vos??? hacé las cosas bien, portate bien y hacete querer.

M: Listo, ta bien, te avivaron las rejas...

Y: Ya fue hermano, cerrá el hocico y dejala ahí nomás.

\section{El motín}

Mustafá lo llevó a Yandel a la pieza de él, se fumaron un par de porros, un par de rochas y se la funden a la yuta: de frente marucha hacen un motín y un par de perros los segundean El motín empezó la mañana del sábado. A todo o nada. Reventaron todo el sector, trabaron el enlace. Hasta que llegó el grupo Eter "Los Enojados" y los pibes se tiraron todos al piso, todos los choros atados barquito. Fue historia

Después del motín Yandel estuvo un tiempo en el aislado, estuvo una semana encerrado en una pieza sufriendo hambre, frío, sed y falta de higiene, pensando, cajeteando al borde de la locura, sintiendo el dolor de los golpes por la verdugueada de la yuta ortiva

\section{Día de visita}

Por fin llegó el día de visita y Yandel entonces se preparó, se puso contento porque al fin iba a poder ver a su familia. Ese día lo esperaba una gran sorpresa...

Vio llegar un hombre de unos 40 años muy parecido a él y se sorprendió... en su cabeza algo le decía que ese hombre era su padre al que no conocía.

El hombre se acercó y lo abrazó y en ese momento se dio cuenta que era Juancho, su padre, entonces Juancho le dijo:

- Hola hijo, soy tu padre, por fin te conozco, no sabes cuánto tiempo esperé este momento, tengo tantas cosas para decirte

- Bueno, te escucho

Entonces se sentaron en un banco y se quedaron conversando felices. Cuando la visita terminó, fue como "tirarse en un volcán de amargura en erupción"

\section{La noticia de Yesi}


La que llegó el domingo siguiente fue Yesi, que le trajo una noticia. Primero le dijo que lo perdone por haberlo dejado tirado, y después le dio la noticia que estaba embarazada.

Yandel le dice "Pero que me querés fabricar un guacho!... si hace tres mosaicos que estoy!" Ella le responde que está de cuatro meses. Igual no le cree, porque es una turrita Yesi.

Yesi se levanta y se va quebrada como una galleta de agua.

Después de la visita Yandel se quedó quebrau en el sector por lo que le había dicho Yesi. Él no le cree pero todavía la quiere

$$
\begin{aligned}
& \text { "Adiós, un beso , una carta, una flor } \\
& \text { esta es mi despedida, te pido perdón } \\
& \text { si marcho, mejor será para los dos } \\
& \text { que me aleje de tu vida } \\
& \text { y que me vaya de tu amor } \\
& \text { donde va el amor, cuando se acaba } \\
& \text { y donde ha quedado } \\
& \text { lo que prometimos los dos..." }
\end{aligned}
$$

\section{Su primer permiso}

Después de 1 año y tres meses, el día de su primer permiso lo primero que hizo Yandel fue volver a su casa y abrazar a su madre, que lo bancó toda la condena.

Angélica cocinó su comida preferida: unos canelones con salsa y queso y de postre una torta helada y para bajarlo un par de Dr Lemonn con hielo.

Después fue a ver un par de percantas (que no eran Yesi) y encontró a la Nicole, a la Melina, a la Johana (la traidora) y enruló con una noche de amor y placer con las tres. Una era poco para Yandel, porque en el Complejo los pibes no tienen visita privada y ese es un derecho que los pibes tienen que tener.

A la vuelta del permiso volvió como quiso: dado vuelta en alto estado pero quebrado a la vez.

\section{Juancho cayó muerto}

Pasó el tiempo y Yandel ya estaba en la calle y se enteró entremedio del noticiero que su padre Juancho había caído muerto en un robo a un banco con toma de rehenes.

Yandel se puso muy mal, muy loco, sacó su pistola, salió a la calle fuera de sí, envenenado, se desahució...

De repente le vino a la mente la imagen del amor de su vida, de su hijo, de su madre y decidió no hacer nada y seguir adelante por ellos. Le dio las Gracias a Dios por todavía seguir vivo, por tener una familia

$$
\text { "Cuantas veces yo pasé hambre }
$$

Soy una abeja de este enjambre 
Que fue a robar por no tener trabajo

Yo me críe en un barrio bajo

Siempre empezando desde abajo

Por eso es que en esta sociedad no encajo"

Se rescató un poco cuando nació su hijo, Juancho -en honor a su padre-. Consiguió un trabajo de plomero, porque algo de caño él sabía.

\section{Su amor}

El amor de su vida era Gaby.

Gaby, su seño del jardín, ella ahora tenía 35 años, y él 20. La había reencontrado en un taller de la escuela del Complejo Esperanza.

Ella lo aconsejó y lo ayudó a dejar su vida de pistolero.

Él lo decidió por su mujer, a la que amó para siempre.

\section{Un tema para su hijo:}

A Yandel siempre le gustó componer temas y decidió escribir un tema para su hijo:

$$
\begin{gathered}
\text { Para Juancho } \\
\text { "Son las } 12 \text { de la noche } \\
\text { y te estoy viendo } \\
\text { te estoy mirando mi angelito } \\
\text { y estas durmiendo. }
\end{gathered}
$$

Me asombra ver lo rápido que estas creciendo,

si parece que fue ayer cuando estabas naciendo

me causa tanta ternura tu tranquilidad

que me llena el alma esa expresión de paz.

Todo lo que siento dentro no puedo expresar

nunca imaginé que tanto a alguien se pueda amar.

Me encanta mirar tus ojos escuchar tu risa que juegues a que sos grande usando mis camisas

que me muestres un juguete que me simpatiza

y que siempre me despiertes con una sonrisa

Sos el aire que respiro

y de mi vida la razón.

Renace mi corazón,

sos todo mi amor:

te amo" 
ANEXO 3: TOTAL ESCRITURA PARED:

REGISTRO PAREDES SAN JORGE/ 2014: TOTAL 100 (firmas/firmados: 26- 28\%)

- Barrios 9

TUMBA. SANTA ROSA

LOS GALPONES A.C.

B. COLON manda

Colonia Lola. Hurraca (5 puntos) (firma)

VILLA PAEZ

La 20

Sol Naciente

Ramada del zur

Villa del Rosario

- Nombres 14

EL GUACHO BUBI B.C. (barrio)

BRAYAN V.L. (barrio)

Dario Saillen/Lautaro Torres (tachado)/Seferino Tolosa -lista-

Alejandro Manzano/Gonzalo Parfalt (tachado)/Maximiliano Soriano -lista-

El Wacho Dani de Bialet (ciudad) (dibujo marihuana)

Teto de Villa del Rosario (ciudad) ¿??

Walter Ciudad Evita (barrio) (dibujo marihuana)

"Ameghino" Cachilon. (barrio)

Colonia Lola .Hurraca (barrio) (signos barrios)

Firma: Cara vieja (acompaña dibujo de revolver)

Beco I. P. V (signo triángulo de Argüello) (barrio)

EL TARTA DE AHÍ (hoja de marihuana)

Pelau 07-04-2014

FACUNDO VARGAS Crosti el orejón (señalando un dibujo)

- DIOS 8

"Dios dame la libertad"

"Dios te ama" (dentro de un corazón)

"JESUS NUNCA AVANDONA" (escrito en vertical)

"Señor dios te pido perdón por todo lo que ise te pido que cuides a mi familia eso nada mas y te 
pido que me ... las rejas te pido perdón mami perdón a toda mi familia chau"

"Amado mio dios y padre nuestro que estas en el cielo a traves de jesus cristo tu hijo nuestro

Te doy gracias

Te pido salir

Te pido perdón

En nombre del padre del hijo del espíritu santo amen"

"Dios te pido perdon ayudame a salir"

"Dios te pido ayudame a salir te pido ayudes a todos los chicos danos fuerza" (es largo está desgastado por el tiempo)

“DIOS/ MADRE /las palabras están cruzadas dentro de una cruz) AYUDAME A SALIR"

- Libertad 6

LIBERTAD PARA TODOS

LIBERTAD

LIBERTAD. BECO (signo del barrio) (firma)

LIBERTAD PARA LOS CHOROS (palimpsesto)

LIBERTAD (escrito en el canto superior de una biblia)

Libertad para los delincuentes (acompañado por un revolver y en u costado MAMA TE AMO)

- Madre 16

MAMA TE AMO(dentro de un corazón)

MAMI TE AMO (dentro de un corazón)

Te amo madre. To tu ijo (dentro de un corazón)

Vieja te extraño y te prometo (no se ve mas)

Vieja te re amo. 12 dias (debajo de)

Madre te amo

Madre te amo. Juan (firmado)

Madre te amo. Tu hijo/ Abuela nunca te olvido

Madre te amo. 29-10-14 (caen gotas de la palabra madre)

Madre te amo

Madre te pido perdón por todo lo que hice cuando era chico pero si no te hubieras ido a buenos aires...(no se entiende es un texto largo y bastante borrado)... me empecé a drogar y robar hasta que de tanto drogarme termine cayendo en cana y fundido...ACCIARRI (firmado)

VIEJA TE AMO

TE AMO MADRE/HERMANO /HIJO/ X100PRE (dentro de un corazón partido, con alas) 
MADRE TE AMO (al lado una rosa)

Mama te amo

Te amo mami (dentro de un corazón)

- Madre Padre 3

PADRE/MADRE (cruzados en una cruz)

PADRE/MADRE (cruzados en una cruz)

PADRE/MADRE (cruzados en una cruz) B.C.

- Hijo 1

Hijo te amo, Yo Raul (firma)

- Marihuana 2

VIVA LA MARIGUANA. HECHO POR TOCARLI/ LUIS/ AGUS (dibujo de una hoja de marihuana) (firma)

(Dibujo rastafari fumando) ECHE (firma)

- Escarches insultos 5

Pasten transa. Vende faso

La concha de tu madre

Tu mamá. Cheto Lucas

Transa. Vende. Vende. Vende. LM LM LM (señalado con flechas) (nombre tachado)

Bordon jajajaja (dibujo de una especie de payaso con un cigarrillo)

- Amor 1

Daniela te amo io Cristian (firma)

- Delincuencia 4 / muerte a la yuta 12

VIVA LA DELINCUENCIA (arriba a la derecha letra más chica: viva dios)

LARGA VIDA AL LADRON

LARGA VIDA PARA LOS LADRONES

LARGA VIDA PARA EL LADRON/MUERTE A LA YUTA

MUERTE A LA YUTA

MUERTE A LA YUTA

MUERTE A LA YUTA

MUERTE A LA YUTA

MUERTE A LA YUTA

MUERTE A LA YUTA

MUERTE!!! A LA YUTA 
MUERTE A TODA LA YUTA, A LOS ANTICHORROS, CULIADOS HIJOS DE PUTA. EL I YO.

VILLA EL TINGLADO (barrio)

MUCHA MUERTE A LA YUTA. MAURO (firma)

MUERTE A LA POLICIA

MUERTE A LOS VIJILANTE JILES HIJOS DE MIL PUTA. CAME LEO LESCANO LUCA V.U. (firma) (barrio)

- Letras canciones 5

"VISITA FANTASMA" (TEMA DE LA MONA G.)

"Yo he visto llorar a un preso mientras leía una carta Porque en ella decía, cosas orribles de casa y al hombre se le clavaban como espinas en el alma” (TEMA DE LA MONA G.)

"nosotros tomamos el control somos los dueños del pavellón estamos cansados de tanta repreción y vamos a tomar esta prición Quiero que todos se amotinen levanten bien las manos que se pongan a rezar los transasas y refujiados"

"Me visita de noche en mis sueños" (tema La liga)

"CFC" (grupo de rap)

- Tumberos 1

TUMBA

- Signos; 2

5 puntos: 1

Signo muerte a la yuta (viborita) 1

- Calendario 4

- Dibujos: 6

Revólver 2

cruz 1

Rosa

Duende/PAYASO 2

marihuana hoja 3

marihuana rastafari

REGISTRO PAREDES CAD /2015: TOTAL: 66 (firmados: 10 - 15\%)

- Dios: 7

"Dios, en estos días dame una solución o ayudame a ser más fuerte con estos conflictos. Manda a tu hijo para que obre en todos estos chicos y sus familias. Anota sus nombres en el libro de la vida" 
(C. 1, lápiz sobre pared blanca)

"Dios dame rápido mi libertad, que prometo cambar mi vida" (C. 1, lápiz sobre pared blanca)

"Dios ayudame a cambiar sácame de este infierno ayudame a ser más fuerte" (C. 1, lápiz sobre pared blanca)

"Dios dame la libertad" (C.1, tamaño grande, bajorrelieve)

DIOS TE (dibujo de una cruz) (grabado)

DIOS AYUDAME A CAMBIAR (grabado)

Gauchito 2

"Gauchito sácame de aca" (C 6)

"Ayudame gauchito por favor sacame" (C. 4, lápiz pared blanca)

- Madre/ Dios: 1

"Madre te pido disculpa perdoname madre Dios espero que bos también me disculpes sácame de aca te lo pido por favor mi padre no lo tengo por eso te lo pido a bos dios" (C. 4?)

- Madre: 11

"Mami te juro que voy a ser un mejor hijo" "Mami te amoo" "madre / mía / siempre en / mi corazón/ te amo/ guille" (C.1, lápiz sobre pared blanca) (firma)

"Mami te extraño mucho" (C.3)

"Hay viejita del alma perdona mis errores ahora me toca ami aser lo que tu isiste $\mathrm{x}$ mi" "Madre te amo con mi vida" "mamá te amo sácame de acá" "Mamá te amo, yo k..." (C. 5, lápiz sobre pared blanca)

MAMI DEL CIELO CUIDAME TE AMO LAUTARO (lápiz) (firma)

"Te quiero viejita y nunk te voy a olvidar te amo yo" (C. 5, grabado sobre la puerta) "SOFÍA Y MAMÁ LAS AMO NERO" (firma)

"Vieja te amo una banda yo Nero" (C.8, grabado sobre pared gris) (firma)

- Papi/ Mami: 2

PAPI MAMI (lápiz)

"papi mami los quiero mucho" (C. 3, lápiz sobre pared blanca)

- Papá: 2

"Pa del cielo ayudame" (C.3, grabado sobre pared gris) "Hasta la muerte papá"

- Familia (abuela hijos): 5

"Lo hice por vos hija" (C.3, grabado sobre pared gris)

"Abuela te extraño, yo Jesus" (firma) 
"Flia los amo mucho y dios nos protege"! (C.1, lapicera sobre pared blanca)

"Ciro y Juli los amo son mi vida" (C. 1, lápiz sobre pared blanca)

"FELIZ CUMPLE HERMANA"

- Novia: 8

“EVE TE AMO MI VIDA YO LAUTARO” (lápiz) (firma)

"Brisa te amo" "Mica te amo" "Lourdes te amo" (C.2, lápiz)

"Myli extraño que hagamos xxx" (C.3. grabado)

"intento volar pero no llevo alas, se me quedaron tantas cosas en tu cama" (C.3, lápiz)

SOL 100/ TE AMO/ POR 1OOPRE

ELMIHTO TE AMO YO (grabado)

- Libertad: 5

“Libertad para los pibes" (C.8, lápiz sobre pared blanca)

"Pido humildemente mi libertad" (C. 3, grabado)

"No te preocupes tu libertad va en camino" (C. 6, lápiz)

"NO TE PREOCUPES TU LIBERTAD VA EN CAMINO"

"PIDO/HUMILDEMENTE/MI LIBERTAD" (grabado)

- Delincuencia: 2

"Yo no corro Yo no engaño Fumo porro Y meto caño" (C. 1, lápiz sobre pared blanca) “\$OMO\$ PERRO\$” (C. 3)

- Muerte a la yuta/guardia/policía: 8

"Muerte a la guardia A. B. C. D." (C. 3)

"La reja no para nada" (C.6)

"Yuta Puta Muerte A la policía Antichorro Hijo de puta" (C.8, grabado sobre pared gris)

"Muerte a la taquería" "Muerte a la yuta" "Stop poli" "MUERTE A LA..." (grabado)

NO A LAS REJAS (lápiz)

- Muerte: 5

"No roba / sufre / muere" (C. 7, grabado)

"Rata Renato tus amigos te extrañan" (C. 7, lápiz sobre pared blanca)

"Q.D E.P."

"Peque presente en nuestros corazones" (dentro de un corazón, en lápiz, C. 3)

LA VIDA ES CORTA MAS SE ACTIVA MAS SE ACORTA - I LA (grabado)

- Barrios: 2

"Los wachos de san Alberto" (barrio)

CIUDAD MI ESPERANZA (barrio) 
- Otros: nombres: 6

“PELIGRO” (C.1, lápiz, Tachado con 5 rayas paralelas)

YONI 2015/ PELAU/ (firma)

NERO Y YONI (firma)

TE AMO /YO DANIEL J../ V.C.P (firma y barrio)

GAMUZA (firma)

SHULII.. B

REGISTROS ESCUELA/ 2015: TOTAL: 56 (firmas/firmados: 20 - \% firmados: 37\%)

- Barrio: 10

Monte cristo/LOS TRONCOS/ PERRO 2013

Neneral Savio (signo)

Mono Las viole (firma)

Los Álamos (barrio)

Guiñazú (barrio)

Santa Rosa (barrio)

Rio II (barrio)

Cuidad Evita (barrio)

La ciuda (barrio)

La ciuda CPR Braian (firma y barrio)

- Nombres: 17

Axel Peligro (signo triángulo) "B" ja (firma)

I.A.C.C. Neroy (signo) (firma) (Futbol)

Neqrito (firma)

Nicolás (firma)

Nicolás (signo $\mathrm{V}$ y triángulo) (firma y barrio)

Gringo <B.V.> (firma y barrio)

Gringo(firma)

PERE V.D.R.. (firma y barrio)

Chispa (firma)

Chispa(firma)

Chispa (firma)

CHISPA (firma)

Manrique Lucas firma 
Fonseca Leonardo (firma) perro (escribe otro)

Chonono (corazón) (firma)

Beco de T.P.V. (triangulo) (firma y barrio)

- Insultos: perro/ tu mamá: 5

La manadota de turno mañana atracalado en perraso Bolaciate jajaja

Perro/Tu mamá en cuero/ puto/ seguro que me viste perriandole a alguien como vos jajaja / CHISPA (firma)

Tu mamá

Tu mamá

Perro

- Muerte a la yuta: 5

Muerte a la yuta

Muerte a la policía

Muerte a la policía

Muerte a la po

Muerte a los maestros

- Libertad: 1

LIVERTAD ¿PARA CUANDO?

- Fútbol: 1

C.A.T (dibujo)

- Novia: 1

Flor te amo

- Marihuana: 1

Mariguana (dibujo)

- Madre: 1

Madre te aprecio...

- Otros: (personal 2) (delincuencia 2) 4

Me muero uuuuuuu (en una historieta una persona tirada en el piso)

Muy fuerza $i$ ?

A la Estela muy fuerza

$\mathrm{No}+$

- Símbolos:11

(Plano de una dado) dado dado dado 1

Cinco puntos dentro de un dado 1 
Cinco puntos: 6

Cuatro puntos: 1

Signo muerte a la yuta (viborita): 2

- Dibujos 7: marihuana 4, araña, duende, revolver, rayas

\section{PATIO HORIZONTES: TOTAL: 14 / Firmado: ninguno}

- Escritura de la institución:

de las alegrías de los jóvenes.

Ellos son dóciles cuando están convencidos de que se los ama DON BOSCO

- Insultos

La concha de tu madre

N G putito

Perro

TRUCHA PERRO DEL "D"

FLACO PERRO (tachaduras)

(tachado) LA GRAN (tachado) DE TU MAMÁ

- Ámbito personal

Diego perroso

(tachado) pará algo, aunque sea por tu hijo

IACC (Instituto Atlético Central Córdoba)

Mirta 135694627821

Córdoba

- Símbolos:

Hoja de marihuana/ espada víbora (muerte a la yuta) (delincuencia)

- LIBERTAD: 1

LA LIBERTAD ES UN ESTADO MENTAL 
ANEXO 4: REGISTRO FOTOGRÁFICO ESCRITURA PARED

SELECCIÓN SAN JORGE
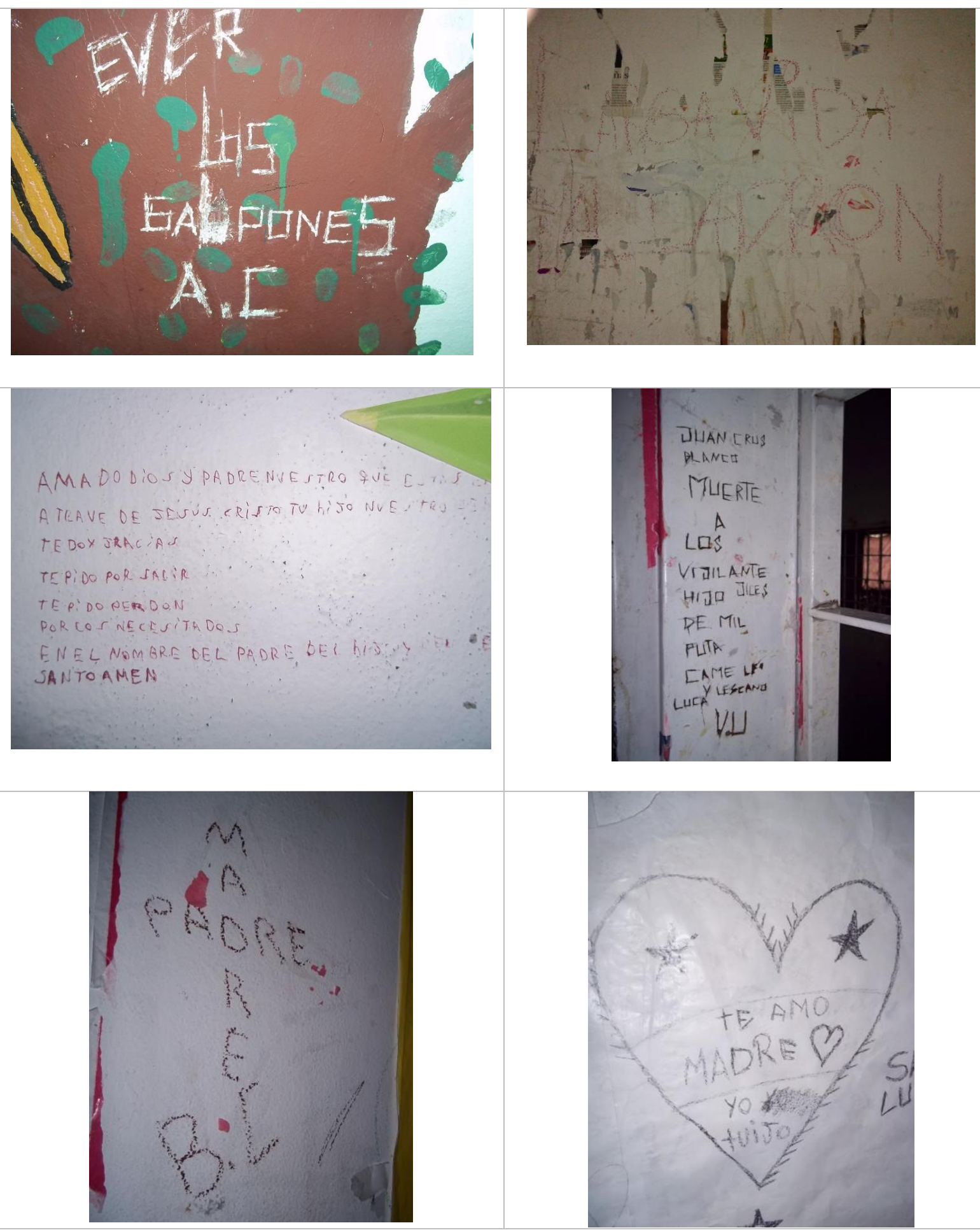


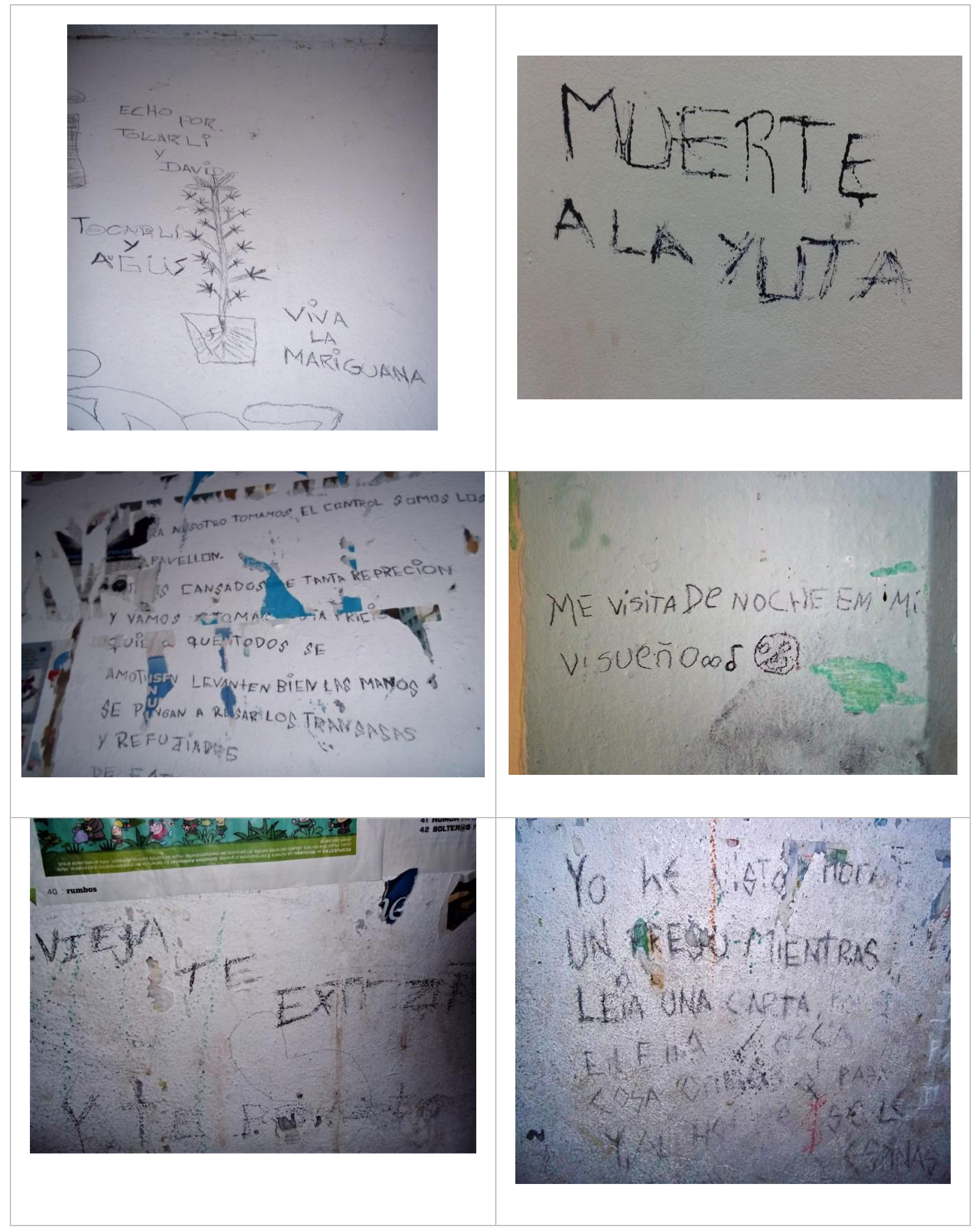




\section{SELECCIÓN PATIO HORIZONTES}
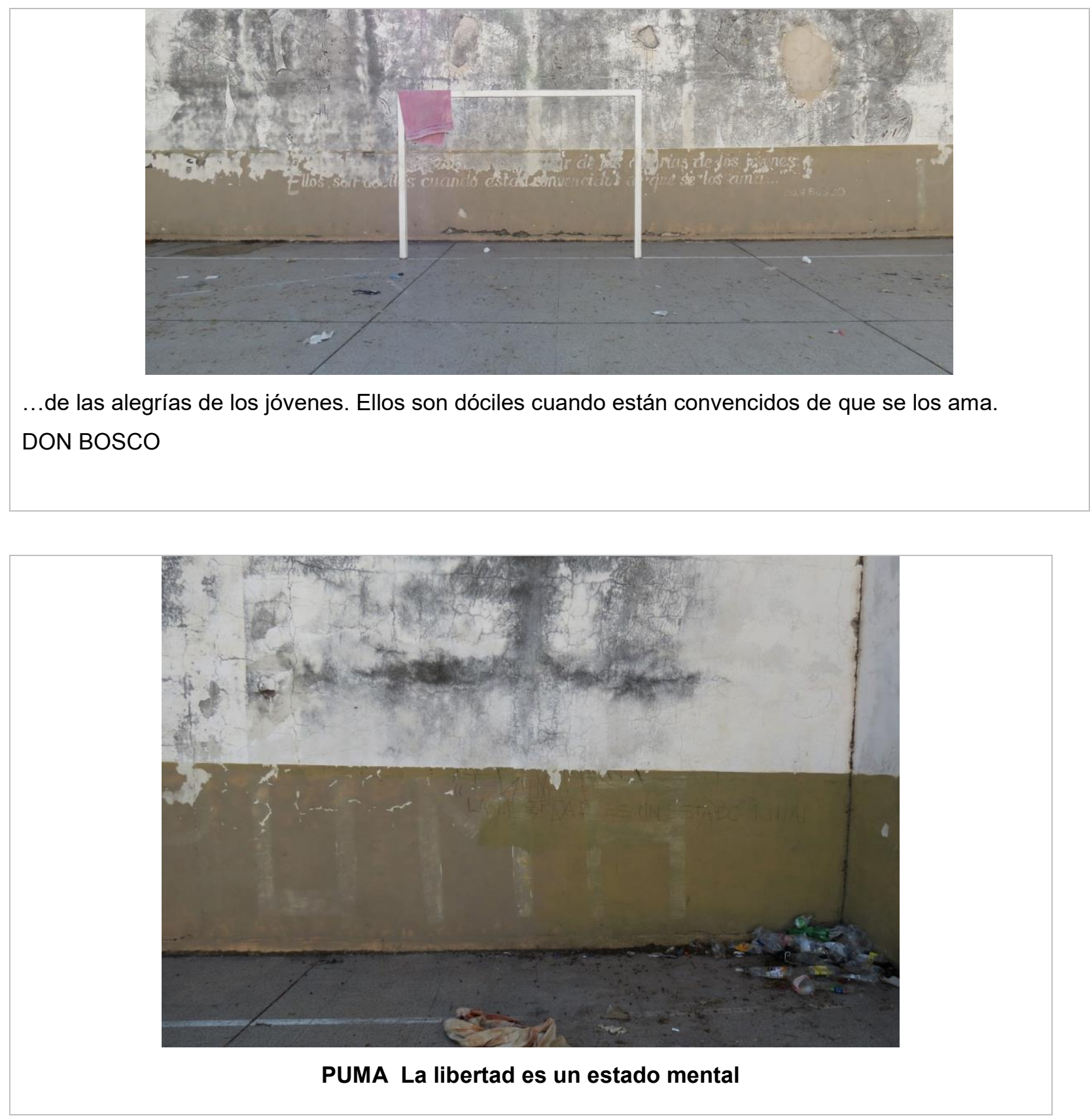


\section{SELECCIÓN CAD}

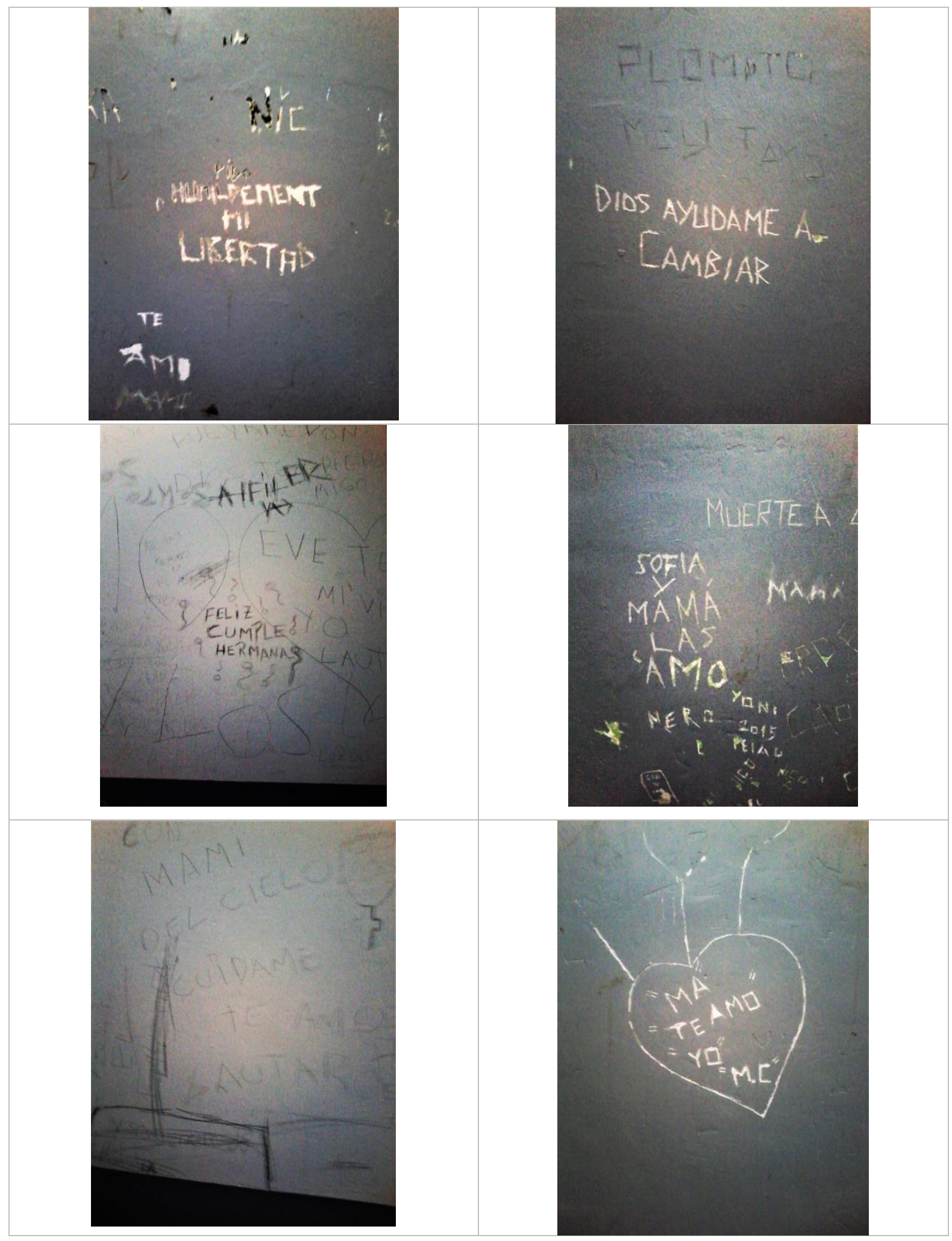


SELECCIÓN ESCUELA

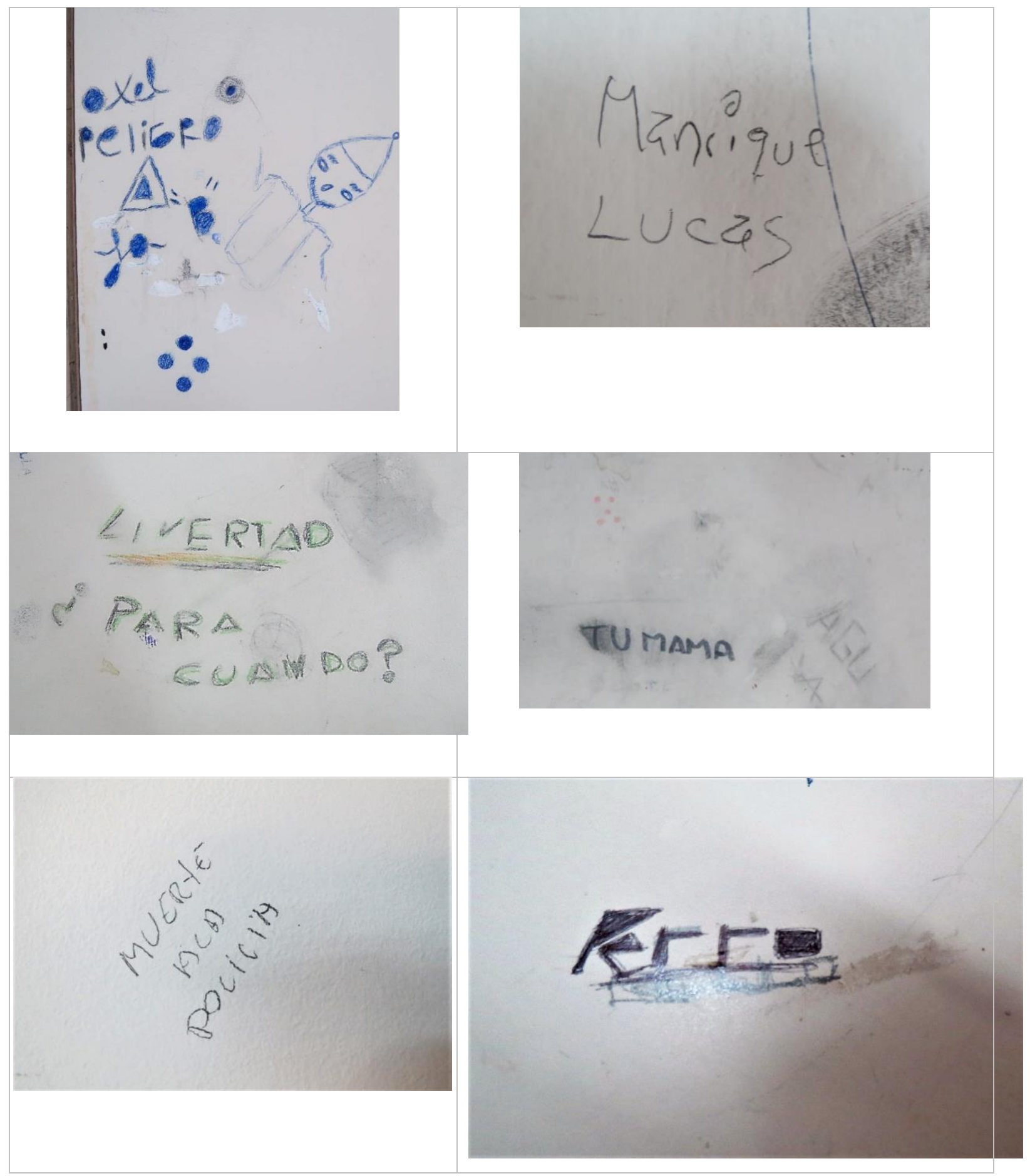




\section{ANEXO 5: Pauta de entrevista}

¿Cómo es tu familia, tus padres, tus hermanos? ¿Tenés novia, hijos...? ¿En qué barrio vivís? ¿Hace cuánto estás privado de la libertad? ¿Cuantas veces estuviste privado de la libertad? ¿Estás viniendo a la escuela? ¿En qué año estás? ¿Habías dejado de estudiar? ¿Cómo te va y/o te iba?

¿Cuándo aprendiste a escribir? ¿Quién te enseñó? ¿Te acordás de alguna cosa de ese momento en particular? (...alguna anécdota, algún libro, alguna maestra) ¿Fue en la escuela? ¿Hasta qué año fuiste a la escuela?

¿Te gustaba escribir? ¿Qué cosas te acordás que escribían en la escuela? ¿Sentís que aprendiste a escribir gracias a quién? ¿Cuánto aprendiste? ¿Sentís que aprendiste lo suficiente? ¿Por qué? ¿Al día de hoy escribís en la escuela? ¿Estás aprendiendo? ¿Qué cosas escriben? ¿Cuando eras chico fuera de la escuela escribías en otro lado? ¿Qué cosas? ¿Para qué? ¿Para quién?

Más adelante, cuando creciste, antes de estar acá en el Complejo, en tu vida en libertad, ¿Escribías algo? ¿Qué cosas escribías? (Cartas, chat, mails, canciones, mensajitos, poesías, tatuajes, graffitis, etc.) ¿Y en este momento escribís? ¿Te gusta escribir hoy en día? ¿Hay algo que no te gusta de la escritura? ¿Alguna vez escribís por tu cuenta cuando estás en el módulo? ¿Qué cosas escribís? ¿Qué sería lo que más escribís? ¿Escribís algo en forma cotidiana? ¿Dónde y cómo escribís? ¿Escribís solo? ¿Con amigos? ¿En grupo? ¿En qué momento del día podés escribir?

¿A quién le escribís o escribirías ahora? ¿Sobre qué cosas escribís o escribirías? ¿Hay algún otro tipo de texto que escribas menos habitualmente? (Cartas, canciones, mensajitos, poesías, tatuajes, graffitis, etc.) ¿Para quién escribís más vos? ¿Escribís para vos o para los otros? ¿Te molesta o te gusta que otros lean lo que escribís, o para vos la escritura es algo privado? ¿Por qué?

¿Cómo te enteraste y por qué viniste al taller de escritura? ¿Qué te parece la experiencia? ¿Sentiste algo nuevo, algo que antes no habías sentido? ¿Qué cosa? ¿Cómo te sentiste con las consignas? ¿Fue diferente esta vez escribir? ¿Notaste algo especial en tu manera de escribir? ¿Hubo algo distinto en los textos, en las formas, en las palabras, etc.? ¿Hay algo que te llamó especialmente la atención? ¿Te hubiera gustado que haya más de algo? ¿Hubo partes que te aburrieron? ¿Algo te tomó por sorpresa? ¿Algo te molestó? 
En relación a tu propia escritura en los talleres: ¿Pensabas que ibas a escribir lo que escribiste? ¿Qué pensabas que ibas a escribir? ¿Hay algo que sea diferente a tus escrituras anteriores? ¿En tus escrituras contás cosas que viviste o sentís? ¿Escribiste algo que te contaron? ¿Algo que viste? ¿Te quedaron cosas sin escribir?

¿Qué es lo que más te gusta escribir? ¿Te gustaría escribir más, escribir algo que todavía no escribiste? ¿Qué cosa por ejemplo? ¿Por qué?

¿Y cuando escribiste, agregaste algo de tu imaginación, inventaste algo? ¿Qué inventaste?

¿Te gustaría decirme alguna cosa más sobre el taller, sobre lo que estas escribiendo que yo no te haya preguntado?

¿Sentís que te ayuda escribir? ¿En qué te ayuda? ¿Escriben los chicos acá? ¿Escriben mucho o poco? ¿Hay algunos que escriben más que los demás? ¿Qué cosas te parece son las que más escriben acá? ¿Cómo te sentís vos cuando escribís? ¿Hay algo que hayas escrito que se haya quedado grabado en tu mente? ¿Te sentiste identificado con alguna escritura tuya o de un compañero alguna vez? ¿Es distinto escribir acá que afuera? ¿Para qué te parece que te sirve escribir en este momento de tu vida?

¿Cómo crees que ven los demás chicos tu escritura? ¿Cómo crees que te ven los demás cuando escribís o leen lo que escribís? ¿Cómo está visto acá entre los chicos el hecho de que un chico se ponga a escribir? ¿Y cómo ves vos a tus compañeros cuando escriben? ¿Lees las cosas que escriben otros pibes? ¿Sobre qué escriben?

Cuando escribís ¿sentís algo distinto en relación a tu vida, en la forma de verte a vos mismo? ¿Tiene algo de importante la escritura para vos en este momento de tu vida? ¿Te interesa guardar las cosas que escribís? ¿Pensás que el día que salgas de acá la escritura va a tener algún sentido para vos? ¿Qué sentido? ¿Va a ser distinto? ¿Creés que seguirás escribiendo? ¿Te gustaría escribir más? ¿Qué te gustaría escribir?

¿Te parece que te puede hacer bien escribir? ¿Por qué?

¿Sentís que la escritura tiene alguna relación con algunas cosas de tu vida? ¿Por qué? ¿Te parece que tiene sentido para vos o también puede ser importante para alguien más? ¿Pensás que escribir puede ayudar a alguien además que a vos mismo?

¿Crees que alguna escritura puede generar algo especial entre tu grupo de compañeros? ¿Te parece que escribiendo algo uno puede cambiar algo de la vida, de la realidad? 